

\title{
ESTUDOS VISANDO À SÍNTESE DE SESQUITERPENOS BACANOS
}

TIAGO DE OLIVEIRA VIEIRA

Tese de Doutorado

Orientadora: Helena Maria Carvalho Ferraz

$$
\begin{gathered}
\text { São Paulo - SP } \\
2005
\end{gathered}
$$




\section{DEDALUS - Acervo - CQ

 \\ 30100011247}

\section{Ficha Catalográfica}

Elaborada pela Divisão de Biblioteca e

Documentação do Conjunto das Químicas da USP.

Vieira, Tiago de Oliveira
Estudos visando à síntese de sesquiterpenos bacanos / Tiago
de Oliveira Vieira. -- São Paulo, 2005.
179p.
Tese (doutorado) - Instituto de Quimica da Universidade
de São Paulo. Departamento de Quimica Fundamental.
Orientador: Ferraz, Helena Maria Carvalho
Sintese : Quimica orgânica 2. Sesquiterpeno I. T.
II. Ferraz, Helena Maria Carvalho, orientador.

547.2 CDD




\section{"Estudos visando à síntese de sesquiterpenos bacanos"}

\section{TIAGO DE OLIVEIRA VIEIRA}

Tese de Doutorado submetida ao Instituto de Química da Universidade de São Paulo como parte dos requisitos necessários à obtenção do grau de Doutor em Química - Área: Química Orgânica.

Aprovado(a) por:



Profa. Dra. HELENA MARIA CARVALHO FERRAZ IQ - USP

(Orientadora e Presidente)



Profa. Dra. URSULA BROCKSOM

UFSCar

Prof. Dr. JOSÉ RICARDO ROMERO

FFCLRP - USP

Prof. Dr. SILVIO DO DESTERRO CUNHA

UFBA

SÃO PAULO

30 DE SETEMBRO 2005 
Ás vezes duvido se

uma vida calma e tranqüila

teria sido conveniente para mim - e no entanto às vezes anseio por isso.

Lord Byron

"Há muito tempo, abandonei a noção de uma vida sem tempestades, ou de um mundo sem estações secas e assassinas. A vida é por demais complicada, é constante demais nas suas mudanças para ser diferente do que realmente é. Eu sou, por natureza, instável demais para ter outra atitude a não ser a de uma profunda desconfiança diante da grave artificialidade inerente a qualquer tentativa de exercer um controle excessivo sobre forças essencialmente incontroláveis. Sempre haverá elementos perturbadores, propulsores; e eles estarão sempre presentes até o momento em que, nas palavras de Lowell, o relógio for retirado do pulso. No final das contas, são os momentos isolados de inquietude, de desolação, de fortes conviç̧ões e entusiasmos enlouquecidos, que caracterizam nossa vida, que mudam a natureza e a direção do trabalho e que dão colorido e significado final ao amor e às amizades."

Kay R. Jamison em Uma Mente Inquieta

"Sentia-se muito jovem; e, ao mesmo tempo, indizivelmente velha. Passava como uma navalha através de tudo; e ao mesmo tempo ficava de fora, olhando. Tinha a perpétua sensação, enquanto olhava os carros, de estar fora, longe e sozinha no meio do mar; sempre sentira que era muito, muito perigoso viver, por um só dia que fosse."

Virginia Woolf em Mrs.Dalloway

Quem passou pela vida em branca nuvem,

E em plácido repouso adormeceu;

Quem não sentiu o frio da desgraça,

Quem passou pela vida e não sofreu;

Foi espectro de homem, não foi homem,

Só passou pela vida, não viveu.

Ilusões da Vida - Francisco Otaviano 
Sendo um pouco mais positivo e otimista...

\section{Cuando pierda todas las partidas \\ Cuando duerma con la soledad \\ Cuando se me cierren las salidas \\ Y la noche no me deje en paz. \\ Cuando sienta miedo del silencio \\ Cuando cueste mantenerse en pié \\ Cuando se rebelen los recuerdos \\ $Y$ me pongan contra la pared.}

Resistiré, erguido frente a todo Me volveré de hierro para endurecer la piel Y aunque los vientos de la vida soplen fuerte

Soy como el junco que se dobla pero siempre sigue en pié.

Resistiré para seguir viviendo Soportaré los golpes y jamas me rendiré $Y$ aunque los sueños se me rompan en pedazos Resistiré, Resistiré...

\section{Cuando el mundo pierda toda magia Cuando mi enemigo sea yo Cuando me apuñale la nostalgia Y no reconozca ni mi voz \\ Cuando me amenace la locura Cuando en mi moneda salga cruz Cuando el diablo pase la factura O si alguna vez me faltas tu.}

Resistiré, erguido frente a todo Me volveré de hierro para endurecer la piel $Y$ aunque los vientos de la vida soplen fuerte soy como el junco que se dobla pero siempre sigue en pié.

Resistiré, para seguir viviendo Soportaré los golpes y jamas me rendiré $Y$ aunque los sueños se me rompan en pedazos Resistiré, Resistiré...

Resistiré - Carlos Toro e Manuel de la Calva 
Dedico esta tese à minha mãe, Sandra, que não só me trouxe ao mundo, mas também me educou, sempre apoiou minhas decisões e fez com que fosse possivel dar mais esse passo. 
À minha irmã, Júlia, e ao meu padrasto, Jô, pelos agradáveis anos que convivemos, pelo suporte financeiro e emocional, por sempre torcerem por mim e por terem tornado possivel, em diversos sentidos, a execução desta tese. 


\section{Agradecimentos}

"...As coisas estão tão esquisitas hoje em dia, que a gente, incrivel, a gente anda ressabiado de dizer que gosta das pessoas. Então a gente inventa coisas, entende? $A$ gente inventa que é tímido e que não encontra jeito de dizer. A gente inventa que está ocupado e que um dia, sei lá, vai ter tempo de sentar e conversar. Ai, de repente, você se toca que não tem mais nada para ser feito, é tarde paca."

Elis Regina, Programa Ensaio 1973.

Gosto muito desta fala da Elis e decidi que iria agradecer - de coração aberto e sem vergonha de incorrer na pieguice - a todas as pessoas que foram importantes em minha vida ao longo destes anos de USP. Aí vai a longa lista...

À Prof. Helena Ferraz (Marilena) - a quem devo toda a minha formação em síntese orgânica e acadêmica -, pelos quase dez anos de convívio desde a iniciação científica, pela orientação cuidadosa, pela liberdade dada para eu expressar minhas idéias químicas, pelo incentivo sempre constante, pelas muitas cervejas bebidas juntos, pelos dias acolhedores que passei em sua casa, pelos papos filosóficos - quando eu estava deveras reticente em relação ao sentido de tudo e da vida -, pelas dicas de gramática principalmente quanto às crases - e literatura, por sempre me incitar a viver outras coisas além da química, pela amizade, enfim.

Ao Prof. Luiz Fernando - meu co-orientador, em caráter informal, com quem também tive a oportunidade de ser supervisionado no laboratório quando eu era IC e ele aluno de doutorado -, por todas as sugestões referentes ao trabalho experimental e ao andamento do projeto.

Aos colegas de laboratório pelo convívio agradável. Os dividi em dois blocos, os antigos e os atuais, dispostos em ordem não alfabética - espero não ter esquecido de ninguém.

Antigos: Mônica, Elena, Myrian, Fernando Beleza, Ricardo, Luiz Sidney, Luiz Rogério, Alberto, Andréa Mané, Andréa Fofi, Eliseu, Elias, Rosana, Caio, Fátima, Patrícia, Walter, Cláudio, Karina e Raquel. Atuais: Graziela, Eliane, Fernanda, Marcus, Samir, Carla, Alexsandra, Ramón, Jaqueline, Mariza, Olga e Fabiana.

Aos meus estagiários Cláudia, Juliano e Pedro, por terem me dado a oportunidade de aprender a transmitir conhecimento teórico e experimental, por terem me ajudado, cada um a sua maneira, no desenvolvimento da parte experimental, e, por fim, por terem tido muita paciência. 
À Dona Rosa, pelos inúmeros momentos de descontração - que às vezes provocavam risadas descontroladas logo no periodo da manhã -, pelo bom humor sempre constante e, sobretudo, pela lição de vida.

Aos "primos" do laboratório ao lado - em especial Priscila, Takeo e Juliano-, pelos empréstimos de reagentes, pelos desabafos e, óbvio, pelas festas.

Ao Peta, amigo desde o primeiro ano da graduação, pela confiança em mim como seu confidente, por todas as discussões teóricas de química - ele é realmente um excelente químico orgânico -, pela sua visão otimista perante a vida e a ciência.

Ao meu "afilhado" George, pela amizade, pelos bons tempos da faculdade, em que fizemos grupo de laboratório, e pela aquela prova de cálculo III.

Aos amigos do tempo de graduação - em especial, Sérgio, Bianca, Ladrão, Gustavo, Chandelle, Fabiana, Denise e Marcelo (in memoriam) - por terem tornado o curso mais ameno através da várias festas, jogos de truco e de sinuca no centro acadêmico.

Ao Prof. Teng, por todas as dicas cinematográficas, por todos os DVDs emprestados e por todas as discussões filosóficas acerca da ciência.

Ao Prof. Borin, pelos tempos de "naquela mesa", em comprávamos livro na física e éramos mais felizes.

Ao Prof. Hélio Stefani e aos seus alunos (Diogo, Iguatemi, Cláudio e Rodrigo) pelos reagentes cedidos - em especial o cloreto de alumínio que salvou minha síntese.

Ao Prof. Leandro e ao Dr. André, do bloco zero, pelo trabalho em colaboração sobre as resoluções enzimáticas.

Aos funcionários da SPG, Central Analítica, Biblioteca e Xerox, em especial Cibele, Milton, Emiliano, Adriana, Fernando, Márcio, Luzia, Chico e Jailton, por todo o suporte - tão essencial - ao longo destes anos.

Ao pessoal da manutenção - em especial Dorian, Walter, Zé Tavolaro e Valério (in memoriam) -, por todos os favores e galhos quebrados e, também, por me aceitarem como convidado em suas festas. 
Ao Joaquim, por todos os churrascos em que fui seu auxiliar, pelas discussões filosóficas (de botequim), pela enologia - ou será enolatria? -, por toda ajuda no laboratório, e até mesmo por aquele THF que ele disse que beberia se não ficasse azul, e não ficou.

À Bombom, por ter aprendido a ser mais paciente comigo e pelo tempo que passamos juntos no laboratório - inclusive nos sábados mais preguiçosos, quando o sol era um convite à piscina, e continuávamos acorrentados à bancada.

À Aguilar Fraude - minha amiga também neurótica quanto à organização do laboratório e tratamento de solventes e reagentes -, pelo convívio agradável, apesar das eventuais discussões, pelas lamentações de ambas as partes quando uma reação não funcionava e foram muitas - por conseguir me entender e por ser tão parecida comigo.

À Pepi (Érika), minha confidente e cúmplice mais do que paciente, pelas crises que me ajudou a superar, pelas cervejas - muitas, por sinal -, por todos os presentes, pelo carinho constante, por tentar me entender e, por fim, por me mostrar como é importante ter amigos.

À Sônia Ula-Ula, pela amizade, pelos anos de Vai-Vai, pelo saudosismo, pelos incontáveis almoços de domingo e pela Aquela feijoada que finalmente saiu.

À "irmã" Bete, por todos os bons momentos vividos tanto no Brasil quanto na Alemanha, pelos dias de "penúria" no 3114 - que se tornaram mais amenos com aquelas cervejinhas -, pela confiança e amizade incondicional e pelos "contrabandos" de guloseimas, apetrechos de cozinha e especiarias trazidos diretamente do velho mundo.

À Martinha, pela amizade sempre fiel - que sempre soube tolerar meus momentos mais implicantes e chatos -, por estar sempre presente mesmo à distância, nos últimos tempos, para compartilharmos nossas vitórias e agruras. Nunca esquecerei daquele pedaço de picanha e das incontáveis garrafas de vinho que bebemos - imagino que ela também não.

Ao Alexandre - fanático por Almodóvar como eu -, pelos bons filmes que assistimos juntos, por sua cultura cinematográfica - mesmo com as falhas quanto aos clássicos -, por ter me disponibilizado um dos melhores filmes do Almodóvar (Qué he hecho Yo para merecer esto?), que eu ainda não havia visto. 
À Morcega (Alessandra), pelos armários que montamos e desmontamos - um deles não conseguimos remontar -, pela paciência de aturar morar comigo por quase três anos, pelos empréstimos de carro, pelo incentivo nos meus momentos mais tristes e, por fim, pela minha nova vida.

À Carranca (Adriana), por sua contagiante alegria de viver, pelo companheirismo, pelos bolos que fizemos e comemos, por me ensinar que vale a pena viver, pelo um ano $e$ meio que moramos juntos e, sobretudo, por aturar minhas manias e implicâncias.

À Valquíria, por compartilhar comigo a vida já há dez anos, por ser minha alma gêmea, ou melhor, minha versão feminina, pelas tortinhas de morango - acompanhadas sempre de capuccino LIGHT na Saint Etienne -, pelos sanduíches de tomate seco, pelas incontáveis calorias que ingerimos juntos, pela amizade incondicional - sempre nos apoiamos até mesmo nos momentos mais Beck Bloom - e por me chamar para a realidade nos momentos mais "surtados".

Ao Babá Akitunde - meu babalorixá e amigo -, por ter cuidado de mim desde 1999, pelo carinho sempre presente, pelos conselhos mais que valiosos e, por fim, por ter me iniciado para Ogun.

À minha família de santo - Tatá, Ominlesi, Toloji, Oyatolu, Ekedi, Alamefá, Odetolá, Fagbenlé, Ominade, Oyadeji, Babátogun, Tomori, Bandele (e família) e Akinielé -, pelo suporte religioso e emocional, pela amizade incondicional e por me ajudarem a superar os momentos mais difíceis que vivi nos últimos tempos.

À minha família da Bahia nas figuras de vó Ziza (in memoriam), tia Nílbia, vó Núrbia, tia Dedé, tia Gaua, tia Sônia, tia Vera, tio Fernando, César, Isa, Sheila e Adel, por todo carinho, mesmo à distância, e pela eterna torcida quanto ao meu futuro.

À FAPESP pela bolsa concedida. 


\section{Índice}

\section{Resumo}

Abstract

\section{Introdução}

1.1.Sobre a (+)-Baquenolida-A 1

1.2.Sinteses da Baquenolida-A 3

1.2.1.Síntese de Evans 3

1.2.2.Síntese Biomimética de Hayashi 5

1.2.3.Sintese Formal de Silva 6

1.2.4.Sintese de Greene $\quad 7$

1.2.5.Sintese de Back 9

$\begin{array}{ll}\text { 1.2.6.Síntese Formal de Kozmin } & 10\end{array}$



1.2.8.Síntese da (-)-7-Epi-baquenolida-A 13

1.3.Reações Mediadas por Sais de Tálio(III) 16

$\begin{array}{ll}\text { 1.3.1.Introdução } & 16\end{array}$

1.3.2. Reações de Ciclização 17

$\begin{array}{ll}\text { 1.3.3.Reações de Contração de Anel } & 18\end{array}$

$\begin{array}{ll}\text { 2.Objetivos } & 21\end{array}$

3.Planejamento Sintético 22

4. Resultados e Discussão 24

4.1.Estudos Visando à Síntese da nor-Baquenolida-A 24

4.1.1.Preparação do Material de Partida 24

4.1.2. Construção do Sistema cis-Hidrindânico 27

4.1.3.Construção do Centro Quaternário 29

4.1.4.Construção do Anel Espirolactônico 31

4.1.4.1.Primeira Abordagem 31

4.1.4.2.Segunda Abordagem 33

4.2. Outros Estudos Visando à Construção de cis-Hidrindanos 38

$\begin{array}{ll}\text { 4.2.1.Introdução } & 38\end{array}$

4.2.2.Preparação do Aduto $67 \quad 39$

4.2.3. Reação da Olefina $68 \mathrm{com} T \pi N$

4.2.4. Reação do 4-Alquenol 71 com TTN 40 
4.2.5. Reação de Contração de Anel da Olefina 74 com TTN 44

4.3.Estudos Visando à Síntese da Baquenolida-A 46

4.3.1.Introdução 46

4.3.2. Definição da Relação cis entre as Metilas da Baquenolida-A 48

4.3.2.1.Primeira Abordagem $\quad 48$

4.3.2.2.Segunda Abordagem $\quad 50$

4.3.3. Outra Possível Rota Sintética para a Baquenolida-A 52

4.3.3.1.Introdução 52

4.3.3.2.Preparação da octalona $91 \quad 58$

4.3.3.3.Reação de Contração de Anel da Octalona 91

4.3.3.4.Tentativas de Contração de Outras Cetonas 66

4.3.3.5.Tentativas de Contração do Dieno 105

4.4.Resolução Enzimática de cis-Octalinas $\quad 69$

4.4.1.Introdução 69

4.4.2.Preparação dos Materiais de Partida $\quad 70$

4.4.3.Resolução Cinética: O "Screening" 71

4.4.4. Resolução Cinética dos cis-Octalóis com Novozyme 435

5.Conclusão

6.Parte Experimental $\quad 79$

Considerações Gerais - Avis aux Lecteurs $\quad 79$

6.1.nor-Baquenolida-A 81

6.2.Outros cis-Hidrindanos $\quad 88$

6.3.Baquenolida-A 93

6.4.Resolução Enzimática $\quad 104$

$\begin{array}{lr}\text { 7.Espectros de RMN } & 110\end{array}$

$\begin{array}{ll}\text { 8.Referências } & 173\end{array}$

$\begin{array}{lr}\text { Curriculum Vitae } & 178\end{array}$ 


\section{Resumo}

Nesta tese, efetuamos estudos visando à síntese de sesquiterpenos bacanos, cuja etapa chave consistiu na construção do sistema cis-hidrindânico, através de reação de contração de anel de cis-octalinas e 2-octalonas mediada por trinitrato de tálio (TTN). Apenas as cis-octalinas como, por exemplo, o cis-4a-metil-1,2,3,4,4a,5,8,8a-octahidronaftaleno e o cis-4a,7-dimetil-1,2,3,4,4a,5,8,8a-octa-hidronaftaleno, foram passíveis de reação de contração de anel em rendimentos satisfatórios; já a cis-5,10dimetil-1(9)-octal-2-ona levou ao produto de contração em baixo rendimento.

Tentamos utilizar a reação de cis-4a-metil-1,2,3,4,4a,5,8,8a-octa-hidronaftaleno com TTN na síntese da nor-baquenolida-A, porém não conseguimos completar a síntese desta, pois não foi possível efetuar a última etapa sintética, nas várias abordagens testadas.

Grandes esforços também foram empregados na preparação diastereosseletiva da cis-5,10-dimetil-1(9)-octal-2-ona através de três abordagens diferentes que foram investigadas, sendo duas delas com êxito. Contudo, o baixo rendimento (38\%) da etapa de contração de anel da cis-5,10-dimetil-1(9)-octal-2-ona não permitiu a continuação da rota sintética proposta para a baquenolida-A.

Também realizamos a resolução cinética de três diferentes cis-octalóis - que foram preparados através da reação de Diels-Alder seguida de redução diastereosseletiva - com a lipase Novozym 435, e os produtos resolvidos foram obtidos em excelentes rendimentos isolados ( $\geq 40 \%$ para cada enantiômero) e excelentes excessos enantioméricos ( $\geq 98 \%)$. 


\section{Abstract}

In this thesis, we have developed studies towards the synthesis of sesquiterpenes bakkanes, which key step consisted on the construction of the cis-hydrindanic system through a thallium(III) mediated ring contraction reaction of cis-decalins and 2octalones. Only the cis-octalins, such as the $1,2,3,4,4 a, 5,8,8 a$-octahydro-4amethylnaphthalene and the 1,2,3,4,4a,5,8,8a-octahydro-4a,7-dimethylnaphthalene, were able to be ring contracted in satisfactory yields; the $4,4 a, 5,6,7,8$-hexahydro- $4 a, 5-$ dimethylnaphthalen-2(3H)-one, however, furnished the ring contraction product in low yield.

We tried to use the reaction of $1,2,3,4,4 a, 5,8,8 a$-octahydro- $4 a-$ methylnaphthalene with $\pi N$ in the synthesis of nor-bakkenolide-A, but we could not accomplish the synthesis because it was not possible to make the last step of the sequence, in all tested approaches.

Great efforts were made in the diastereoselective preparation of the $4,4 a, 5,6,7,8$ hexahydro-4a,5-dimethylnaphthalen-2(3H)-one, through three different approaches that were investigated, being two of them with profit. However, the low yield (38\%) of the ring contraction reaction of 4,4a,5,6,7,8-hexahydro-4a,5-dimethylnaphthalen-2(3H)-one, precluded the continuation of the synthetic rout proposed to the bakkenolide-A.

We have also performed the kinetic resolution of three different cis-octalols - that were prepared through Diels-Alder reaction followed by diastereoselective reduction with the Novozym 435 lipase, and the resolved products were isolated in excellent yields ( $\geq 40 \%$ for each enantiomer) and excellent ee 's ( $\geq 98 \%$ ). 


\section{Introdução}

\subsection{Sobre a $(+)$-Baquenolida- $A^{*}$}

A (+)-baquenolida-A (1) (Figura 1) é uma $\beta$-metileno- $\gamma$-espirolactona sesquiterpênica - primeiro membro da família dos bacanos - que foi isolada em 1968, por dois grupos independentes, ${ }^{1,2}$ da planta japonesa Petasites japonicus. Foi batizada pelos autores como baquenolida ou fuquinanolida, em virtude do nome local da planta (Bakke ou Fuki) da qual foi isolada. Esta substância apresenta atividade citotóxica e antitumoral, ${ }^{3,4}$ além de impedir o crescimento larval e de ser um pesticida natural..$^{5-11}$



Figura 1

Embora não seja determinada a biossíntese dos bacanos - um esqueleto rearranjado em relação às unidades isoprênicas -, acredita-se que eles derivem dos eremofilanos, $^{2,12}$ através de um rearranjo envolvendo uma contração de anel, que, por sua vez, derivam dos eudesmanos, através de uma migração 1,2 de metila, como sugerido no Esquema 1.

\section{Esquema 1}<smiles>CC(C)C1CCC2(C)CCCC(C)C2C1</smiles>

eudesmanos



eremofilanos

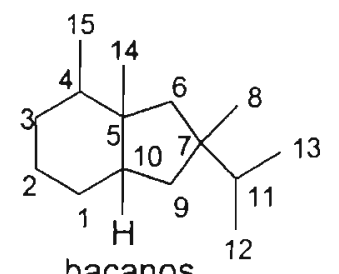

bacanos

\footnotetext{
- Para efeito de melhor visualização e didatismo, optamos por adotar a representação da direita na Figura 1 para a baquenolida-A, para todas as sinteses racêmicas, bem como para os nossos resultados apresentados ao longo dessa tese. Para as sinteses assimétricas, mostramos a representação que condiz com a configuração absoluta da baquenolida-A, ou seja, a da esquerda na Figura 1.
} 
Foram isolados, até o momento, aproximadamente cinquenta bacanos, tendo sido a maioria em plantas do Japão e Taiwan. Também foram encontrados bacanos em plantas da China, República Tcheca, Suiça, França, Irã, Noruega, Escócia e Espanha, e em ortocorais do Oceano Índico. ${ }^{13}$

A relação cis entre as metilas, bem como a junção cis entre os anéis de cinco e seis membros, é uma característica estereoquímica marcante desta classe de compostos, além do fato de que a configuração relativa do centro quaternário do anel de cinco membros é aquela em que o grupo carboxílico está em cis com as metilas - só existe um bacano com a estereoquímica oposta: o palmosolídeo-C. Outros exemplos de bacanos, com diferentes oxidações, estão mostrados na Figura 2.



Figura 2

Até o momento foram publicadas quatro sínteses totais racêmicas, ${ }^{14-19}$ uma biomimética, ${ }^{20}$ duas formais ${ }^{21,22}$ e uma total assimétrica ${ }^{23}$ da baquenolida-A (1), sendo a primeira em 1973 e a última em 2004. Recentemente, foram publicados dois artigos versando sobre a síntese dos bacanos: o primeiro, um artigo de revisão escrito por Silva $\mathrm{Jr}^{13}$ e o outro um artigo completo sobre as sínteses dos bacanos efetuadas no grupo de Greene. ${ }^{24}$

Descreveremos, detalhadamente, nos itens que se seguem, as referidas sínteses da baquenolida-A em ordem cronológica. Mostraremos, também, um pouco da química de tálio(III) que vem sendo desenvolvida em nosso grupo de pesquisa, uma vez que utilizamos uma reação de contração de anel, mediada por estes sais, nos estudos visando à síntese de bacanos. 


\subsection{Sínteses da Baquenolida-A}

\subsubsection{Síntese de Evans}

A primeira síntese de 1 (Esquema 2), concluída cinco anos após o seu isolamento, foi efetuada por Evans e col., ${ }^{14,15}$ numa seqüência de treze etapas. Os autores partiram da 2,3-dimetilciclo-hexanona e, após quatro etapas - rota esta anteriormente descrita por Piers ${ }^{25}$-, obtiveram a cetona 3 , na forma de uma mistura diastereoisomérica 4:1. Após degradação oxidativa, separação das dicetonas isoméricas 4 e $\mathbf{5}$, condensação aldólica e hidrogenação, a hidrindanona 6, material de partida chave para a síntese de $\mathbf{1}$, fol obtida.

A etapa chave da síntese de Evans consiste de um rearranjo [2,3]-sigmatrópico mediado por hidreto de sódio do intermediário 8 (sintetizado em três etapas), gerando o centro quaternário - que dará origem ao anel espirolactônico - em rendimento razoável e total estereosseletividade, o que indica que o rearranjo deve ocorrer através da face convexa da molécula. O mecanismo de tal transformação está mostrado no Esquema 3. 10 foi convertido em 1 via oxidação alílica, mediada por ácido selenioso, seguida de lactonização in situ do álcool formado, como mostrado no Esquema 2.

Os pontos fracos da sintese de Evans são: a baixa estereosseletividade (4:1) no estabelecimento da relação cis entre as metilas, na etapa de alquilação da cetona $\mathbf{2}$ embora tenha sido possivel a separação posterior das dicetonas isoméricas 4 e 5; o baixo rendimento na última etapa sintética; e o grande número de etapas envolvidas. 0 que há de mais elegante nesta síntese é, de fato, o rearranjo [2,3]-sigmatrópico que ocorre com total estereosseletividade, embora em rendimento moderado. 


\section{Esquema 2}

4:1 (cis:trans)

$(93 \%, 1: 4)$


(2 etapas) Mes N-NHTs


\section{Esquema 3}






\subsubsection{Síntese Biomimética de Hayashi}

Ainda em 1973, Hayashi e col. ${ }^{20}$ publicaram uma síntese biomimética parcial de 1 (Esquema 4), numa seqüência de quatro etapas partindo da enona natural fuquinona, isolada da Cacalia hastata. Deve-se salientar que a biossintese da baquenolida-A, bem como dos bacanos em geral, não foi determindada; entretanto, os autores acreditam que a fuquinona é o precursor biossintético de 1.

Assim, "imitando" a natureza, a fuquinona foi epoxidada em rendimento razoável; o epóxido 11 foi submetido à reação de contração de anel, que ocorre através de rearranjo do tipo Favorskii, fornecendo uma mistura de três produtos, em que 13 é proveniente de 12; o álcool terciário 14 foi desidratado na presença de cloreto de tionila levando à olefina 15, que foi oxidada com dióxido de selênio formando uma mistura do produto natural desejado, a baquenolida-A, e do aldeido 16. Este pôde ser convertido em 1 através de redução com boro-hidreto de sódio, em $47 \%$ de rendimento - melhorando assim o rendimento global da transformação -, como mostrado no Esquema 4.

Vale a pena ressaltar que Hayashi e col. ${ }^{20}$ separaram os dois epóxidos diastereoisoméricos 11 e efetuaram, em separado, o rearranjo de Favorskii; ambos os isômeros levaram à mesma proporção de produtos (com a mesma configuração absoluta). Os autores não explicaram a distribuição dos produtos formados e, tampouco, a estereosseletividade da referida transformação.

O maior problema da síntese de Hayashi é a baixa regiosseletividade na etapa de contração de anel via rearranjo de Favorskii, em que o produto 14 desejado é obtido como componente minoritário da mistura. Outro ponto fraco é o baixo rendimento da etapa de lactonização envolvendo dióxido de selênio como oxidante. 




\subsubsection{Síntese Formal de Silva}

Em 1984, Silva descreveu, em sua tese de doutorado ${ }^{21}$ orientada por Petragnani, a síntese formal de 1, como mostrado no Esquema 5, em que a etapa chave consistiu de uma reação de contração de anel via rearranjo fotoquímico de Wolff. Assim como Evans, ${ }^{14,15}$ os autores partiram da 2,3-dimetilciclo-hexanona e, após 4 etapas - anelação de Robinson, bloqueamento da posição $\alpha$-carbonila e hidrogenação catalítica - a decalona 17 foi obtida e transformada na $\alpha$-diazocetona 18 correspondente através de tratamento com nitreto de $\rho$-toluenossulfonila. Sem purificação prévia, 18 foi submetida à irradiação e forneceu o produto de contração de anel 19, em $75 \%$ de rendimento, cujo enolato formado na presença de LDA foi adicionado ao formaldeido. Após adição de metil lítio, o 
diol 20 foi obtido e o álcool primário foi oxidado e esterificado, levando ao hidróxi-ester

14. Desidratação da hidroxila terciária com cloreto de tionila deu origem à olefina $\mathbf{1 5}$ que, segundo o procedimento de Hayashi ${ }^{20}$ poderia ser convertida em duas etapas na baquenolida-A.

\section{Esquema 5}<smiles>CC1CCCC(=O)C1C</smiles>





$(30 \%)$



$(79 \%)$<smiles>CC1CCC[C@H]2CC(=O)/C(=C/O)C[C@]12C</smiles>

$17(89 \%)$



<smiles>C=C(C)[C@]1(C(C)=O)C[C@H]2CCC[C@@H](C)[C@]2(C)C1</smiles>

$15(92 \%)$



(士)-1

O maior problema da síntese de Silva talvez seja a seqüência que leva de $\mathbf{1 9}$ a 15, durante a definição do centro quaternário em C-7, em que cinco etapas sintéticas foram gastas. Não podemos deixar de mencionar também o baixo rendimento na primeira etapa da seqüência sintética, a anelação de Robinson.

\subsubsection{Síntese de Greene}

Em 1985, Greene e col. ${ }^{16}$ publicaram a sintese racêmica de 1 - primeiro bacano de uma série que foi sintetizado por este grupo - num trabalho em colaboração com Timothy J. Brocksom, da Universidade Federal de São Carlos-SP, em seis etapas. Já em $1988{ }^{23}$ este mesmo grupo publicou a síntese assimétrica de $\mathbf{1}$, numa rota idêntica porém 
partindo-se do (S)-1,6-dimetil-1-ciclo-hexeno, cuja preparação custou cinco etapas sintéticas. Como as duas rotas só diferem na preparação do material de partida, mostraremos exclusivamente a rota assimétrica.

A 2-metil-2-ciclo-hexenona foi assimetricamente reduzida ao álcool correspondente que foi transformado na respectiva carbamida. Esta, através de acoplamento com o dimetilcuprato de Guillman, com total inversão de configuração, levou ao (S)-1,6-dimetil-1-ciclo-hexeno (21) em ótimo rendimento. A reação de cicloadição entre $\mathbf{2 1}$ e dicloroceteno, gerado in situ na presença de zinco, levou ao biciclo 22 em ótimo rendimento. Em três etapas, efetuadas "one-pot", 22 foi clivado oxidativamente e posteriormente transformado no respectivo diiodeto $\mathbf{2 3}$ que, então, foi submetido à reação de dupla adição com o intermediário 24, levando a 25 como uma mistura diastereosomérica na proporção de 3:1. A mistura de $\mathbf{2 5}$ foi tratada com HF e levou a (+)-1, juntamente com o seu epímero em C-7, numa razão de $3: 1$, conforme mostrado no Esquema 6.

\section{Esquema 6}



$(49 \%, 2$ etapas $)$



2) $\mathrm{O}=\mathrm{C}=\mathrm{N}-\mathrm{Ph}$

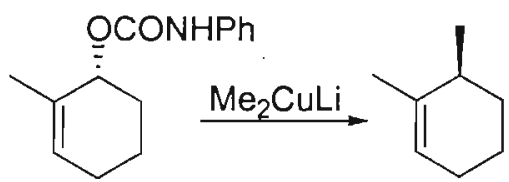

(66\%, 2 etapas)
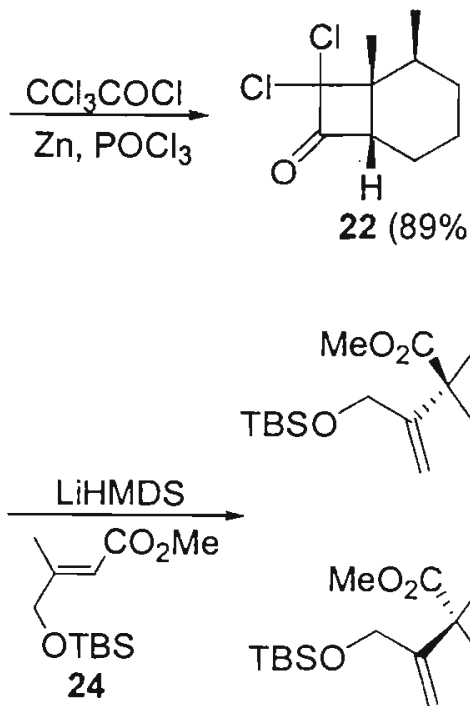

$22(89 \%)$
1) BuLi
2) $\mathrm{Ac}_{2} \mathrm{O}$ 3) $\mathrm{RuO}_{2}, \mathrm{NaIO}_{4}$
"one-pot"<smiles>C=C(COC(C)(C)C)[C@]1(C(=O)OC)C[C@H]2CCC[C@H](C)[C@]2(C)C[C@@H]1C</smiles>



$25(3: 1)$



$3: 1(59 \%)$ $\frac{\text { 1) } \mathrm{LiAlH}_{4}}{\text { 2) } \mathrm{TMSI}}$<smiles>C[C@H]1CCC[C@H]2C[IH][IH]C[C@]12C</smiles>

23

rendimento não mencionado 
O maior problema da síntese de Greene é a baixa estereosseletividade (3:1) na etapa de formação do centro quaternário do anel espirolactônico; entretanto, a abordagem é bastante convergente e insere todos os carbonos que faltavam de uma só vez.

\subsubsection{Síntese de Back}

Outra abordagem muito elegante e convergente visando à síntese de 1 , que também lançou mão de uma reação de cicloadição, foi recentemente publicada por Back e Payne. ${ }^{17,18}$ A etapa chave da síntese consistiu de uma reação de Diels-Alder intramolecular de um trieno altamente funcionalizado, levando à construção do esqueleto cis-hidrindânico numa única etapa.

Desta maneira, três fragmentos (26, 27 e 28) foram preparados, através de transformações triviais, e foram acoplados, levando ao trieno 29, que sofreu reação térmica de Diels-Alder, levando ao aduto $\mathbf{3 0}$ como uma mistura de isômeros em rendimento moderado. A hidrogenação catalítica de $\mathbf{3 0}$ não só reduziu a dupla ligação remanescente, mas também desprotegeu o grupamento benzila, levando a um álcool intermediário que, após tratamento ácido, prontamente sofreu reação de lactonização, em excelente rendimento. Após olefinação de Wittig, a baquenolida-A foi obtida como componente majoritário de uma mistura de quatro isômeros, como mostrado no Esquema 7.

Esta síntese, de modo geral, apresenta bons rendimentos para a maioria das etapas sintéticas. o único ponto fraco que deveria ser salientado é a baixa diastereosseletividade da etapa chave - a reação de Diels-Alder - em que há formação dos quatro possíveis diastereoisômeros, além de um rendimento apenas moderado. 


\section{Esquema 7}






$30(54 \%)$

$(93 \%)$



\subsubsection{Síntese Formal de Kozmin}

Recentemente, Reddy e Kozmin ${ }^{22}$ publicaram uma abordagem muito interessante, baseada numa reação de metátese de um enino, para a síntese de eremofilanos. Nesta publicação, os autores efetuaram a sintese da fuquinona, precursor biossintético da baquenolida-A, como mostrado por Hayashi, ${ }^{20}$ podendo então ser considerada como uma síntese formal de 1.

Na primeira etapa - que consiste da reação de Diels-Alder, catalisada por dicloreto de metilaluminio, entre o aldeído tíglico e o dieno 31 -, três dos quatro centros estereogênicos de $\mathbf{1}$ foram estabelecidos e o aduto $\mathbf{3 2}$ foi obtido em ótimo excesso diastereoisomérico e excelente rendimento. Após homologação do aldeído através de olefinação de Wittig, seguida por oxidação e esterificação, o éster $\mathbf{3 3}$ foi obtido em $74 \%$ 
de rendimento. Este foi submetido à reação de hidrogenação - em que ocorreu redução da dupla ligação e desproteção do álcool benzílico -, oxidação de Swern e olefinação de Wittig levando, por fim, à olefina $\mathbf{3 4}$ em ótimo rendimento. Esta foi convertida no enino 35 que, por sua vez, foi tratado com catalisador de Grubbs de segunda geração - para promover a referida reação de metátese - e ácido fluorídrico para efetuar a desproteção do éter enólico de silício intermediário 36, levando então à enona 37 em 85\% de rendimento. A enona 37, após quatro etapas - adição de metil lítio, hidroboração, oxidação com reagente de Jones e desidratação do álcool terciário com cloreto de tionila - pôde ser convertida na fuquinona em rendimento bastante satisfatório, como mostrado no Esquema 8.

\section{Esquema 8}

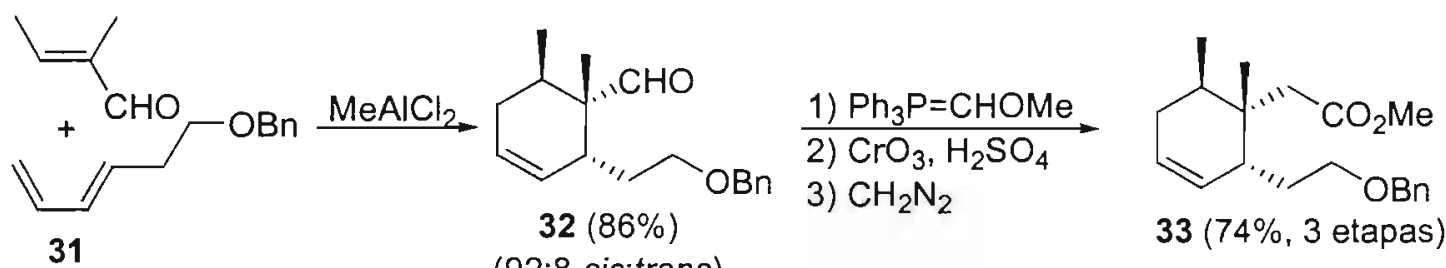
(92:8 cis:trans)
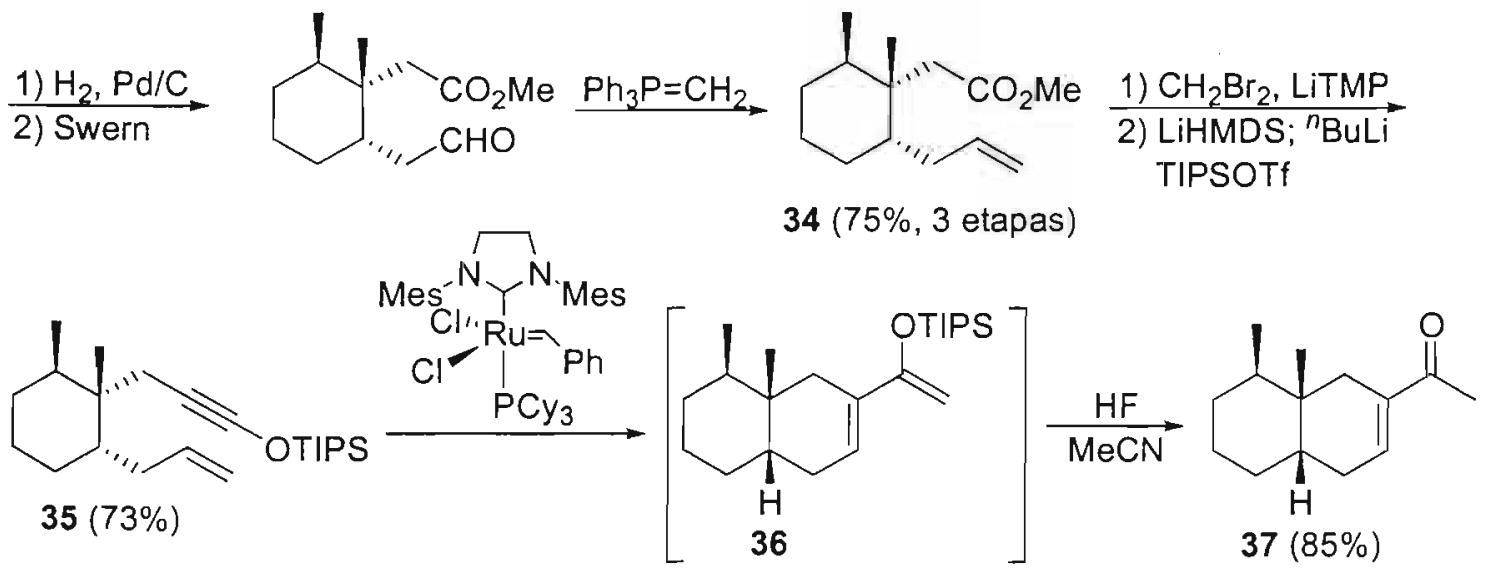

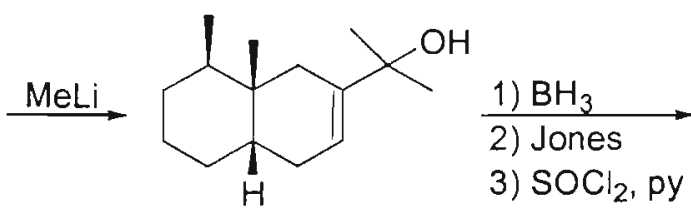

$(85 \%)$<smiles>CC(C)=C1C[C@]2(C)C(C)CCC[C@H]2CC1=O</smiles>

Fuquinona (61\%, 3 etapas)

A abordagem de Kozmin, embora elegante e atual - haja vista a utilização de uma reação de "ring-closing metathesis" (RCM) entre um alcino e um alceno, em que não há 
perda de carbonos -, conta com um número muito grande de etapas (leia-se quinze) para chegar à fuquinona que, para ser convertida em 1, consumiria mais quatro etapas, segundo a abordagem de Hayashi. ${ }^{20}$ Outro fato que dever ser mencionado é que o dieno 31, utilizado na primeira etapa da sintese, não é comercial e são necessárias três etapas para prepará-lo, apesar dos autores não mencionarem tal fato.

Embora a reação de metátese olefínica seja de vasta aplicação em química sintética, assim como seus mecanismos sejam relativamente bem estabelecidos, julgamos por bem ilustrar simplificadamente, no Esquema 9, o processo pelo qual ocorre a reação de metátese do alcenino $\mathbf{3 5}$, levando ao éter enólico de silício 36.

\section{Esquema 9}

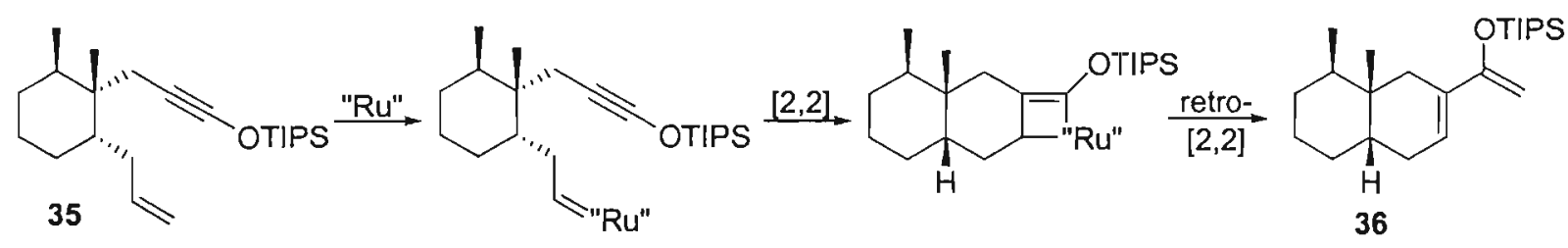

\subsubsection{Síntese de Reddy}

A síntese mais recente da baquenolida-A foi publicada em 2004 por Reddy, ${ }^{19}$ colaborador de Kozmin na síntese da fuquinona ${ }^{22}$ (cf Esquema 8). A etapa chave consistiu, também, de uma reação de Diels-Alder - aliás, muito parecida com a descrita anteriormente por Kozmin ${ }^{22}$ - entre o aldeído tíglico e a dienona 39, preparada em uma única etapa, a partir do divinil carbinol 38, através de um rearranjo de Claisen. O aduto 40 sofreu condensação aldólica, levando à enona 41 que, por sua vez, foi hidrogenada sobre óxido de platina dando origem à hidrindenona 42. Esta foi seletivamente carboxilada, fornecendo 43, que sofreu olefinação de Wittig para instaurar o grupamento metileno. Por fim, a olefina $\mathbf{1 5}$ foi convertida em 1 através de oxidação alílica mediada por dióxido de selênio, seguida de redução com boroidreto de sódio, num procedimento muito similar ao utilizado por Hayashi, ${ }^{20}$ como mostrado no Esquema 10. 


\section{Esquema 10}




A síntese de Reddy conta com uma abordagem extremamente inteligente, envolvendo um número curto de etapas. Entretanto, os rendimentos, de modo geral, são moderados.

\subsubsection{Síntese da (-)-7-Epi-baquenolida-A}

Em 1998, numa tentativa de sintese assimétrica de 1, através de uma abordagem de espiro-anelação radicalar, Srikrishna e col. ${ }^{26}$ efetuaram a síntese da (-)-7-epibaquenolida-A em doze etapas (Esquema 11). Para tal, os autores investiram na preparação da hidrindanona (+)-6, já preparada anteriormente por Evans, porém numa versão racêmica. Partindo-se da $R$-carvona, através de uma seqüência de adição de Michael/interceptação do enolato intermediário com brometo de alila, oxidação de Wacker - em que foi possível isolar o isômero 44 desejado em $70 \%$ de rendimento - e rearranjo de Criegee seguido de tratamento com DBU, foi obtida a dicetona 45. Após três etapas - hidrogenação catalítica, reação de condensação aldólica e, mais uma vez, hidrogenação catalítica -, a hidrindanona enantiomericamente pura (+)-6 foi obtida em 
rendimento global de $26 \%$. Esta foi convertida em um éter enólico através de olefinação de Wittig e, após tratamento com NBS na presença de álcool propargílico, o bromo acetal 46 foi obtido em ótimo rendimento. Através de uma ciclização radicalar do tipo 5-exodig, mediada por hidreto de tributil estanho - gerando in situ pelo par cloreto de tributil estanho e ciano boro-hidreto de sódio - o espirociclo foi construído e, após hidrólise do acetal 47 com posterior oxidação do lactol $\mathbf{4 8}$, mediada por clorocromato de piridínio (PCC) suportado em silica, a (-)-7-epi-baquenolida-A foi obtida.

\section{Esquema 11}<smiles>C=CCC1(C)C(=O)C[C@H](C(C)=CC(=O)O)CC1C</smiles><smiles>CC(=O)C[C@]1(C)C(=O)C=C[C@@H](C)[C@@]1(C)CC(C)=O</smiles>



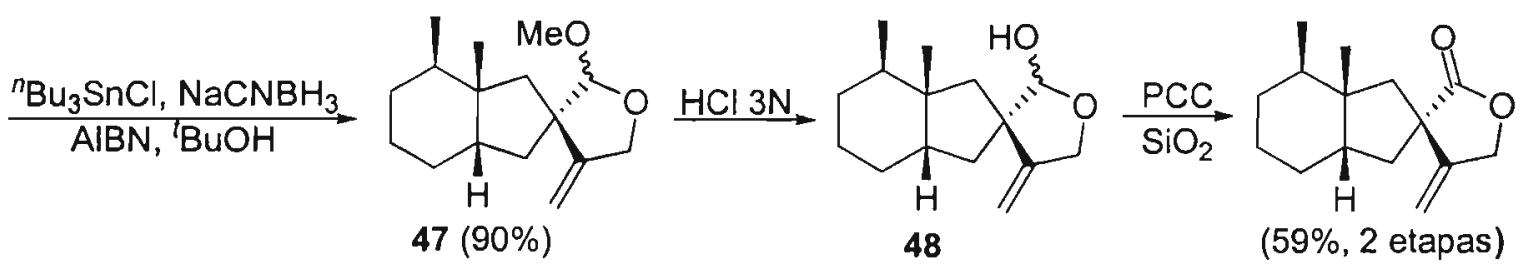

(-)-7-epi-baquenolida-A

Embora este protocolo de espirociclização radicalar seja bastante eficiente, os autores desconsideraram os efeitos estéricos envolvidos em sistemas bicíclicos de junção cis, em que, assim como na síntese de Evans, ${ }^{14,15}$ a formação da ligação quaternária do espirociclo ocorre pela face convexa (menos impedida) da molécula, como mostrado no Esquema 12. 


\section{Esquema 12}
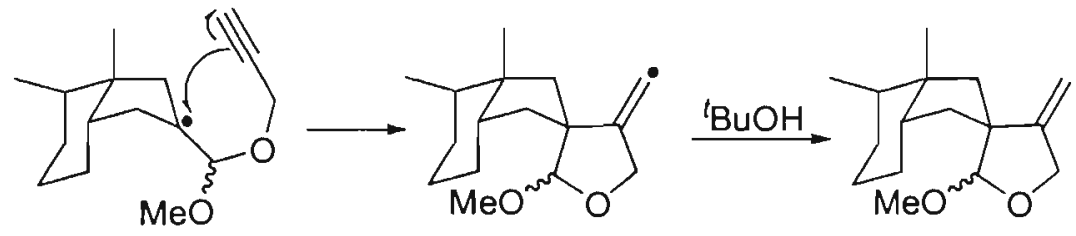

47

Afora os aspectos estereoquímicos negativos da síntese de Srikrishna, devemos mencionar a perda de três átomos de carbono, que ocorre através do rearranjo de Criegee, durante a preparação da hidrindanona (+)-6; porém, esta isopropenila que é perdida é a responsável pela diastereosseletividade na etapa de adição de Michael. À parte isso, esta síntese, embora longa, conta com bons rendimentos ao longo da maioria das etapas.

Os mesmos autores ${ }^{27}$ empregaram esta metodologia na síntese da norbaquenolida-A (49), que foi realizada em doze etapas, como mostrado no Esquema 13. 49 foi obtida, juntamente com seu isômero em C-7 (49 $)$, numa proporção de 5:1.

\section{Esquema 13}<smiles>CC1=CC(=O)CCC1</smiles><smiles>CC1=CC(O)CCC1</smiles>

1) $\mathrm{MeC}(\mathrm{OEt})_{3}$ $\underset{\text { 2) } \mathrm{EaOH} / \mathrm{MeOH}}{\stackrel{\mathrm{NaO}}{\mathrm{H}} \text { cat. }}$<smiles>CC1(CC(=O)O)C=CCCC1</smiles>
1) $(\mathrm{COCl})_{2}$ (95\%) $\mathrm{OH}$ (60\%)<smiles>C[C@]1(CC(=O)C=[W])C=CCCC1</smiles>

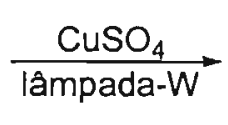<smiles>C[C@]12CCCC3C(C1)C3C2=O</smiles>
(48\%, 3 etapas)<smiles>CC12CCCC[C@H]1CC(=O)C2</smiles>
$(80 \%)$<smiles>COC=C1C[C@H]2CCCC[C@]2(C)C/C1=C\OC</smiles>
(96\%)<smiles>C#CCOC(OC)C1(Br)CC2(C)CCCC[C@]2(C)C1</smiles>

(93\%)

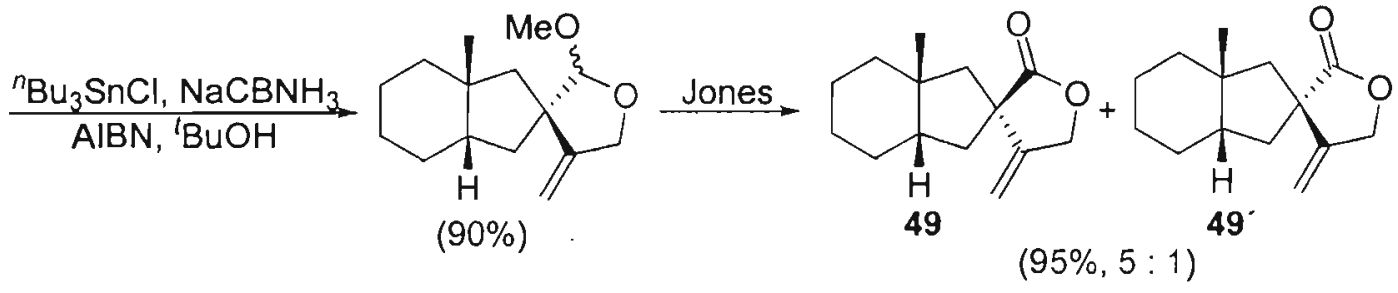




\subsection{Reações Mediadas por Sais de Tálio(III)}

"(...) One thing always happens sooner or later: the hair falls out. Thallium used to be used for depilation at one timeparticularly for children with ringworm. Then it was found to be dangerous. But it's occasionally given internally, but with very careful dosage going by the weight of the patient. It's mainly used nowadays for rats, I believe. It's tasteless, soluble, and easy to buy. There's only one thing: poisoning mustn't be suspected." Pale Horse - Agatha Christie

\subsubsection{Introdução}

Nosso grupo de pesquisa vem se dedicando já há quase duas décadas à aplicação, em síntese orgânica, de sais de tálio(III) - especificamente trinitrato e triacetato (TTN e TTA, respectivamente) -, versáteis reagentes capazes de promover uma vasta gama de rearranjos oxidativos, conforme mostrado em diversos artigos de revisão..$^{28-33}$

Limitar-nos-emos a uma curta discussão e revisão a respeito da química do tálio, uma vez que recentemente já publicamos dois artigos de revisão 28,29 sobre o assunto, e também pelo fato deste não ser o foco de estudo dessa tese. Entretanto, julgamos ser conveniente e oportuno mostrar algumas das reações de contração de anel - reação da qual fizemos uso em nossos estudos visando à síntese de bacanos - e de ciclização, mediadas por sais de tálio(III), que foram desenvolvidas no nosso grupo de pesquisa. Vale a pena ressaltar também que o desenvolvimento da química do tálio teve início na década de 60, mas foi nos anos 70 que McKillop e Taylor - os quais informalmente apelidamos de "os pais do tálio" - a exploraram amplamente.

Ao longo destes anos, foi efetuada uma série de estudos sistemáticos que culminaram na sintese total de alguns produtos naturais. A seguir mostraremos alguns exemplos ilustrativos. 


\subsubsection{Reações de Ciclização}

Tudo começou em meados da década de oitenta, com o estudo de ciclização de álcoois monoterpênicos mediada por TTA, reações que foram feitas pelas mãos da própria Helena Ferraz. ${ }^{34}$ Outros substratos foram investigados ${ }^{35}$ e este protocolo foi aplicado, com êxito, na sintese da lactona monoterpênica (+)-mintlactona ${ }^{36}$ e do feromônio trans-pitiol, ${ }^{37}$ como mostrado resumidamente no Esquema 14.

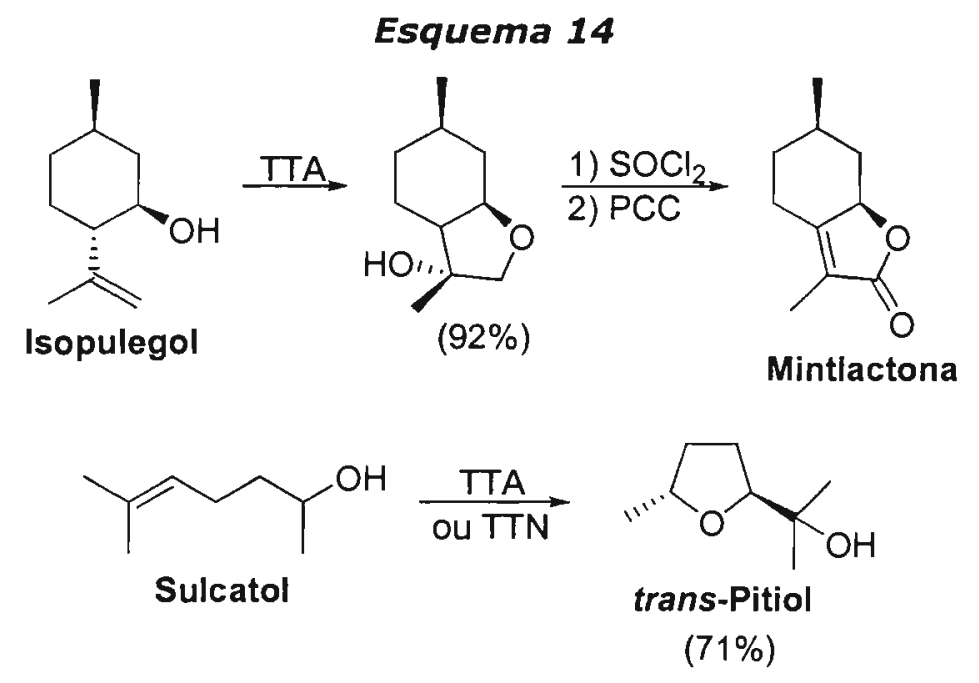

Deve-se mencionar que se trata, formalmente, de uma ciclização eletrofílica, porém, diferentemente de outros eletrófilos como, por exemplo, iodo, bromo, selênio, mercúrio e telúrio, o tálio não se incorpora ao produto final.

Recentemente, foi estudada a reação de 3-alquenóis derivados de ciclohexanonas. ${ }^{38}$ Os produtos de ciclização correspondentes se mostraram excelentes precursores de lactonas de anel médio, através de clivagem oxidativa mediada por rutênio, como mostrado no Esquema $15 .^{39}$

\section{Esquema 15}

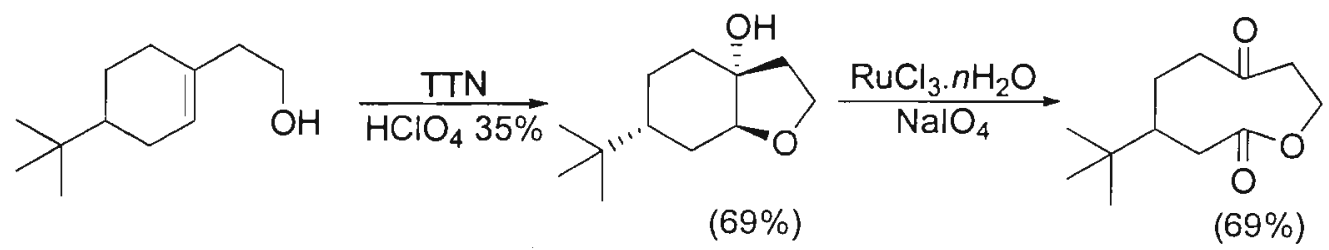


Ácidos carboxílicos insaturados também são passíveis de sofrer reação de ciclização, levando a $\delta$-hidroxi- $\gamma$-lactonas, na presença de sais de tálio(III), porém em rendimentos moderados e baixa diastereosseletividade. ${ }^{40}$ No Esquema 16 está mostrado um exemplo ilustrativo.

\section{Esquema 16}

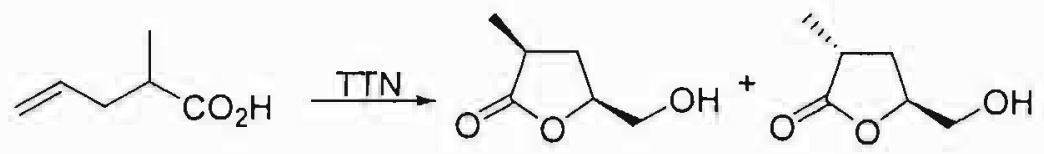

$(57 \%, 1: 1)$

\subsubsection{Reações de Contração de Anel}

Reações de contração de anel também foram alvo de estudo em nosso grupo de pesquisa, uma vez que anéis de cinco membros fazem parte de uma infinidade de produtos naturais e sintéticos de pronunciada atividade biológica. Diferentes protocolos podem ser empregados para obter tal unidade estrutural, e as reações de contração de anel são, sem sombra de dúvidas, uma excelente abordagem, como revisado recentemente por Silva Jr. ${ }^{41}$

O primeiro estudo consistiu na preparação de ácidos ciclo-pentanocarboxílicos a partir de ciclo-hexanonas, em que os aspectos mecanísticos foram amplamente discutidos com base na estereoquímica dos produtos formados. De modo geral, a referida transformação foi alcançada em excelentes rendimentos, contanto que não houvesse grupos alquila na posição $\alpha$-carbonila. ${ }^{42}$

Em relação a sistemas bicíclicos, foi estudada a reação de contração de anel de trans e de cis-decalonas. ${ }^{43}$ No primeiro caso, trans-hidrindanos ${ }^{44}$ foram obtidos em excelentes rendimentos e total diastereosseletividade, como exemplificado no Esquema 17. 




(93\%)

Porém, para as cis-decalonas os resultados não foram tão satisfatórios: os produtos de contração de anel foram obtidos com baixa diastereo- e regiosseletividade, apesar do bom rendimento da transformação. ${ }^{43}$ Não abordaremos, por enquanto, aspectos mecanísticos das reações de contração de anel mediadas por tálio(III), mas devemos lembrar que estas reações ocorrem, para as cetonas, via forma enólica. É, portanto, em virtude da mobilidade do sistema cis-decalínico - que possibilita então duas formas enólicas - que podemos explicar a baixa regiosseletividade da reação, como mostrado no Esquema 18.

\section{Esquema 18}



$(2: 1,95 \%)$

Visando à obtenção de indanos funcionalizados, três protocolos foram por nós amplamente investigados: contração de anel de $\alpha$-tetralonas, de 1,2-di-hidronaftalenos e de 3-alquenóis. As $\alpha$-tetralonas não se mostraram bons candidatos a precursores de indanos, uma vez que os produtos de contração de anel foram obtidos em rendimentos apenas moderados, juntamente com produtos de $\alpha$-oxidação (Esquema 19), ${ }^{45}$ num protocolo em que se fez uso de TTN suportado em Montmorilonite $\mathrm{K}-10$. 


\section{Esquema 19}<smiles>CO[C@H]1C[C@@H](C)c2ccccc2C1=O</smiles>

Já os 1,2-di-hidronaftalenos, preparados em 2 etapas a partir de $\alpha$-tetralonas comerciais, forneceram os respectivos indanos em ótimos rendimentos e total diastereosseletividade. ${ }^{46}$ Este protocolo foi recentemente aplicado com êxito na síntese total do sesquiterpeno Mutisiantol, ${ }^{47-49}$ como mostrado no Esquema 20.

\section{Esquema 20}<smiles>COc1cc2c(cc1C)C(C)CC=C2c1ccc(OC)c(OC)c1</smiles>

3-Alquenóis derivados de 1,2-di-hidronaftalenos também levaram à formação de indanos funcionalizados em excelentes rendimentos, ${ }^{38,50-52}$ como ilustrado no Esquema 21.

\section{Esquema 21}
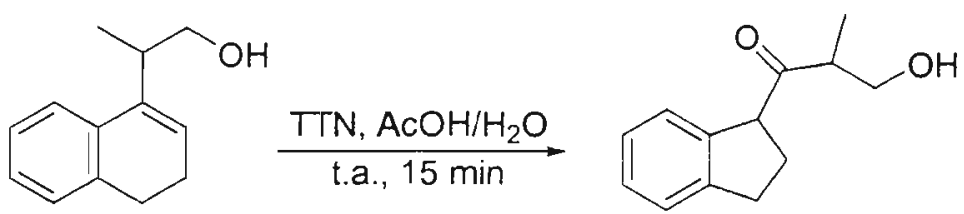

$(92 \%)$ 


\section{Objetivos}

O objetivo geral desta tese foi realizar estudos que propiciassem o estabelecimento de uma abordagem eficaz para a sintese de bacanos. A metodologia proposta inclui como etapa-chave uma reação de contração de anel mediada por tálio(III), que forneceria a unidade cis-hidrindânica presente no esqueleto dos bacanos.

O alvo sintético escolhido foi a baquenolida-A - membro mais simples da família dos bacanos; contudo, nos pareceu importante investigar antes a síntese de um composto modelo, a nor-baquenolida-A. Portanto, o objetivo específico desta tese foi o de efetuar estudos visando à síntese destas duas moléculas. 


\section{Planejamento Sintético}

Quando propusemos a sintese da baquenolida-A nos focamos em três aspectos estereoquímicos da molécula: a fusão cis entre os anéis de cinco e de seis membros, a relação cis entre as metilas, e a estereoquímica relativa do centro quaternário em C-7, em que o grupamento carboxílico está também em cis com as metilas.

Para alcançar o esqueleto cis-hidrindânico da baquenolida-A, imaginamos ser possivel lançar mão de uma reação de contração de anel como etapa chave. Como já sabido, olefinas cíclicas são substratos passiveis de sofrer rearranjo oxidativo com sais de tálio(III), ${ }^{28,29,33}$ levando a produtos de contração de anel, sendo possivel assim obter o esqueleto central da molécula.

Desta maneira, propusemos a seguinte retrossíntese (Esquema 22): o anel espirolactônico de 1 poderia ser alcançado através de reação de lactonização, seguida de olefinação, do ceto éster $\mathbf{4 3}$ - mas a seqüência poderia ser invertida; $\mathbf{4 3}$ seria fruto de uma reação de carboxilação de uma metil cetona preparada a partir de $\mathbf{4 9}$ que, por sua vez, seria proveniente de uma reação de contração de anel, mediada por $T 1^{3+}$, da olefina 50, oriunda de uma reação de Diels-Alder, seguida de algumas transformações de grupos funcionais.

\section{Esquema 22}


$\underset{\text { Carboxilação }}{\stackrel{\text { IGF }}{\longrightarrow}}$



$\underset{\text { de Anel }}{\stackrel{\text { Contração }}{\rightleftharpoons}}$ 50<smiles>[B]C12CC=CCC1(C)C(C)CCC2</smiles>

<smiles>CC1=CCCCC1=O</smiles> 
Antes de iniciar a síntese de $\mathbf{1}$, julgamos por bem testar a rota sintética proposta para 1 em um composto modelo, a nor-baquenolida-A (49), que difere de 1 apenas pela ausência da metila em C-15. Desta maneira, propusemos a rota descrita no Esquema 23 para a síntese de $\mathbf{4 9 .}$

\section{Esquema 23}<smiles>C=CC=CC1=CCCCC1=O</smiles><smiles>COC(=O)C(C)(C)C</smiles><smiles>CC1(C)CC=CCC12CCCCC2=O</smiles>

<smiles>CCC12CC=CCC1(C)CCCC2(C)[Al]</smiles><smiles>C[C@]12CCCC[C@H]1C[C@H](C=O)C2</smiles><smiles>CCCCCCCCCCCC</smiles><smiles>CC(=O)[C@@H]1C[C@H]2CCCC[C@]2(C)C1</smiles>

1) $\frac{\mathrm{HMDS}, \mathrm{TMSI}}{\mathrm{MeLi}}$

54<smiles>COC(=O)[C@]1(C(C)=O)C[C@]2(C)CCCC[C@]2([18SH])C1</smiles>
$\frac{\text { 1) } \mathrm{HMDS}, \mathrm{TMSI}}{\text { 2) } \mathrm{OSO}_{4}, \mathrm{NMO}}$
3) $\mathrm{H}^{+}$

55<smiles>[B][C@]12CCCC[C@]1(C)C[C@]1(C2)C(=O)COC1=O</smiles>

Wittig 57<smiles>C=C1COC(=O)[C@]12CC(=O)[C@H]1CCCC[C@]1(C)C2</smiles>

Limitar-nos-emos, por enquanto, a esta proposta sintética para 49 e não mostraremos, portanto, a rota que inicialmente imaginamos para a baquenolida-A. Ao longo do capítulo intitulado "Resultados e Discussão", discutiremos mais detalhadamente as alterações efetuadas nas referidas rotas sintéticas, bem como as rotas alternativas que também foram investigadas.

Alea jacta est. 


\section{Resultados e Discussão}

\subsection{Estudos Visando à Síntese da nor-Baquenolida-A}

\subsubsection{Preparação do Material de Partida 53}

A abordagem óbvia para obtenção de anéis de seis membros fundidos com junção cis é a reação de Diels-Alder. Teoricamente, seria possível preparar a olefina $\mathbf{5 3}$ (cf Esquema 23) através da reação entre 1-metil-1-ciclo-hexeno e butadieno; todavia, tanto o dieno como o dienófilo são desativados e, portanto, tal protocolo deveria envolver condições drásticas como, por exemplo, alta pressão e temperatura. Desta maneira, decidimos por um dienófilo ativado (2-metilciclo-hexen-2-ona) e assim poderíamos efetuar uma reação de Diels-Alder catalisada por ácido de Lewis. Porém, tivemos que incluir mais uma etapa sintética para realizar a redução total da carbonila presente no aduto obtido.

Muito embora a 2-metilciclo-hexen-2-ona seja comercial, ela foi preparada a partir da 2-metilciclo-hexanona, através de uma seqüência de $\alpha$-bromação termodinâmica seguida de desidro-halogenação, em $68 \%$ de rendimento global (Esquema 24). ${ }^{53}$

\section{Esquema 24}



(68\%, 2 etapas)

Apesar da reação entre a 2-metilciclo-hexen-2-ona e o butadieno - catalisada por tricloreto de alumínio em $10 \%$ - ser descrita na literatura, ${ }^{54,55}$ encontramos dificuldades pouco usuais na repetição deste protocolo. Porém, aumentando a quantidade do ácido de Lewis para 50 mol\% conseguimos obter o aduto 52 desejado, em escala de multigramas, em $76 \%$ de rendimento, como mostrado no Esquema 25. 


\section{Esquema 25}

PI B LIOTECA


NSTITUTO DE QUVISECA universidade de Sío Paulo

$52(76 \%)$

Devido à presença de uma ligação dupla no aduto 52, descartamos a possibilidade de efetuar a redução da carbonila através de um protocolo que envolvesse condições ácidas como, por exemplo, a redução de Clemmensen e optamos então pela redução de Wolff-Kishner.

A redução de Wolff-Kishner - que parece ser muito simples e que consiste do tratamento do composto carbonílico com hidrazina, para formar a hidrazona, que é in situ decomposta pela ação de base, levando ao hidrocarboneto correspondente ofereceu algumas dificuidades pouco usuais logo de início.

Segundo procedimento clássico, uma mistura do composto carbonílico, hidrazina (10 equivalentes) e $\mathrm{KOH}$ (12 equivalente) é refluxada em etilenoglicol ou trietilenoglicol até redução completa. Quando esta condição foi utilizada, o produto foi obtido em baixíssimo rendimento (13\%). Outra possibilidade é formar primeiro a hidrazona, refluxar, em balão aberto, acima de $200{ }^{\circ} \mathrm{C}$ para eliminar o excesso de hidrazina, para então adicionar a base, que pode ser $\mathrm{KOH}$ ou $\mathrm{Na}_{2} \mathrm{CO}_{3} .{ }^{56}$ Mais uma vez o rendimento foi baixo e houve formação de subprodutos cuja caracterização estrutural não foi possível.

Tentativas de mudança da hidrazina para a tosil-hidrazina, ${ }^{57}$ o que implicou em uma etapa a mais de redução com boro-hidreto de sódio, também não levaram a resultados satisfatórios (Esquema 26).

\section{Esquema 26}



52
TsHN,<smiles>CN=C1CCC[C@H]2CC=CC[C@]12C</smiles>

$\underset{\mathrm{NaBH}_{4}, \mathrm{AcOH}}{70^{\circ} \mathrm{C}, 6 \mathrm{~h}}$<smiles>C[C@]12CCCC[C@H]1CCCC2</smiles>

$53(15 \%, 2$ etapas) 
Paralelamente, tentamos efetuar um outro protocolo que não passasse pela formação de hidrazonas. Nesta abordagem, a cetona $\mathbf{5 2}$ foi seletivamente reduzida ao álcool 58 (comentaremos posteriormente - nos Esquemas 52 e 53 - os aspectos estereoquímicos destas reduções para um substrato análogo a 52), e este foi tratado com cianoboro-hidreto de sódio na presença brometo de zinco; ${ }^{58}$ contudo, houve apenas recuperação do material de partida (Esquema 27).

\section{Esquema 27}<smiles>C[C@@H]1C(=O)CCC[C@@H]2CC=CC[C@]12C</smiles>

52



$58(95 \%)$
$\frac{\mathrm{ZnBr}_{2}, \mathrm{NaBH}_{3} \mathrm{CN}}{\mathrm{Et}_{2} \mathrm{O}, \text { t.a., } 24 \mathrm{~h}}$ recuperação de 58

Por fim, decidimos retomar as condições clássicas e diminuir a quantidade dos reagentes pela metade, além da seguinte modificação: primeiro formou-se a hidrazona, depois adicionou-se $\mathrm{KOH}$. Após otimização, foi possível obter o produto desejado em $80 \%$ de rendimento, como mostrado no Esquema 28.

\section{Esquema 28}<smiles>C[C@]12CC=CC[C@H]1CCCC2=O</smiles>

52
1) 5 eq. $\mathrm{NH}_{2} \mathrm{NH}_{2} \cdot \mathrm{H}_{2} \mathrm{O}$ trietilenoglicol $130^{\circ} \mathrm{C}, 1,5 \mathrm{~h}$

2) $6 \mathrm{eq} \cdot \mathrm{KOH}$ $130^{\circ} \mathrm{C}, 4,5 \mathrm{~h}$<smiles>C[C@H]1CCCC[C@@H]2CC=CC[C@]12C</smiles>

$53(80 \%)$

Desta maneira, foi possível obter a olefina $\mathbf{5 3}$ numa seqüência de quatro etapas em bons rendimentos. 


\subsubsection{Construção do Sistema cis-Hidrindânico}

Passamos então ao estudo da reação de contração de anel 53, em condições já bem estabelecidas por nosso grupo de pesquisa. ${ }^{46}$ Assim, quando a olefina $\mathbf{5 3}$ foi tratada com TTN em trimetilortoformiato (TMOF), o produto de contração de anel $\mathbf{5 9}$ foi obtido. Contudo, enfrentamos dificuldades na purificação do acetal formado, que se mostrou muito lábil e espontaneamente hidrolisou para o aldeído $\mathbf{5 4}$ durante a coluna cromatográfica.

Optamos então por efetuar a hidrólise do produto bruto da reação com ácido trifluoroacético, ${ }^{59}$ para obter diretamente o aldeído 54. Mais uma vez, o produto formado se mostrou pouco estável, impossibilitando uma caracterização espectroscópica completa. Decidimos dar continuidade à seqüência sintética, com a reação de adição de metil lítio à carbonila do aldeído, chegando, por fim, ao álcool 60, que é estável. Esta seqüência de três etapas reacionais foi efetuada em $68 \%$ de rendimento global e está descrita no Esquema 29.

\section{Esquema 29}

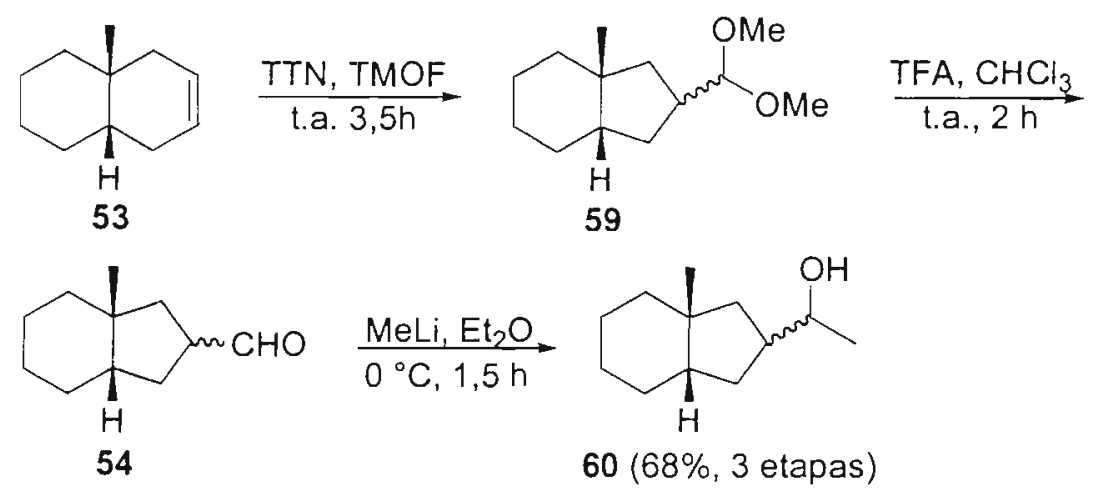

O álcool 60 foi obtido como uma mistura de quatro diastereoisômeros, o que já era de se esperar, uma vez que nesta seqüência sintética 2 centros estereogênicos foram gerados.

A etapa seguinte - a oxidação do álcool 60 à cetona 55 - foi efetuada utilizandose reagente de Jones, ${ }^{60}$ em $94 \%$ de rendimento (Esquema 30 ). 


\section{Esquema 30}



60

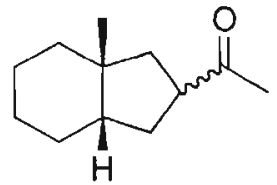

$55(94 \%)$

A cetona $\mathbf{5 5}$ foi obtida como uma mistura de diastereoisômeros na proporção de 5:1, porém não nos preocupamos em determinar a estereoquímica relativa. Na realidade, esta estereoquímica é pouco relevante uma vez que na próxima etapa é que a estereoquímica correta deste centro será definida.

Em escala de $10 \mathrm{mmol}$, estas quatro etapas foram efetuadas consecutivamente, sem purificação do álcool 60, e foi possivel isolar a metil cetona 55 em $65 \%$ de rendimento global, de onde podemos inferir um rendimento médio por etapa de cerca de $80 \%$.

O mecanismo proposto, e aceito, para a contração de olefinas, como mostrado em três dimensões no Esquema 31 para 53, é o seguinte: i) o primeiro passo é o ataque eletrofílico do tálio à ligação dupla, com perda de um dos ligantes, formando um complexo do tipo $\pi$, o ín talônio; ii) depois ocorre a abertura trans-diaxial do íon talônio por uma molécula de metanol, proveniente da hidrólise do TMOF; para ocorrer o rearranjo oxidativo tipo Wagner-Meerwein, há que haver inversão da conformação, de modo a alcançar a anti-periplanaridade necessária entre a ligação que vai migrar e a ligação carbono-tálio; iii) ocorre a migração formal com expulsão e concomitante redução do tálio(III) a tálio(I); iv) por fim, o íon oxônio é atacado por uma molécula de metanol, levando ao produto final de contração na forma de um acetal.

Com base no mecanismo da reação, podemos sugerir que o isômero formado em maior proporção seja o de configuração relativa cis entre a metila em C-14 e o grupo acetal. Para explicar a formação do isômero trans, temos que lançar mão de um mecanismo iônico, em que haja a formação de um carbocátion formal, através da quebra da ligação carbono-tálio, antes da migração ocorrer. 


\section{Esquema 31}

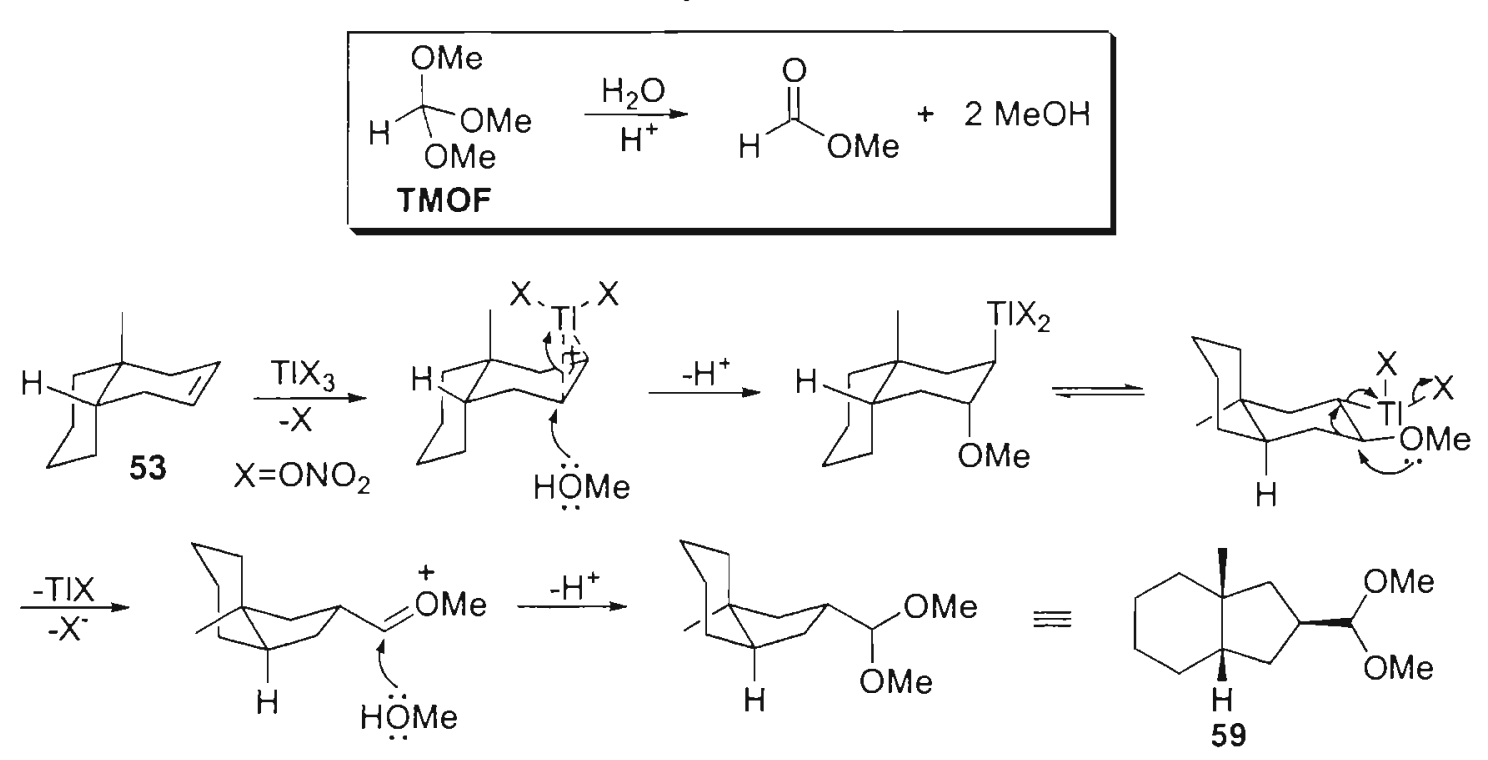

\subsubsection{Construção do Centro Quaternário}

A próxima etapa consiste da formação do centro quaternário, que pode ser feita através da carboxilação de um enolato de lítio. Entretanto, há que se preparar o enolato termodinâmico, o que não pode ser feito, portanto, com LDA. Tendo isso em mente, o que parece óbvio, e foi utilizado na síntese da homoginolideo-A por Mori, ${ }^{61}$ é preparar o éter enólico de silício termodinânico, efetuar a troca silício-lítio com MeLi, para depois efetuar a etapa de carboxilação.

Na preparação de $\mathbf{6 1}$, utilizamos um procedimento caro porém deveras eficiente: iodotrimetilsilano (TMSI) e hexametildisilazano (HMDS) como base. Não tivemos problema algum, e $\mathbf{6 1}$ foi obtido em $95 \%$ de rendimento como uma mistura 1:1 dos isômeros geométricos $E: Z$, como mostrado no Esquema 32.

\section{Esquema 32}



55



$61(95 \%)$ 
A etapa de carboxilação, também já descrita ${ }^{61}$ para um substrato análogo e que supostamente não apresentaria complicações experimentais, ofereceu dificuldades pouco usuais. Não foi possível efetuar a troca silicio-lítio em 61 com MeLi nas condições descritas, isso é, utilizando-se 2 equivalentes do organolítio a $-40{ }^{\circ} \mathrm{C}$. Contudo, conseguimos efetuar a transformação desejada utilizando dois equivalentes de MeLi a 0 ${ }^{\circ} \mathrm{C}$. Vale a pena ressaltar que o acompanhamento da reação foi efetuado através da verificação da formação da cetona 55, que é o produto de hidrólise do enolato de lítio, que é mais sensível à água do que o éter enólico de silício.

Superada esta barreira, a carboxilação foi feita pela adição in situ de cianoformiato de metila ao enolato de lítio intermediário, e o ceto éster $\mathbf{5 6}$ foi obtido em apenas $20 \%$ rendimento. Porém, aumentando a quantidade de MeLi para três equivalentes e mantendo a temperatura a $-40^{\circ} \mathrm{C}$, foi possível obter o ceto éster em $47 \%$ de rendimento, como mostrado no Esquema 33.

\section{Esquema 33}<smiles>COC(C)=C1C[C@H]2CCCC[C@]2(C)C1</smiles>

61
1) MeLi, THF

$\frac{-40^{\circ} \mathrm{C}, 30 \mathrm{~min}}{\text { 2) } \mathrm{CNCO}_{2} \mathrm{Me}}$ $\mathrm{THF},-40^{\circ} \mathrm{C}, 1 \mathrm{~h}$



$56(47 \%)$

Após otimização, foi possível obter 56 em 54\% de rendimento, partindo-se da metil cetona 55. Vale a pena ressaltar que Mori, ${ }^{61}$ na síntese do homoginolídeo-A, obteve rendimentos na faixa de $60 \%$ para a mesma etapa de carboxilação.

Acredita-se ${ }^{61}$ que a estereoquímica proposta para o centro quaternário é a descrita acima, com base na conformação do enolato formado, em que o ataque deve ocorrer pela face convexa e, portanto, menos impedida da molécula, como mostrado na Figura 3. 


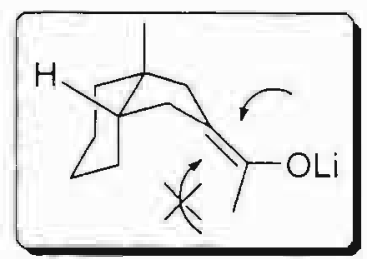

Figura 3

\subsubsection{Construção do Anel Espirolactônico}

\subsubsection{Primeira Abordagem}

Para a formação do espirociclo da nor-baquenolida-A planejamos efetuar a $\alpha$ hidroxilação da metil cetona $\mathbf{5 6}$, seguida de lactonização, através de catálise ácida. ${ }^{62}$ Para efetuar a $\alpha$-hidroxilação preparamos o éter enólico de silício 62 - de maneira análoga à preparação de $\mathbf{6 1}$ (Esquema 32), uma vez que já estávamos habituados a este procedimento -, e o tratamos com tetróxido de ósmio, em condições catalíticas, utilizando $\mathrm{N}$-óxido de morfolina (NMO) como co-oxidante. Após "work-up" e tratamento com $\mathrm{HCl}$, a ceto lactona $\mathbf{5 7}$ foi obtida em $\mathbf{4 0 \%}$ de rendimento, para as três etapas, após purificação. Foram recuperados também cerca de $20 \%$ do ceto éster $\mathbf{5 6}$, proveniente da hidrólise do éter enólico de silíco 62. No Esquema 34 está resumido este parágrafo.

\section{Esquema 34}
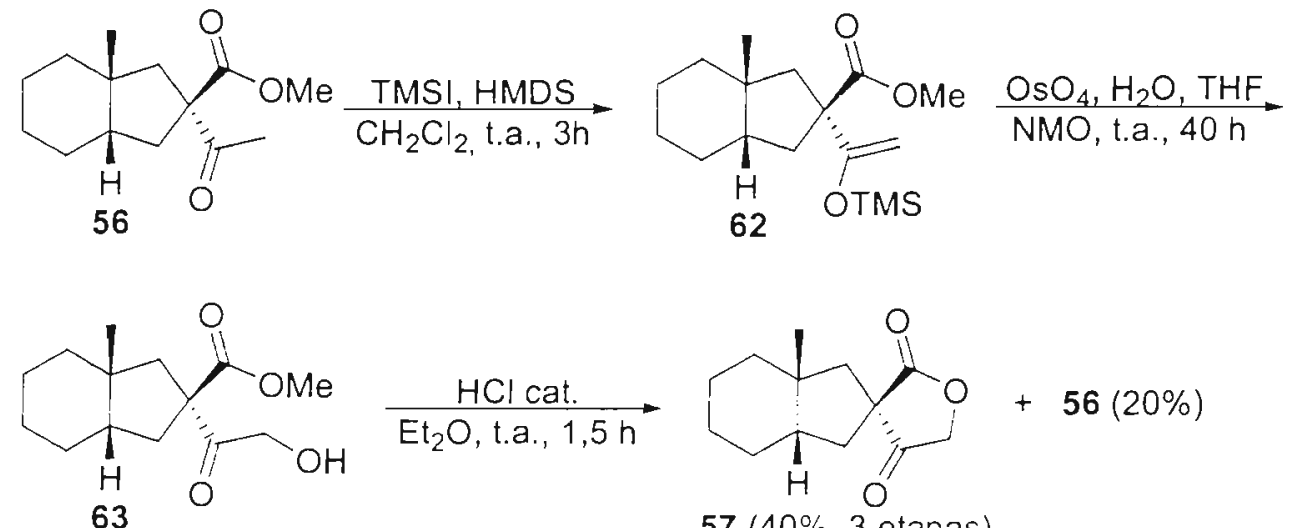

$\frac{\mathrm{HCl} \text { cat. }}{\mathrm{Et}_{2} \mathrm{O}, \mathrm{t.a}, 1,5 \mathrm{~h}}$

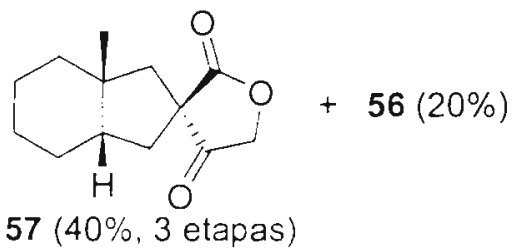

$57(40 \%, 3$ etapas $)$ 
Em termos mecanísticos, a $\alpha$-hidroxilação pode ser entendida da seguinte forma: o éter enólico de silício 62 é-di-hidroxilado, formando uma espécie de hemicetal sililado 64 que, após hidrólise, é convertido na $\alpha$-hidróxi cetona 63 (Esquema 35).

\section{Esquema 35}

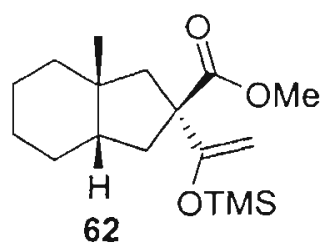
62

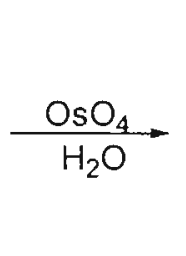<smiles>COC(=O)[C@]1(C(O)(CO)O[Na])C[C@H]2CCCC[C@]2(C)C1</smiles>

64<smiles>C[In]</smiles>

Tentativas de outras condições reacionais para a oxidação com tetróxido de ósmio foram pouco frutíferas, levando a resultados similares quando THF foi substituído por uma mistura acetona/t-butanol. ${ }^{63}$

Embora o procedimento utilizado seja satisfatório, não é o ideal, pois a quantidade de tetróxido de ósmio é grande (13 mol\%), e ele é manuseado na forma de um sólido que apresenta grande volatilidade e toxicidade. Em virtude disso decidimos tentar utilizar uma fonte de ósmio "estabilizada", AD-mix- $\alpha$, embora seja um reagente utilizado para dihidroxilação assimétrica. ${ }^{64}$

Quando efetuamos a referida oxidação do éter enólico de silício 62 com AD-mix- $\alpha$, obtivemos, para a nossa surpresa, exclusivamente o produto de hidrólise de $\mathbf{6 2}$, isto é, o ceto éster 56, como mostrado do Esquema 36.

\section{Esquema 36}

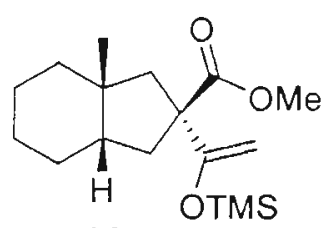

62

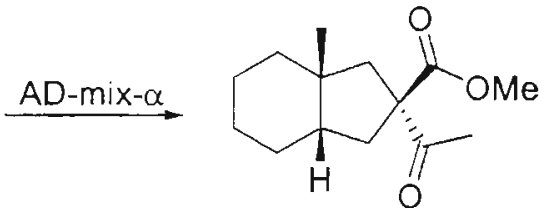

$56(90 \%)$

Uma vez que já tínhamos em mãos a ceto lactona 57 e só faltava uma etapa sintética para chegar à nor-baquenolida-A, demos continuidade à síntese proposta, ou seja, tentamos a olefinação de Wittig. 
Utilizamos o procedimento descrito por Mori para a sintese do homoginolideo- $A^{61}$ em que uma solução da ceto lactona foi tratada com quatro equivalentes de uma solução da fosforana apropriada $\left(\mathrm{Ph}_{3} \mathrm{P}=\mathrm{CH}_{2}\right)$, gerada previamente em outro balão reacional. Neste protocolo, não foi possivel obter a nor-baquenolida-A: houve apenas recuperação do material de partida e formação de produtos de decomposição (Esquema 37), cuja determinação estrutural não foi possivel.

\section{Esquema 37}

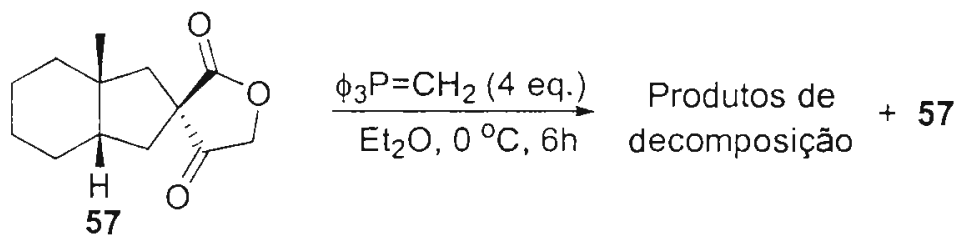

\subsubsection{Segunda Abordagem}

Tendo em vista as dificuldades enfrentadas não só na etapa de $\alpha$-hidroxilação do ceto éster, bem como na olefinação da ceto lactona 57, imaginamos ser possivel inverter a ordem da seqüência sintética e efetuar a reação de Wittig na porção cetônica de 56, para então efetuar a lactonização - que poderia ser feita através de oxidação alílica -, chegando, por fim, à nor-baquenolida-A.

A olefinação de Wittig de $\mathbf{5 6}$ também apresentou dificuldades pouco usuais, tendo sido possível obter o produto desejado 65 em baixo rendimento (33\%) mesmo utilizando quatro equivalentes da fosforana. ${ }^{19}$ Através de modificação do procedimento clássico, ${ }^{61}$ ou seja, realizando-se a adição da fosforana, gerada em um balão à parte, ao ceto éster 56, foi possivel obter $\mathbf{6 5}$, após laboriosa otimização, em rendimento superior $(60 \%)$ e bastante satisfatório para reações de Wittig com fosforanas não estabilizadas. As condições otimizadas para tal transformação estão mostradas no Esquema 38. Vale a pena ressaltar que foram recuperados cerca de $24 \%$ do material de partida e, portanto, se levarmos em consideração tal fato, podemos chegar a um rendimento de $79 \%$. 


\section{Esquema 38}<smiles>COC(=O)[C@]1(C(C)=O)C[C@]2(C)CCCC[C@]2(C)C1</smiles>
56

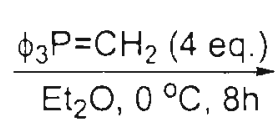<smiles>C=C(C)[C@]1(C(=O)OC)C[C@H]2CCCC[C@]2(C)C1</smiles>

$(60 \%, 79 \%$ brmp $)$

O aumento do tempo reacional, da temperatura, ou mesmo da quantidade de fosforana, não levou a resultados melhores; muito pelo contrário, houve diminuição no rendimento global e em alguns casos foi obtido o produto de descarboxilação, isto é, a metil cetona 55 .

Devemos lembrar que esta mesma abordagem foi utilizada em algumas sínteses da baquenolida-A e tais complicações não foram evidenciadas. Para explicar a baixa reatividade de $\mathbf{5 6}$, recorremos a um modelo molecular tridimensional comparativo. 0 ceto éster 43, precursor da baquenolida-A, pode ser representado em duas conformações (A e B, Esquema 39). Em ambas as conformações os substituintes do anel de seis membros ocupam duas posições axiais e duas equatoriais e, portanto, A e B seriam de estabilidade comparável. Entretanto, acreditamos que o equilíbrio está deslocado em direção a B, uma vez que há alivio da tensão estérica entre a metil cetona e o anel de seis membros. Portanto, a carbonila estaria mais disponivel a qualquer tipo de ataque nucleofílico.

Ao extrapolar este raciocínio para o ceto éster $\mathbf{5 6}$, vemos que a conformação mais estável poderia muito bem ser aquela em que a metil cetona está voltada para a face côncava da molécula, já que dois dos três grupos substituintes ocupam posição equatorial (veja as conformações A'e B“no Esquema 39). Sendo assim, neste caso o ataque da fosforana à carbonila ficaria mais dificultado, conferindo uma menor reatividade ao sistema, como evidenciado experimentalmente. Se non è vero, è ben trovato. 
Esquema 39

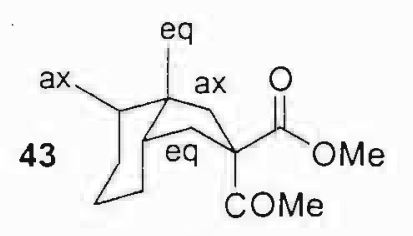

A

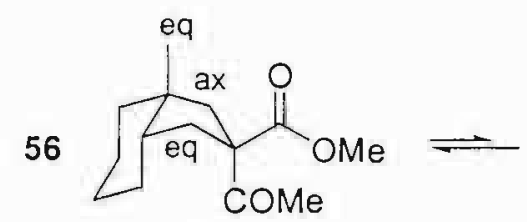

$A^{\prime}$

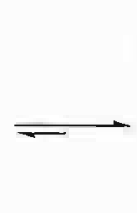

B

Favorecida

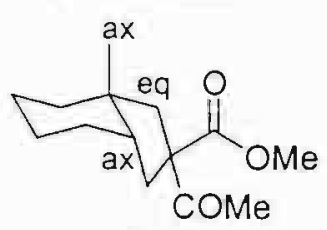

$B^{\prime}$

Favorecida

Tendo em mente os argumentos acima discutidos, julgamos desnecessário investigar outras reações de olefinação como, por exemplo, Petasis ou Paterson - ou mesmo protocolos mais recentes, utilizando catalisador de Wilkinson e $\operatorname{TMSCHN}_{2} \cdot{ }^{65}$

Para efetuar a etapa de lactonização, pareceu-nos interessante empregar as condições utilizadas por Hayashi, ${ }^{20}$ e recentemente otimizadas por Reddy, ${ }^{19}$ na sintese da baquenolida-A. Neste protocolo, lançou-se mão de uma oxidação alílica mediada por dióxido de selênio em ácido acético aquoso, seguida de tratamento com boro-hidreto de sódio para reduzir o aldeído - proveniente de um processo de oxidação exaustiva formando, assim, um hidróxi éster que lactonizou espontaneamente no meio reacional (Esquema 4).

Infelizmente não conseguimos adaptar as referidas condições experimentais para a lactonização de 65. Recuperamos apenas o material de partida, parcialmente decomposto, após 24 horas de aquecimento a $150{ }^{\circ} \mathrm{C}$, como mostrado no Esquema 40 .

\section{Esquema 40}

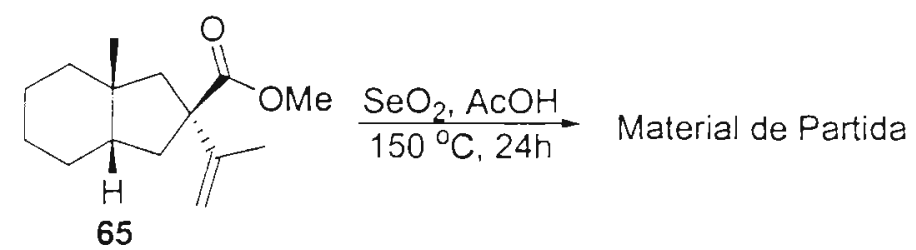


Alternativamente, tentamos efetuar a lactonização através de um protocolo em que não estivesse envolvida uma oxidação alílica. Para tal, preparamos o epóxido 66, em excelente rendimento, pelo tratamento da olefina 65 com Oxone ${ }^{\circledR},{ }^{66}$ como mostrado no Esquema 41.

\section{Esquema 41}<smiles>C=C(C)[C@]1(C(=O)OC)C[C@H]2CCCC[C@]2(C)C1</smiles>

65

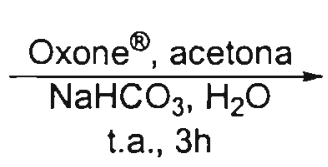

t.a., $3 \mathrm{~h}$

$66(95 \%)$

Tendo em mãos o epóxido 66, imaginamos ser possível realizar sua abertura, seguida de lactonização in situ, através de um mecanismo iônico ${ }^{67}$ - que pode ser visto no Esquema 42 - ou radicalar. ${ }^{68}$

\section{Esquema 42}

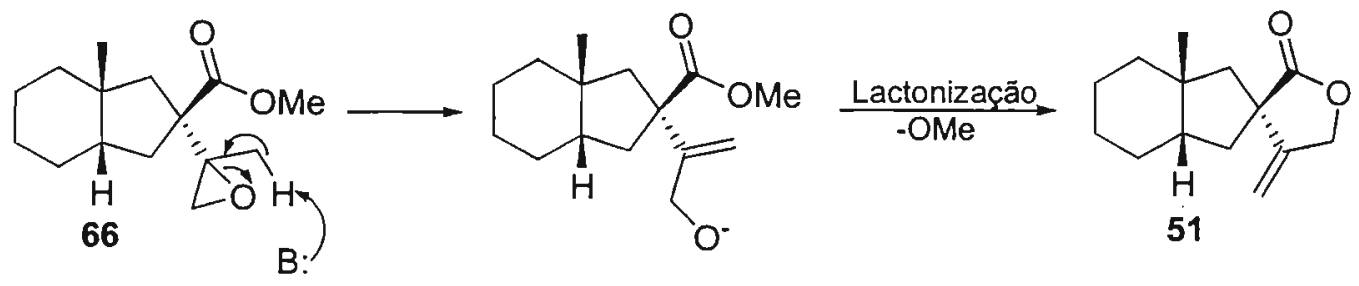

Na primeira tentativa, utilizamos como base não nucleofílica o amideto de lítio da isopropilciclo-hexilamina (LICA) e apenas ocorreu a recuperação do material de partida, como mostrado no Esquema 43.

\section{Esquema 43}

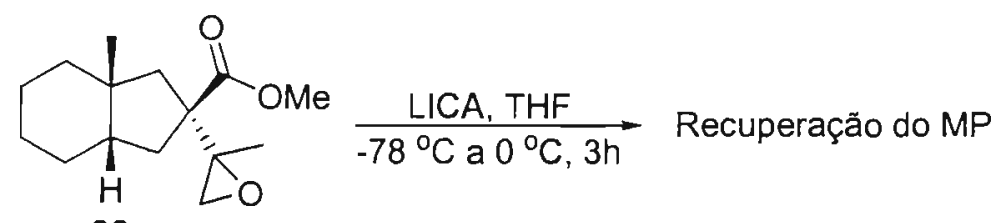

66 
Na segunda tentativa, ou seja, a abordagem radicalar, lançamos mão de um protocolo bastante elegante que faz uso de um titanoceno. ${ }^{68}$ Contudo, também não foi possivel aplicar estas condições para o epóxido 66 (Esquema 44).

\section{Esquema 44}

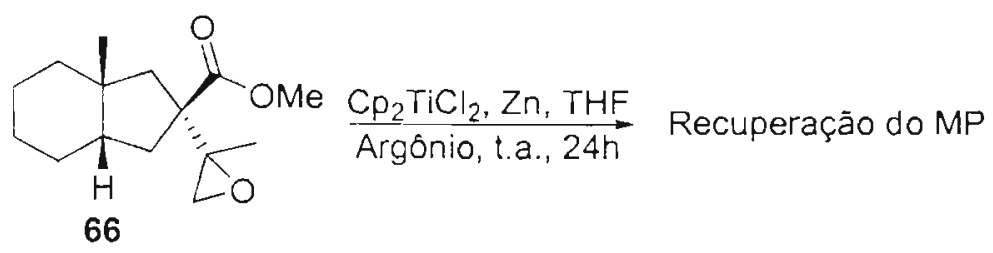

Em virtude desta falta de reatividade, resolvemos interromper os estudos visando à síntese da nor-baquenolida-A, deixando esta última etapa em "standby"; todavia, não podemos deixar de salientar que estes estudos serão continuados em nosso grupo de pesquisa. 


\subsection{0utros Estudos Visando à Construção de cis-Hidrindanos}

\subsubsection{Introdução}

Antes de discutir os esforços despendidos em relação à sintese da baquenolida-A, mostraremos alguns estudos que fizemos visando à construção de cis-hidrindanos.

Imaginando ser possivel encurtar a sintese da nor-baquenolida-A, pensamos em estudar a reação de contração de anel de substratos que contivessem ligação dupla trissubstituída. O único exemplo estudado em nosso grupo de pesquisa foi a reação de 4alquil-1,2-di-hidronaftalenos, sendo que estes substratos não se mostraram bons candidatos ao rearranjo oxidativo com sais de tálio; simplesmente foram obtidos produtos de adição, como exemplificado no Esquema $45 .{ }^{46}$

\section{Esquema 45}<smiles>CC1=CCCc2ccccc21</smiles><smiles>CON(C)O</smiles><smiles>CO[C@H]1CCc2ccccc2C1(C)C</smiles>

$(38 \%)$<smiles>CO[C@H]1CCc2ccccc2C1(C)C</smiles>

$(31 \%)$

Entretanto, existem precedentes na literatura ${ }^{32,69}$ de reação de contração de olefinas cíclicas que contém duplas trissubstituidas com sais de tálio(III) (Esquema 46), por isso decidimos investigar outros substratos que não contivessem um anel aromático em sua estrutura.

\section{Esquema 46}
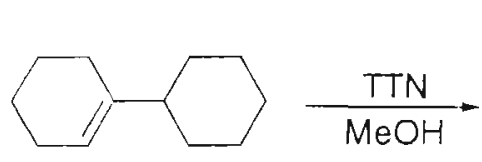<smiles>O=C(C1CCCCC1)C1CCCC1</smiles>

$(50 \%)$
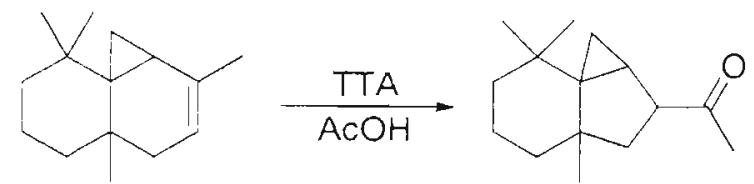

$(76 \%)$ 


\subsubsection{Preparação do Aduto 67}

Preparamos então o aduto de Diels-Alder 67, através da cicloadição entre a 2metil-2-ciclo-hexenona e isopreno, catalisada por tricloreto de alumínio - de maneira análoga à preparação de 52, material de partida da síntese da nor-baquenolida-A -, como descrito no Esquema 47. Não conseguimos reproduzir o rendimento de $88 \%$ descrito pelos autores que, inclusive, não relataram o método de purificação utilizado; e é de antemão sabido que há formação de material polimérico.

\section{Esquema 47}<smiles>C=CC(=C)C</smiles>
$\underset{\text { t.a. } 24 \mathrm{~h}}{\stackrel{\mathrm{AlCl}_{3} \text {, benzeno }}{\longrightarrow}}$<smiles>CC1=CCC2(C)C(=O)CCC[C@H]2C1</smiles>

$67(54 \%)$

\subsubsection{Reação da Olefina $68 \mathrm{com}$ TTN}

Cetonas cíclicas reagem com tálio(III) fornecendo produtos de contração de anel ou de $\alpha$-oxidação. ${ }^{42,44,45,70}$ Levando tal fato em consideração, a carbonila de $\mathbf{6 7}$ foi protegida na forma clássica de seu derivado dioxolano $\mathbf{6 8}$, em $91 \%$ de rendimento (Esquema 48), para então iniciar os primeiros testes com TTN.

\section{Esquema 47}

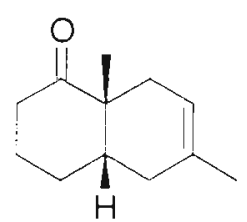

67

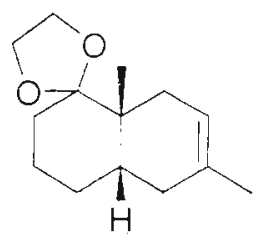

$68(91 \%)$

O cetal 68 foi submetido então às condições clássicas de contração de olefinas com tálio(III), isto é, TTN em MeOH. Entretanto, ocorreu desproteção da carbonila, com 
formação de dois produtos de adição à dupla ligação (69 e 70, Esquema 49). Mais uma vez foi possivel comprovar a resistência à contração de anel de ligações duplas trissubstituidas em sistemas cíclicos.

\section{Esquema 49}

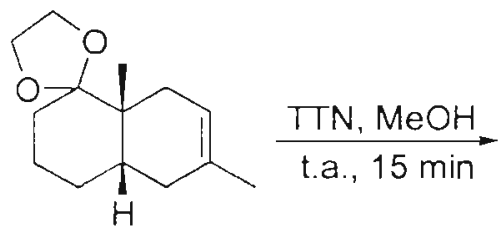

68<smiles>COC1C[C@]2(C)C(=O)CCC[C@H]2C[C@]1(C)O[N+](=O)[O-]</smiles>

$69(25 \%)$<smiles>COC1C[C@H]2CCCC(=O)[C@@]2(C)C[C@H]1C</smiles>

$70(30 \%)$

A presença do grupo nitrato em $\mathbf{6 9}$ pôde ser confirmada através das bandas características de absorção forte no infravermelho em 1607 e $1300 \mathrm{~cm}^{-1}$ mas a estereoquímica relativa dos compostos 69 e $\mathbf{7 0}$ não foi determinada.

Como a desproteção da carbonila ocorreu espontaneamente - devemos lembrar que há liberação de ácido nítrico no meio reacional durante a reação com TTN decidimos preparar outros substratos que não contêm a função carbonila, a partir de 67 .

\subsubsection{Reação do 4-Alquenol 71 com TTN}

3-Alquenóis contendo ligação dupla trissubstituída são passiveis de contração de anel ou reação de ciclização, dependendo da natureza do substrato, como já discutido na introdução desta tese.

Como se pode observar no exemplo mostrado no Esquema 49, o material de partida contém uma ligação dupla trissubstituída, e mesmo assim, só é observada a formação do produto de contração de anel. Acreditamos, portanto, que o grupo hidroxílico deve desempenhar um papel fundamental durante o rearranjo oxidativo, que certamente deve ser o de coordenação intramolecular com o tálio. No Esquema 50 está descrito, simplificadamente e levando em conta a estereoquímica da reação, o mecanismo de contração com $\pi N{ }^{51}$ 


\section{Esquema 50}

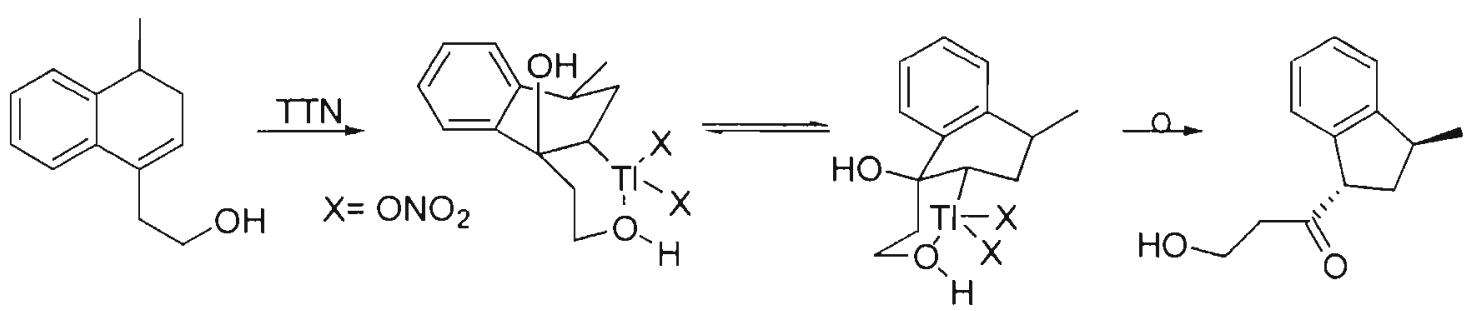

Sendo assim, pensamos ser possível lançar mão desta complexação para alcançar a contração do sistema cis-octalínico. Desta maneira, precisávamos primeiro efetuar a redução estereosseletiva da carbonila de $\mathbf{6 7}$. A redução de 67 com boro-hidreto de sódio em metanol, à temperatura ambiente, levou a uma mistura 5:1 dos álcoois trans e cis em $88 \%$ de rendimento. Quando a reação foi efetuada a $-78^{\circ} \mathrm{C}$, obteve-se uma mistura 12:1 dos referidos álcoois $\mathbf{7 1}$ e $\mathbf{7 1 ^ { \prime }}$ em $92 \%$ de rendimento, como mostrado no Esquema 51.

\section{Esquema 51}<smiles>CC1=CC[C@]2(C)C(=O)CCC[C@H]2C1</smiles>

67<smiles>CC1=CC[C@H]2[C@@H](O)CCC[C@H]2C1</smiles>

71<smiles>CC1=CC[C@@]2(C)[C@@H](CCC[C@H]2O)C1</smiles>

$71^{\prime}$

$12: 1(92 \%)$

Uma possivel explicação para a estereosseletividade destas reações de redução é proposta a seguir. Em primeiro lugar, devemos lembrar que estamos lidando com sistemas cis-decalínicos, em que a mobilidade dos dois anéis é grande, pelo menos quando comparado com o sistema trans-decalínico. Fazendo o modelo molecular dos dois álcoois (Esquema 52), e levando em consideração as interações 1,3-diaxiais entre os grupos substituintes, intuitivamente atribuímos ao álcool trans a maior estabilidade. Com base nos resultados das reações efetuadas em diferentes temperaturas (t.a. e $-78^{\circ} \mathrm{C}$ ) somos levados a acreditar que o álcool trans é não só o produto termodinâmico como também o cinético. 


\section{Esquema 52}

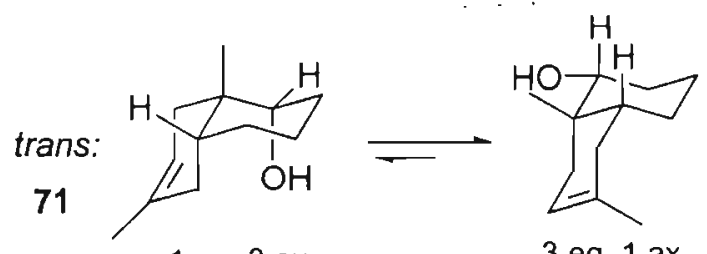

$1 \mathrm{eq}, 3$ ax
3 eq, 1 ax

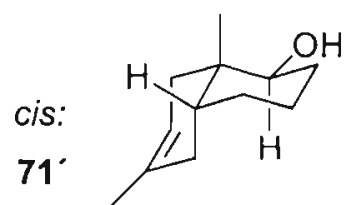

2 eq, 2 ax

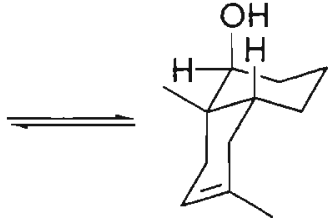

2 eq, 2 ax

Para a redução de ciclo-hexanonas, tanto o modelo de Felkin-Ahn, quanto o de Cram, falham na predição do produto favorecido; ambos os modelos indicam o álcool de configuração relativa cis, enquanto experimentalmente se observa o trans como majoritário, dependendo, é claro, da natureza do substrato. Posto isso, há que se levar em consideração fatores conformacionais e não esquecer da angulação de aproximadamente $110^{\circ} \mathrm{em}$ que ocorre 0 ataque do hidreto (trajetória de Bürgi-Dunitz). ${ }^{71}$

Vendo a molécula pelo ângulo da carbonila, temos que a conformação mais estável é aquela em que a metila ocupa uma posição equatorial (Esquema 53), em que o impedimento estérico deste grupo é pouco pronunciado. Desta maneira, o hidreto atacará preferencialmente em axial, levando ao álcool equatorial - e mais estável -, portanto trans.

\section{Esquema 53}
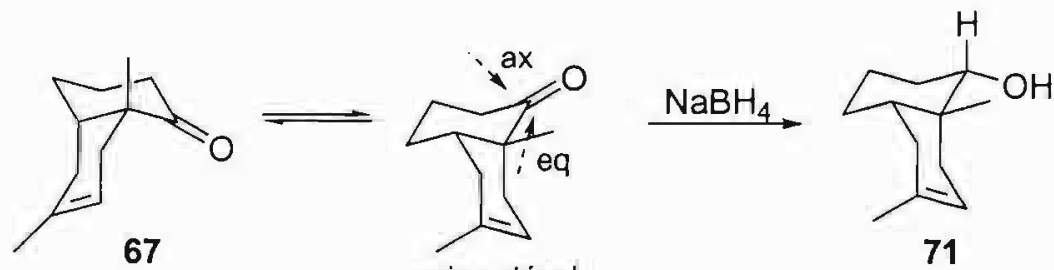

Preparado o álcool 71 em ótima diastereosseletividade, efetuamos a sua reação com TTN em TMOF e, para a nossa surpresa, obtivemos o éter cíclico 72 em $63 \%$ de rendimento como único produto formado, conforme mostrado no Esquema 54. 


\section{Esquema 54}

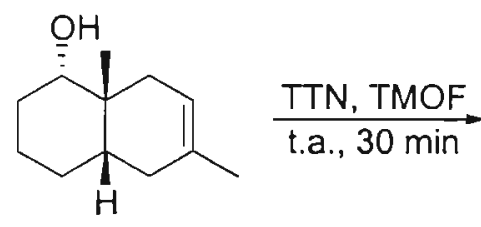

71<smiles>CO[C@H]1CC2(C)CC3CCCC2C3(C)C[C@H]1C</smiles>

$72(63 \%)$

Vista em 3 dimensões talvez seja mais fácil de entender, em termos mecanísticos, esta reação de ciclização. Assim, em primeiro lugar ocorre o ataque nucleofílico da ligação dupla ao TTN, formando o íon talônio I (uma espécie de complexo $\pi$ ). Posteriormente, ocorre a abertura trans-diaxial de talônio - o que só pode ocorrer através da conformação menos estável: aquela em que a hidroxila está em axial através do ataque intramolecular da hidroxila, levando ao aduto oxitaliado II, que sofre solvólise, originando finalmente o produto de ciclização 72 (Esquema 55). Cabe ressaltar que a estereoquímica do álcool é fundamental para que a ciclização ocorra, uma vez que a hidroxila se encontra bem perto da ligação dupla. O isômero 71' (hidroxila em cis com a metila angular) não atingiria a conformação adequada para a reação ocorrer.

\section{Esquema 55}

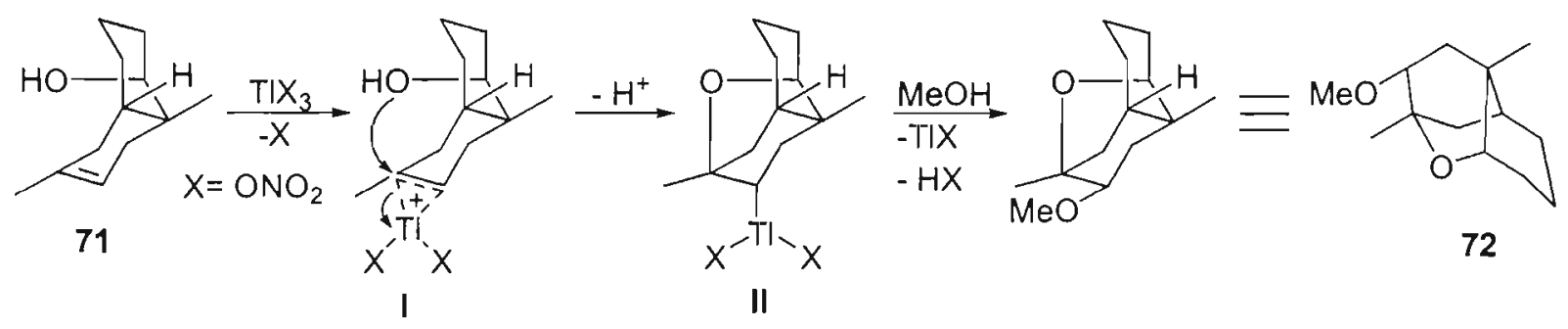

Num primeiro momento, este resultado pode até parecer surpreendente, mas há precedentes na literatura de ciclização de 4 -alquenóis com sais de mercúrio ${ }^{72}$ e de tálio. $^{35,37,73}$ No Esquema 56 está mostrada uma reação de ciclização de um substrato similar a $\mathbf{7 1}$ com acetato de mercúrio(II). ${ }^{72}$ Vale a pena ressaltar que estas reações de oxidação com sais de mercúrio se procedem por um mecanismo análogo ao dos sais de tálio(III). 


\section{Esquema 56}

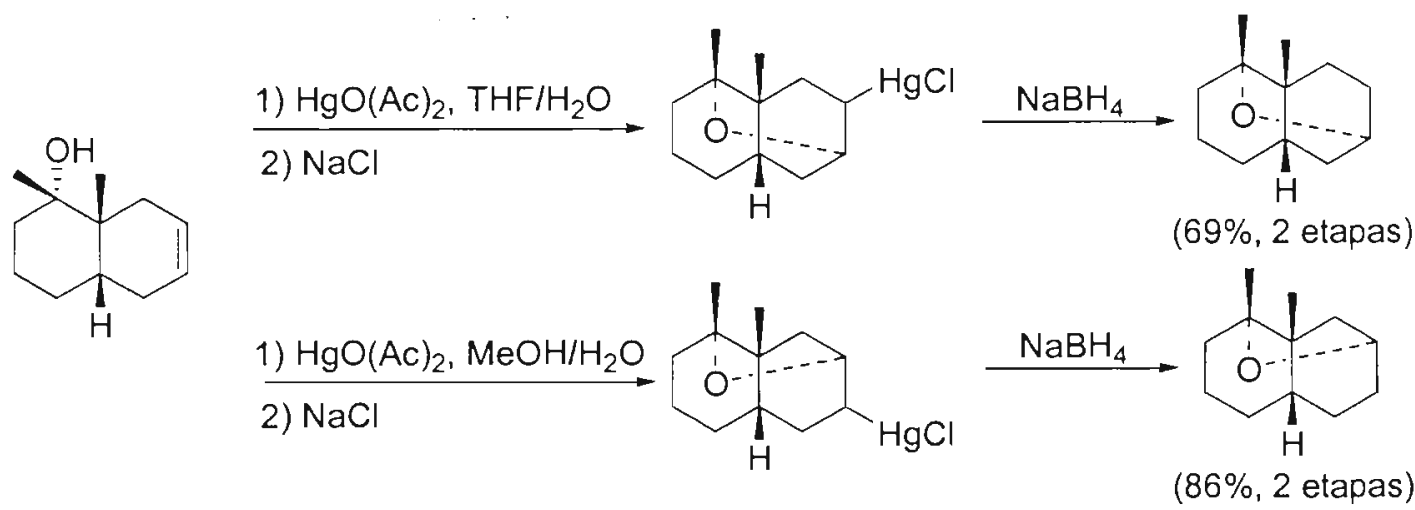

Apesar da natureza interessante do triciclo $\mathbf{7 2}$, não encontramos até o momento nenhuma classe de compostos com o mesmo esqueleto, para que pudéssemos propor uma possivel aplicação sintética para tal reação.

\subsubsection{Reação de Contração de Anel da Olefina 74 com TTN}

Por fim, efetuamos a redução total da carbonila de 67 (Esquema 57) nas mesmas condições de Wolff-Kishner utilizadas para o aduto $\mathbf{5 2}$, nos estudos visando à na síntese da nor-baquenolida-A (Esquema 28).

\section{Esquema 57}

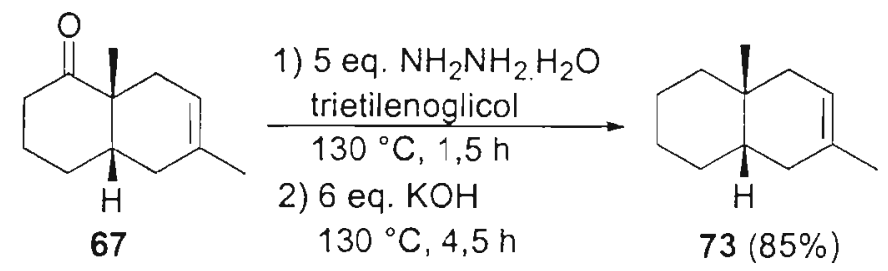

Realizamos a reação da olefina 73 com TTN e TTA em diversos solventes, a saber: metanol, TMOF, diclorometano, ácido acético e ácido acético-água (1:1). Para os três primeiros solventes, houve recuperação do material de partida, mesmo após longos tempos de reação (até 48 horas), parcialmente decomposto. Para os dois últimos, houve formação de uma mistura complexa de produtos. Resolvemos, então, efetuar a reação 
em metanol e adicionar apenas algumas gotas de ácido acético e, para nossa surpresa, foi possivel obter o produto de contração, embora em rendimento baixo, uma vez que houve a formação de uma gama bastante grande de produtos minoritários. A metil cetona $\mathbf{5 5}$ foi obtida na forma de uma mistura 1:1 dos isômeros cis e trans, como mostrado no Esquema 58.

\section{Esquema 58}

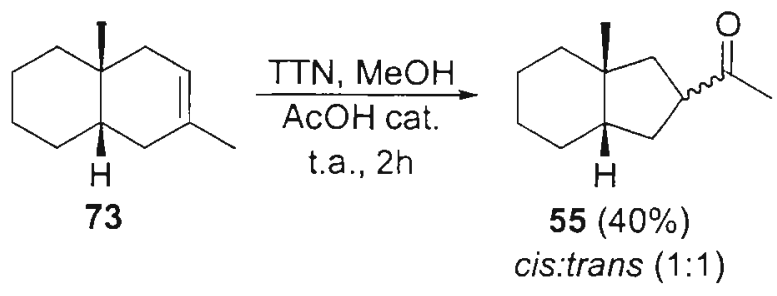

Para efeitos sintéticos, esta ausência de diastereosseletividade não é relevante, uma vez que na nossa proposta para a síntese de bacanos, a estereoquímica do centro quaternário em C-7 é determinada a posteriori. Por outro lado, o rendimento da reação não é satisfatório, embora tenha sido possivel obter numa só etapa a metil cetona $\mathbf{5 5}$ deve-se lembrar que na síntese da nor-baquenolida-A são necessárias quatro etapas para se chegar a $5 \mathbf{5}$ (Esquemas 29 e 30). De qualquer maneira, estes estudos devem ser continuados em nosso grupo de pesquisa, esperando obter resultados mais conclusivos. 


\subsection{Estudos Visando à Síntese da Baquenolida-A}

\subsubsection{Introdução}

Tendo em vista os estudos descritos no item 4.1 - isto é, as tentativas de síntese da nor-baquenolida-A -, imaginamos ser possivel aplicar a mesma seqüência para a sintese de 1, em que se empregaria também uma reação de contração de anel, mediada por tálio(III), da olefina $\mathbf{5 0}$, como mostrado na rota sintética descrita no Esquema 59 (cf Esquema 23 para melhor entendimento da rota sintética aqui proposta).<smiles>C[C@H]1CCC[C@H]2CC=CC[C@]12C</smiles>

51

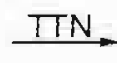<smiles>C[C@H]1CCC[C@@H]2C[C@H](C=O)C[C@]12C</smiles>

50

\section{Esquema 59}

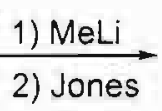

)<smiles>CC(=O)[C@@H]1C[C@H]2CCC[C@@H](C)[C@]2(C)C1</smiles>

42
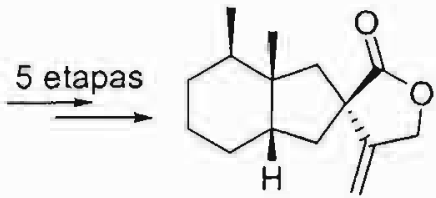

1

O ponto crítico da preparação da olefina 51 é o estabelecimento da relação cis entre as metilas em C-14 e C-15. Seria natural pensar que poderíamos preparar, numa única etapa, um aduto de Diels-Alder que contivesse o sistema bibíclico e as duas metilas em relação cis. Assim, teríamos de partir do 1,6-dimetilciclo-hexeno e butadieno, ou seja, uma reação de Diels-Alder tipo ciclo-hexeno/butadieno, em que o dieno e o dienófilo são desativados, existindo um grande "gap" de energia entre HOMO e LUMO. Reações como estas só acontecem em fase gasosa e a altas pressões e temperaturas, e não encontramos nenhuma descrição na literatura para a referida reação. Além do mais, não teríamos controle algum sobre a relação entre as metilas.

Apenas a título de curiosidade, mostramos a seguir duas possiveis rotas sintéticas que levariam inequivocamente a esta relação estereoquímica. Na primeira (Esquema 60), valer-nos-íamos de uma adição conjugada de dimetilzinco ${ }^{74}$ ou dimetilcuprato de lítio ${ }^{75,76}$ à enona $\mathbf{7 5}$, prepara através da reação de cicloadição regiosseletiva de $\mathbf{7 4}$ com o dieno de Danishefsky. Adição conjugada a $\mathbf{7 5}$ levaria à cetona $\mathbf{7 6}$, com relação correta entre as 
metilas, como previșto por nós com base em modelo molecular, levando em consideração - impedimento relativo entre as faces. Redução dos grupos éster e cetona aos álcoois correspondentes, seguida de redução com zinco em ácido acético, levaria, por fim, à olefina 51.

\section{Esquema 60}

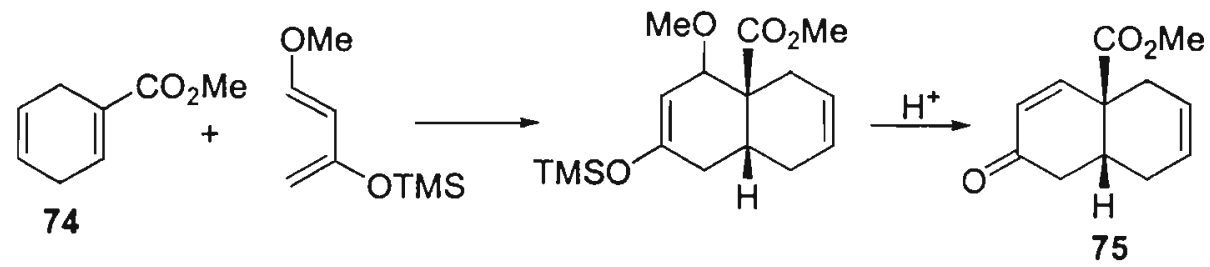

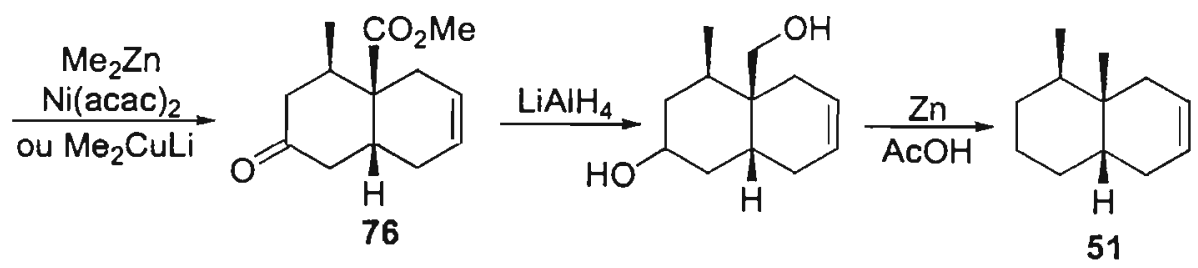

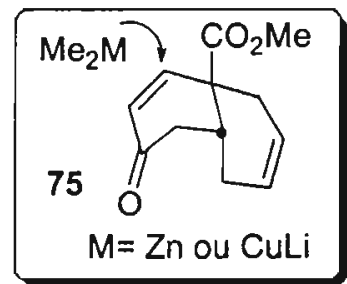

Na segunda abordagem (Esquema 61), prevalecer-nos-iamos da reação de DielsAlder, descrita por Kozmin, ${ }^{22}$ para a preparação de 32 . Homologação de 32, através de reação de Wittig seguida de hidrólise, levaria ao aldeído 77. Após hidrogenação catalítica e oxidação seletiva, o di-aldeído $\mathbf{7 8}$ seria obtido e poderia ser facilmente transformado no dieno 79, substrato adequado para reação de metátese, que daria origem então à olefina $\mathbf{5 1 .}$

\section{Esquema 61}

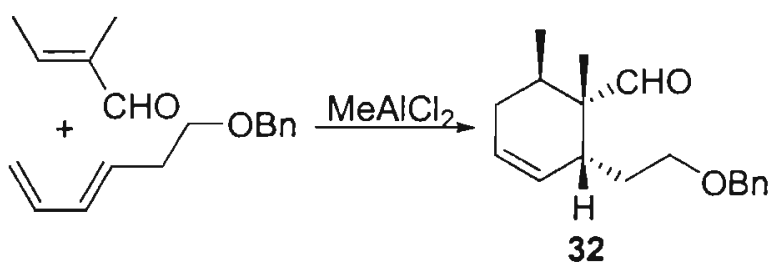

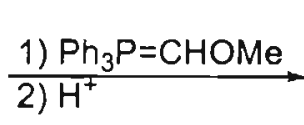

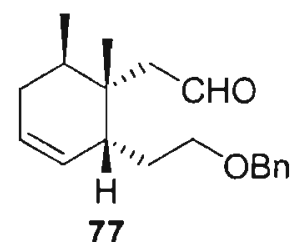

77<smiles>CC1CCCC(CC=O)(CC=O)[C@@]1(C)CCO</smiles>

78<smiles>c1ccccc1</smiles>

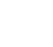<smiles>C=CC[C@H]1CCCC(C)[C@]1(C)CC=C</smiles>

79<smiles>[10BH2]C12CC=CCC(C)(C(C)CCC1)C2(C)C</smiles> 
Embora estas rotas sintéticas se mostrem interessantes e promissoras, elas são um pouco longas e muito elaboradas, uma vez que se trata da preparação do material de partida numa versão racêmica. Assim, decidimos investir em uma rota mais simples, que será discutida e mostrada no próximo item.

De mais a mais, devemos comentar que durante nossos estudos visando à síntese de bacanos, Reddy ${ }^{19}$ publicou a síntese da baquenolida-A (Esquema 10) na qual a metil cetona $\mathbf{4 2}$ foi preparada; portanto, a sintese desta cetona, conforme a rota descrita no Esquema 59, poderia ser caracterizada como uma sintese formal de 1.

\subsubsection{Definição da Relação cis entre as Metilas da Baquenolida-A}

\subsubsection{Primeira Abordagem}

Tendo sido possível a obtenção de álcool 71 - cuja hidroxila é trans em relação à metila - em excelentes rendimento e diastereosseletividade, imaginamos efetuar inversão do centro carbinólico, através de uma reação de acoplamento com um cuprato, - que levaria ao estabelecimento da relação cis entre as metilas da baquenolida-A. Assim, preparamos o tosilato $\mathbf{8 0}$, em rendimento bastante satisfatório, segundo condições clássicas : cloreto de tosila e piridina como base ${ }^{77}$ (Esquema 62).

\section{Esquema 62}

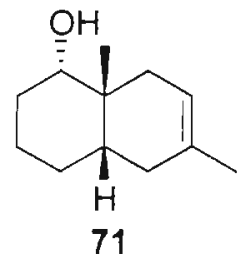

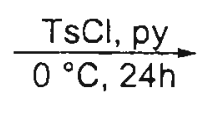

71

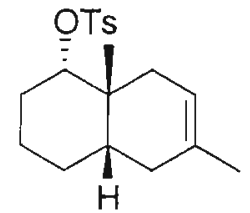

$81(62 \%)$

Todas as tentativas de acoplamento do tosilato $\mathbf{8 0}$ com dimetilcuprato de lítio foram infrutíferas (Esquema 63) e atribuímos esta falta de reatividade ao fato do centro a ser invertido ser um carbono tipo neopentílico, portanto muito impedido. Poderíamos 
tentar fazer o acoplamento com um reagente de Grignard, mas teríamos o mesmo efeito estérico. O mais surpreendente foi o fato de não ter sido obtido nem mesmo o produto de eliminação do grupo tosila.

\section{Esquema 63}

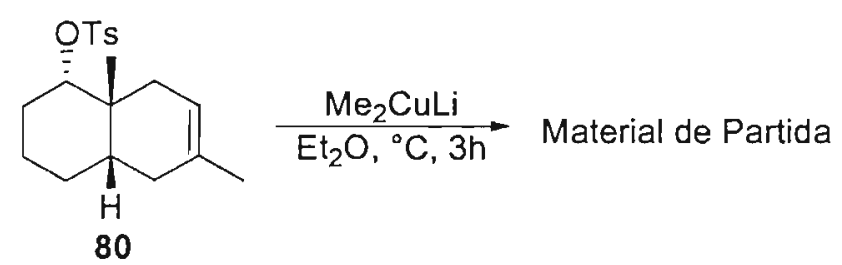

Mesmo assim, imaginamos que em condições mais drásticas talvez fosse possivel efetuar a inversão do centro carbinólico. Deste modo, planejamos a reação do tosilato com cianeto, que ocorre exclusivamente via mecanismo $S_{N} 2$. Através de transformações de grupo funcional, chegaríamos à olefina de interesse 81 (Esquema 64).

\section{Esquema 64}<smiles>CC1=CC[C@@]2([Se-])[C@@H](CCC[C@H]2[O-])C1</smiles>

80<smiles>CC1=CC[C@@]2(C#N)[C@@H](CCC[C@H]2C)C1</smiles>

$\mathrm{H}$<smiles>CC1=CC[C@]2(C)[C@@H](CO)CCC[C@H]2C1</smiles>
$\mathrm{H}$ $\frac{\text { 1) } \mathrm{MsCl}}{2) \mathrm{LiB}(\mathrm{Et})_{3} \mathrm{H}}$<smiles>CC1=CC[C@@]2(C)[C@@H](CCC[C@H]2C)C1</smiles>

81

Testamos a reação do tosilato $\mathbf{8 0}$ com cianeto de potássio e de sódio e, mesmo após aquecimento em DMSO por 48 horas, este se mostrou resistente à reação de substituição (Esquema 65).

\section{Esquema 65}

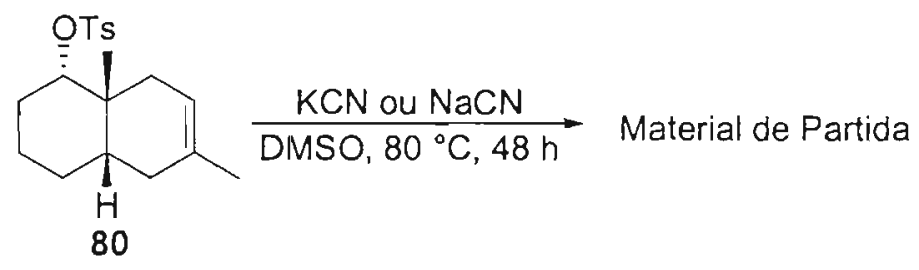

Em vista destes resultados, abandonamos esta abordagem e iniciamos uma outra, que será discutida no item subseqüente. 


\subsubsection{Segunda Abordagem}

Alternativamente, imaginamos ser possivel adaptar um procedimento descrito por Paquette $^{78}$ para a definição da relação cis entre as metilas. Assim, a metila seria colocada de maneira indireta, envolvendo a homologação da carbonila através da seguinte seqüência: reação de Wittig e hidrólise do enol éter $\mathbf{8 2}$ (ou $\mathbf{8 3}$ ), levando ao aldeído 84 (ou 85). 84 (ou 85 ) poderia ser submetido à reação de Wolff-Kishner, levando diretamente à olefina $\mathbf{8 1}$ (ou $\mathbf{5 1}$ ). No Esquema 66 está descrita a seqüência sintética proposta.

\section{Esquema 66}<smiles>CC1=CCC2(C)C(=O)CCC[C@H]2C1</smiles>

$\mathrm{R}=\mathrm{Me}(67)$ $\mathrm{R}=\mathrm{H} \quad$ (52)

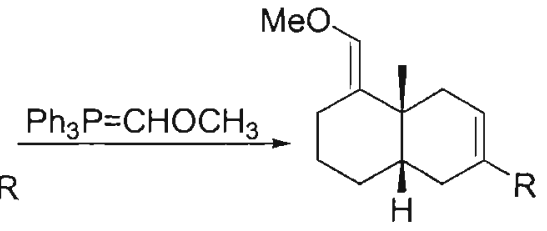

82

83<smiles>[R]C1=CC[C@]2(C)[C@@H](C=O)CC[C@H](C(C)Cl)C[C@H]2C1</smiles>

84

85

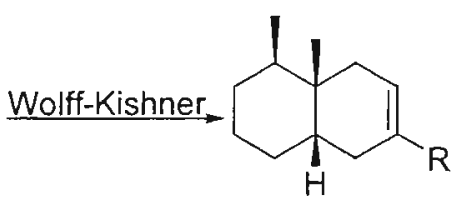

81

51

Efetuamos então a reação de Wittig da cetona 67 com cloreto de (metóximetil)trifenilfosfônio, utilizando hexametildissilazida de potássio (KHMDS) e tratamento com $\mathrm{HCl}$ no próprio meio reacional, como descrito na literatura. ${ }^{78}$ Para nossa surpresa, não obtivemos o aldeído 84 e, sim, o derivado tricíclico 86 em $37 \%$ de rendimento, como mostrado no Esquema 67.

\section{Esquema 67}<smiles>CC1=CC[C@]2(C)C(=O)CCC[C@H]2C1</smiles>

67
1) $\mathrm{Ph}_{3} \stackrel{+}{\mathrm{PCH}} \mathrm{CH}_{2} \mathrm{OCH}_{3}$ $\stackrel{\text { KHMDS, THF }}{-30^{\circ} \mathrm{C} \text { a t.a. } 17 \mathrm{~h}}$

2) $\mathrm{HCl} 4 \mathrm{~N}, \mathrm{MeOH}$ เ.a., $24 \mathrm{~h}$<smiles>CC1=C[C@H]2CCCC3C(O)[C@H](C1)[C@]32C</smiles>

$86(37 \%)$

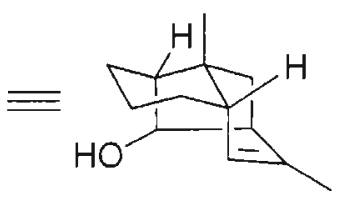


A formação de $\mathbf{8 7}$ pode ter se dado através do mecanismo mostrado no Esquema 68, em que a etapa de ciclização supostamente ocorre durante a hidrólise do éter enólico intermediário 83.

\section{Esquema 68}

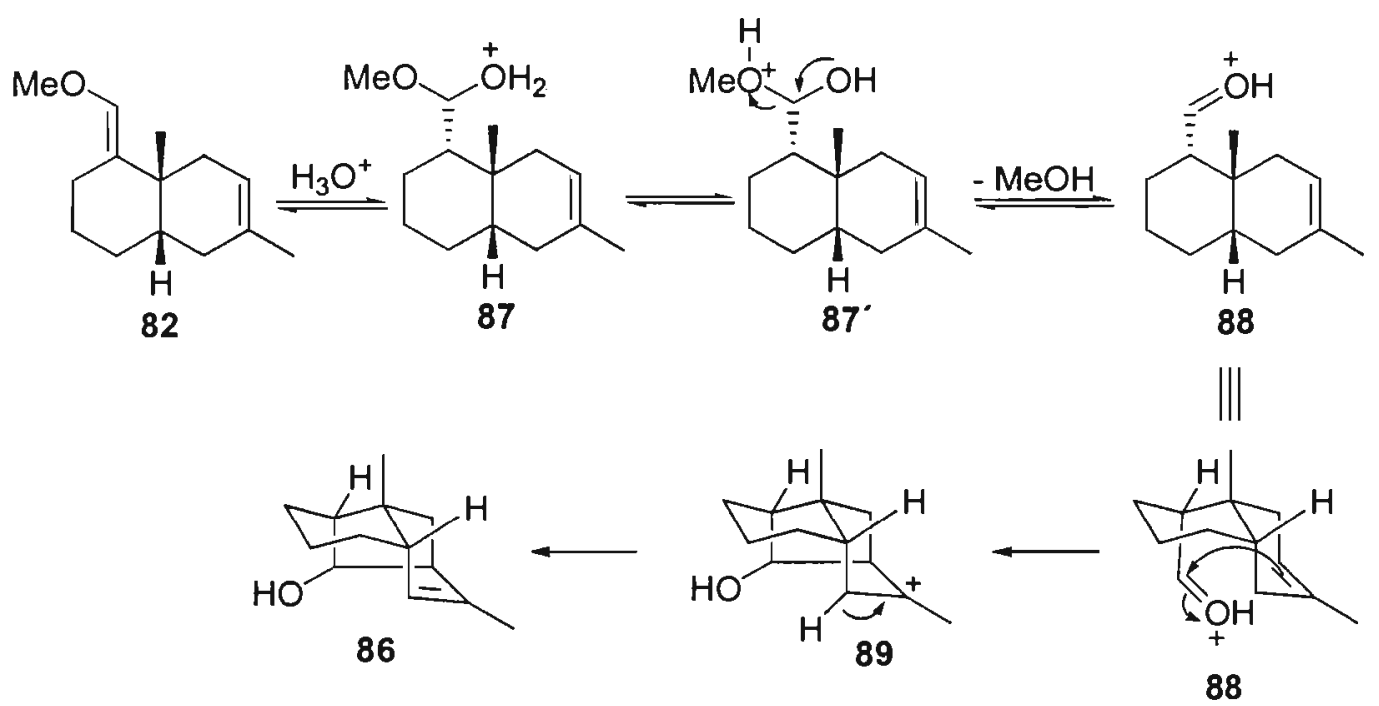

O primeiro passo do mecanismo descrito trata-se da hidratação da ligação dupla do enol éter, dando origem ao hemi-acetal protonado $\mathbf{8 7}$, que pode eliminar tanto água como metanol. No atual caso ocorreu a segunda possibilidade, valendo a pena ressaltar que estas reações são todas de equilíbrio. Assim, há formação do aldeído protonado $\mathbf{8 8}$, que sofre ataque nucleofílico da ligação dupla, gerando o carbocátion terciário 89, que leva ao triciclo $\mathbf{8 6}$, através da perda de um próton.

Entretanto, quando a octalona 52, que não contém dupla ligação trissubstituída, foi submetida às reações condicionais descritas acima, ${ }^{78}$ o aldeído 85 foi obtido como uma mistura 5:1 dos dois possíveis isômeros (Esquema 69), cujas configurações relativas não foi possivel determinar, embora acreditemos que o isômero majoritário seja trans. Tal suspeita é fruto da formação do triciclo $\mathbf{8 6}$ - obtido através da hidrólise do éter enólico 82, que contém a dupla ligação substituída -, uma vez que o rearranjo do oxônio para um carbocátion terciário só seria possivel se o grupo estiver em trans com a metila e em axial. 


\section{Esquema 69}

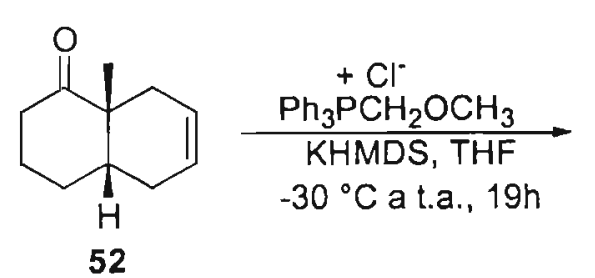<smiles>CO/C=C1\CCC[C@]2(C)CCCC[C@]12C</smiles>

$\underset{\mathrm{HCl} 4 \mathrm{~N}, \mathrm{MeOH}}{\stackrel{\mathrm{t} \text {.a., } 6 \mathrm{~h}}{\longrightarrow}}$<smiles>O=CC1CCC[C@]2([18F])CC=CC[C@H]12</smiles>

$(91 \%, 5: 1)$

Como a reação apresentou baixa diastereosseletividade, e não foi possível a determinação da estereoquímica relativa dos produtos formados, resolvemos abandonar esta rota sintética.

\subsubsection{Outra Possível Rota Sintética para a Baquenolida-A}

\subsubsection{Introdução}

Tendo em vista as dificuldades de estabelecer a relação cis entre as metilas do anel cis-octalínico que daria origem ao esqueleto central da baquenolida-A, propusemos uma rota alternativa em que partiríamos da 2-octalona 90 e, em quatro etapas, teríamos efetuado a síntese formal de 1, já que 42 é intermediário da síntese de Reddy (Esquema 10), ${ }^{19}$ como mostrado no Esquema 70.

\section{Esquema 70}<smiles>C[C@H]1CCCC2=CC(=O)CC[C@@]21C</smiles>

90<smiles>C[C@H]1CCCC2=CCC[C@@]21C</smiles>

91

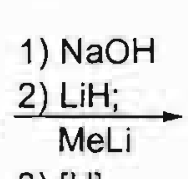

3) $[\mathrm{H}]$<smiles>C[C@H]1CCC[C@H]2CCC[C@@]12C</smiles>

42

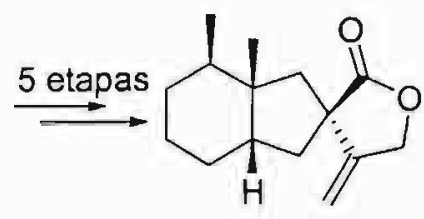

Baquenolida-A

Antes de descrevermos as três abordagens que utilizamos para a preparação da octalona 90, faremos uma breve descrição das rotas descritas na literatura até o 
momento. Mostraremos, nos itens que se seguem, tanto as sínteses racêmicas como as assimétricas de 90, uma vez que também tencionávamos uma abordagem assimétrica para a baquenolida-A.

\section{As sinteses racêmicas de 90}

O protocolo óbvio para a preparação de 901 é a anelação Robinson direta entre a 2,3-dimetilciclo-hexanona e a metil vinil cetona (MVK), catalisada por base. Neste procedimento, ${ }^{79-82}$ a base utilizada foi metóxido de sódio e os resultados não foram muito satisfatórios, uma vez que 90 foi obtida em apenas $15 \%$ de rendimento e numa proporção 3:2 para com o seu diastereoisômero trans 90', como ilustrado no Esquema 71.

\section{Esquema 71}<smiles>CC1CCCC(=O)C1C</smiles><smiles>COc1ccc(OC)cc1</smiles><smiles>CC1CCCC2=CC(=O)CCC21C</smiles>

90<smiles>C[C@H]1CCCC2=CC(=O)CCC21C</smiles>

$90^{\circ}$

$(15 \%, 3: 2)$

Também num protocolo de anelação de Robinson, Zoretic e Golen ${ }^{83}$ efetuaram a preparação de 90, em duas etapas, através de uma adição de Michael catalisada por ácido, seguida de condensação aldólica, mediada por base, das dicetonas intermediárias. Segundo os autores, foi obtida uma mistura $9: 1$, em $33 \%$ de rendimento das octalonas diastereoisoméricas 90 e 90', como mostrado no Esquema 72

\section{Esquema 72}

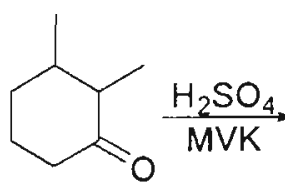<smiles>CONC(=O)CC[C@]1(C)C(=O)CCC[C@@H]1C</smiles><smiles>CC1CCCC2=CC(=O)CCC21C</smiles>

90<smiles>C[C@H]1CCCC2=CC(=O)CC[C@]21C</smiles>

90

$(33 \%, 9: 1)$ 
Porém, Huffman e col. $^{84}$ não conseguiram reproduzir os resultados supramencionados e afirmaram que a maior diastereosseletividade alcançada entre $\mathbf{9 0}$ e 90' foi de 3:1. Os autores propuseram uma outra abordagem para a preparação destas octalonas: adição de Michael do éter enólico de silício a um derivado dioxolano da MVK. Assim, após condensação aldólica, mediada por hidróxido de potássio, 90 foi obtida numa razão de 6:1 junto com seu diastereoisômero 90'; entretanto, o rendimento da reação de adição de Michael apresentado é cromatográfico e o da etapa de ciclização não foi mencionado, como pode ser visto no Esquema 73.

\section{Esquema 73}<smiles>CCOC1=C(C)C(C)CCC1</smiles>

MS<smiles>C=CC1(C)OCCO1</smiles><smiles>CC(=O)CCC1(C)C(=O)CCC[C@H]1C</smiles>

$(81 \%, C G)$

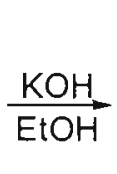

$\mathrm{EOH}$<smiles>CC1CCCC2=CC(=O)CCC21C</smiles>

90<smiles>C[C@H]1CCCC2=CC(=O)CC[C@@]21C</smiles>

$90^{\circ}$

Em um protocolo muito parecido com o de $\operatorname{Huffman}^{84}$ - utilizando um éter enólico de silício de TBDMS no lugar de TMS -, Duhamel e col. ${ }^{85}$ prepararam 90, em ótimo rendimento e excelente seletividade de 98:2, numa reação com MVK catalisada por ácido e $\mathrm{BF}_{3} \cdot \mathrm{Et}_{2} \mathrm{O}$, seguida de condensação aldólica em solução diluída de metóxido de sódio (Esquema 74).

\section{Esquema 74}<smiles>CC1=CCCCC1=O</smiles>
TBSTf<smiles>CCCCCCCCCCCCC</smiles>

$(73 \%)$<smiles>CCOC(=O)CCC1(C)C(=O)CCC(OC)C1CC(=O)OC</smiles>

$(72 \%)$<smiles>C[C@H]1CCCC2=CC(=O)CC[C@@]21C</smiles>

$90(85 \%)$

Os principais problemas envolvidos nas adições do tipo Michael a vinil cetonas são polimerização da vinil cetona e perda da regiosseletividade do enolato, em virtude da troca rápida de prótons. Com o intuito de superar tais complicações, Boeckman ${ }^{86-88}$ propôs uma rota alternativa para a preparação de $\mathbf{9 0}$, valendo-se de um aceptor de Michael estabilizado por silício (laboriosamente preparado em quatro etapas ${ }^{89}$ ) e de um 
enolato de cobre preparado regiosseletivamente através da alquilação da 2-metil-2-ciclohexenona (preparada em 2 etapas), como mostrado no Esquema 75.

\section{Esquema 75}

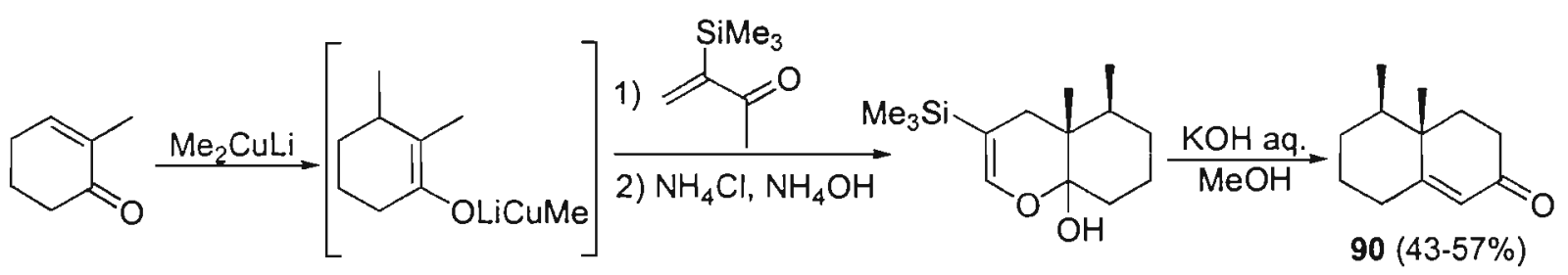

Piers e col. ${ }^{80}$ prepararam 90, diastereoisomericamente pura, através de uma rota longa, entretanto com alta seletividade na etapa de definição da relação cis entre as metilas, e envolvendo transformações com rendimentos médios muito superiores às rotas anteriores, conforme descrito no Esquema 76.

\section{Esquema 76}
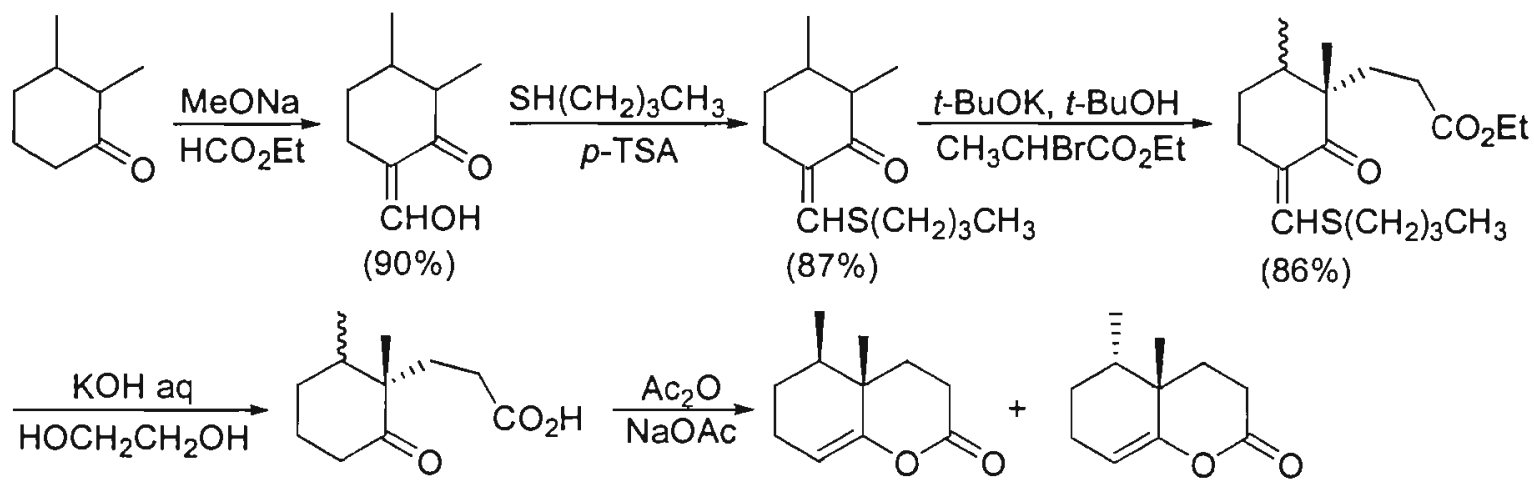

(90\%)

$(85 \%, 9: 1)$

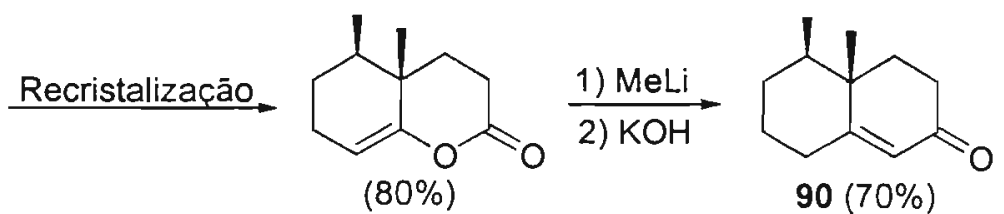

Por fim, Bonjoch e col. ${ }^{90}$ prepararam 90 numa sequência de 8 etapas e análoga à de Piers, ${ }^{80}$ porém partindo-se da 3-metilciclo-hexanona e utilizando uma enamina como grupo bloqueador da posição $\alpha$ da carbonila, em rendimento total de $24 \%$. 


\section{As sinteses assimétricas de 90}

(+)-90 é o enantiômero que poderia ser usado na síntese da (+)-baquenolida-A e há apenas duas sínteses laboriosas publicadas até 0 momento. ${ }^{78,91} \mathrm{~A}$ primeira delas, de seis etapas, foi descrita por Paquette ${ }^{78}$ (Esquema 77), partindo-se da (+)-cetona de Wieland-Miescher (92), cuja preparação assimétrica catalisada por S-(-)-prolina é bem estabelecida. ${ }^{92}$ Vale a pena ressaltar que Bui e Barbas III $^{93}$ recentemente mostraram a preparação "one-pot" de $\mathbf{9 2}$, entretanto em rendimento moderado (49\%) e baixo excesso enantiomérico (76\%).

\section{Esquema 77}

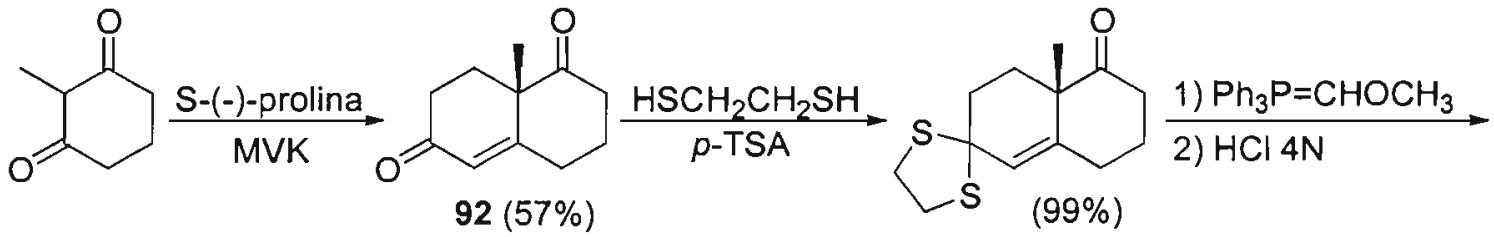<smiles>C[C@]12CCC3(C=C1CCC[C@H]2C=O)SCCS3</smiles>

7:1 (cis:trans) $(93 \%)$

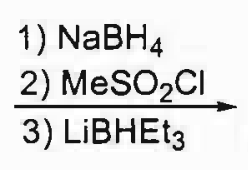

1) $\mathrm{NaBH}_{4}$
3) $\mathrm{LiBHEt}_{3}$<smiles>C[C@H]1CCCC2=CC3(CCC21C)SCCS3</smiles>

$(72 \%)$<smiles>CC1CCCC2=CC(=O)CCC21C</smiles>

$(+)-90(93 \%)$

Na rota descrita por Jenniskens e De Groot $^{91}$ para a preparação de (+)-90, que envolve nove etapas (Esquema 78), parte-se de S-carvona e, é portanto, a isopropenila a responsável pela diastereosseletividade das transformações químicas. O material de partida é caro, pois não se trata do enantiômero abundante da carvona, e há perda de três carbonos durante o rearranjo de Criegee sendo, portanto, uma síntese de baixa economia de átomos. 

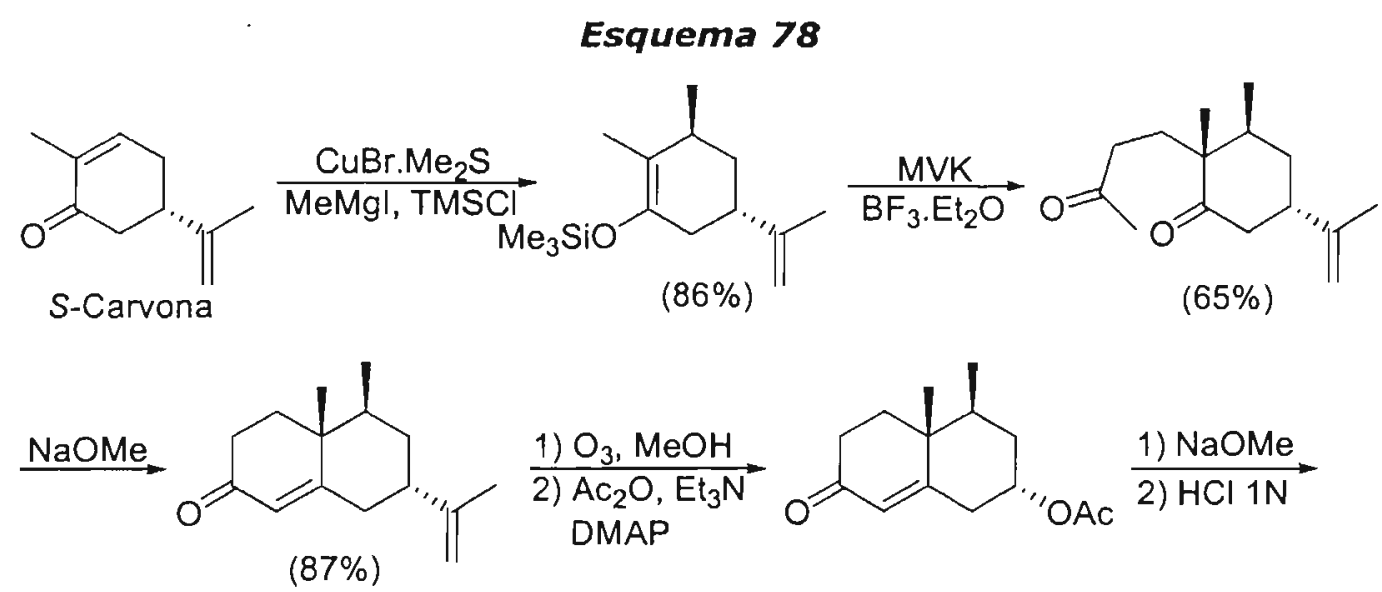<smiles>C[C@H]1CC=CC2=CC(=O)CC[C@]21C</smiles>

$61 \%$ (2 etapas)

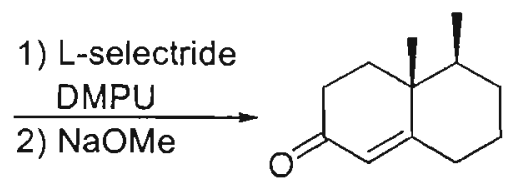

$(+)-90(58 \%)$

Na síntese descrita por Cuesta e col., ${ }^{94}$ parte-se da $(R)$-3-metilciclo-hexanona e, numa sequência de 8 etapas, muito semelhante à de Piers, ${ }^{80}$ chega-se a (-)-90. Além do grande número de etapas, a maior desvantagem é o preço elevado do material de partida.

Tenius e col. ${ }^{95}$ prepararam (-)-90 em seis etapas, partindo da (+)- $R$-pulegona e valendo-se de uma enamina quiral na etapa de adição de Michael, conforme mostrado no Esquema 76.

\section{Esquema 79}<smiles>CC(C)=C1CC[C@@H](C)CC1=O</smiles>

$$
\frac{\text { 1) } \mathrm{LDA}, \mathrm{Mel}}{\text { 2) } \mathrm{KOH}, \mathrm{MeOH}}
$$

R-Pulegona<smiles>C[C@H]1CCCC(=O)[C@@H]1C</smiles>

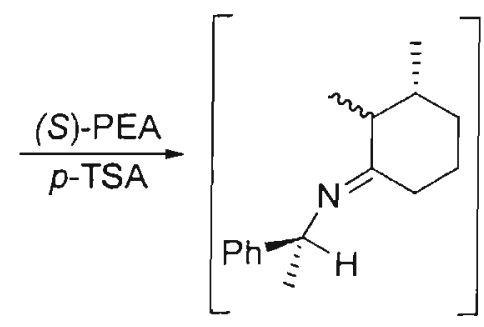<smiles>CC(=O)CC[C@]1(C)C(=O)CCC[C@H]1C</smiles>

(69\%)
NaOMe<smiles>C[C@H]1CCCC2=CC(=O)CC[C@@]21C</smiles>

(-)-90 (43\%) 
Apesar de não estar mostrado no Esquema 79, a etapa de adição de Michael leva à formação de subprodutos, que são carregados até a última etapa, daí o motivo do baixo rendimento desta.

\subsubsection{Preparação da Octalona 90}

\section{Procedimento de Zoretic}

Dentre todos os métodos de preparação de $\mathbf{9 0}$ descritos no item anterior, julgamos melhor tentar repetir as condições descritas por Zoretic, ${ }^{83}$ uma vez que era a rota mais simples e curta e com suposta alta seletividade.

O material de partida, a 2,3-dimetilciclo-hexanona, por não ser comercial, foi preparado em grande escala através da oxidação direta do 2,3-dimetilciclo-hexanol com reagente de Jones, ${ }^{60}$ em ótimo rendimento (Esquema 80 ).

\section{Esquema 80}

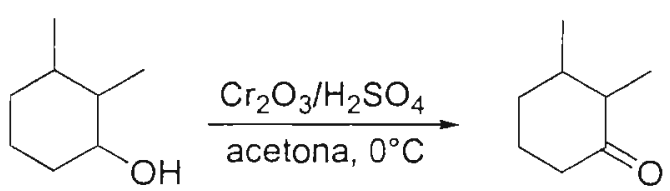

$(80 \%)$

A 2,3-dimetilciclo-hexanona foi submetida à reação de anelação de Robinson com MVK em meio de benzeno e ácido sulfúrico. Foi necessária etapa posterior de ciclização da dicetona 93 em metóxido de sódio. Em todas as tentativas, não foi possivel conseguir rendimento superior a $23 \%$, e mais, a diastereosseletividade, determinada por ${ }^{1} \mathrm{H}-\mathrm{RMN}$, foi de $4: 1$ e não de 9:1, como publicado pelos autores. Os resultados estão resumidos no Esquema 81. 


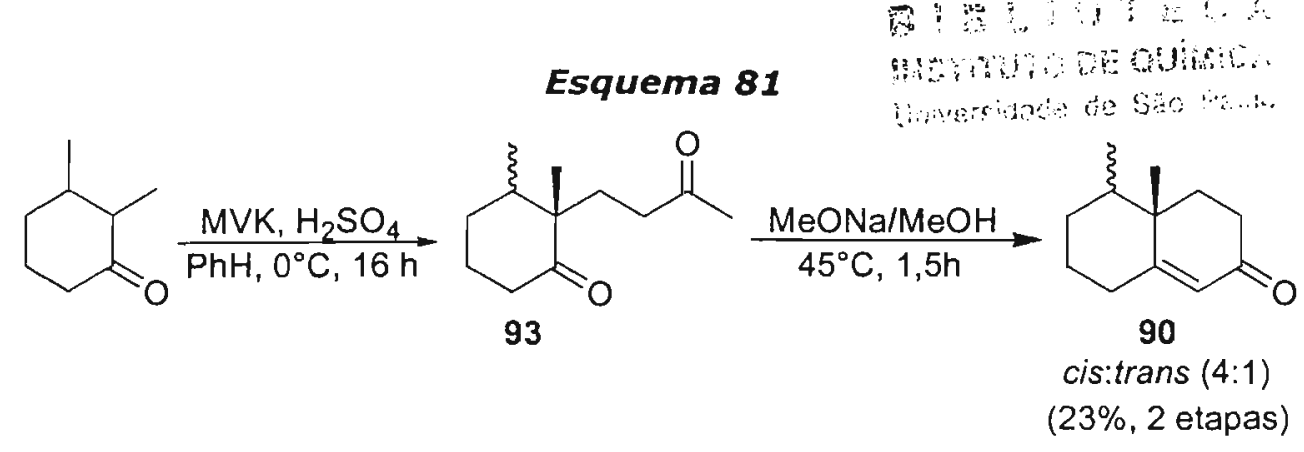

A preparação mencionada acima apresenta alguns fatores complicadores, como, por exemplo, a extensa polimerização da MVK, que é utilizada em grande excesso, tornando-se necessária a utilização de agitação mecânica. Após extração, o material polimérico formado é destilado na trompa de vácuo, para retirar a 2,3-dimetilciclohexanona não consumida ( $c a$. de $30 \%$ ) e depois à pressão reduzida, para fornecer a mistura de 90 e das dicetonas 93. Outros subprodutos da reação são as cetonas bicíclicas (ca. $5 \%$ conforme descrito pelos autores) mostradas na Figura 4 . Tendo em vista o baixo rendimento da transformação e, sobretudo, a baixa seletividade, decidimos testar outra rota de preparação da 2-octalona $\mathbf{9 0 .}$

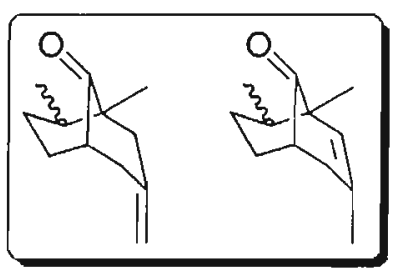

Figura 4

\section{Procedimento de Duhamel Adaptado}

Em vista da baixa estereosseletividade do procedimento de Zoretic, decidimos preparar 90, utilizando a segunda parte do protocolo descrito por Duhamel et al. ${ }^{85}$ (Esquema 74). Como na época não tínhamos TBSTf em nosso laboratório, optamos por preparar o éter enólico de silício na forma de TMS, a partir da 2,3-dimetilciclo-hexanona, já preparada em grande escala. 
Várias são as possibilidades de preparação de éteres enólicos de silicio termodinâmicos, como descrito por Krafft e Holton ${ }^{96}$. Seguindo um procedimento clássico, ${ }^{97,98}$ os éteres enólicos de silício termodinâmico 94 e cinético 95 foram obtidos na forma de uma mistura 1:1 (Esquema 82).

\section{Esquema 82}<smiles>CC1CCCC(=O)C1C</smiles>
$\frac{\text { TMSCl, Nal, EtN }}{\mathrm{CH}_{3} \mathrm{CN}, \text { t.a., } 3,5 \mathrm{~h}}$<smiles>COC1=C(C)C(C)CCC1</smiles>

94<smiles>COC1=CCCC(C)C1C</smiles>

95

$(80 \%, 1: 1)$

Tendo em vista a baixa regiosseletividade supramencionada, empregamos uma outra condição ${ }^{99,100}$ para a preparação de 94 ; este foi obtido junto com ca. de $20 \%$, determinado por CG, dos outros isômeros cinéticos 95 em $92 \%$ de rendimento (Esquema 83).

\section{Esquema 83}<smiles>CC1CCCC(=O)C1C</smiles><smiles>CCC(C)[AsH2][Mg]</smiles><smiles>CCOC1=C(C)C(C)CCC1</smiles>

94<smiles>COC1=CCCC(C)C1C</smiles>

95

$(92 \%, 4: 1)$

Apesar da seletividade não ser das melhores, decidimos prosseguir usando esta mistura de éteres enólicos de silício. Vale a pena lembrar que Duhamel et al. ${ }^{85}$ obtiveram os enóis éteres de silício de análogos a 94 e 95 (TBDS no lugar de TMS) em uma proporção de 97:3.

Sendo assim, a mistura de 94 e 95 em nitrometano foi tratada com MVK, ácido dibenzoiltartárico (DBAT) e $\mathrm{BF}_{3} . \mathrm{Et}_{2} \mathrm{O}$, a $-20^{\circ} \mathrm{C}$. Em todas as tentativas, houve principalmente desproteção do éter enólico de silício e apenas 20-30\% de formação do produto de adição. Trata-se de uma reação extremamente sensível, de modo que vários fatores podem ter influenciado: controle da temperatura do banho criogênico, traços de 
água no solvente e problemas de secagem do DBAT, que é relativamente higroscópico. Há uma grande desvantagem neste método, que, de certa forma, inviabiliza sua extensão a maiores escalas: a quantidade elevada de nitrometano utilizado, solvente caro, pelo menos no Brasil.

Em vista destes resultados desanimadores, adaptamos o procedimento descrito por Jenniskens, ${ }^{91}$ uma vez que o enol éter de silício empregado também era de TMS. As condições experimentais utilizadas estão resumidas no Esquema 84.

\section{Esquema 84}

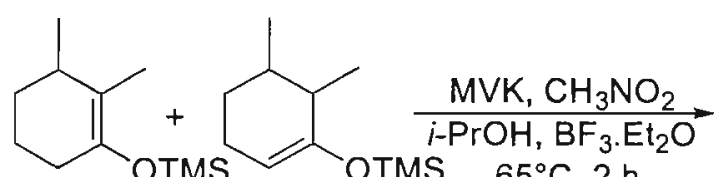

94 $4: 1$<smiles>CC(=O)CCC1(C)C(=O)CCC[C@H]1C</smiles>

$93(48 \%, 2$ etapas $)$<smiles>CO[N+]([O-])(O)[C@H]1CCCC2=CC(=O)CC[C@]2(C)[C@@H]1C</smiles>

90 cis:trans $(9: 1)$

$(72 \%)$

Deve-se ressaltar que o rendimento das primeiras duas etapas (48\%) pode ser perfeitamente aceitável, tendo em vista a pureza do silil enol éter intermediário (80\%), e o fato de que sempre é recuperada 2,3-dimetilcicloexanona, proveniente da desproteção dos éteres enólicos de silício 94 e $\mathbf{9 5}$. Então, 90 foi obtida junto com seu isômero 90' numa proporção de 9:1. Portanto, acreditamos que este seja um bom método para a preparação de $\mathbf{9 0}$, que foi feita em escala de multigramas.

A diastereosseletividade observada pode ser facilmente racionalizada com base na análise conformacional dos enolatos intermediários formados (Esquema 85). A reação via o confôrmero B permite alívio da interação do tipo $A^{(1,2)}$, como discutido por Johnson, ${ }^{101}$ entre os grupos metila e favorece uma aproximação axial do agente alquilante, em virtude de fatores estereoeletrônicos, levando assim, à relação cis observada entre as metilas, ou seja, adição trans, quase que total, do eletrófilo. 


\section{Esquema 85}

A

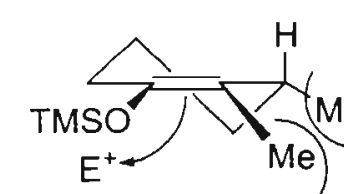

ataque axial por baixo $A^{(1,2)}$

B<smiles>CCCC1CC(OC)CC(C)C1C</smiles>
ataque axial por cima<smiles>C#CC(=O)C1(F)CCCCC1C#C</smiles><smiles>C[C@H]1CCCC(=O)C1(C)C</smiles><smiles>O=C1CC2CCCC(C1)C2</smiles><smiles>C#CCC[C@H](C)[C@@]1(C)CCCC(=O)[C]1F</smiles>

O procedimento descrito nos Esquemas 83 e 84 para a preparação de 90 é bastante sucinto, entretanto envolve reagentes caros como, por exemplo, iodotrimetilsilano e nitrometano. Além disso, não só a seletividade na preparação do éter enólico de silício termodinâmico 94 é baixa (4:1), como também o próprio rendimento da etapa de adição de Michael não é tão satisfatório. Além do mais, a escala tem de ser limitada (máximo de $80 \mathrm{mmol}$ ) em virtude da manipulação de grandes volumes de solvente (Vide Parte Experimental). Estes já seriam motivos suficientes para a alteração da rota sintética.

\section{Procedimento de Cuesta e Piers adaptado}

Com base nos motivos supramencionados, decidimos efetuar a preparação de $\mathbf{9 0}$ adaptando o procedimento descrito por Cuesta et al. ${ }^{94}$ para a síntese assimétrica de (-)90, numa seqüência muito parecida com a descrita por Piers et al. ${ }^{80}$ (Esquema 76).

Partimos, mais uma vez, da 2,3-dimetilciclo-hexanona, e efetuamos o bloqueio da posição alfa através de reação de formilação, seguida de transformação na respectiva 
enamina 96 em $73 \%$ de rendimento. Esta foi então alquilada com 3-bromoacetato de etila na única posição alfa disponível. O aduto foi então tratado com $\mathrm{HCl}$, com intuito de hidrolisar a função enamina, e em seguida tratado com $\mathrm{NaOH}$ para hidrolisar o éster, fornecendo, assim, o ácido $97 \mathrm{em} 78 \%$ de rendimento. Este foi transformado numa mistura epimérica (6:1) das enóis lactonas 98 e $\mathbf{9 8}$ em 75\%. As lactonas puderam ser separadas por recristalização em hexano, sendo possível obter 98 pura em $62 \%$ de rendimento. Reação de $\mathbf{9 8} \mathrm{com} \mathrm{MeLi}$, seguida de tratamento com KOH metanólico, levou à octalona 91 em $60 \%$. O resumo da rota sintética, em rendimento total de $16 \%$, está mostrado no Esquema 86.

\section{Esquema 86}
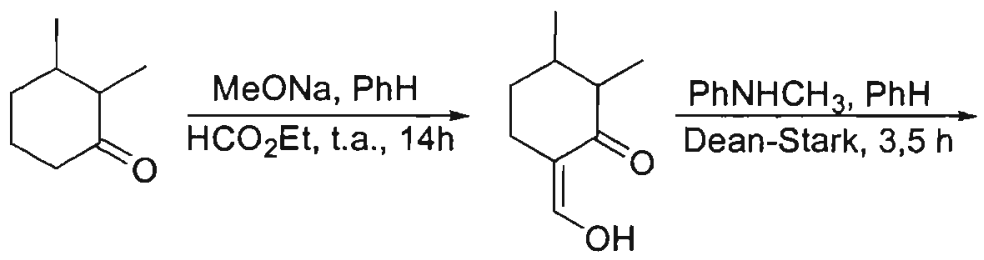<smiles>CN/C=C1/CCC(C)C(C)C1=O</smiles>

73\% (2 etapas) $\mathrm{Ph} 96$

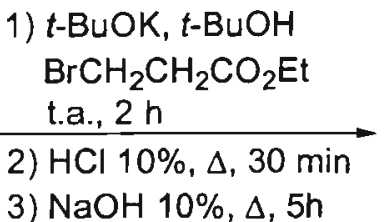

3) $\mathrm{NaOH} 10 \%, \Delta, 5 \mathrm{~h}$<smiles>C[C@H]1CCCC(=O)[C@]1(C)CCC(=O)O</smiles>

97 (78\%)

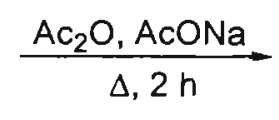<smiles>C[C@H]1CCC=C2OC(=O)CC[C@]21C</smiles>

$98+98^{\circ}(75 \%)$ cis:trans $(6: 1)$<smiles>CC1CCC=C2OC(=O)CC[C@]2(C)C1(C)C(C)(C)C</smiles>

$98(62 \%)$

$$
\begin{aligned}
& \text { 1) } \mathrm{MeLi}, \mathrm{Et}_{2} \mathrm{O} \\
& \text { t.a., } 1,5 \mathrm{~h} \\
& \text { 2) } \mathrm{KOH}, \mathrm{MeOH}
\end{aligned}
$$
$\triangle, 2 \mathrm{~h}$<smiles>CC1CCCC2=CC(=O)CC[C@]21C</smiles>

$90(60 \%)$

A transformação da enol lactona 98 em 90 pode ser facilmente racionalizada como sendo a abertura de um éster cíclico para formar a dicetona 93 (cf Esquema 84), seguida de condensação aldólica intramolecular, como nas preparações descritas anteriormente, porém utilizando $\mathrm{KOH}$ como base. A vantagem do uso de $\mathrm{KOH}$ metanólico é a eliminação das condições anidras. 


\subsubsection{Reação de Contração de Anel da Octalona 90}

Mincione et al. ${ }^{102}$ mostraram a contração de anel de 1-octalonas, 2-octalonas e enonas esteroidais em rendimentos bastante variáveis. Como mostrado no Esquema 87, a 2-octalona 99, quando tratada com TTN em uma mistura de trimetilortoformiato (TMOF) e MeOH, forneceu o produto de contração 100 em $61 \%$ de rendimento.

\section{Esquema 87}<smiles>C[C@H]1CCC[C@]2(C)CCC(=O)C=C12</smiles>

99

\section{$\frac{\text { TTN, TMOF }}{\mathrm{MeOH}, 0^{\circ} \mathrm{C}, 30 \mathrm{~min}}$}<smiles>CC(=O)[C@H]1C=C2[C@@H](C)CCC[C@]2(C)C1</smiles>

$100(61 \%)$

Aplicando as mesmas condições experimentais de Mincione para a octalona 90, foi possivel isolar, de uma mistura de produtos e em apenas $36 \%$ de rendimento, o produto de contração 91, como mostrado no Esquema 88.

\section{Esquema 88}<smiles>CC1CCCC2=CC(=O)CCC21C</smiles>

90

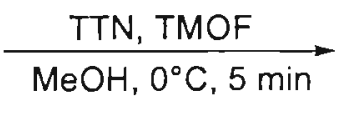

$\mathrm{MeOH}, 0^{\circ} \mathrm{C}, 5 \mathrm{~min}$

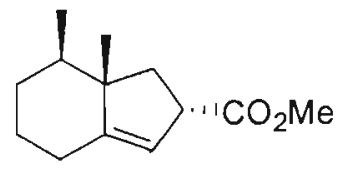

$91(36 \%)$

Utilizando apenas TMOF como solvente, $\mathbf{9 1}$ foi obtido em $38 \%$ de rendimento, ou seja, não houve melhora no método. Outros solventes, como, por exemplo, $\mathrm{CH}_{2} \mathrm{Cl}_{2}$ e $\mathrm{HClO}_{4}$ foram testados e houve recuperação do material de partida, no primeiro caso, e formação de mistura complexa de produtos, no segundo caso.

É curioso notar que a reação de contração de anel da octalona 101, que também não contém uma metila em C-8, levou à formação do produto de contração 102 em apenas $36 \%$ de rendimento, como mostrado no Esquema $89 .{ }^{102}$ 


\title{
Esquema 89
}<smiles>C[C@]12CCCCC1=CC(=O)CC2</smiles>

101

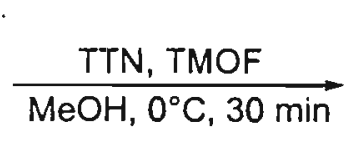

$\mathrm{MeOH}, 0^{\circ} \mathrm{C}, 30 \mathrm{~min}$

\begin{abstract}
(1)
\end{abstract}
.

Embora não saibamos exatamente o porquê desta diferença de comportamento, nos parece claro que a metila em C-8 desempenha algum papel que favorece a contração de anel de 99. Aventamos a proposta de que a ausência da metila em C-8 eventualmente possibilitasse a formação de uma outra forma enólica (Figura 5) que originaria outros produtos de adição à dupla ligação. De qualquer forma, não podemos ser categóricos em afirmar tal fato, uma vez que não foi possível o isolamento, e tampouco a caracterização, dos subprodutos; ademais, não houve formação de nenhum subproduto em proporções relevantes, como comprovado por análise por cromatografia gasosa.

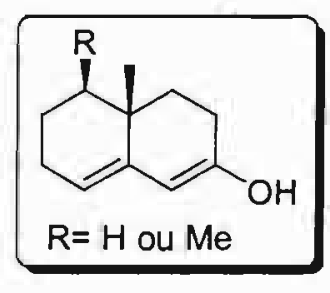

Figura 5

Tendo em vista este resultado pouco satisfatório, decidimos procurar outras condições para a contração de anel de $\mathbf{9 0}$. Como é bem conhecido na literatura, ${ }^{103}$ compostos de iodo hipervalente promovem rearranjos oxidativos, como, por exemplo, contrações de anéis de cetonas cíclicas. Exempios de contração de cetonas $\alpha, \beta-$ insaturadas com iodobenzeno diacetato (IBD) estão mostrados no Esquema $90 .{ }^{104}$

\section{Esquema 90}<smiles>[R]c1ccc(C=C2CCCCC2=O)cc1</smiles>

$\mathrm{R}=\mathrm{H}, \mathrm{Me}, \mathrm{OMe}, \mathrm{Cl}$

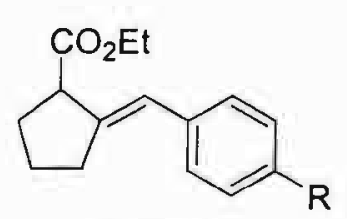

$58-74 \%$ 
Nas mesmạs condições referidas acima e também trocando trietilortoformiato (TEOF) por TMOF, 90 sofreu decomposição. Na ausência de ácido como catalisador, 90 não reagiu com IBD, mesmo após 24 horas de reação, em metanol, etanol, TMOF ou TEOF. Fizemos o "branco" da reação e, na ausência de IBD, o substrato também sofreu decomposição, em menos de cinco minutos, em meio de ácido perclórico ou sulfúrico. Assim, não foi possivel contração de $\mathbf{9 0}$ em nenhuma das condições testadas.

Em virtude do baixo rendimento $(38 \%)$ da etapa chave da síntese proposta para a baquenolida- $A$, isto é, a reação de contração de anel da octalona $\mathbf{9 0}$, decidimos abandonar esta seqüência sintética.

\subsubsection{Tentativas de Contração de Outras Cetonas}

Pensamos também na possibilidade de utilizar a cetona de Wieland-Miescher (92), bem como seu respectivo álcool 103, como possiveis materiais de partida para a síntese da baquenolida-A. Embora comercial, preparamos 92 em duas etapas, através de procedimentos clássicos, a partir da 1,3-ciclo-hexanodiona (Esquema 91). ${ }^{105,106}$

\section{Esquema 91}<smiles>O=C(O)OC1(O)C(=O)CCCC1=O</smiles>
$\Delta$, overnight<smiles>CC1C(=O)CCCC1=O</smiles>

1) $\mathrm{KOH}, \mathrm{MeOH}$ $\underset{\text { 2) pirrolidina, } \phi \mathrm{H}}{\mathrm{MVK}, \Delta, 3 \mathrm{~h}}$ Dean-Stark, $1 \mathrm{~h}$

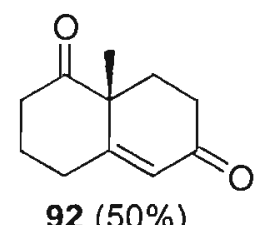

$92(50 \%)$

Por sua vez, 103 foi obtido através do protocolo clássico de redução seletiva de 92 com boro-hidreto de sódio em etanol ${ }^{107}$ (Esquema 92).

\section{Esquema 92}<smiles>C[C@]12CCC(=O)C=C1CCCC2=O</smiles>

92<smiles>C[C@@]12CCC(=O)C=C1CCC[C@@H]2O</smiles>

103 (67\%) 
Muito embora a preparação dos materiais de partida 92 e 103 tenha sido trivial, as tentativas de contração deles com TTN levaram à formação de uma mistura complexa de produtos em todas os solventes testados ( $\mathrm{MeOH}$, TMOF e $\mathrm{CH}_{2} \mathrm{Cl}_{2}$ ).

\subsubsection{Tentativas de Contração do Dieno 105}

A migração vinílica de dienos no rearranjo oxidativo com sais de tálio(III), geralmente ocorre em conjunto com a formação de produtos de adição 1,2 e 1,4. ${ }^{108-110}$ Um exemplo de reação do 1,3-ciclo-hexadieno com TTN está mostrado no Esquema 93. ${ }^{110}$

\section{Esquema 93}

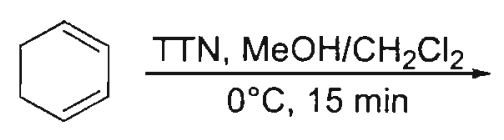

$(31 \%)$<smiles>COC(OC)C1C=CCC1</smiles><smiles>COC1C=CCCC1OC</smiles>

$(10 \%)$<smiles>COC1C=CC(OC)CC1</smiles>

$(12 \%)$

Rigby e Pigge ${ }^{111}$ aplicaram, entretanto, a contração de um dieno na síntese da (+)-ferruginina, como mostrado no Esquema 94.

\section{Esquema 94}
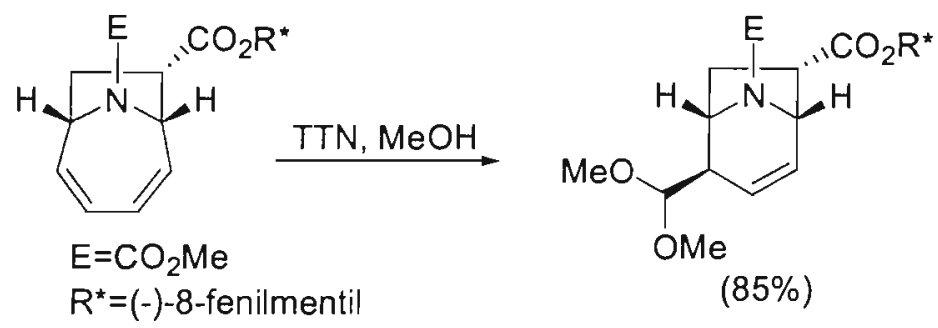

$(85 \%)$

Com base nos resultados de Rigby ${ }^{11}$ e no baixo rendimento obtido para a contração de $\mathbf{9 0}$, decidimos investigar a reação de TTN com o dieno conjugado 104, que seria facilmente preparado em duas etapas a partir de $\mathbf{9 0}$, como mostrado no Esquema 95. 


\section{Esquema 95}<smiles>C[C@H]1CCCC2=CC(=O)CC[C@]21C</smiles>

90
$\stackrel{\mathrm{NaBH}_{4}}{\longrightarrow}$<smiles>C[IH+]</smiles><smiles>CC1CCCC2=CC=CCC21C</smiles>

104

Como a preparação da octalona 90 é bastante laboriosa, decidimos preparar um substrato análogo, que difere apenas de uma metila em C-5 isto é, a o 2-octalona 101, para então preparar o dieno 105, análogo a 104. 101 foi preparada segundo procedimento clássico de anelação de Robinson entre a 2-metilciclo-hexanona e metilvinil cetona, ${ }^{112}$ em rendimento apenas moderado, como mostrado no Esquema 96.

\section{Esquema 96}

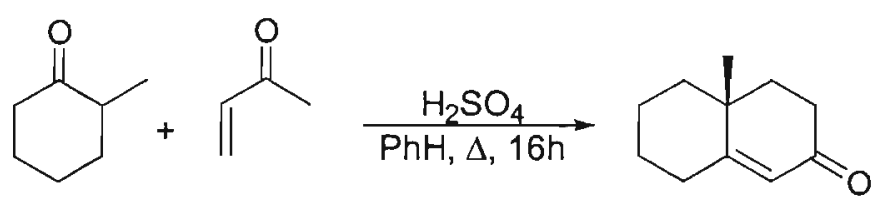

$101(40 \%)$

A seguir, o dieno 105 foi preparado, em ótimo rendimento, através da redução de 101 com boro-hidreto de sódio - sem necessidade de adição de tricloreto de cério -, seguida de desidratação, em meio de ácido fosfórico, do álcool alílico intermediário formado, como mostrado no Esquema 97.

\section{Esquema 97}<smiles>CC12CCCCC1=CC(=O)CC2</smiles>

101

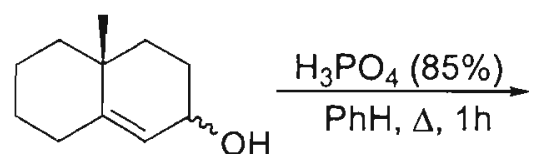
$\mathrm{PhH}, \Delta, 1 \mathrm{~h}$<smiles>CC12CC=CC=C1CCCC2</smiles>

105

(84\%, 2 etapas)

Na tentativa de contração de $\mathbf{1 0 5}$ mais uma vez nos deparamos com resultados nada satisfatórios; isto é, quando $\mathbf{1 0 5}$ foi tratado com TTN em MeOH, TMOF, $\mathrm{MeOH} / \mathrm{CH}_{2} \mathrm{Cl}_{2}$, EtOH ou TEOF, em todos os casos houve formação de uma mistura complexa de produtos. 
Em vista destes resultados pouco animadores, decidimos também abandonar esta rota para a sintese da baquenolida-A.

\subsection{Resolução Enzimática de cis-Octalinas`}

\subsubsection{Introdução}

O sistema cis-decalínico está presente numa vasta gama de classes de produtos naturais, como, por exemplo, cis-clerodanos, calirienos, telepoganos, cadinanos, eremofilanos e valerononanos. ${ }^{113} \mathrm{~A}$ síntese assimétrica de anéis decalínicos de junção cis ainda é restrita e poucos trabalhos nesta área, até o momento, foram realizados. ${ }^{113}$ Como exemplo representativo, podemos citar a abordagem que envolve a aplicação de ácidos de Lewis quirais como catalisadores de reações de Diels-Alder iônicas. ${ }^{114}$

É bem verdade que a biocatálise vem se mostrando uma boa ferramenta alternativa para a obtenção de moléculas quirais, através de reações enzimáticas mediadas por lipases, como, por exemplo, a dessimetrização de cis-octalinas. ${ }^{115}$

Durante os nossos estudos visando à sintese de bacanos, os álcoois $\mathbf{5 8}$ e 71 foram preparados em ótimos rendimentos e excelentes diastereosseletividades. Tendo em vista a importância do sistema cis-octalínico, imaginamos ser possível realizar a resolução enzimática dos referidos octalóis, com intuito de obter representantes desta classe de moléculas enantiomericamente enriquecidos.

Como a resolução enzimática não é o alvo central dos nossos estudos, limitar-nosemos à discussão sucinta dos resultados obtidos, como descrito a seguir.

\footnotetext{
- Deve-se salientar que este trabalho foi efetuado em colaboração com o Dr. André Porto e o agora Prof. Dr. Leandro Andrade (outrora colaboradores do Prof. Dr. Comasseto no programa de Jovem Pesquisador da FAPESP).
} 


\subsubsection{Preparação dos Materiais de Partida}

A preparação dos álcoois $\mathbf{5 8}$ e $\mathbf{7 1}$ já foi descrita em itens anteriores (Esquema 27 e 50). Além destes dois substratos, preparamos o álcool 107, através da redução seletiva do aduto de Diels-Alder 106, cuja preparação está mostrada no Esquema 98.

\section{Esquema 98}

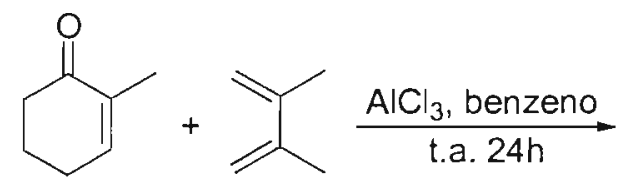<smiles>CC1=C(C)C(=O)[C@@H]2CCCC[C@@]2(C)C1</smiles>

$106(36 \%)$

A redução das cetonas 52, 67 e 106 está sumarizada no Esquema 99.

\section{Esquema 99}<smiles>[R]C1=C([R])C(=O)CC2(C)C(=O)CCCC2(C)C1</smiles>

52: $\mathrm{R}_{1}=\mathrm{R}_{2}=\mathrm{H}$

67: $\mathrm{R}_{1}=\mathrm{H}, \mathrm{R}_{2}=\mathrm{Me}$ 106: $R_{1}=R_{2}=M e$

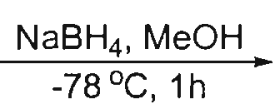<smiles>[R]C1=C([R])CC2(CCCC[C@H]2O)[C@@H](O)CC1</smiles>

$58(95 \%)$

$71(92 \%)$ $107(93 \%)$

Os acetatos 108, 109 e 110, utilizados como padrões racêmicos, foram preparados através da clássica ${ }^{116}$ acetilação dos álcoois 58, 71 e 107, respectivamente, como mostrado no Esquema 100.

\section{Esquema 100}<smiles>[R]C1=C([R])C([R])C[C@]2(C)[C@H](O)CCCC2(C=O)C1</smiles>

58: $\mathrm{R}_{1}=\mathrm{R}_{2}=\mathrm{H}$

71: $\mathrm{R}_{1}=\mathrm{H}, \mathrm{R}_{2}=\mathrm{Me}$

107: $R_{1}=R_{2}=M e$

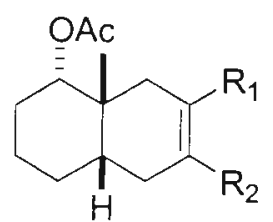

racêmico

$108(85 \%)$

$109(83 \%)$

$110(91 \%)$ 


\subsubsection{Resolução Cinética: O "Screening"}

Com o intuito de identificar a melhor lipase, dentre as disponiveis em nossos laboratórios, para efetuar a resolução cinética dos referidos octalóis, escolhemos aleatoriamente $\mathbf{7 1}$ para fazer o estudo de "screening" com nove diferentes enzimas.

As lipases utilizadas foram: CAL-B (Novozyme 435 - Candida antarctica tipo B imobilizada - 10,000 PLU/g); CAL-A (Novozyme 735, liquida); CAL-B L (Novozyme, líquida); Lipozyme TL 100L (Novozyme, líquida); Lipozyme 1M (Novo Nordisk - Mucor miehei imobilizada); Lipolase 100T (imobilizada); Lipase E.C. 3.1.1.3 (Sigma - Candida rugosa liofilizada); Lipase E.C. 3.1.1.3 (Sigma- Mucor javanicus liofilizada) e Lipase E.C. 3.1.1.3 (Sigma-Type II - pâncreas de porco).

Conforme pode ser visto na Tabela 1, apenas quatro das nove enzimas testadas se mostraram ativas para a resolução cinética do álcool 71 (entradas 1, 2, 5 e 7). Contudo, apenas CAL-B e CAL-A (entradas 1 e 2) mostraram resultados satisfatórios, em que foi possivel obter o acetato 109b em excelente excesso enantiomérico (98\%). Porém, só com a CAL-B (entrada 1) foi possível obter o álcool 71a em excesso enantiomérico razoável ( $82 \%)$. 
Tabela 1. Resolução Cinética do octalol 71 com diferentes lipases. ${ }^{a}$<smiles>CC1=CC[C@H]2[C@@H](O)CCC[C@H]2C1</smiles>

$71 a$<smiles>CC1=CC[C@]2(C)CCCC[C@H]2C1</smiles>

$71 b$

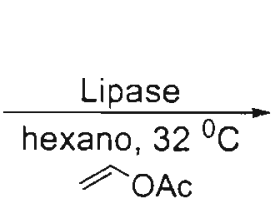

OAC

\section{c}

$71 \mathrm{~b}$

(Lipases)

1

2

3

4

5

6

7

8

9<smiles>CC1=CC[C@H]2[C@@H](O)CCC[C@H]2C1</smiles>

$71 \mathrm{a}$

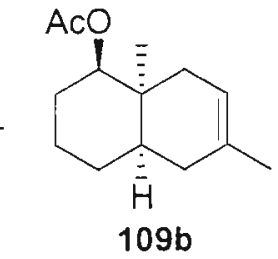

$109 b$

\begin{tabular}{|c|c|c|c|c|c|}
\hline Entrada & $\begin{array}{l}\text { Enzimas } \\
\text { (Lipases) }\end{array}$ & $\begin{array}{c}c \\
71 b\end{array}$ & $\begin{array}{l}\text { e.e. } \\
71 a\end{array}$ & $\begin{array}{c}\text { e.e. } \\
109 b\end{array}$ & $\bar{E}$ \\
\hline 1 & Novozyme 435 CAL-B & 45 & 82 & $>98$ & 510 \\
\hline 2 & Novozyme 735 CAL-A & 14 & 16 & $>98$ & 232 \\
\hline 3 & CAL-B L & - & - & - & - \\
\hline 4 & Lipozyme TL $100 \mathrm{~L}$ & - & - & - & - \\
\hline 5 & Lipozyme IM & 2 & 4 & $>98$ & $\mathrm{Nc}$ \\
\hline 6 & Lipolase & - & - & - & - \\
\hline 7 & $\begin{array}{l}\text { Lipase E.C. 3.1.1.3 } \\
\text { (Candida rugosa) }\end{array}$ & 9 & 10 & $>98$ & NC \\
\hline 8 & $\begin{array}{l}\text { Lipase E.C. 3.1.1.3 } \\
\text { (Mucor javanicus) }\end{array}$ & - & - & - & - \\
\hline 9 & $\begin{array}{l}\text { Lipase E.C. 3.1.1.3 } \\
\text { (Pâncreas de Porco) }\end{array}$ & - & - & - & - \\
\hline
\end{tabular}

${ }^{\mathrm{a}} \mathrm{A}$ reação foi efetuada a $32^{\circ} \mathrm{C}$, usando $( \pm)$-cis-octalol $71(3 \mu \mathrm{L})$, acetato de vinila $(60 \mu \mathrm{L})$, hexano $(600 \mu \mathrm{L})$ e uma lipase $(6 \mathrm{mg})$. c $(\%)$ - conversão calculada a partir da seguinte equação: c = $\left(e e_{s}\right) /\left(e_{p}+e e_{s}\right) ;$ ee $(\%)$ - excesso enantiomérico; $E$ - razão enantiomérica.

\subsubsection{Resolução Cinética dos cis-Octalóis com Novozyme 435}

Tendo sido encontrada a melhor enzima para a resolução cinética, efetuamos um acompanhamento periódico da resolução cinética dos álcoois 58, 71 e 107 com Novozyme 435 em duas temperaturas diferentes $\left(32\right.$ e $40^{\circ} \mathrm{C}$ ). Os resultados obtidos estão mostrados nas Tabelas 2, 3 e 4 . 
Tabela 2. Resolução cinética de 58 com Novozyme 435.<smiles>O[C@H]1CCC[C@H]2[C@@H](Pc3ccccc3)CC=CC[C@@H]12</smiles>

58 a<smiles>OC1CCCC2CC=CCC12</smiles>

$58 b$ $\frac{\text { Novozyme } 435}{\text { hexano, t.a. }}$ $\widehat{O A C}$<smiles>CCCCC1(C)CCCC[C@]12CC=CC[C@H]2O</smiles>

$58 \mathrm{a}$

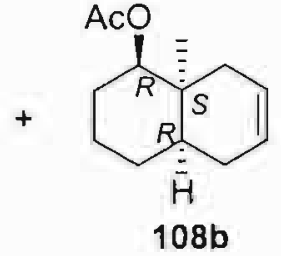

\begin{tabular}{|c|c|c|c|c|c|c|c|c|c|}
\hline \multirow[b]{2}{*}{ Entrada } & \multirow[b]{2}{*}{ Tempo } & \multicolumn{4}{|c|}{ Temperatura $32^{\circ} \mathrm{C}$} & \multicolumn{4}{|c|}{ Temperatura $40^{\circ} \mathrm{C}$} \\
\hline & & $\begin{array}{c}c \\
(\%) \\
58 b\end{array}$ & $\begin{array}{c}\text { e.e. } \\
(\%) \\
108 b\end{array}$ & $\begin{array}{l}\text { e.e. } \\
(\%) \\
58 a\end{array}$ & 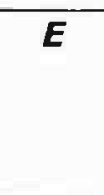 & $\begin{array}{c}c \\
(\%) \\
58 b\end{array}$ & $\begin{array}{c}\text { e.e. } \\
(\%) \\
108 b\end{array}$ & $\begin{array}{l}\text { e.e. } \\
(\%) \\
58 a\end{array}$ & $E$ \\
\hline 1 & 20 & 1 & $>98$ & 1 & Nc & 2 & $>98$ & 2 & NC \\
\hline 2 & 70 & 4 & $>98$ & 4 & NC & 8 & $>98$ & 8 & Nc \\
\hline 3 & 160 & 8 & $>98$ & 9 & Nc & 16 & $>98$ & 19 & 119 \\
\hline 4 & 280 & 16 & $>98$ & 18 & 118 & 26 & $>98$ & 35 & 139 \\
\hline 5 & 400 & 21 & $>98$ & 26 & 127 & 36 & $>98$ & 56 & 174 \\
\hline 6 & 460 & 23 & $>98$ & 30 & 132 & 42 & $>98$ & 70 & 208 \\
\hline 7 & 520 & 26 & $>98$ & 35 & 139 & 44 & $>98$ & 76 & 228 \\
\hline 8 & $24 h$ & 45 & $>98$ & 80 & 244 & 50 & $>98$ & $>98$ & 458 \\
\hline 9 & $48 \mathrm{~h}$ & 50 & $>98$ & $>98$ & 458 & 50 & $>98$ & $>98$ & 458 \\
\hline 10 & $48 h *$ & - & - & - & - & 50 & $>98$ & $>98$ & 458 \\
\hline
\end{tabular}


Tabela 3. Resolução cinética de 71 com Novozyme 435.

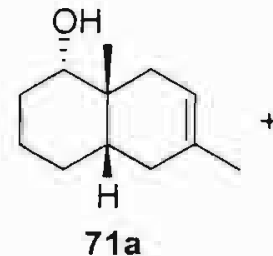

$71 \mathrm{a}$<smiles>CC1=CC[C@H]2C(O)CCC[C@H]2C1</smiles>

$71 b$

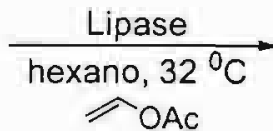

$\widehat{O A C}$<smiles>[Y10]C1CCC[C@@H](O)[C@@H]1CC=C(C)C</smiles>

$71 \mathrm{a}$

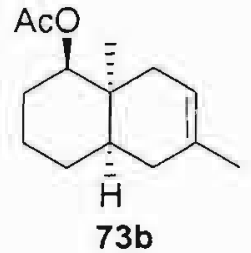

$73 b$

Temperatura $32^{\circ} \mathrm{C}$

Temperatura $40^{\circ} \mathrm{C}$

\begin{tabular}{|c|c|c|c|c|c|c|c|c|c|}
\hline Entrada & Tempo & $\begin{array}{c}c \\
(\%) \\
71 b\end{array}$ & $\begin{array}{c}\text { e.e. } \\
(\%) \\
109 b\end{array}$ & $\begin{array}{l}\text { e.e. } \\
(\%) \\
71 a\end{array}$ & $E$ & $\begin{array}{c}c \\
(\%) \\
71 b\end{array}$ & $\begin{array}{c}\text { e.e. } \\
(\%) \\
109 b\end{array}$ & $\begin{array}{l}\text { e.e. } \\
(\%) \\
71 a\end{array}$ & $E$ \\
\hline 1 & 20 & 4 & $>98$ & 4 & Nc & 4 & $>98$ & 4 & NC \\
\hline 2 & 70 & 8 & $>98$ & 5 & Nc & 8 & $>98$ & 8 & Nc \\
\hline 3 & 160 & 8 & $>98$ & 8 & NC & 18 & $>98$ & 21 & 121 \\
\hline 4 & 280 & 14 & $>98$ & 16 & 16 & 27 & $>98$ & 36 & 140 \\
\hline 5 & 400 & 18 & $>98$ & 22 & 22 & 34 & $>98$ & 51 & 164 \\
\hline 6 & 460 & 22 & $>98$ & 28 & 28 & 37 & $>98$ & 58 & 178 \\
\hline 7 & 520 & 23 & $>98$ & 30 & 30 & 39 & $>98$ & 63 & 189 \\
\hline 8 & $24 h$ & 44 & $>98$ & 78 & 78 & 50 & $>98$ & 97 & 419 \\
\hline 9 & $48 \mathrm{~h}$ & 50 & $>98$ & 97 & 97 & 50 & 96 & 96 & 193 \\
\hline 10 & $48 h^{*}$ & - & - & - & - & 48 & $>98$ & 92 & 327 \\
\hline
\end{tabular}


Tabela 4. Resolução cinética de 107 com Novozyme 435.<smiles>CC1=C(C)C[C@H]2CCC[C@@H](O)[C@H]2C1</smiles>

$107 a$<smiles>CC1=C(C)C[C@H]2CCC[C@@H](O)[C@H]2C1</smiles>

107b

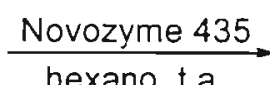

>Ac<smiles>[R][C@@]12CCC[C@H](O)[C@@H]1CC(CC)=C(C)C2</smiles>

$107 a$

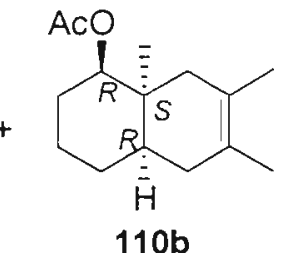

$110 \mathrm{~b}$

Temperatura $32^{\circ} \mathrm{C}$

\begin{tabular}{|c|c|c|c|c|c|c|c|c|c|}
\hline Entrada & Tempo & $\begin{array}{c}c \\
(\%) \\
107 b\end{array}$ & $\begin{array}{c}\text { e.e. } \\
(\%) \\
110 b\end{array}$ & $\begin{array}{c}\text { e.e. } \\
(\%) \\
107 a\end{array}$ & $E$ & $\begin{array}{c}c \\
(\%) \\
107 b\end{array}$ & $\begin{array}{l}\text { e.e. } \\
(\%) \\
110 b\end{array}$ & $\begin{array}{l}\text { e.e. } \\
(\%) \\
107 a\end{array}$ & $E$ \\
\hline 1 & 20 & - & - & - & - & - & - & - & - \\
\hline 2 & 70 & - & - & - & - & 2 & $>98$ & 1 & Ne \\
\hline 3 & 160 & - & - & - & - & 2 & $>98$ & 1 & NC \\
\hline 4 & 280 & 2 & $>98$ & 2 & $\mathrm{NC}$ & 4 & $>98$ & 3 & NC \\
\hline 5 & 400 & 4 & $>98$ & 3 & $\mathrm{NC}$ & 4 & $>98$ & 3 & NC \\
\hline 6 & 460 & 4 & $>98$ & 3 & $\mathrm{Nc}$ & 10 & $>98$ & 7 & NC \\
\hline 7 & 520 & 4 & $>98$ & 3 & $\mathrm{NC}$ & 10 & $>98$ & 8 & Nc \\
\hline 8 & $24 \mathrm{~h}$ & 10 & $>98$ & 11 & 110 & 32 & $>98$ & 46 & 156 \\
\hline 9 & $48 \mathrm{~h}$ & 19 & $>98$ & 23 & 123 & 32 & $>98$ & 46 & 156 \\
\hline 10 & $48 h *$ & - & - & - & - & 50 & $>98$ & $>98$ & 458 \\
\hline
\end{tabular}

t: minutos; c (\%): conversão calculada do ee's do substrato (e.e.s) e do produto (e.e.p): c: e.e.s/(e.e.p + e.e.s); e.e.(\%): excesso enantiomérico; E: Razão Enantiomérica; *rendimento; Nc: não calculado.

Uma vez otimizadas as condições experimentais - 48 horas de reação a $40{ }^{\circ} \mathrm{C}$-, as reações foram repetidas sem a retirada de aliquotas, e os produtos foram separados cromatograficamente. Como pode ser visto no Esquema 101, os rendimentos dos produtos resolvidos isolados, bem como os respectivos excessos enantioméricos foram excelentes. 


\section{Esquema 101}

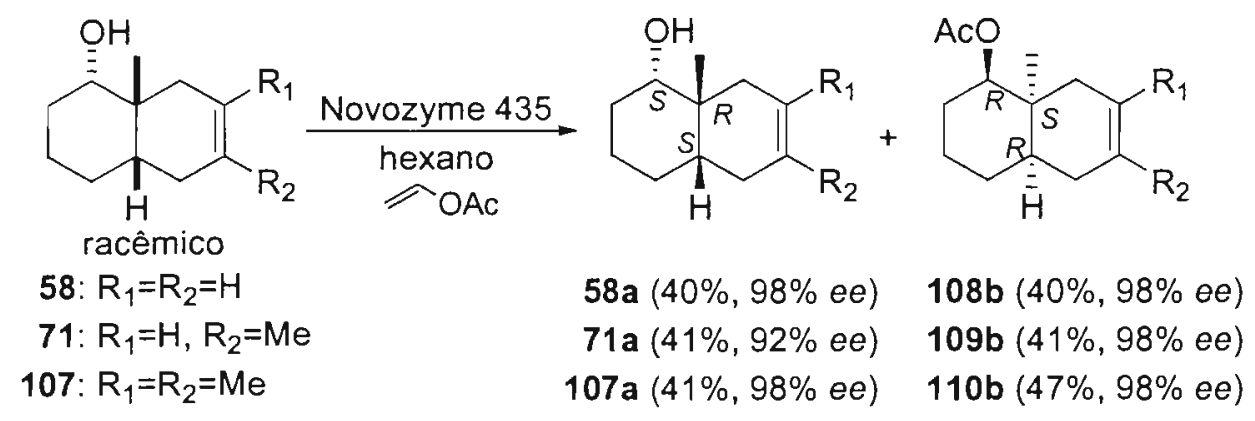

Os valores de rotação especifica encontrados foram: 58a $[\alpha]_{D}^{25}=+6.6^{\circ}$ (c 8.6, $\left.\mathrm{CHCl}_{3}\right) ; \mathbf{1 0 8 b}[\alpha]_{\mathrm{D}}{ }^{25}=-24,0^{\circ}\left(c 3.25, \mathrm{CHCl}_{3}\right) ; 71 \mathbf{a}[\alpha]_{\mathrm{D}}{ }^{25}=-1.6^{\circ}\left(\mathrm{c} 3.02, \mathrm{CHCl}_{3}\right) ; \mathbf{1 0 9 b}$ $[\alpha]_{D}^{25}=-8.5^{\circ}\left(c 2.95, \mathrm{CHCl}_{3}\right) ; 107 \mathbf{a}[\alpha]_{D}^{25}=-8.0^{\circ}\left(c 1.35, \mathrm{CHCl}_{3}\right) ; 110 \mathrm{~b}[\alpha]_{D}^{25}=+13.5^{\circ}$ (c $\left.2.73, \mathrm{CHCl}_{3}\right)$.

A determinação da configuração absoluta de 107 a como sendo $S, S, R$ foi efetuada através da comparação do valor da rotação específica obtido com o descrito na literatura $\left(-9.7^{\circ}, \mathrm{C}^{1.49}, \mathrm{CHCl}_{3}\right) .{ }^{114} \mathrm{~A}$ configuração absoluta dos demais compostos foi atribuída por extrapolação. Uma vez que usamos a mesma enzima para a resolução cinética dos três álcoois, que diferem entre si pela presença de grupos metilas na dupla ligação, acreditamos que tal extrapolação possa ser feita; e mais, o centro carbinólico a ser resolvido se encontra distante da ligação dupla. 


\section{Conclusão}

Apesar dos longos esforços investidos na sintese tanto da nor-baquenolida-A (49) como da baquenolida-A (1), não conseguimos completar as referidas seqüências sintéticas propostas.

Durante a síntese de $\mathbf{4 9}$ enfrentamos algumas dificuldades pouco usuais que foram sanadas após muito empenho de bancada, com exceção da última etapa, que deverá ser re-estudada e completada, assim que possível, em nosso grupo de pesquisa.

Dentre as várias abordagens investigadas para a síntese da baquenolida- $A$, nenhuma delas mostrou resultados satisfatórios, uma vez que foi difícil efetuar a etapa chave de contração de anel dos vários substratos testados. A única reação de contração com TTN que ocorreu foi a da octalona 90 (Esquema 88), porém em baixo rendimento; o que de fato foi surpresa, pois, afinal, tal metodologia havia sido empregada para uma 2octalona regio-isomérica de 90 (Esquema 87 ). Tal era nossa confiança no funcionamento desta reação, que despendemos tempo relativamente longo de bancada na otimização de uma rota que levasse à obtenção da octalona $90 \mathrm{em}$ bom rendimento e boa diastereosseletividade; e tal propósito foi alcançado (cf item 4.3.3.2).

Quanto à resolução cinética dos cis-octalóis, ótimos resultados foram alcançados, já que os produtos resolvidos com a lipase Novozyme 435 foram obtidos em excelentes rendimentos isolados e também excelentes excessos enantioméricos, através de um protocolo de grande praticidade laboratorial.

De certa maneira, os objetivos específicos aos quais nos propusemos não foram completamente alcançados; todavia, através dos estudos apresentados nesta tese, demonstramos, pela primeira vez, a possibilidade de preparar o sistema cis-hidrindânico - unidade estrutural central dos bacanos - através de uma reação de contração de anel mediada por tálio(III) de cis-octalinas; portanto, em parte alcançamos o objetivo geral a que esta tese se propunha. 
Esta reação poderia muito bem ser aplicada na contração de anel da cis-octalina 51 (Esquema 59) - que já contém as metilas com a configuração relativa cis entre si - e assim seria possivel completar pelo menos a sintese formal da baquenolida-A. Porém, por uma questão de tempo, as propostas sintéticas para $\mathbf{5 1}$, descritas nos Esquemas 60 e 61 , não foram efetuadas. Ademais, a publicação de Reddy ${ }^{19}$ versando sobre a sintese de 1 nesse ínterim, também nos tirou o incentivo de continuar com tal proposta.

Two roads diverged in a yellow wood, And sorry I could not travel both And be one traveler, long I stood And looked down one as far as I could To where it bent in the undergrowth;

Then took the other, as just as fair, And having perhaps the better claim, Because it was grassy and wanted wear; Though as for that the passing there Had worn them really about the same.

And both that morning equally lay In leaves no step had trodden black. oh, I kept the first for another day! Yet knowing how way leads on to way, I doubted if I should ever come back.

I shall be telling this with a sigh Somewhere ages and ages hence: Two roads diverged in a wood, and II took the one less traveled by, And that has made all the difference. The Road not Taken - Robert Frost

E agora José?
A festa acabou,
a luz apagou,
o povo sumiu,
a noite esfriou,
e agora José?
e agora você,
você que é sem nome,
que zomba dos outros,
você que faz versos,
que ama, protesta,
e agora, José?
Carlos Drummond de Andrade




\section{Parte Experimental}

\section{Considerações gerais - Avis aux lecteurs}

As reações foram acompanhadas utilizando-se um cromatógrafo a gás modelo HP 6890 (coluna capilar HP-5 de natureza apolar, contendo 5\% de difenil- e 95\% de dimetilpolisiloxano). Também foi utilizada cromatografia em camada delgada, empregando-se placas de sílica gel do tipo $60-F_{254}$ sobre alumínio, comercializadas pela Merck, as quais foram reveladas com iodo, com luz ultravioleta, com solução de vanilina ou com solução de para-anisaldeído.

As purificações em coluna cromatográfica e coluna cromatográfica flash foram realizadas utilizando-se silica gel Acros 80-230 Mesh e 200-400 Mesh, respectivamente.

Os reagentes e solventes foram tratados e/ou secos antes do uso, quando necessário, conforme os métodos usuais.

Os pontos de fusão - determinados em um aparelho Buchi, modelo B-545 - não foram corrigidos.

Os espectros no infravermelho, os espectros de massas e as análises elementares foram realizados pelos técnicos da Central Analítica do Instituto de Química da USP, utilizando-se os seguintes aparelhos, respectivamente: Perkin-Elmer 1750-FT, FininganMAT INCOS $50 B$ acoplado a um cromatógrafo a gás Varian 3400 e Perkin-Elmer $2400 / C H N$.

As análises de Espectroscopia de Massas de Alta Resolução (EMAR) foram realizadas na Central Analítica do Instituto de Química da Universidade Estadual de Campinas.

Os espectros de Ressonância Magnética Nuclear foram realizados utilizando os aparelhos Varian INOVA 300, Bruker AC-200, Bruker DPX-300 e Bruker DPX-500. As amostras foram preparadas utilizando $\mathrm{CDCl}_{3}$ como solvente e tetrametilsilano como padrão interno. Para fins de atribuição dos sinais dos espectros de $R M N$ de ${ }^{1} \mathrm{H}$ e de ${ }^{13} \mathrm{C}$, a numeração dos compostos foi feita arbitrariamente. Apenas para os compostos inéditos 
foi efetuada a atribuição dos sinais e caracterização completa - leia-se ${ }^{1} H-R M N,{ }^{13} \mathrm{C}-R M N$, massa, IV e CHN. Os espectros de ${ }^{1} H-R M N$ e de ${ }^{13} C-R M N$ encontram-se em anexo, junto com os de intermediários sintéticos de relevância, cujos dados estão listados na parte experimental, mesmo que já previamente descritos na literatura.

Os compostos foram nomeados utilizando o programa CS ChemDraw U/tra ${ }^{\circledR}$ (versão 6.0), o qual utiliza o programa para nomenclatura de compostos orgânicos AutoNom (versão 2.1) sob licença da Beilstein Informationssysteme (Copyright ${ }^{\circledR} 1988$ 1998, Beilstein Institut fuer Literatur der Organischen Chemie). 


\section{1.nor-Baquenolida-A}

\subsubsection{Preparação da 2-metilciclo-hexen-2-ona ${ }^{53}$}

II

Uma solução da 2-metilciclo-hexanona $(15,0 \mathrm{~g} ; 0,134 \mathrm{~mol})$ e NBS recém recristalizada $(23,8 \mathrm{~g} ; 0,134 \mathrm{~mol})$ em tetracloreto de carbono $(150 \mathrm{~mL})$ foi agitada e refluxada sob atmosfera de nitrogênio por $13 \mathrm{~h}$. A suspensão resultante foi filtrada sob Celite ${ }^{\circledR}$, para a remoção da succinimida formada. O sólido foi lavado com éter $(150 \mathrm{~mL})$ e o filtrado foi evaporado à pressão reduzida. O resíduo foi dissolvido em DMF seco $(300 \mathrm{~mL})$ e foram adicionados $\mathrm{Li}_{2} \mathrm{CO}_{3}(29,7 \mathrm{~g} ; 0,400 \mathrm{~mol})$ e $\mathrm{LiBr}$ $(34,9 \mathrm{~g} ; 0,400 \mathrm{~mol})$. A suspensão resultante foi refluxada por 3 horas sob atmosfera de nitrogênio. A mistura reacional foi resfriada, o sólido decantado, a fase líquida foi diluída com água $(400 \mathrm{~mL})$ e extraída com éter $(300+2 \times 200 \mathrm{~mL})$. A fase etérea foi lavada com água, solução saturada de $\mathrm{NaCl}$, secada com $\mathrm{MgSO}_{4}$, e o solvente foi evaporado à pressão reduzida. $O$ produto bruto foi destilado à pressão atmosférica (PE: $172-176^{\circ} \mathrm{C}$ ), rendendo $9,92 \mathrm{~g}(90,0 \mathrm{mmol}, 67 \%)$ da 2-metilciclo-hexen-2-ona, na forma de um líquido levemente amarelado.

\subsection{Preparação da cis-8a-metil-3,4,4a,5,8,8a-hexa-hidro-2H-naftalen-1-ona} $(52)^{54}$<smiles>C[C@]12CC=CC[C@H]1CCCC2=O</smiles>

52

A uma suspensão de $\mathrm{AlCl}_{3}(10,0 \mathrm{~g} ; 75,0 \mathrm{mmol})$ em diclorometano seco (150 $\mathrm{mL}$ ), em banho de gelo, foi adicionada a 2-metilciclo-hexen-2-ona (16,5 g; $0,150 \mathrm{~mol}) . \mathrm{O} \mathrm{AlCl}_{3}$ foi gradualmente dissolvido para formar uma solução de coloração amarela. Adicionou-se uma ponta de espátula de hidroquinona e 1,3-butadieno ( $30 \mathrm{~g} ; 0,60 \mathrm{~mol}$ ) recém condensado. O balão foi tampado, o banho de gelo foi retirado, e a solução foi agitada a temperatura ambiente por 24 horas. 0 solvente foi removido à pressão reduzida e o resíduo foi particionado entre água e éter. A fase etérea foi lavada com água, solução saturada de $\mathrm{NaCl}$, secada com $\mathrm{MgSO}_{4}$, e o solvente foi 
evaporado à pressão reduzida. O produto bruto foi destilado à pressão reduzida (PE: 66$69^{\circ} \mathrm{C}$ a $\left.0,5 \mathrm{mmHg}\right)$ rendendo $18,9 \mathrm{~g}$ de $52(0,114 \mathrm{mmol}, 76 \%)$ na forma de um líquido levemente amarelado.

${ }^{1} \mathrm{H}-\mathrm{RMN}(200 \mathrm{MHz}, \delta): 1,05(\mathrm{~s}, 3 \mathrm{H}) ; 1,59-2,70(\mathrm{~m}, 11 \mathrm{H}) ; 5,55-5,69(\mathrm{~m}, 2 \mathrm{H})$.

${ }^{13} \mathrm{C}-\mathrm{RMN}(50 \mathrm{MHz}, \delta): 20,4 ; 25,1 ; 27,7 ; 28,0 ; 31,2 ; 37,1 ; 40,9 ; 47,6 ; 122,9 ; 127,1 ;$ 214,9 .

\subsubsection{Preparação do cis-4a-metil-1,2,3,4,4a,5,8,8a-octa-hidronaftaleno (53)}<smiles>CC12CC=CCC1([13CH3])CCCCC21CCCCC1</smiles>

A uma solução da cetona 52 (3,27 g; $20,0 \mathrm{mmol})$ em trietilenoglicol (20 mL) foi adicionado $\mathrm{NH}_{2} \mathrm{NH}_{2} . \mathrm{H}_{2} \mathrm{O}(5,0 \mathrm{~mL} ; 5,0 \mathrm{~g} ; 0,10 \mathrm{~mol})$ e a solução resultante foi refluxada a $130{ }^{\circ} \mathrm{C}$ por 1,5 horas. A mistura reacional foi resfriada para então se adicionar $\mathrm{KOH}$ em pastilhas $(6,7 \mathrm{~g} ; 0,12 \mathrm{mmol})$ e depois foi refluxada a $130^{\circ} \mathrm{C}$ por mais 4,5 horas. A mistura reacional foi vertida em gelo e acidificada com $\mathrm{HCl} 6 \mathrm{M}$. A fase aquosa foi extraída com pentano $(3 \times 150 \mathrm{~mL})$ e a fase orgânica foi lavada com solução saturada de cloreto de sódio, secada com $\mathrm{MgSO}_{4}$ e o solvente foi evaporado à pressão reduzida. O produto bruto foi purificado em coluna cromatográfica de sílica (80230 mesh), eluindo-se com pentano, rendendo $2,41 \mathrm{~g}$ de 53 ( $16,0 \mathrm{mmol} ; 80 \%$ ) como um líquido incolor.

${ }^{1} \mathrm{H}-\mathrm{RMN}(200 \mathrm{MHz}, \mathrm{ppm}): 0,89(\mathrm{~s}, 3 \mathrm{H}) ; 1,09-1,70(\mathrm{~m}, 11 \mathrm{H}) ; 2,23-2,39(\mathrm{~m}, 2 \mathrm{H}) ; 5,47-$ $5,59(m, 2 H)$.

${ }^{13} \mathrm{C}-\mathrm{RMN}(50 \mathrm{MHz}, \mathrm{ppm}): 22,6 ; 26,7 ; 28,7 ; 29,6 ; 30,1 ; 31,6 ; 31,9 ; 39,6 ; 40,3 ; 124,2 ;$ 124,7 .

CAS: $21789-58-2$ 


\subsubsection{Preparação da 1-(3a-metil-octa-hidro-inden-2-il)-etanona (55)}

\section{Primeira Parte:}

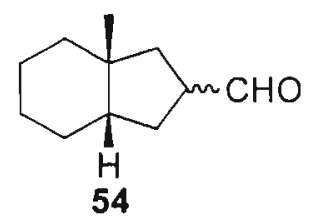

A uma solução da olefina $\mathbf{5 3}(1,50 \mathrm{~g} ; 10,0 \mathrm{mmol})$ em

trimetilortoformiato $(50 \mathrm{~mL})$ foi adicionado $\pi \mathrm{N} .3 \mathrm{H}_{2} \mathrm{O}(5,11 \mathrm{~g} ; 11,5$ mmol) e agitou-se à temperatura ambiente por 3,5 horas. Observouse uma precipitação abundante durante este periodo. O precipitado de $\mathrm{TINO}_{3}$ formado foi filtrado, sob pressão, numa coluna curta de sílica, eluindo-se com diclorometano. 0 filtrado foi sucessivamente lavado com água e solução saturada de cloreto de sódio e secado com $\mathrm{MgSO}_{4}$. O solvente foi evaporado à pressão reduzia e o produto bruto foi dissolvido em clorofórmio (30 mL). A esta solução adicionou-se uma mistura 1:1 de ácido trifluoroacético/água $(10 \mathrm{~mL})$ a $0^{\circ} \mathrm{C}$ e agitou-se por 2 horas à temperatura ambiente. Adicionou-se água e a fase aquosa foi extraída com clorofórmio. A fase orgânica foi sucessivamente lavada com solução saturada de $\mathrm{NaHCO}_{3}$, solução saturada de $\mathrm{NaCl}$, secada com $\mathrm{MgSO}_{4}$, e o solvente foi evaporado a pressão reduzida.

\section{Segunda Parte:}

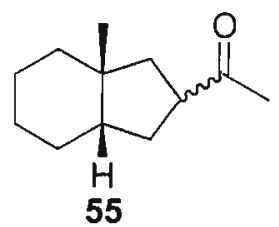

O produto bruto foi dissolvido em éter etílico anidro $(40 \mathrm{~mL})$ e então adicionou-se, a $-78^{\circ} \mathrm{C}$, uma solução $1,6 \mathrm{M}$ de MeLi em éter etílico (10,0 $\mathrm{mL} ; 16,0 \mathrm{mmol})$. A solução foi agitada por 1,5 horas à temperatura ambiente e a mistura reacional foi vertida em gelo/ $\mathrm{NH}_{4} \mathrm{Cl}$. A fase aquosa foi extraída com éter. A fase etérea foi lavada com água, solução saturada de $\mathrm{NaCl}$, secada com $\mathrm{MgSO}_{4}$, e o solvente foi evaporado à pressão reduzida. Dissolveu-se o álcool em acetona $(40 \mathrm{~mL})$, resfriou-se a solução em banho de gelo e titulou-se lentamente, sob agitação, com a solução do reagente de Jones $8 \mathrm{M}(20 \mathrm{~mL})$. Após a adição, a mistura foi agitada por 15 minutos e o excesso de oxidante foi destruído com isopropanol. A mistura foi particionada em $\mathrm{H}_{2} \mathrm{O}$ e AcOEt e a fase orgânica lavada com água, solução saturada de $\mathrm{NaHCO}_{3}$, solução saturada de $\mathrm{NaCl}$ e seca com $\mathrm{MgSO}_{4}$. O solvente foi evaporado à pressão reduzida e o produto bruto foi purificado em coluna cromatográfica de sílica flash 
(200-400 mesh), com eluição gradiente de uma mistura acetato/hexano (5-25\%), rendendo $1,18 \mathrm{~g}$ de $\mathbf{5 5}(6,55 \mathrm{~mol} ; 65 \%)$ como um óleo incolor. $\mathbf{5 5}$ foi obtida como uma mistura 5:1 de diastereoisômeros. Os dados espectroscópicos para o isômero majoritário estão listados a seguir.

${ }^{1} \mathrm{H}-\mathrm{RMN}(300 \mathrm{MHz}, \delta): 0,98(\mathrm{~s}, 3 \mathrm{H}) ; 1,16-2,00(\mathrm{~m}, 13 \mathrm{H}) ; 2,99-3,12(\mathrm{~m}, 1 \mathrm{H}) ; 2,15$ $(\mathrm{s}, 3 \mathrm{H})$.

${ }^{13} \mathrm{C}-\mathrm{RMN}(75 \mathrm{MHz}, \delta): 21,5 ; 22,1 ; 25,2 ; 25,7 ; 28,6 ; 30,9 ; 33,3 ; 41,0 ; 42,2 ; 44,2 ; 48,5$; $211,0$.

$\operatorname{IV}_{\text {filme }}\left(v, \mathrm{~cm}^{-1}\right): 1711$.

$M / Z: 180(M+, 13 \%) ; 81(100 \%)$.

CAS: $33020-76-7$

\subsubsection{Preparação do 2-acetil-3a-metil-octa-hidro-indeno-2-carboxilato de metila} $(56)^{61}$

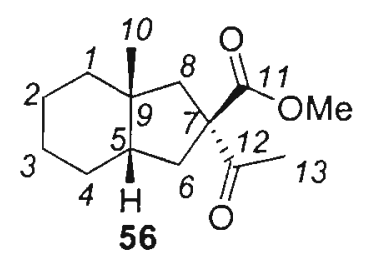

A uma solução da cetona $\mathbf{5 5}(0,721 \mathrm{~g} ; 4,00 \mathrm{mmol})$ em diclorometano anidro (40 mL) foram adicionados sob agitação, atmosfera de $\mathrm{N}_{2}$ e a $-40{ }^{\circ} \mathrm{C}$, hexametildissilasano $(4,2 \mathrm{~mL} ; 20$ mmol) e iodotrimetilsilano $(1,42 \mathrm{~mL} ; 10,0 \mathrm{mmol})$. A solução levemente amarelada foi agitada por 10 minutos a $-40^{\circ} \mathrm{C}$ e 1 hora a $0{ }^{\circ} \mathrm{C}$. A mistura reacional foi vertida em uma mistura pentano/solução saturada de $\mathrm{NaHCO}_{3}$. A fase aquosa foi extraída com pentano $(3 \times 50 \mathrm{~mL})$ e a fase orgânica foi lavada com solução saturada de cloreto de sódio e secada com $\mathrm{MgSO}_{4}$. O solvente foi evaporado à pressão reduzida e o produto bruto foi dissolvido em THF anidro $(40 \mathrm{~mL})$. A esta solução foi adicionada, a $-40{ }^{\circ} \mathrm{C}$ e sob atmosfera de $\mathrm{N}_{2}$, uma solução $1,6 \mathrm{M}$ de MeLi em éter etílico $(7,5 \mathrm{~mL} ; 12 \mathrm{mmol})$ e agitou-se por 30 minutos. Adicionou-se uma solução de cianoformiato de metila $(1,39 \mathrm{~g} ; 12,0 \mathrm{mmol})$ em THF $(5 \mathrm{~mL})$ e a solução resultante foi agitada por 1 hora. A mistura reacional foi vertida em gelo e a fase aquosa foi extraída 
com érter etílico. A fase etérea foi lavada com solução saturada de $\mathrm{NaHCO}_{3}$, solução saturada de $\mathrm{NaCl}$ e secada com $\mathrm{MgSO}_{4}$. O solvente foi evaporado à pressão reduzida e o produto bruto foi purificado em coluna cromatográfica de sílica flash (200-400 mesh), com eluição gradiente de uma mistura acetato/hexano (10-30\%), fornecendo 0,515 g de $56(2,16 \mathrm{mmol} ; 54 \%)$ como um sólido branco amorfo. Todo o material utilizado após a etapa de carboxilação foi lavado com solução saturada de sulfato ferroso, com o intuito de promover a complexação dos íons cianeto gerados no meio reacional!

${ }^{1} \mathrm{H}-\mathrm{RMN}(300 \mathrm{MHz}, \delta): 1,03\left(\mathrm{~s}, 3 \mathrm{H},-H C_{10}\right) ; 1,1-1,6\left(\mathrm{~m}, 8 \mathrm{H}-H C_{1}+H C_{2}+H C_{3}+H C_{4}\right)$; $1,74-1,82\left(\mathrm{~m}, 1 \mathrm{H}-H C_{5}\right) ; 1,92\left(\mathrm{~d}, \mathrm{~J}=13,8 \mathrm{~Hz}, 1 \mathrm{H}-H C_{8}\right) ; 2,13\left(\mathrm{~s}, 3 \mathrm{H}-H C_{13}\right) ; 2,22-$ $2,27\left(\mathrm{~m}, 2 \mathrm{H}-H \mathrm{C}_{6}\right) ; 2,44\left(\mathrm{~d}, \mathrm{~J}=13,8 \mathrm{~Hz}, 1 \mathrm{H}-H^{\prime} \mathrm{C}_{8}\right) ; 3,72\left(\mathrm{~s}, 3 \mathrm{H}-\mathrm{OCH}_{3}\right)$.

${ }^{13} \mathrm{C}-\mathrm{RMN}(75 \mathrm{MHz}, \delta): 33,6\left(C_{1}\right) ; 21,2\left(C_{2}\right) ; 22,3\left(C_{3}\right) * ; 24,6\left(C_{4}\right) ; 44,4\left(C_{5}\right) ; 36,1\left(C_{6}\right)$; $64,6\left(C_{7}\right) ; 45,8\left(C_{8}\right) ; 40,6\left(C_{9}\right) ; 26,6\left(C_{10}\right)^{*} ; 174,7\left(C_{11}\right) ; 203,6\left(C_{12}\right) ; 25,6\left(C_{13}\right)^{*} ; 52,7$ $\left(\mathrm{OCH}_{3}\right)$. *os sinais podem estar trocados entre si.

IV $\left(\nu, \mathrm{cm}^{-1}\right): 1711 ; 1746$.

CHN: calculado (C 70.46; H 9.30), obtido (C 70,03; H 9,12).

\subsubsection{Preparação da ceto lactona 57}

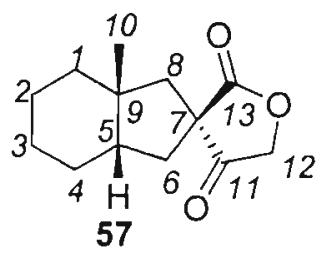

A uma solução do ceto éster $56(0,184 \mathrm{~g} ; 0,773 \mathrm{mmol})$ em diclorometano anidro (8 $\mathrm{mL})$ foram adicionados sob agitação, atmosfera de $\mathrm{N}_{2}$ e a $0^{\circ} \mathrm{C}$, hexametildissilasano $(0,82 \mathrm{~mL} ; 0,62 \mathrm{~g} ; 3,9$ mmol) e iodotrimetilsilano $(0,28 \mathrm{~mL} ; 0,39 \mathrm{~g}, 1,9 \mathrm{mmol})$. A solução levemente amarelada foi agitada por 10 minutos a $0{ }^{\circ} \mathrm{C}$ e 3 horas a temperatura ambiente. A mistura reacional foi vertida em uma mistura pentano/ $\mathrm{NaHCO}_{3}$. A fase aquosa foi extraída com pentano e a fase orgânica foi lavada com solução saturada de cloreto de sódio e secada $\mathrm{com} \mathrm{MgSO}_{4}$. O solvente foi evaporado à pressão reduzida e o produto bruto dissolvido em THF $(9 \mathrm{~mL})$. A esta solução foram sucessivamente adicionados água $(3 \mathrm{~mL})$, NMO $(0,21 \mathrm{~g} ; 1,5 \mathrm{mmol})$ e $\mathrm{OsO}_{4}\left(19,6 \mathrm{mg} ; 7,73 \times 10^{-2} \mathrm{mmol}\right)$. 
A suspensão resultante foi agitada por 40 horas à temperatura ambiente e então se adicionou metabissulfito de sódio sólido. A suspensão preta obtida foi filtrada sobre celite e o sólido lavado com diclorometano. O filtrado foi concentrado à pressão reduzida e particionado entre água e éter etílico. A fase etérea foi lavada com água e solução saturada de cloreto de sódio. O solvente foi evaporado e o resíduo foi dissolvido em éter etílico (10 mL) e adicionou-se $\mathrm{HCl} 10 \%$ (5 gotas). A solução resultante foi agitada por 2 horas a temperatura ambiente, lavada com solução saturada de $\mathrm{NaHCO}_{3}$ e secada com $\mathrm{MgSO}_{4}$. O solvente foi evaporado à pressão reduzida e o produto bruto foi purificado em coluna cromatográfica de sílica flash (200-400 mesh), com eluição gradiente de uma mistura acetato de etila/hexano (5-30\%), fornecendo $0,0668 \mathrm{~g}$ de $57(0,300 \mathrm{mmol}$; $39 \%$ ) como um sólido branco amorfo.

${ }^{1} \mathrm{H}-\mathrm{RMN}(500 \mathrm{MHz}, \delta): 1,15\left(\mathrm{~s}, 3 \mathrm{H}-H C_{10}\right) ; 1,20-1,60\left(\mathrm{~m}, 8 \mathrm{H}-H C_{1}+H C_{2}+H C_{3}+H C_{4}\right) ;$ $1,7-1,8\left(\mathrm{~m}, 1 \mathrm{H}-H C_{5}\right) ; 1,87\left(\mathrm{~d}, \mathrm{~J}=13,4 \mathrm{~Hz}, 1 \mathrm{H}-H C_{8}\right) ; 1,92\left(\mathrm{~d}, \mathrm{~J}=13,4 \mathrm{~Hz}, 1 \mathrm{H}-H^{\prime} \mathrm{C}_{8}\right)$; $2,1-2,2\left(\mathrm{~m}, 2 \mathrm{H}-H C_{6}\right) ; 4,62\left(\mathrm{~s}, 2 \mathrm{H}-H C_{13}\right)$.

${ }^{13} \mathrm{C}-\mathrm{RMN}(50 \mathrm{MHz}, \delta): 32,8\left(C_{1}\right) ; 22,3\left(C_{2}\right) * ; 20,7\left(C_{3}\right) * ; 24,0\left(C_{4}\right) * ; 45,3\left(C_{5}\right) ; 40,1\left(C_{6}\right) ;$ $51,7\left(C_{7}\right) ; 49,2\left(C_{8}\right) ; 42,2\left(C_{9}\right) ; 25,0\left(C_{10}\right) ; 210,5\left(C_{11}\right) ; 72,3\left(C_{12}\right) ; 179,0\left(C_{13}\right) ;$. *os sinais podem estar trocados entre si.

IV $\left(v, \mathrm{~cm}^{-1}\right): 1747 ; 1794$.

CHN: calculado (C 70,24; H 8,16), obtido (C 69,90; H 8,13).

\subsubsection{Preparação do octaidro-3a-metil-2-(prop-1-en-2-il)-1H-indeno-2- carboxilato de metila (65)}

Preparação da solução 0,1 mM da fosforana: A uma suspensão de cloreto de metiltrifenilfosfônio $(0,79 \mathrm{~g} ; 2,1 \mathrm{mmol})$ em éter $(20 \mathrm{~mL})$ foi adicionado BuLi 2,25M $(0,90 \mathrm{~mL}$; $2,0 \mathrm{mmol}$ ) sob atmosfera de $\mathrm{N}_{2}$ e a $-20^{\circ} \mathrm{C}$. A suspensão amarela foi agitada por 30 min e deixou-se decantar o sólido. 


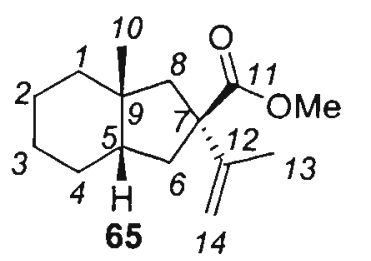

6514

A uma solução do ceto éster $56(0,153 \mathrm{~g} ; 0,645 \mathrm{mmol})$ em éter anidro anidro ( $7 \mathrm{~mL}$ ) foi adicionada sob agitação, atmosfera de $\mathrm{N}_{2}$ e a $0{ }^{\circ} \mathrm{C}$, uma solução de fosforana recém preparada $(13 \mathrm{~mL})$ e mistura reacional foi agitada a esta temperatura por 8 horas, para então se adicionar água. A fase aquosa foi extraída com éter e a fase orgânica foi lavada com água, solução saturada de cloreto de sódio e seca com $\mathrm{MgSO}_{4}$. O solvente foi evaporado à pressão reduzida e o produto bruto foi purificado em coluna cromatográfica de sílica flash (200-400 mesh), com eluição gradiente de uma mistura acetato/hexano (5-10\%), fornecendo $91,5 \mathrm{mg}$ de $65(0,387 \mathrm{mmol} ; 60 \%)$ como um líquido incolor. Se levarmos em consideração recuperação de $24 \%(36,8 \mathrm{mg}, 0,154 \mathrm{mmol})$ do material de partida (56), o rendimento pode ser entendido como $79 \%$.

${ }^{1} \mathrm{H}-\mathrm{RMN}(300 \mathrm{MHz}, \delta): 1,03\left(\mathrm{~s}, 3 \mathrm{H}-H C_{10}\right) ; 1,2-1,7\left(\mathrm{~m}, 9 \mathrm{H}-H C_{1}+H C_{2}+H C_{3}+H C_{4}+\right.$ $\left.H C_{5}\right) ; 1,72\left(\mathrm{sl}, 3 \mathrm{H}-H C_{13}\right) ; 1,83\left(\mathrm{~d}, \mathrm{~J}=13,9 \mathrm{~Hz}, 1 \mathrm{H}-H C_{8}\right) ; 2,04\left(\mathrm{t}_{\mathrm{ap}}, \mathrm{J}=12,8 \mathrm{~Hz}, 1 \mathrm{H}-\right.$ $\left.H C_{6}\right) ; 2,17\left(\mathrm{~d}, \mathrm{~J}=13,9 \mathrm{~Hz}, 1 \mathrm{H}-H^{\prime} \mathrm{C}_{8}\right) ; 2,25$ (dd, J=12,8 e $6,3 \mathrm{~Hz}, 1 \mathrm{H}-H^{\prime} \mathrm{C}_{6}$ ); 3,67 (s, $\left.3 \mathrm{H}-\mathrm{OCH}_{3}\right) ; 4,85$ (quinteto $_{\mathrm{ap}}, \mathrm{J}=1,3 \mathrm{~Hz}, 1 \mathrm{H}-H \mathrm{C}_{6}$ ); 4,96 (sl, $1 \mathrm{H}-H C_{14}$ ).

${ }^{13} \mathrm{C}-\mathrm{RMN}(75 \mathrm{MHz}, \delta): 35,2\left(C_{1}\right) ; 21,2\left(C_{2}\right) * ; 22,6\left(C_{3}\right) * ; 24,5\left(C_{4}\right) * ; 44,0\left(C_{5}\right) ; 38,2$ $\left(C_{6}\right) ; 57,6\left(C_{7}\right) ; 48,7\left(C_{8}\right) ; 39,6\left(C_{9}\right) ; 25,7\left(C_{10}\right) ; 177,5\left(C_{11}\right) ; 147,6\left(C_{12}\right) ; 21,1\left(C_{13}\right) ;$ $110,0\left(\mathrm{C}_{14}\right) ; 52,3\left(\mathrm{OCH}_{3}\right) .{ }^{*}$ os sinais podem estar trocados entre si.

$M / Z: 236(M+, 28 \%) ; 95(100 \%)$. 


\subsection{Outros cis-Hidrindanos}

\subsubsection{Preparação da 6,8a-dimetil-3,4,4a,5,8,8a-hexa-hidro- $2 H$-naftalen-1-ona} $(67)^{54}$

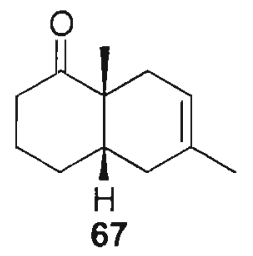

A uma suspensão de $\mathrm{AlCl}_{3}(3,30 \mathrm{~g} ; 25,0 \mathrm{mmol}$ ) em benzeno seco (120 $\mathrm{mL}$ ) foi adicionada a 2-metilciclo-hexen-2-ona $(11,0 \mathrm{~g} ; 0,100 \mathrm{~mol})$. $\mathrm{O}$ $\mathrm{AlCl}_{3}$ formou uma pasta no fundo do balão e então se adicionou, em banho de gelo, isopreno ( $20 \mathrm{~mL} ; 0,40 \mathrm{~mol}$ ). O balão foi tampado e o banho de gelo foi retirado, e a solução agitada a temperatura ambiente por 24 horas. O solvente foi evaporado à pressão reduzida e o resíduo foi particionado entre água e éter. A fase etérea foi lavada com água, solução saturada de $\mathrm{NaCl}$, secada com $\mathrm{MgSO}_{4}$, e o solvente foi evaporado à pressão reduzida. O produto bruto foi destilado em trompa de vácuo (PE: $135-140{ }^{\circ} \mathrm{C}$ ) rendendo $9,54 \mathrm{~g}$ de $67(53,5 \mathrm{mmol}, 54 \%)$ na forma de um líquido levemente amarelado.

${ }^{1} \mathrm{H}-\mathrm{RMN}(300 \mathrm{MHz}, \delta): 1,09(\mathrm{~s}, 3 \mathrm{H}) ; 1,55-1,77(\mathrm{~m}, 9 \mathrm{H}) ; 1,98-2,61(\mathrm{~m}, 5 \mathrm{H}) ; 5,29-5,34$ $(\mathrm{m}, 1 \mathrm{H})$.

${ }^{13} \mathrm{C}-\mathrm{RMN}(75 \mathrm{MHz}, 8): 20,5 ; 23,7 ; 25,2 ; 28,0 ; 31,7 ; 33,1 ; 37,2 ; 41,7 ; 47,5 ; 116,9 ;$ 130,$9 ; 215,5$.

\subsection{Preparação do 6,8a-dimetil-3,4,4a,5,8,8a-hexa-hidro-2H-naftalen-1-ona- dixolano (68)}

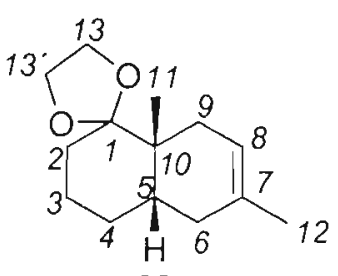

68
Uma solução da cetona 67 (1,78 g; 10,0 mmol), etilenoglicol $(1,86 \mathrm{~g} ; 30,0 \mathrm{mmol})$ e ácido $p$-toluenosulfônico $(0,019 \mathrm{~g} ; 0,10$ $\mathrm{mmol}$ ) em benzeno seco $(30 \mathrm{~mL})$ foi refluxada por 2 horas em um aparelho de Dean-Stark. Após resfriamento, foi adicionada solução saturada de $\mathrm{NaHCO}_{3}$ e a fase aquosa foi extraída com AcOEt, lavada com água, solução 
saturada de $\mathrm{NaCl}$, secada com $\mathrm{MgSO}_{4}$, e o solvente foi evaporado à pressão reduzida. $\mathrm{O}$ produto bruto foi purificado em coluna de sílica flash (200-400 mesh), eluindo-se com uma mistura hexano/ACOEt (75:25), rendendo $2,02 \mathrm{~g}$ de 68 (9,09 mmol; $91 \%)$ na forma de um óleo incolor.

${ }^{1} \mathrm{H}-\mathrm{RMN}(300 \mathrm{MHz}, \delta): 0,87\left(\mathrm{~s}, 3 \mathrm{H}-H C_{11}\right) ; 1,2-1,8\left(\mathrm{~m}, 9 \mathrm{H}-H C_{2}+H C_{3}+H C_{4}+H C_{5}+\right.$ $\left.H C_{9}\right) ; 1,63\left(\mathrm{sl}, H C_{12}\right) ;, 15-2,27\left(\mathrm{~m}, 2 \mathrm{H}-H C_{6}\right) ; 3,9-4,0\left(\mathrm{~m}, 4 \mathrm{H}-H C_{13}+H C_{13}{ }^{\prime}\right) ; 5,24-$ $5,26\left(\mathrm{~m}, 1 \mathrm{H}-H \mathrm{C}_{8}\right)$.

${ }^{13} \mathrm{C}-\mathrm{RMN}(75 \mathrm{MHz}, \delta): 113,0\left(C_{1}\right) ; 34,0\left(C_{2}\right) ; 22,9\left(C_{3}\right) ; 28,6\left(C_{4}\right) * ; 38,2\left(C_{5}\right) ; 30,1$ $\left(C_{6}\right)^{*} ; 130,5\left(C_{7}\right) ; 117,9\left(C_{8}\right) ; 30,4\left(C_{9}\right)^{*} ; 40,4\left(C_{10}\right) ; 18,1\left(C_{11}\right) ; 23,7\left(C_{12}\right) ; 64,9$ e 65,1 $\left(C_{13}\right.$ e $\left.C_{13}\right)$. *os sinais podem estar trocados entre si.

\subsubsection{Preparação da 6,7-dimetóxi-6,8a-dimetil-octa-hidronaftalen-1-ona (70) e da 7-metóxi-6,8a-dimetil-6-nitróxi-octa-hidronaftalen-1-ona (69)}

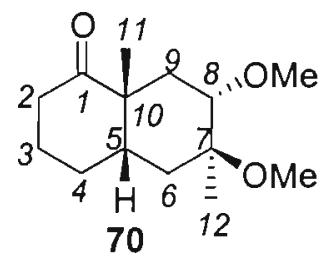

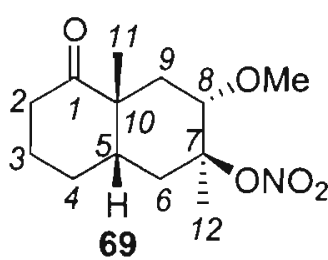

A uma solução do cetal $68(0,334 \mathrm{~g} ; 1,50 \mathrm{mmol})$ em $\mathrm{MeOH}(7,5 \mathrm{~mL})$ adicionou-se $T \mathrm{~N} .3 \mathrm{H}_{2} \mathrm{O}(0,73 \mathrm{~g} ; 1,65 \mathrm{mmol})$ e este foi prontamente dissolvido. Alguns minutos após a adição de TTN observou-se uma precipitação abundante e deixou-se reagir por 15 minutos. A suspensão foi filtrada, sob pressão, em uma pequena coluna de sílica $(10 \mathrm{~cm})$, eluindo-se com $\mathrm{CH}_{2} \mathrm{Cl}_{2}(100 \mathrm{~mL})$. A solução foi lavada com água, solução saturada de $\mathrm{NaCl}$ e secada com $\mathrm{MgSO}_{4}$. O

solvente foi evaporado à pressão reduzida e o produto bruto purificado em coluna gradiente de sílica flash (200-400 mesh), eluindo-se com AcOEt/hexano (30-40\%). Foram obtidas $0,0833 \mathrm{~g}$ de $70(0,370 \mathrm{mmol} ; 25 \%)$ como um sólido amorfo e 0,108 $\mathrm{g}$ de $69(0,450 \mathrm{mmol} ; 30 \%)$ na forma de um sólido branco.

$70-{ }^{1} \mathrm{H}-\mathrm{RMN}(200 \mathrm{MHz}, \delta): 0,87$ (dd, $\mathrm{J}=13,2$ e $\left.11,8 \mathrm{~Hz}, 1 \mathrm{H}-H_{a x} C_{9}\right) ; 1,16(\mathrm{~s}, 3 \mathrm{H}-$ $\left.H C_{11}\right) ; 1,26\left(\mathrm{~s}, 3 \mathrm{H}-H C_{12}\right) ; 1,41-2,32\left(\mathrm{~m}, 8 \mathrm{H}-H C_{3}+H C_{4}+H C_{5}+H C_{6}\right) ; 2,48-2,66(\mathrm{~m}$, 
$\left.2 \mathrm{H})-H C_{2}\right) ; 3,24\left(\mathrm{~s}, 3 \mathrm{H}-\mathrm{OCH}_{3}\right) ; 3,33\left(\mathrm{dd}, \mathrm{J}=10,7\right.$ e $\left.4,8 \mathrm{~Hz}, 1 \mathrm{H}-H C_{8}\right) ; 3,46(\mathrm{~s}, 3 \mathrm{H}-$ $\mathrm{OCH}_{3}$.

$\mathrm{RMN}-{ }^{-1} \mathrm{H}(50 \mathrm{MHz}, \delta): 214,0\left(C_{1}\right) ; 37,8\left(C_{2}\right)^{*} ; 22,0\left(C_{3}\right) ; 25,5\left(C_{4}\right) ; 41,8\left(C_{5}\right) ; 37,4\left(C_{6}\right)^{*}$; $77,8\left(C_{7}\right) ; 80,3\left(C_{8}\right) ; 36,1\left(C_{9}\right) * ; 49,4\left(C_{10}\right) ; 15,2\left(C_{11}\right) ; 26,6\left(C_{12}\right) ; 49,1$ e $57,3\left(\mathrm{OCH}_{3}\right)$. *os sinais podem estar trocados entre si.

$69-{ }^{1} \mathrm{H}-\mathrm{RMN}(200 \mathrm{MHz}, \delta): 0,98$ (dd, J=13,6 e 11,9 Hz, $\left.1 \mathrm{H}-H_{\mathrm{ax}} C_{9}\right) ; 1,14-2,32(\mathrm{~m}, 8 \mathrm{H}-$ $\left.H C_{3}+H C_{4}+H C_{5}+H C_{6}+H_{e q} C_{9}\right) ; 1,28\left(s, 3 \mathrm{H}-H C_{11}\right) ; 1,59\left(\mathrm{~s}, 3 \mathrm{H}-H C_{12}\right) ; 2,52-2,62$ $\left(\mathrm{m}, 2 \mathrm{H}-H C_{2}\right) ; 3,42-3,54\left(\mathrm{~m}, 1 \mathrm{H}-H C_{8}\right) ; 3,46\left(\mathrm{~s}, 3 \mathrm{H}-\mathrm{OCH}_{3}\right)$.

${ }^{1} \mathrm{H}-\mathrm{RMN}(50 \mathrm{MHz}, 8): 213,4\left(C_{1}\right) ; 37,3\left(C_{2}\right)^{*} ; 21,9\left(C_{3}\right) ; 25,3\left(C_{4}\right) ; 41,8\left(C_{5}\right) ; 36,3\left(C_{6}\right)^{*}$; $95,8\left(C_{7}\right) ; 78,3\left(C_{8}\right) ; 36,4\left(C_{9}\right)^{*} ; 49,0\left(C_{10}\right) ; 15,4\left(C_{11}\right) ; 26,3\left(C_{12}\right) ; 58,4\left(O_{3} H_{3}\right) . *_{o s}$ sinais podem estar trocados entre si.

IV $\left(\nu, \mathrm{cm}^{-1}\right): 1696 ; 1607,1300$.

\subsubsection{Preparação do trans-6,8a-Dimetil-1,2,3,4,4a,5,8,8a-octa-hidronaftalen-1- ol (71)}

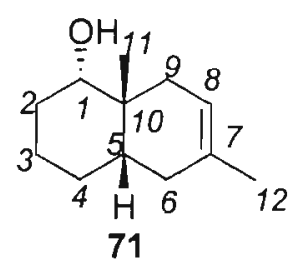

A uma solução da octalona $67(1,79 \mathrm{~g} ; 10,1 \mathrm{mmol})$ em MeOH $(50 \mathrm{~mL})$ mantida a $-78^{\circ} \mathrm{C}$ foi adicionado $\mathrm{NaBH}_{4}(0,38 \mathrm{~g} ; 10,0 \mathrm{mmol})$ sólido, numa única porção. A suspensão foi agitada por uma hora para então se adicionar água $(30 \mathrm{~mL})$. A fase aquosa foi extraida com AcOEt ( $3 \times$ $30 \mathrm{~mL}$ ), lavada com solução saturada de $\mathrm{NaCl}$ e secada com $\mathrm{MgSO}_{4}$. O solvente foi evaporado à pressão reduzida, para render $1,67 \mathrm{~g}$ de $71(9,24 \mathrm{mmol} ; 92 \%)$ na forma de um óleo incolor.

${ }^{1} \mathrm{H}-\mathrm{RMN}(300 \mathrm{MHz}, \delta): 1,01\left(\mathrm{~s}, 3 \mathrm{H}-H C_{11}\right) ; 1,2-1,7\left(\mathrm{~m}, 10 \mathrm{H}-H C_{2}+H C_{3}+H C_{4}+H C_{5}+\right.$ $\left.H C_{6}+\mathrm{OH}\right) ; 1,64\left(\mathrm{sl}, 3 \mathrm{H}-H C_{12}\right) ; 2,13-2,33\left(\mathrm{~m}, 2 \mathrm{H}-H C_{9}\right) ; 3,32(\mathrm{dd}, \mathrm{J}=11,1$ e 4,4 Hz, $\left.1 \mathrm{H}-H C_{1}\right) ; 5,27\left(\mathrm{sl}, 1 \mathrm{H}-H C_{8}\right)$. 
${ }^{13} \mathrm{C}-\mathrm{RMN}(75 \mathrm{MHz}, \delta): 78,2\left(C_{1}\right) ; 34,0\left(C_{2}\right) ; 23,7\left(C_{3}\right)^{*} ; 24,0\left(C_{4}\right)^{*} ; 39,9\left(C_{5}\right) ; 28,9$ $\left(C_{6}\right)^{* *} ; 130,7\left(C_{7}\right) ; 117,7\left(C_{8}\right) ; 30,6\left(C_{9}\right)^{* *} ; 36,5\left(C_{10}\right) ; 26,1\left(C_{11}\right)^{*} ; 23,4\left(C_{12}\right)^{*} . *^{*}$ os sinais podem estar trocados entre si. **os sinais podem estar trocados entre si. $\operatorname{IV}_{\text {filme }}\left(v, \mathrm{~cm}^{-1}\right): 3388$

\subsubsection{Preparação do 10 -Metóxi-1,8-dimetil-2-oxa-triciclo $\left[5.3 .1 .0^{3,8}\right]$ undecano} (72)

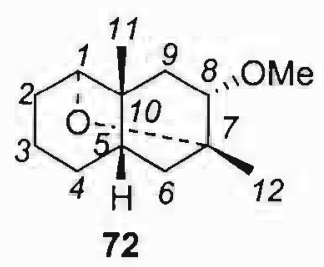

A uma solução do álcool $71(0,275 \mathrm{~g} ; 1,53 \mathrm{mmol})$ em TMOF $(7,5 \mathrm{~mL})$ foi adicionado TTN. $3 \mathrm{H}_{2} \mathrm{O}(0,75 \mathrm{~g} ; 1,68 \mathrm{mmol})$ e este foi prontamente dissolvido. Alguns minutos após a adição de TTN, uma precipitação abundante foi observada e deixou-se reagir por 30 minutos. A suspensão foi filtrada em uma pequena coluna de sílica $(10 \mathrm{~cm})$, eluindo-se $\operatorname{com} \mathrm{CH}_{2} \mathrm{Cl}_{2}$ $(100 \mathrm{~mL})$. A solução foi lavada com água, solução saturada de $\mathrm{NaCl}$ e seca sob $\mathrm{MgSO}_{4}$. O solvente foi evaporado à pressão reduzida e o produto bruto purificado em coluna gradiente de sílica flash (200-400 mesh), eluindo-se com hexano/AcOEt (7:3). Foram obtidas $0,202 \mathrm{~g}$ de $72(0,961 \mathrm{mmol} ; 63 \%)$ como um líquido fluido incolor.

${ }^{1} \mathrm{H}-\mathrm{RMN}(300 \mathrm{MHz}, \delta): 0,86\left(\mathrm{~s}, 3 \mathrm{H}-H C_{11}\right) ; 1,15\left(\mathrm{~s}, 3 \mathrm{H}-H C_{13}\right) ; 1,24-1,33\left(\mathrm{~m}, 4 \mathrm{H}-H C_{2}\right.$ $\left.+H C_{3}+H_{e q} C_{6}+H_{e q} C_{9}\right) ; 1,45-1,77\left(\mathrm{~m}, 4 \mathrm{H}-H^{\prime} C_{2}+H C_{4}+H C_{5}\right) ; 1,79-1,95(\mathrm{~m}, 1 \mathrm{H}-$ $H^{\prime} C_{3}$ ); 1,87 (dd, $J=13,6$ e $9,2 \mathrm{~Hz}, 1 \mathrm{H}-H_{a x} C_{9}$ ); 2,07 (dd, $\mathrm{J}=14,0$ e $11,5 \mathrm{~Hz}, 1 \mathrm{H}-$ $\left.H_{a x} C_{6}\right) ; 3,23$ (ddd, $J=9,3 ; 4,8$ e $\left.1,9 \mathrm{~Hz}, 1 \mathrm{H}-H C_{8}\right) ; 3,33\left(\mathrm{~s}, 3 \mathrm{H}-O \mathrm{OCH}_{3}\right) ; 3,55-3,57(\mathrm{~m}$, $\left.1 \mathrm{H}-H C_{1}\right)$.

${ }^{13} \mathrm{C}-\mathrm{RMN}(75 \mathrm{MHz}, \delta): 76,0\left(C_{1}\right) ; 26,7\left(C_{2}\right) ; 14,2\left(C_{3}\right) ; 27,2\left(C_{4}\right) ; 33,8\left(C_{5}\right) ; 32,5\left(C_{6}\right)$; $70,2\left(C_{7}\right) ; 80,7\left(C_{8}\right) ; 42,4\left(C_{9}\right) ; 33,8\left(C_{10}\right) ; 22,0\left(C_{11}\right)^{*} ; 23,5\left(C_{12}\right)^{*}$. *os sinais podem estar trocados entre si.

$\operatorname{IV}_{\text {filme }}\left(v, \mathrm{~cm}^{-1}\right): 1443,1463$.

$M / Z: 210(M+, 45 \%) ; 94(100 \%)$.

CHN: calculado (C 74.24; H 10.54), obtido (C 74,03; H 10,72). 


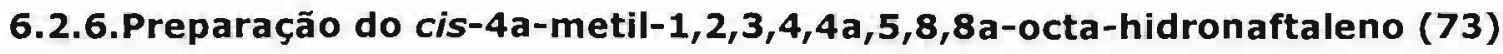

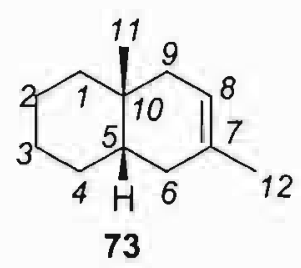

A uma solução da cetona $67(0,891 \mathrm{~g} ; 5,00 \mathrm{mmol})$ em trietilenoglicol (5 mL) foi adicionado $\mathrm{NH}_{2} \mathrm{NH}_{2} \cdot \mathrm{H}_{2} \mathrm{O}(1,25 \mathrm{~mL} ; 25,0 \mathrm{mmol})$. A solução resultante foi refluxada a $130^{\circ} \mathrm{C}$ por 1,5 horas. A mistura reacional foi resfriada para então se adicionar $\mathrm{KOH}$ em pastilhas $(1,67 \mathrm{~g} ; 30,0$ mmol) e depois refluxada a $130^{\circ} \mathrm{C}$ por 4,5 horas. A mistura reacional foi vertida em gelo e acidificada com $\mathrm{HCl} 6 \mathrm{M}$. A fase aquosa foi extraída com pentano ( $3 \times 50 \mathrm{~mL}$ ) e a fase orgânica foi lavada com solução saturada de cloreto de sódio, seca com $\mathrm{MgSO}_{4}$ e o solvente foi evaporado à pressão reduzida. O produto bruto foi purificado em coluna cromatográfica de sílica (80-230 mesh), eluindo-se com pentano, rendendo 0,696 g de 73 (4,24 mmol; 85\%) como um líquido incolor.

${ }^{1} \mathrm{H}-\mathrm{RMN}(200 \mathrm{MHz}, \delta): 0,87(\mathrm{~s}, 3 \mathrm{H}) ; 1,13-1,70(\mathrm{~m}, 8 \mathrm{H}) ; 1,67(\mathrm{~s}, 3 \mathrm{H}) ; 2,18-2,39(\mathrm{~m}, 2 \mathrm{H})$; $5,24(\mathrm{sl}, 1 \mathrm{H})$.

${ }^{13} \mathrm{C}-\mathrm{RMN}(50 \mathrm{MHz}, 8): 22,4 ; 23,7 ; 26,4 ; 28,5 ; 29,5 ; 31,3 ; 31,5 ; 34,8 ; 39,0 ; 40,5 ; 118,4 ;$ 130,5 .

\subsubsection{Preparação da 1-(3a-metil-octa-hidro-inden-2-il)-etanona (55)}

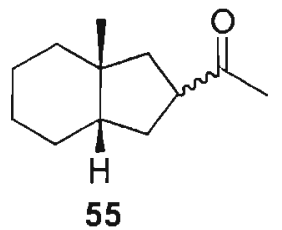

A uma solução da olefina 74 em MeOH ( $3 \mathrm{~mL}$ ) AcOH (10 gotas) adicionou-se $T \mathrm{TN} .3 \mathrm{H}_{2} \mathrm{O}(0,25 \mathrm{~g} ; 0,56 \mathrm{mmol})$ e este foi prontamente dissolvido. Deixou-se reagir por 2 horas e a suspensão foi filtrada, sobre pressão, em uma pequena coluna de sílica $(10 \mathrm{~cm})$, eluindo-se $\mathrm{com} \mathrm{CH}_{2} \mathrm{Cl}_{2}(100 \mathrm{~mL})$. $\mathrm{A}$ solução foi lavada com água, solução saturada de $\mathrm{NaCl}$ e secada com $\mathrm{MgSO}_{4}$. O solvente foi evaporado à pressão reduzida e o produto bruto purificado em coluna gradiente de sílica flash (200-400 mesh), eluindo-se com AcOEt/hexano (10-30\%). Foram obtidas $40,4 \mathrm{mg}$ de 55 (0,224 mmol; 40\%), como uma mistura 1:1 (cis:trans), na forma de um líquido incolor. 


\subsection{Baquenolida-A}

\subsubsection{Preparação do éster $6,8 a$-dimetil-1, $2,3,4,4 a, 5,8,8 a$-octa-hidronaftalen-1-il tolueno sulfônico ( 80$)$}

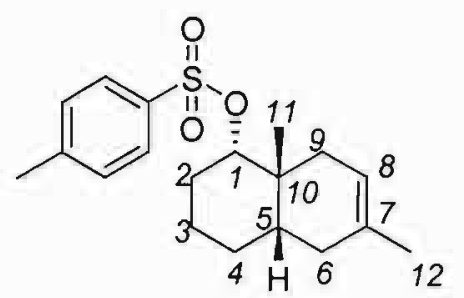

80

A uma solução do álcool $71(0,754 \mathrm{~g} ; 4,18 \mathrm{mmol})$ em piridina seca (13 mL) foi adicionado, sob agitação e atmosfera de nitrogênio, cloreto de tosila $(1,19 \mathrm{~g} ; 6,27 \mathrm{mmol})$. A solução foi agitada por 24 horas e a mistura diluída com água gelada. A fase aquosa foi extraída com éter e os extratos orgânicos combinados foram lavados com solução saturada de $\mathrm{CuSO}_{4}$, água, solução saturada de cloreto de sódio, e secada com $\mathrm{MgSO}_{4}$. O solvente foi evaporado à pressão reduzida e o produto bruto purificado em coluna de sílica flash (200-400 mesh), eluindo-se com uma mistura hexano/acetato $(4: 1)$, rendendo $0,866 \mathrm{~g}$ de $80(2,59 \mathrm{mmol}, 62 \%)$ na forma de um sólido branco.

${ }^{1} \mathrm{H}-\mathrm{RMN}(200 \mathrm{MHz}, \delta): 0,82\left(\mathrm{~s}, 3 \mathrm{H}-H C_{11}\right) ; 1,2-1,89\left(\mathrm{~m}, 9 \mathrm{H}-H C_{2}+H C_{3}+H C_{4}+H C_{5}+\right.$ $\left.H C_{6}\right) ; 1,60\left(\mathrm{~s}, 3 \mathrm{H}-H C_{12}\right) ; 2,1-2,3\left(\mathrm{~m}, 2 \mathrm{H}-H C_{9}\right) ; 2,43(\mathrm{~s}, 3 \mathrm{H}-H C P h) ; 4,33(\mathrm{dd}, \mathrm{J}=10,8$ e $\left.5,5 \mathrm{~Hz}, 1 \mathrm{H}-H C_{1}\right) ; 5,21$ (sl, $\left.1 \mathrm{H}-H C_{8}\right) ; 7,3$ e 7,8 (4H - grupo tosila).

${ }^{13} \mathrm{C}-\mathrm{RMN}(50 \mathrm{MHz}, \delta): 90,1\left(C_{1}\right) ; 33,8\left(C_{2}\right) ; 23,2\left(C_{3}\right)^{*} ; 26,4\left(C_{4}\right) * * ; 40,1\left(C_{5}\right) ; 28,1$ $\left(C_{6}\right)^{* *} ; 130,2\left(C_{7}\right) ; 117,1\left(C_{8}\right) ; 28,3\left(C_{9}\right)^{* *} ; 36,6\left(C_{10}\right) ; 23,4\left(C_{11}\right)^{*} ; 23,7\left(C_{12}\right)^{*} ;$ 21,5/127,6/129,6/135,0/144,2 (grupo tosila). *os sinais podem estar trocados entre si. **os sinais podem estar trocados entre si. 


\subsubsection{Preparação do 6,8a-dimetil-1,2,3,4,4a,7,8,8a-ocata-hidro-1,7- metanonaftalen-9-ol (86)}

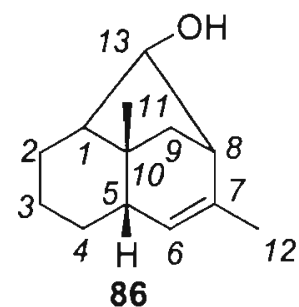

A uma solução do cloreto de (metóximetil)-trifenilfosfônio (1,03 g; 3,00 mmol) em THF $(10 \mathrm{~mL})$ foi adicionada, a $-30^{\circ} \mathrm{C}$ e sob nitrogênio, uma solução $0,5 \mathrm{M}$ de $\operatorname{KHMDS}$ em tolueno $(5,0 \mathrm{~mL} ; 2,50 \mathrm{mmol})$. A solução de cor vermelho intenso foi agitada a $0^{\circ} \mathrm{C}$ por 15 minutos, para então se adicionar uma solução da cetona $67(0,178 \mathrm{~g} ; 1,00 \mathrm{mmol})$ em THF $(2,5$ $\mathrm{mL}$ ). A mistura reacional foi agitada por 19 horas à temperatura ambiente e para então se adicionar, a $0{ }^{\circ} \mathrm{C}$, uma solução $1: 1$ de $\mathrm{MeOH} / \mathrm{THF}(2,5 \mathrm{~mL})$ e $\mathrm{HCl} 4 \mathrm{~N}(2,5 \mathrm{~mL})$. A solução foi agitada à temperatura ambiente por mais 24 horas e depois vertida em água $(10 \mathrm{~mL})$ e a fase aquosa foi extraída com éter $(4 \times 30 \mathrm{~mL})$. A fase etérea foi lavada com água, solução saturada de cloreto de sódio, e secada com $\mathrm{MgSO}_{4}$. O solvente foi evaporado à pressão reduzida e o produto bruto purificado em coluna de sílica flash (200-400 mesh), eluindo-se com uma mistura hexano/acetato (4:1), rendendo 0,0708 g de $86(0,368 \mathrm{mmol}, 37 \%)$ na forma de um óleo incolor.

${ }^{1} \mathrm{H}-\mathrm{RMN}(200 \mathrm{MHz}, \delta): 1,21\left(\mathrm{~s}, 3 \mathrm{H}-H C_{11}\right) ; 1,2-2,1\left(\mathrm{~m}, 12 \mathrm{H}-H C_{1}+H C_{2}+H C_{3}+H C_{4}+\right.$ $\left.H C_{5}+H C_{8}+H C_{9}+O H\right) ; 1,73\left(\mathrm{t}, \mathrm{J}=1,3 \mathrm{~Hz}, 3 \mathrm{H}-H C_{12}\right) ; 3,70\left(\mathrm{sl}, 1 \mathrm{H}-H C_{13}\right) ; 4,90(\mathrm{sl}, 1 \mathrm{H}$ $\left.-H C_{6}\right)$.

${ }^{13} \mathrm{C}-\mathrm{RMN}(50 \mathrm{MHz}, \delta): 49,9\left(C_{1}\right) ; 22,8\left(C_{2}\right) * 16,7\left(C_{3}\right) ; 26,2\left(C_{4}\right) * ; 42,0\left(C_{5}\right) ; 124,7$ $\left(C_{6}\right) ; 139,1\left(C_{7}\right) ; 55,9\left(C_{8}\right) ; 43,7\left(C_{9}\right) ; 40,3\left(C_{10}\right) ; 22,3\left(C_{11}\right)^{* *} ; 24,5\left(C_{12}\right)^{* *}$. *os sinais podem estar trocados entre si. **os sinais podem estar trocados entre si. 


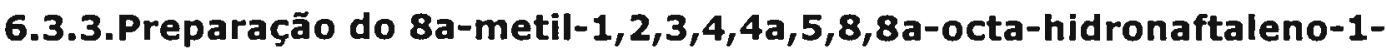 carbaldeído (85)}<smiles>C[C@]12CC=CC[C@@]1([R5](F)(F)F)CCCC2C=O</smiles>

A uma solução do cloreto de (metóximetil)-trifenilfosfônio (3,09 g; 9,00 $\mathrm{mmol})$ em THF $(20 \mathrm{~mL})$ foi adicionado, a $-30^{\circ} \mathrm{C}$ e sob nitrigênio, solução 0,5 M de KHMDS em tolueno $(15,0 \mathrm{~mL} ; 7,5 \mathrm{mmol})$. A solução de coloração vermelha intensa foi agitada a $0{ }^{\circ} \mathrm{C}$ por 15 minutos, para então se adicionar uma solução da cetona $52(0,493 \mathrm{~g} ; 3,00 \mathrm{mmol})$ em $\operatorname{THF}(2,5 \mathrm{~mL})$. A mistura reacional foi agitada por 19 horas à temperatura ambiente e foi então adicionada, a $0{ }^{\circ} \mathrm{C}$, uma solução $1: 1$ de $\mathrm{MeOH} / \mathrm{THF}(7,5 \mathrm{~mL})$ e $\mathrm{HCl} 4 \mathrm{~N}(7,5 \mathrm{~mL})$. A solução foi agitada à temperatura ambiente por 24 horas e depois vertida em água $(10 \mathrm{~mL})$ e a fase aquosa foi extraída com éter $(4 \times 50 \mathrm{~mL})$. A fase etérea foi lavada com água, solução saturada de cloreto de sódio, e secada com $\mathrm{MgSO}_{4}$. O solvente foi evaporado e o produto bruto purificado por destilação horizontal $\left(0,40 \mathrm{mmHg} ; \sim 150{ }^{\circ} \mathrm{C}\right)$, rendendo $0,485 \mathrm{~g}$ de 85 $(2,72 \mathrm{mmol}, 91 \%)$ na forma de um óleo incolor.

${ }^{1} \mathrm{H}-\mathrm{RMN}(200 \mathrm{MHz}, \delta): 1,14(\mathrm{~s}, 3 \mathrm{H}) ; 1,33-3,48(\mathrm{~m}, 13 \mathrm{H}) ; 5,47-5,61(\mathrm{~m}, 2 \mathrm{H}) ; 9,81(\mathrm{~d}, \mathrm{~J}=$ $3,8 \mathrm{~Hz})$.

\subsubsection{Preparação da 2,3-dimetilciclo-hexanona ${ }^{60}$}

Preparação do Reagente de Jones:a 25,0 $\mathrm{g}$ de $\mathrm{CrO}_{3}$, mantidos em banho de gelo, foram adicionados vagarosamente e sob agitação $22 \mathrm{~mL}$ de $\mathrm{H}_{2} \mathrm{SO}_{4}$ concentrado. A solução obtida foi diluída a $200 \mathrm{~mL}$ com água destilada. O reagente é estável e pode ser estocado em vidro âmbar por tempo indeterminado.<smiles>CC1CCCC(=O)C1C</smiles>

Dissolveu-se 2,3-dimetilciclo-hexanol (40,1 $\mathrm{g} ; 0,31 \mathrm{~mol})$ em acetona (150 $\mathrm{mL}$ ). Resfriou-se a solução em banho de gelo e titulou-se lentamente, sob agitação, com a solução do reagente de Jones $(\sim 80 \mathrm{~mL})$. Após a adição, a mistura foi agitada por 15 minutos e o excesso de oxidante foi destruído com 
isopropanol. A mistura foi particionada em $\mathrm{H}_{2} \mathrm{O}$ e AcOEt e a fase orgânica lavada com água, solução saturada de $\mathrm{NaHCO}_{3}$, solução saturada de $\mathrm{NaCl}$ e secada com $\mathrm{MgSO}_{4}$. O solvente foi evaporado à pressão reduzida e o produto bruto destilado em trompa de vácuo (PE: $79-80^{\circ} \mathrm{C}$ ), obtendo-se $31,15 \mathrm{~g}$ da 2,3-dimetilcicloexanona (0,25 mol; 80\%) como um óleo incolor.

\subsubsection{Preparação da ( \pm )-cis-5,10-Dimetil-1(9)-octal-2-ona (90): Método de} Zoretic $^{83}$<smiles>CC1CCCC2=CC(=O)CCC21C</smiles>

90

A uma solução de 2.3-dimetilciclo-hexanona (19,0 g; 0,15 mol) e metilvinilcetona $(0,15 \mathrm{~mol} ; 12,1 \mathrm{~mL})$ em benzeno $(100 \mathrm{~mL})$, resfriada a 0 ${ }^{\circ} \mathrm{C}$, foram adicionados, sob agitação mecânica, $\mathrm{H}_{2} \mathrm{SO}_{4}$ concentrado $(3 \mathrm{~mL})$ Deixou-se sob agitação por 2 horas à mesma temperatura e adicionou-se então uma segunda porção de $\mathrm{MVK}(0,075 \mathrm{~mol} ; 6,1 \mathrm{~mL})$ e $\mathrm{H}_{2} \mathrm{SO}_{4}$ concentrado (1 mL). Agitou-se por mais 2 horas e adicionou-se uma porção final de $\operatorname{MVK}(0,075 \mathrm{~mol} ; 6,1 \mathrm{~mL})$. Agitou-se por mais 12 horas a $0^{\circ} \mathrm{C}$. A mistura reacional foi diluída em éter (400 mL) e o material polimérico foi lavado com 2 porções de $200 \mathrm{~mL}$ de éter. A fase etérea foi lavada com $\mathrm{NaOH} 1 \mathrm{~N}(200 \mathrm{~mL})$ e com solução saturada de $\mathrm{NaCl}(2 \times 200 \mathrm{~mL})$. A fase aquosa foi reextraida com éter $\left(2 \times 200 \mathrm{~mL}\right.$ ) e as fases etéreas foram secadas com $\mathrm{MgSO}_{4}$. O solvente foi evaporado à pressão reduzida e a 2,3-dimetilcicloexanona que não reagiu foi recuperada $(5,2 \mathrm{~g})$ através de destilação em trompa de vácuo. O restante foi destilado à pressão reduzida $\left(75-100^{\circ} \mathrm{C}, 0,4 \mathrm{mmHg}\right)$, fornecendo $6,75 \mathrm{~g}$. Foi preparada uma solução de metóxido de sódio ( $1,1 \mathrm{~g}$ em $100 \mathrm{~mL}$ de $\mathrm{MeOH}$ anidro) e adicionou-se ao destilado. A solução foi refluxada por 1 hora entre $45-50^{\circ} \mathrm{C}$. Resfriou-se a solução, adicionou-se água e a fase orgânica foi extraida com éter, lavada com solução saturada de $\mathrm{NaCl}$ e secada com $\mathrm{MgSO}_{4}$. O solvente foi evaporado à pressão reduzida, e o produto bruto destilado à pressão reduzida $\left(100-108^{\circ} \mathrm{C}, 1 \mathrm{mmHg}\right)$, fornecendo $6,15 \mathrm{~g}$ de $90(0,035 \mathrm{~mol}, 23 \%)$ como um óleo incolor. 


\subsubsection{Preparação da ( \pm )-cis-5,10-Dimetil-1(9)-octal-2-ona (90): Método de Duhamel adaptado ${ }^{85}$}

Primeira parte:<smiles>CC(=O)CC[C@]1(C)C(=O)CCC[C@@H]1C</smiles>

93

A uma solução contendo 2,3-dimetilciclo-hexanona $(10,1 \mathrm{~g} ; 0,08 \mathrm{mmol})$ e 1,1,1,3,3,3-hexametildissilazano (19,8 $\mathrm{g} ; 0,12 \mathrm{~mol})$ em $\mathrm{CH}_{2} \mathrm{Cl}_{2}$ anidro (200 mL), resfriada à $0^{\circ} \mathrm{C}$ e sob nitrogênio, foi vagarosamente adicionado iodotrimetilsilano $(24,2 \mathrm{~g} ; 0,12 \mathrm{~mol})$. A mistura foi agitada por 10 minutos a $0^{\circ} \mathrm{C}$ e 1,5 horas à temperatura ambiente. A mistura reacional foi diluída em hexano e filtrada sob Florisil (60-100 mesh). O solvente foi evaporado, rendendo $15,7 \mathrm{~g}$ de uma mistura de sililenoléteres. Esta massa bruta foi dissolvida em $\mathrm{CH}_{2} \mathrm{Cl}_{2}$ anidro ( $80 \mathrm{~mL}$ ) e adicionou-se $\mathrm{CH}_{3} \mathrm{NO}_{2}(9,66 \mathrm{~g} ; 0,16 \mathrm{~mol})$, para então ser resfriada a $-78^{\circ} \mathrm{C}$. Adicionou-se então uma mistura de $\operatorname{MVK}(11,06 \mathrm{~g} ; 0,16 \mathrm{~mol})$ e isopropanol $(9,50 \mathrm{~g} ; 0,16 \mathrm{~mol})$ e agitou-se por 30 minutos. A esta solução foi adicionado, vagarosamente, $\mathrm{BF}_{3}$. $\mathrm{Et}_{2} \mathrm{O}(11,23$ g; $0,079 \mathrm{~mol}$ ). Elevou-se a temperatura para $-65^{\circ} \mathrm{C}$ e agitou-se por mais 2 horas. Retirou-se o banho refrigerante e adicionou-se solução saturada de $\mathrm{NaHCO}_{3}(80 \mathrm{~mL})$. A fase orgânica foi extraída com $\mathrm{CH}_{2} \mathrm{Cl}_{2}(3 \times 100 \mathrm{~mL})$, lavada com água, solução saturada de $\mathrm{NaCl}$ e saca sob MgSO4. O solvente foi evaporado à pressão reduzida e o produto bruto destilado a pressão reduzida $\left(103-110^{\circ} \mathrm{C}, 0,8 \mathrm{mmg}\right)$, rendendo $7,51 \mathrm{~g}$ de $93(38,26$ $\mathrm{mmol} ; 48 \%$ ) como um óleo incolor.

${ }^{1} \mathrm{H}-\mathrm{RMN}(200 \mathrm{MHz}, \delta): 0,92(\mathrm{~d} J=6,6 \mathrm{~Hz}, 3 \mathrm{H}) ; 1,02(\mathrm{~s}, 3 \mathrm{H}) ; 1,51-2,60(\mathrm{~m}, 11 \mathrm{H}) ; 2,16(\mathrm{~s}$, $3 \mathrm{H})$.

${ }^{13} \mathrm{C}-\mathrm{RMN}(50 \mathrm{MHz}, \delta): 15,4 ; 18,6 ; 24,5 ; 29,1 ; 29,4 ; 29,9 ; 38,3 ; 38,8 ; 51,4 ; 208,8 ;$ 215,5 . 
Segunda Parte:<smiles>CC1CCCC2=CC(=O)CC[C@]21C</smiles>

90

Sódio metálico $(0,98 \mathrm{~g} ; 42,5 \mathrm{mmol})$ foi dissolvido em metanol anidro $(140 \mathrm{~mL})$. A esta solução foi adicionada a dicetona $93(7,51 \mathrm{~g} ; 38,3)$. A mistura foi refluxada por 1 hora a $45^{\circ} \mathrm{C}$, para então se adicionar solução saturada de $\mathrm{NaCl}(140 \mathrm{~mL})$. A fase orgânica foi extraída com éter etílico e secada com $\mathrm{MgSO}_{4}$. O solvente foi evaporado à pressão reduzida e o produto bruto destilado à pressão reduzida $\left(108-112^{\circ} \mathrm{C}, 1,1 \mathrm{mmHg}\right)$, fornecendo $4,35 \mathrm{~g}$ de $90(24,4 \mathrm{mmol} ; 64 \%)$ como um óleo incolor.

${ }^{1} \mathrm{H}-\mathrm{RMN}(200 \mathrm{MHz}, \delta): 0,92(\mathrm{~d} \mathrm{~J}=5,7 \mathrm{~Hz}, 3 \mathrm{H}) ; 1,11(\mathrm{~s}, 3 \mathrm{H}) ; 1,31-2,47(\mathrm{~m}, 11 \mathrm{H}) ; 5,73$ $(\mathrm{s}, 1 \mathrm{H})$.

${ }^{13} \mathrm{C}-\mathrm{RMN}(50 \mathrm{MHz}, \delta): 15,2 ; 16,0 ; 26,6 ; 30,5 ; 33,4 ; 34,0 ; 35,6 ; 39,0 ; 43,2 ; 124,0 ;$ 171,$2 ; 199,5$.

\subsubsection{Preparação da ( \pm )-cis-5,10-Dimetil-1(9)-octal-2-ona (90): Método de Piers adaptado 80,94}

Primeira Parte:<smiles>CC1CCC(=CN(C)C)C(=O)C1C</smiles>

A uma suspensão de NaOMe - preparado a partir da evaporação de uma solução de sódio metálico $(6,6 \mathrm{~g} ; 0,28 \mathrm{~mol})$ e $\mathrm{MeOH}(85 \mathrm{~mL})$ - em benzeno seco (160 mL), foi adicionada, em banho de gelo, gota a gota e sob agitação mecânica, 2,3-dimetilmetilciclo-hexanona $(14,1 \mathrm{~g} ; 0,11 \mathrm{~mol})$. Após 10 minutos foi adicionado, gota a gota, formiato de etila $(14,1 \mathrm{~g} ; 15,3 \mathrm{~mL} ; 0,19 \mathrm{~mol})$. A mistura reacional foi agita por $14 \mathrm{~h}$ a temperatura ambiente para então se adicionar água gelada (150 mL). A fase orgânica foi separada e foi lavada com $\mathrm{NaOH}$ a $10 \%$. Os extratos aquosos foram neutralizados com $\mathrm{HCl} 6 \mathrm{~N}$ e extraidos com éter etílico $(3 \times 150$ $\mathrm{mL}$ ). Os extratos orgânicos combinados foram lavados com água, solução saturada de $\mathrm{NaCl}$ e secados com $\mathrm{MgSO}_{4}$. O solvente foi evaporado à pressão reduzida. O resíduo foi dissolvido em benzeno seco $(190 \mathrm{~mL})$ e a esta solução foi adicionada $\mathrm{N}$-metilanilina $(11,8$ 
$\mathrm{g} ; 12,0 \mathrm{~mL}, 0,11 \mathrm{~mol}$ ), para então se refluxar por 3,5 h em um aparelho de Dean-Stark. O solvente foi evaporado e o produto bruto destilado à pressão reduzida (PE: 158-160 $\left.{ }^{\circ} \mathrm{C} ; 0,6 \mathrm{mmHg}\right)$, rendendo $19,6 \mathrm{~g}$ de $96(0,081 \mathrm{~mol} ; 73 \%)$, na forma de um óleo alaranjado viscoso.

Segunda Parte:<smiles>CC1CCCC(=O)C1(C)CCC(=O)O</smiles>

97

A uma suspensão de t-ButoK $(43,8 \mathrm{~g} ; 0,39 \mathrm{~mol})$ em t-ButOH $(330 \mathrm{~mL})$ foi adicionada a enamina $96(32,2 \mathrm{~g} ; 0,13 \mathrm{~mol})$. A solução resultante foi agitada por 20 minutos para então se adicionar, gota a gota e sob atmosfera de $\mathrm{N}_{2}$, 3-bromopropionato de etila $(51,2 \mathrm{~g} ; 36,0 \mathrm{~mL} ; 0,28 \mathrm{~mol})$. A reação é bastante exotérmica! A solução resultante foi agitada por $2 \mathrm{~h}$ a temperatura ambiente e depois concentrada à pressão reduzida. O resíduo foi vertido em água/gelo e a fase aquosa foi extraída com éter, lavada com água, solução saturada de $\mathrm{NaCl}$ e secada com $\mathrm{MgSO}_{4}$. O solvente foi evaporado à pressão reduzida e o resíduo refluxado por 30 minutos com $\mathrm{HCl}$ a $10 \%(150 \mathrm{~mL})$. A fase aquosa foi extraída com éter. O solvente foi evaporado e o resíduo tratado com $\mathrm{NaOH}$ a $10 \%(150 \mathrm{~mL})$ e a solução resultante refluxada por $5 \mathrm{~h}$. A solução foi resfriada e acidificada com $\mathrm{HCl} 6 \mathrm{~N}$ e extraída com éter. A fase orgânica foi lavada com água, solução saturada de $\mathrm{NaCl}$ e secada com $\mathrm{MgSO}_{4}$. O solvente foi evaporado à pressão reduzida e o produto bruto destilado à pressão reduzida (PE: $160-165^{\circ} \mathrm{C} ; 1,0 \mathrm{mmHg}$ ) rendendo $20,1 \mathrm{~g}$ de 97 (0,10 mol; 78\%), na forma de um óleo incolor viscoso.

Terceira Parte:

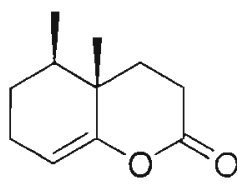

98

A uma solução do ácido 97 (20,1 g; 0,101 mol) em anidrido acético, recém destilado $(100 \mathrm{~mL})$, foi adicionado acetato de sódio $(4,1 \mathrm{~g} ; 0,030$ mol). A solução resultante foi refluxada por $2 \mathrm{~h}$ e o anidrido acético destilado em trompa de vácuo. O resíduo foi particionado entre água e éter. A fase orgânica foi lavada com solução saturada de $\mathrm{NaHCO}_{3}$, solução saturada de $\mathrm{NaCl}$, secada com $\mathrm{MgSO}_{4}$, e o solvente foi rotoevaporado. O produto bruto foi destilado à pressão 
$B / B L \mid O T E C A$

reduzida (PE: $110-114{ }^{\circ} \mathrm{C} ; 1,0 \mathrm{mmHg}$ ) rendendo $13,5 \mathrm{~g}$ de uma mistura $6: 1$ das enol lactonas epiméricas 98 e $98^{\prime} \cdot(75,0$ mmol; 75\%). A mistura foi recristalizada de hexano gelado, fornecendo $8,40 \mathrm{~g}$ de $98(46,6 \mathrm{mmol}, 62 \%)$, na forma de um sólido branco (PF: $47,0-47,1)$.

${ }^{1} \mathrm{H}-\mathrm{RMN}(300 \mathrm{MHz}, \delta): 0,95(\mathrm{~d}, \mathrm{~J}=6,6 \mathrm{~Hz}, 3 \mathrm{H}) ; 1,04(\mathrm{~s}, 3 \mathrm{H}) ; 1,47-1,68(\mathrm{~m}, 4 \mathrm{H}) ; 1,84-$ $1,92(m, 1 H) ; 2,01-2,14(m, 2 H) ; 2,61-2,66(m, 2 H) ; 5,28(t, j=4,2 H z)$.

${ }^{13} \mathrm{C}-\mathrm{RMN}(75 \mathrm{MHz}, \delta): 15,0 ; 17,2 ; 22,8 ; 26,2 ; 27,6 ; 30,7 ; 34,8 ; 39,1 ; 106,3 ; 154,5$; 168,5 .

Quarta Parte:<smiles>C[C@H]1CCCC2=CC(=O)CCC21C</smiles>

90

A uma solução da enol lactona $98(1,04 \mathrm{~g} ; 5,77 \mathrm{mmol})$ em éter seco (10 $\mathrm{mL})$ à $-20^{\circ} \mathrm{C}$ foi rapidamente adicionado $\mathrm{MeLi} 1,6 \mathrm{M}(5,8 \mathrm{~mL} ; 9,3 \mathrm{mmol})$. A solução resultante foi agitada à temperatura ambiente por $1,5 \mathrm{~h}$ e então vertida em $\mathrm{HCl} 1 \mathrm{~N}(5 \mathrm{~mL})$. A fase aquosa foi extraída com éter e concentrada, para então se adicionar $\mathrm{KOH}$ aquoso $2,5 \mathrm{~N}(6 \mathrm{~mL})$ e $\mathrm{MeOH}(54 \mathrm{~mL})$. A mistura foi refluxada por 2 h, o solvente foi evaporado à pressão reduzida e o resíduo particionado entre água e éter. A fase orgânica foi lavada com água, solução saturada de $\mathrm{NaCl}$, secada com $\mathrm{MgSO}_{4}$, e o solvente foi evaporado à presão reduzida. O produto bruto foi purificado em coluna de sílica flash (200-400 mesh) eluindo-se com uma mistura hexano/acetato 7:3, rendendo $0,613 \mathrm{~g}$ de $90(3,44 \mathrm{mmol} ; 60 \%)$ na forma de um óleo incolor.

\subsubsection{Preparação do 7,7a-Dimetil-2,4,5,6,7,7a-1H-indeno-2-carboxilato de metila $(91)^{102}$}<smiles>COC(=O)C1C=C2CCCC(C)C2(C)C1</smiles>

91

A uma solução de $90(208,8$ mg; $1,17 \mathrm{mmol})$ em TMOF/MeOH (4:3) (7 $\mathrm{mL})$ adicionou-se $T \mathrm{~N}(0,62 \mathrm{~g} ; 1,41 \mathrm{mmol})$ e este foi prontamente dissolvido. 2 minutos após a adição de TTN observouse uma precipitação abundante e deixou-se reagir por 30 minutos. A suspensão foi 
filtrada em uma pequena coluna de sílica $(10 \mathrm{~cm})$, eluindo-se com $\mathrm{CH}_{2} \mathrm{Cl}_{2}(100 \mathrm{ml})$. A solução foi lavada com água, solução saturada de $\mathrm{NaCl}$ e secada com $\mathrm{MgSO}_{4}$. O solvente foi evaporado à pressão reduzida e o produto bruto purificado em coluna gradiente de sílica flash (230-400 mesh), eluindo-se com AcOEt/hexano (0-20\%). Foram obtidas 88,8 $\mathrm{mg}$ de $91(0,43 \mathrm{mmol} ; 36 \%)$ como um óleo incolor. Em um procedimento análogo, empregando apenas TMOF como solvente, $\mathbf{9 1}$ foi obtido em $38 \%$ de rendimento.

${ }^{1} \mathrm{H}-\mathrm{RMN}(200 \mathrm{MHz}, \delta): 0,84(\mathrm{~d} \mathrm{~J}=6,1 \mathrm{~Hz}, 3 \mathrm{H}) ; 0,91(\mathrm{~s}, 3 \mathrm{H}) ; 1,12-1,46(\mathrm{~m}, 4 \mathrm{H}) ; 1,71-2,10$ $(m, 4 H) ; 2,27-2,33(m, 1 H) ; 3,51-3,55(m, 1 H) ; 3,67(s, 3 H)$.

${ }^{13} \mathrm{C}-\mathrm{RMN}(50 \mathrm{MHz}, 8): 16,6 ; 17,0 ; 25,8 ; 26,7 ; 30,4 ; 42,9 ; 44,1 ; 47,6 ; 49,6 ; 51,7 ; 117,1$; 153,$7 ; 176,1$.

\subsubsection{Preparação da 2-metil-1,3-ciclo-hexanodiona ${ }^{105}$}<smiles>CC1C(=O)CCCC1=O</smiles>

Uma mistura de $\mathrm{KOH}(30,0 \mathrm{~g} ; 0,53 \mathrm{~mol})$ e 1,3 -cicloexanodiona $(60,0 \mathrm{~g} ; 0,535$ $\mathrm{mol})$ em solução aquosa de metanol a $50 \%(180 \mathrm{~mL})$ foi refluxada até dissolução total da cetona. Após resfriamento foi adicionado iodeto de metila $(88,8 \mathrm{~g} ; 0,62 \mathrm{~mol})$ e a solução foi refluxada "overnight". A mistura reacional foi resfriada e o precipitado formado foi filtrado. O filtrado foi evaporado à pressão reduzida e os dois resíduos foram dissolvidos em solução aquosa de $\mathrm{NaOH}$ a $3 \%$ (540 mL). A solução resultante foi lavada com éter $(2 \times 15 \mathrm{~mL})$ e acidulada com $\mathrm{HCl} 4 \mathrm{~N}$ até $\mathrm{pH} 4.0$ precipitado foi filtrado e recristalizado de metanol a quente, e secado a vácuo, para render $33,7 \mathrm{~g}$ da 2 -metil-1,3-cicoexanodiona $(0,267 \mathrm{~mol} ; 50 \%)$. 


\subsubsection{Preparação da cetona de Wieland-Miescher $(92)^{106}$}<smiles>C[C@]12CCC(=O)C=C1CCCC2=O</smiles>

92

Uma mistura da 2-metil-1,3-ciclo-hexanodiona (9,00 g; 71,4 mmol), MVK $(7,50 \mathrm{~g} ; 0,107 \mathrm{~mol})$ e $\mathrm{KOH}$ (uma pastilha) foi dissolvida em $\mathrm{MeOH}$ seco

$(30 \mathrm{~mL}$ ) e refluxada por 3 horas. A solução foi resfriada e o metanol e o excesso de MVK foram evaporados à pressão reduzida e o resíduo dissolvido em benzeno seco (30 mL). A solução foi refluxada por 30 minutos em aparelho de Dean-Stark e depois resfriada à temperatura ambiente, para então se adicionar pirrolidina $(1 \mathrm{~mL})$ refluxar-se por mais 1 hora. Após resfriamento, a solução foi diluída em éter e foi lavada com $\mathrm{HCl}$ 0,15 M. A fase aquosa foi extraída com éter e os extratos orgânicos combinados foram lavados sucessivamente com água, solução saturada de cloreto de sódio e secados com $\mathrm{MgSO}_{4}$. O solvente foi evaporado à pressão reduzida e o resíduo filtrado sob sílica (60-230 mesh), eluindo-se com uma mistura 9:1 de hexano/acetato. O filtrado foi evaporado e o produto destilado a pressão reduzida (PE: $120-130{ }^{\circ} \mathrm{C} ; 0,2 \mathrm{mmHg}$ ) e cristalizado de éter, para render $6,34 \mathrm{~g}$ de 92 (35,7 mmol; 50\%), como um sólido branco.

\subsubsection{Preparação da 5- $\beta$-hidróxi-4a-metil-4,4a,5,6,7,8-hexa-hidro-3H-naftalen-} 2-ona (103) 107<smiles>C[C@@]12CCC(=O)C=C1CCCC2O</smiles>

103

A uma solução de $92(1,78 \mathrm{~g} ; 10,0 \mathrm{mmol})$ em etanol seco $(13 \mathrm{~mL})$, foi adicionada gota a gota e a $0{ }^{\circ} \mathrm{C}$, por um periodo de 45 minutos, uma solução de boro-hidreto de sódio em etanol $(25 \mathrm{~mL})$. A solução foi agitada por mais 15 minutos e a reação foi interrompida pela adição de algumas gotas de ácido acético. O solvente foi evaporado à pressão reduzida e o resíduo foi dissolvido em água. A fase aquosa foi extraída com diclorometano e os extratos orgânicos combinados foram lavados sucessivamente com água, solução saturada de cloreto de sódio e secado com $\mathrm{MgSO}_{4}$. O solvente foi evaporado e o produto bruto foi purificado por cromatografia 
em coluna de sílica flash (200-400 mesh), com eluição gradiente de acetato/hexano (10$50 \%)$, para render $1,20 \mathrm{~g}$ de $103(6,70 \mathrm{mmol} ; 67 \%)$.

\subsubsection{2..Preparação da 10-Metil-1(9)-octal-2-ona $(101)^{112}$}<smiles>CC12CCCCC1=CC(=O)CC2</smiles>

101

Refluxou-se suavemente uma mistura de 2-metilcicloexanona $(29,0 \mathrm{~g}$; $0,26 \mathrm{~mol})$, metilvinilcetona recém destilada $(23,3 \mathrm{~g} ; 0,32 \mathrm{~mol}), \mathrm{H}_{2} \mathrm{SO}_{4}$ concentrado $(0,2 \mathrm{~mL})$ e benzeno seco $(70 \mathrm{~mL})$ por 16 horas. A solução resultante foi resfriada, diluída com $100 \mathrm{~mL}$ de hexano, lavada com solução aquosa de $\mathrm{KOH}$ a $5 \%$, solução saturada de $\mathrm{NaCl}$, secada com $\mathrm{MgSO}_{4}$ e o solvente foi evaporado à pressão reduzida. O produto bruto foi destilado à pressão reduzida $\left(80-95^{\circ} \mathrm{C}, 0,6 \mathrm{mmHg}\right)$ fornecendo uma mistura de 101 e sua dicetona intermediária. Esta mistura de produtos foi refluxada por 6 horas em benzeno seco contendo 5 gotas de $\mathrm{H}_{2} \mathrm{SO}_{4}$ concentrado. Seguiu-se o mesmo work-up descrito acima e o produto foi destilado à pressão reduzida $\left(77-80^{\circ} \mathrm{C}, 0,5 \mathrm{mmHg}\right)$, fornecendo $17,0 \mathrm{~g}(0,10 \mathrm{~mol}, 40 \%)$ de 101 como um óleo incolor.

${ }^{1} \mathrm{H}-\mathrm{RMN}(300 \mathrm{MHz}, \delta): 1,25(\mathrm{~s}, 3 \mathrm{H}) ; 1,30-1,47(\mathrm{~m}, 2 \mathrm{H}) ; 1,64-1,95(\mathrm{~m}, 6 \mathrm{H}) ; 2,21-2,57$ $(\mathrm{m}, 4 \mathrm{H}) ; 5,72(\mathrm{~m}, 1 \mathrm{H})$.

${ }^{13} \mathrm{C}-\mathrm{RMN}(75 \mathrm{MHz}, \delta): 21,7 ; 22,0 ; 27,1 ; 32,7 ; 33,9 ; 35,9 ; 38,0 ; 41,5 ; 124,0 ; 170,4 ;$ $199,5$.

\subsubsection{Preparação do 4 a-Metil-1,2,3,4,4a,5-hexa-hidronaftaleno (105)}<smiles>CC12CC=CC=C1CCCC2</smiles>

A uma solução de 10-metil-1(9)-octal-2-ona (106) $(3,29 \mathrm{~g} ; 20,0 \mathrm{mmol})$ em metanol (100 mL) foi adicionado boro-hidreto de sódio $(0,76 \mathrm{~g} ; 20,0 \mathrm{mmol})$. 105 A solução foi agitada por 1 hora e adicionaram-se $100 \mathrm{~mL}$ de água. A fase orgânica foi extraída com acetato de etila, lavada com solução saturada de $\mathrm{NaCl}$ e secada 
com $\mathrm{MgSO}_{4}$. O solvente foi evaporado à pressão reduzida e o resíduo dissolvido em THF (30 mL). Adicionou-se $\mathrm{H}_{3} \mathrm{PO}_{4} 85 \%(5 \mathrm{~mL})$ e refluxou-se por 1 hora. Após resfriamento a mistura foi neutralizada com $\mathrm{NaHCO}_{3}$ sólido e a fase orgânica foi extraída com acetato de etila, lavada com água, solução saturada de $\mathrm{NaCl}$ e secada com $\mathrm{MgSO}_{4}$. O solvente foi evaporado à pressão reduzida, fornecendo um óleo levemente amarelado que foi filtrado numa coluna curta de sílica (60-200 mesh), eluindo-se com hexano, fornecendo então $2,49 \mathrm{~g}$ de 105 ( $16,8 \mathrm{mmol} ; 84 \%)$ como um óleo incolor.

${ }^{1} \mathrm{H}-\mathrm{RMN}(200 \mathrm{MHz}, \delta): 1,01(\mathrm{~s}, 3 \mathrm{H}) ; 1,26-2,15(\mathrm{~m}, 10 \mathrm{H}) ; 5,37-5,41(\mathrm{~m}, 1 \mathrm{H}) ; 5,57-5,61$ $(m, 1 H) ; 5,91-5,96(M, 1 H)$.

${ }^{13} \mathrm{C}-\mathrm{RMN}(50 \mathrm{MHz}, \delta): 18,5 ; 23,1 ; 23,2 ; 25,7 ; 32,3 ; 37,0 ; 37,6 ; 123,3 ; 125,7 ; 128,8$; 140,9 .

\subsection{Resolução Enzimática}

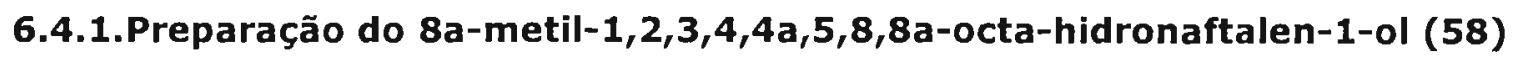

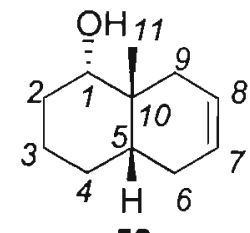

58

A uma solução da octalona 52 (1,00 g; 6,11 mmol) em MeOH (30 mL) mantida a $-78^{\circ} \mathrm{C}$ foi adicionado $\mathrm{NaBH}_{4}(0,23 \mathrm{~g} ; 6,11 \mathrm{mmol})$ sólido. A suspensão foi agitada por uma hora para então se adicionar água (30 $\mathrm{mL}$ ). A fase aquosa foi extraída com AcOEt ( $3 \times 30 \mathrm{~mL})$, lavada com solução saturada de $\mathrm{NaCl}$ e seca sob $\mathrm{MgSO}_{4}$. O solvente foi evaporado à pressão reduzida, para render 0,962 g de 58 (5,79 mmol; 95\%) na forma de um óleo incolor. ${ }^{1} \mathrm{H}-\mathrm{RMN}(200 \mathrm{MHz}, \mathrm{ppm}): 1,05(\mathrm{~s}, 3 \mathrm{H}) ; 1,22-1,77(\mathrm{~m}, 10 \mathrm{H}) ; 2,13-2,39(\mathrm{~m}, 2 \mathrm{H}) ; 3,31$ (dd, $\mathrm{J}=10,7$ e $4,6 \mathrm{~Hz}, 1 \mathrm{H}) ; 5,50-5,64(\mathrm{~m}, 2 \mathrm{H})$. 


\subsubsection{Preparação do éster $8 a-$ metil-1,2,3,4,4a,5,8,8a-octa-hidronaftalen-1-il acético (108)}

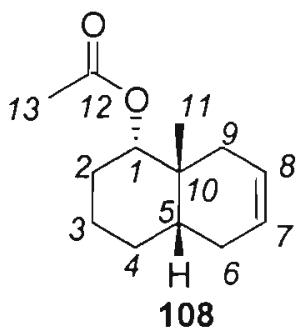

A uma solução do álcool $58(0,332 \mathrm{~g} ; 2,02 \mathrm{mmol})$ e DMAP $(0,049 \mathrm{~g}$; $0,404 \mathrm{mmol})$ em trietilamina $(2 \mathrm{~mL})$, sob atmosfera de nitrogênio, foi adicionado o anidrido acético $(0,57 \mathrm{~mL} ; 0,62 \mathrm{~g} ; 6,02 \mathrm{mmol})$. A reação foi agitada por 30 minutos a temperatura ambiente para então se adicionar metanol $(2 \mathrm{~mL})$. O solvente foi evaporado e o resíduo particionado entre água e acetato de etila. A fase orgânica foi lavada com solução saturada de cloreto de sódio, seca sob MgSO4 e o solvente foi evaporado. O produto bruto foi purificado em coluna de sílica flash (200-400 mesh), eluindo-se com uma mistura hexano/acetato (85\%), rendendo 0,352 g de $108(1,69 \mathrm{mmol} ; 84 \%)$ como um óleo incolor.

${ }^{1} \mathrm{H}-\mathrm{RMN}(200 \mathrm{MHz}, \mathrm{ppm}): 0,93(\mathrm{~s}, 3 \mathrm{H}) ; 1,24-1,82(\mathrm{~m}, 9 \mathrm{H}) ; 2,27-2,39(\mathrm{~m}, 2 \mathrm{H}) ; 4,56$ (dd, $J=10,5$ e $4,8 \mathrm{~Hz}) ; 5,50-5,62(\mathrm{~m}, 2 \mathrm{H})$

\subsubsection{Preparação do éster 6,8 a-dimetil-1, $2,3,4,4 a, 5,8,8$ a-octa-hidronaftalen-1-il acético (109)}

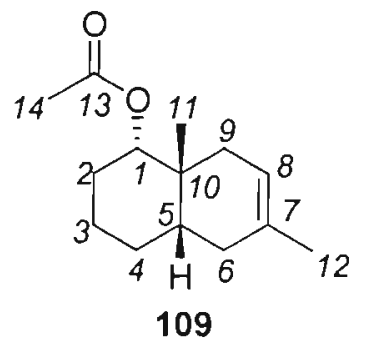

A uma solução do álcool $71(0,578 \mathrm{~g} ; 3,21 \mathrm{mmol})$ e DMAP $(0,078$ $\mathrm{g} ; 0,642 \mathrm{mmol})$ em trietilamina $(3,5 \mathrm{~mL})$, sob atmosfera de nitrogênio, foi adicionado o anidrido acético $(0,90 \mathrm{~mL} ; 0,98 \mathrm{~g} ; 9,63$ mmol). A reação foi agitada por 30 minutos a temperatura ambiente para então se adicionar metanol $(2 \mathrm{~mL})$. O solvente foi evaporado e o resíduo particionado entre água e acetato de etila. A fase orgânica foi lavada com solução saturada de cloreto de sódio, secada com $\mathrm{MgSO}_{4}$ e o solvente foi evaporado. O produto bruto foi purificado em coluna de sílica flash (200-400 mesh), eluindo-se com uma mistura hexano/acetato (85\%), rendendo 0,595 g de 109 (2,68 $\mathrm{mmol} ; 83 \%$ ) como um óleo incolor. 
${ }^{1} \mathrm{H}-\mathrm{RMN}(300 \mathrm{MHz}, \delta): 0,89\left(\mathrm{~s}, 3 \mathrm{H}-H C_{11}\right) ; 1,2-1,8\left(\mathrm{~m}, 9 \mathrm{H}-H C_{2}+H C_{3}+H C_{4}+H C_{5}+\right.$ $\left.H C_{6}\right) ; 2,04\left(\mathrm{~s}, 3 \mathrm{H}-H C_{12}\right) ; 2,25-2,32\left(\mathrm{~m}, 2 \mathrm{H}-H C_{9}\right) ; 4,58(\mathrm{dd}, \mathrm{J}=11,2$ e $4,6 \mathrm{~Hz}, 1 \mathrm{H}-$ $\left.H C_{1}\right) ; 5,22-5,27\left(\mathrm{~m}, 1 \mathrm{H}-H C_{8}\right)$.

${ }^{13} \mathrm{C}-\mathrm{RMN}(75 \mathrm{MHz}, 8): 80,1\left(C_{1}\right) ; 33,9\left(C_{2}\right) ; 23,7\left(C_{3}\right)^{*} ; 26,9\left(C_{4}\right) * * ; 39,9\left(C_{5}\right) ; 28,6$ $\left(C_{6}\right)^{* *} ; 130,5\left(C_{7}\right) ; 117,5\left(C_{8}\right) ; 27,0\left(C_{9}\right)^{* *} ; 35,8\left(C_{10}\right) ; 23,3\left(C_{11}\right)^{*} ; 23,6\left(C_{12}\right)^{*} ; 170,9$ $\left(C_{13}\right) ; 21,2\left(C_{14}\right)$. *os sinais podem estar trocados entre si. **os sinais podem estar trocados entre si.

$\operatorname{IV}_{\text {filme }}\left(v, \mathrm{~cm}^{-1}\right): 1736$

\subsubsection{Preparação da cis-3,4,4a,5,8,8a-hexa-hidro-6,7,8a-trimetilnaftalen-1- (2H)-ona (106)}

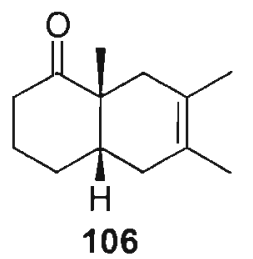

A uma suspensão de $\mathrm{AlCl}_{3}(0,40 \mathrm{~g} ; 7,50 \mathrm{mmol})$ em benzeno seco $(20 \mathrm{~mL})$, em banho de gelo, foi adicionada a 2-metilciclo-hexen-2-ona (1,10 g; $10,0 \mathrm{~mol}$ ) e houve a formação de uma pasta no fundo do balão. Adicionou-se uma ponta de espátula de hidroquinona e 2,3-dimetil-1,3butadieno $(3,28 \mathrm{~g} ; 40,0 \mathrm{mmol})$. O balão foi tampado, o banho de gelo foi retirado, e a solução foi agitada a temperatura ambiente por 24 horas. O solvente foi removido à pressão reduzida e o resíduo foi particionado entre água e éter. A fase etérea foi lavada com água, solução saturada de $\mathrm{NaCl}$, secada com $\mathrm{MgSO}_{4}$, e o solvente foi evaporado à pressão reduzida. O produto bruto foi purificado em coluna de sílica flash (200-400 mesh), eluindo-se com uma mistura hexano/acetato (85\%), rendendo 0,649 g de 106 $(3,64 \mathrm{mmol} ; 36 \%)$ como um óleo incolor.

${ }^{1} \mathrm{H}-\mathrm{RMN}(200 \mathrm{MHz}, \delta): 1,09(\mathrm{~s}, 3 \mathrm{H}) ; 1,47-2,63(\mathrm{~m}, 11 \mathrm{H}) ; 1,62(\mathrm{~s}, 6 \mathrm{H})$.

${ }^{13} \mathrm{C}-\mathrm{RMN}(50 \mathrm{MHz}, \delta): 18,9 ; 19,0 ; 20,6 ; 25,1 ; 27,7 ; 34,7 ; 37,2 ; 37,6 ; 41,6 ; 48,5 ; 121,3 ;$ 122,$5 ; 215,6$. 


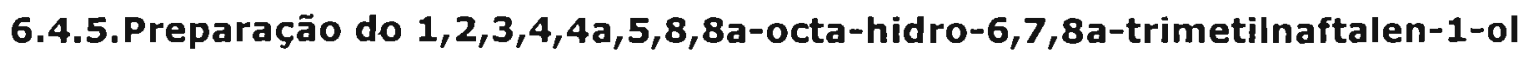

(107)<smiles>CC1=C(C)[C@@H]2C[C@@]([18O])(CCC[C@H]2O)C1</smiles>

A uma solução da octalona $106(0,310 \mathrm{~g} ; 1,74 \mathrm{mmol})$ em $\mathrm{MeOH}(9 \mathrm{~mL})$ mantida a $-78^{\circ} \mathrm{C}$ foi adicionado $\mathrm{NaBH}_{4}(46,0 \mathrm{mg} ; 1,74 \mathrm{mmol})$ sólido. A suspensão foi agitada por uma hora para então se adicionar água ( 30 $\mathrm{mL})$. A fase aquosa foi extraída com AcOEt $(3 \times 30 \mathrm{~mL})$, lavada com solução saturada de $\mathrm{NaCl}$ e secada com $\mathrm{MgSO}_{4}$. O solvente foi evaporado à pressão reduzida, para render 0,292 g de 107 (1,62 mmol; 95\%) na forma de um óleo incolor.

\subsubsection{Preparação do éster $1,2,3,4,4 a, 5,8,8 a$-octa-hidro-6,7,8a-trimetilnaftalen-} 1-il acético (110)

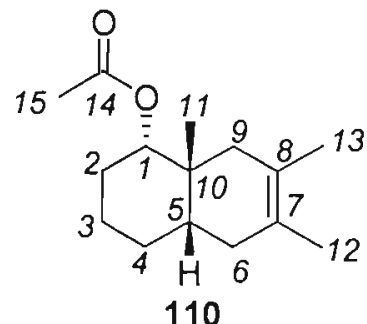

A uma solução do álcool $107(0,121 \mathrm{~g} ; 0,67 \mathrm{mmol})$ e DMAP $(0,016$ g; $0,135 \mathrm{mmol}$ ) em trietilamina (1 $\mathrm{mL})$, sob atmosfera de nitrogênio, foi adicionado o anidrido acético $(0,19 \mathrm{~mL} ; 0,21 \mathrm{~g}$;

$2,01 \mathrm{mmol})$. A reação foi agitada por 30 minutos a temperatura ambiente para então se adicionar metanol $(1 \mathrm{~mL})$. O solvente foi evaporado e o resíduo particionado entre água e acetato de etila. A fase orgânica foi lavada com solução saturada de cloreto de sódio, secada com $\mathrm{MgSO}_{4}$ e o solvente foi evaporado. O produto bruto foi purificado em coluna de sílica flash (200-400 mesh), eluindo-se com uma mistura hexano/acetato (85\%), rendendo $0,144 \mathrm{~g}$ de $110(0,61 \mathrm{mmol}$; $91 \%$ ) como um óleo incolor. 


\subsubsection{Procedimento Geral para a Resolução Enzimática}

A um Erlenmeyer contendo hexano (20 mL, pureza de HPLC), acetato de vinila (1 $\mathrm{mL}$ ) e Novozyme 435 (200 mg) foi adicionado o álcool apropriado (58 - 0,195 g ou 71 $0,280 \mathrm{~g}$ ou $107-0,280 \mathrm{~g})$. A mistura reacional foi agitada por $48 \mathrm{~h}$ a $40{ }^{\circ} \mathrm{C}(160 \mathrm{rpm})$ para então ser filtrada e o solvente ser evaporado à pressão reduzida. O resíduo foi purificado em coluna de sílica flash (200-400 mesh), eluindo-se com uma mistura hexano/acetato ( $85 \%)$. Os compostos foram analisados em uma coluna capilar quiral de $\beta$-ciclodextrina. Condições do CG: injetor $-200{ }^{\circ} \mathrm{C}$; detector $-220^{\circ} \mathrm{C}$; pressão $-100 \mathrm{kPa}$

(1S,4aS,8aR)-8a-Metil-1,2,3,4,4a,5,8,8a-octa-hidronaftalen-1-ol (58a)

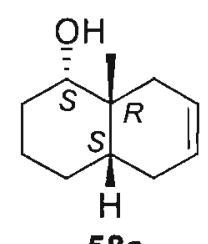

Forno: $100-180^{\circ} \mathrm{C}$, razão $1^{\circ} \mathrm{C} / \mathrm{min}$;

Tempo de retenção: $S=25.5 \mathrm{~min}, R=26.3 \mathrm{~min}-$ e.e. $=98 \%$;

Coluna: CHIRASIL DEX CB;

$58 \mathbf{a}$ $[\alpha]^{\mathrm{D}}{ }_{25}=+6,6^{\circ}\left(\mathrm{c} 8.6, \mathrm{CHCl}_{3}\right)$.

(1R,4aR,8aS)-Éster 8a-metil-1,2,3,4,4a,5,8,8a-octa-hidronaftalen-1-il acético (108b)

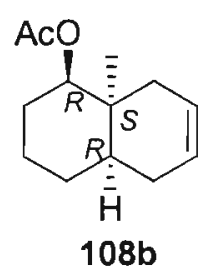

Forno: $100-180^{\circ} \mathrm{C}$, razão $1^{\circ} \mathrm{C} / \mathrm{min}$;

Tempo de retenção: $S=20.9 \mathrm{~min}, R=22.8 \mathrm{~min}-$ e.e. $=98 \%$;

Coluna: CHIRASIL DEX CB;

$\left[\alpha\left[{ }^{\mathrm{D}}{ }_{25}=-24,0^{\circ}\left(\mathrm{c} 3.25 \mathrm{CHCl}_{3}\right)\right.\right.$. 
(15,4aS, 8aR)-6,8a-Dimetil-1,2,3,4,4a,5,8,8a-octa-hidronaftalen-1-ol (71a)

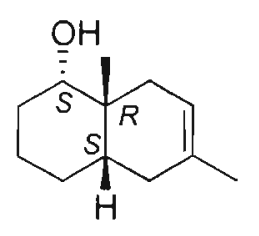

Forno: $100-180^{\circ} \mathrm{C}$, razão $1^{\circ} \mathrm{C} / \mathrm{min}$;

Tempo de retenção: $S=27.0 \mathrm{~min}, R=28.8 \mathrm{~min}-$ e.e. $=98 \%$;

Coluna: CHIRASIL DEX CB;

$71 a$

$[\alpha]_{25}{ }_{25}=-1,6^{\circ}\left(c 3.02, \mathrm{CHCl}_{3}\right)$.

(1R,4aR,8aS)-Éster 6,8a-dimetil-1,2,3,4,4a,5,8,8a-octa-hidronaftalen-1-il acético (109b)

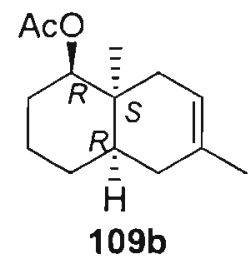

Forno: $100-180^{\circ} \mathrm{C}$, razão $10^{\circ} \mathrm{C} / \mathrm{min}$;

Tempo de retençao: $S=64.4 \mathrm{~min}, R=64.8 \mathrm{~min}-e . e=92 \%$;

Coluna: GAMA DEX ${ }^{T M}$ (Supelco);

$[\alpha]^{\mathrm{D}}{ }_{25}=-8,5^{\circ}\left(\mathrm{c} 2.95, \mathrm{CHCl}_{3}\right)$.

(1S,4aS,8aR)-1,2,3,4,4a,5,8,8a-Octa-hidro-6,7,8a-trimetilnaftalen-1-ol (107a)

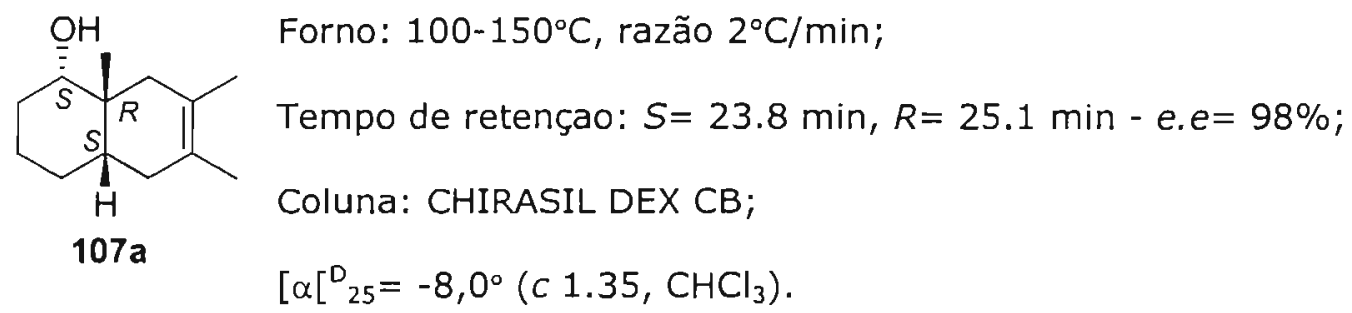

(1R,4aR,8aS)-Éster 1,2,3,4,4a,5,8,8a-octa-hidro-6,7,8a-trimetilnaftalen-1-il acético (110b)

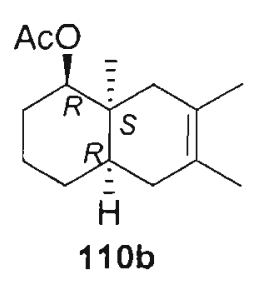

Forno: $100-180^{\circ} \mathrm{C}$, razão $10^{\circ} \mathrm{C} / \mathrm{min}$;

Tempo de retençao: $S=66.8 \mathrm{~min}, R=67.0 \mathrm{~min}-e . e=98 \%$;

Coluna: GAMA DEX ${ }^{T M}$ (Supelco);

$[\alpha]^{\mathrm{D}}{ }_{25}=+13,5^{\circ}\left(\mathrm{c} 2.73, \mathrm{CHCl}_{3}\right)$. 


\section{Espectros de RMN}




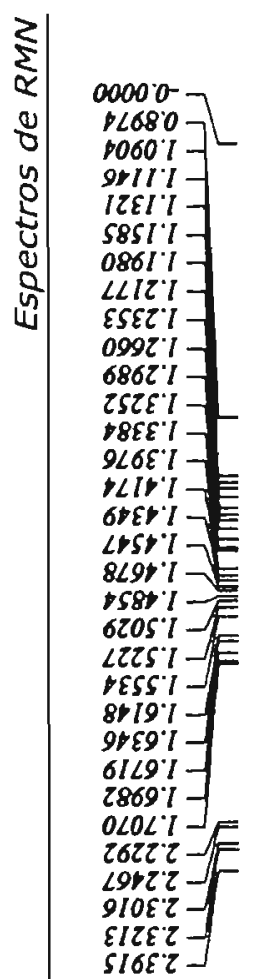

BIELIOTECA

WSTITUTO DE QUIAATCA

Universidade de Gão Pullo

SI6E $]$
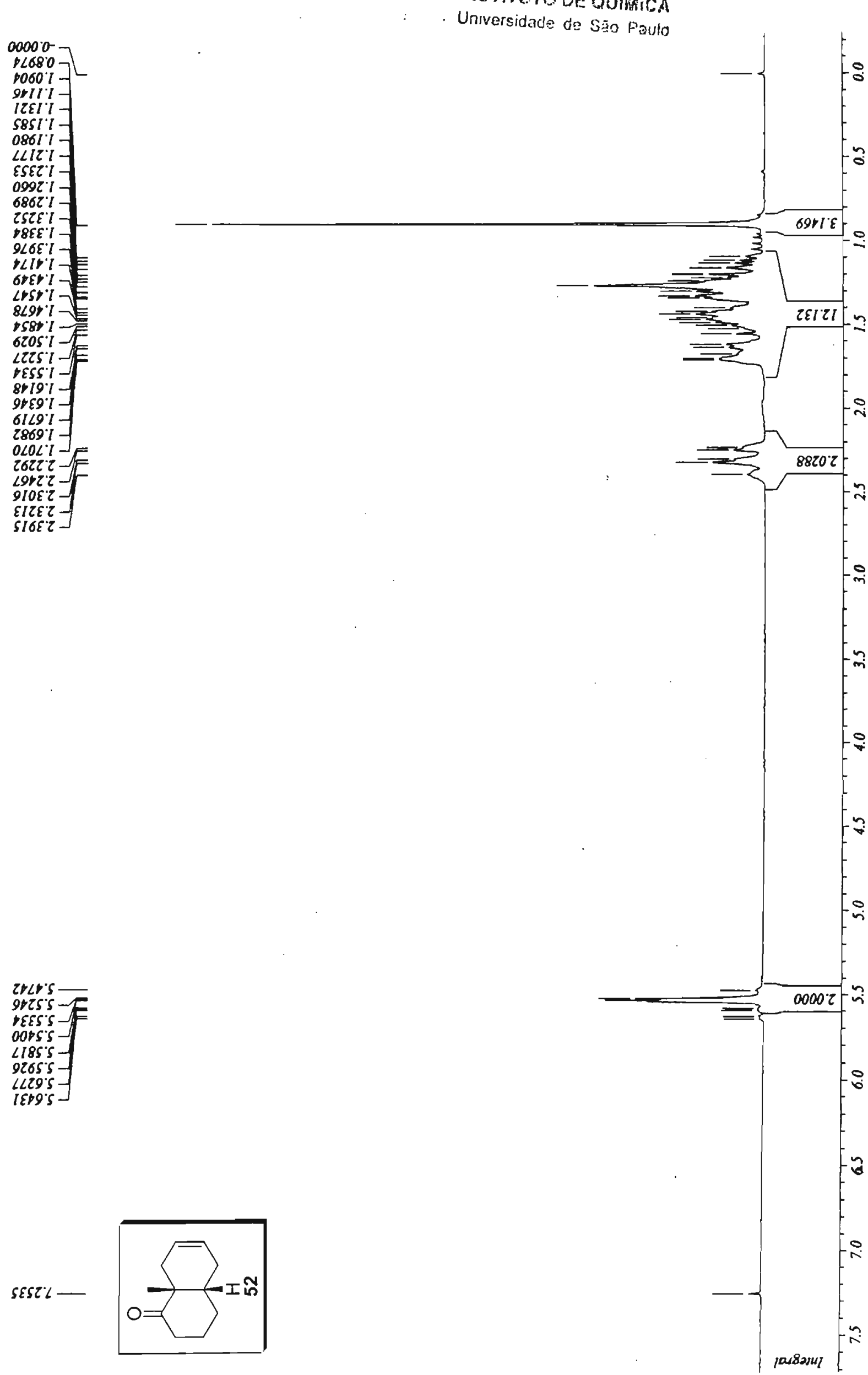


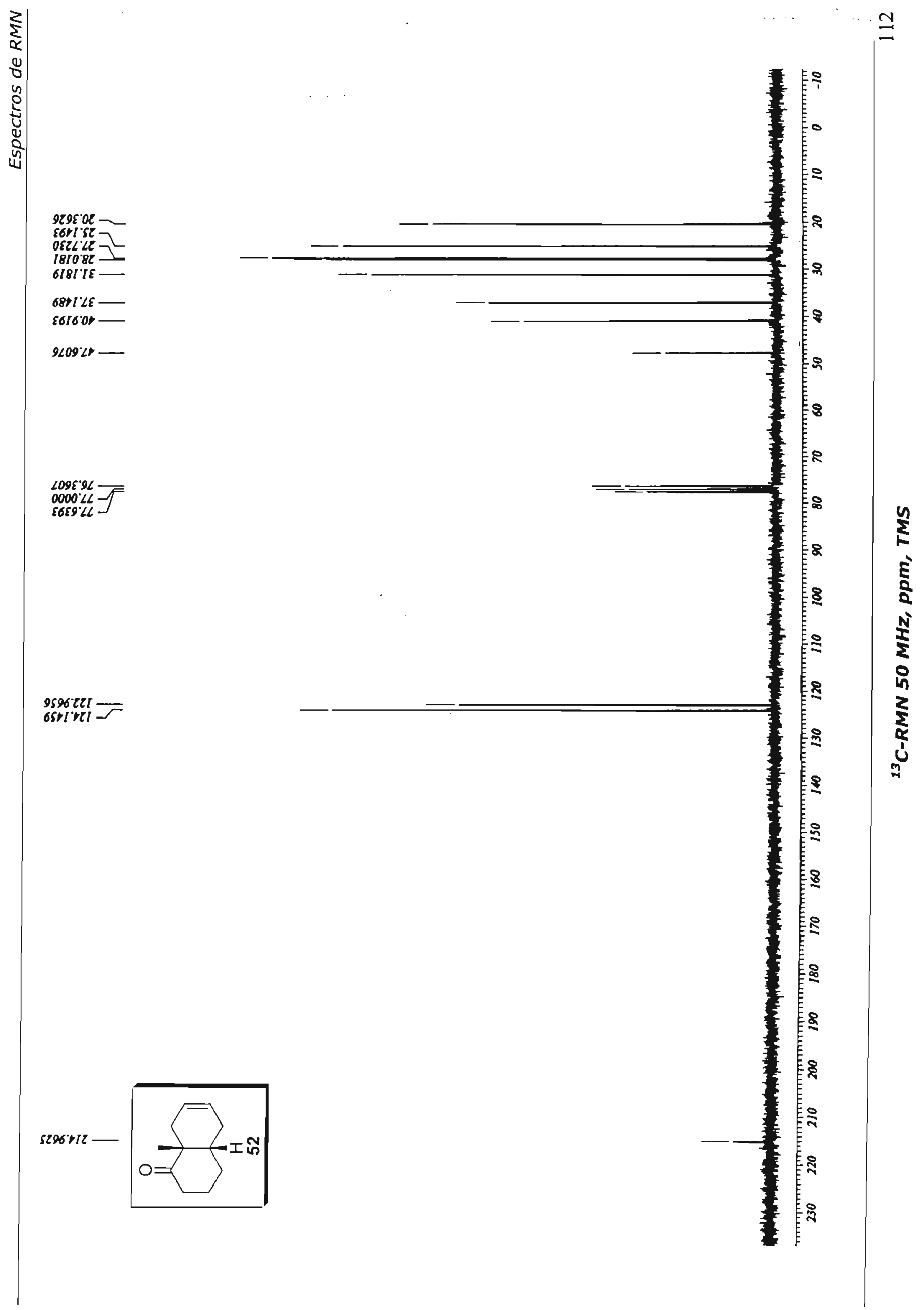



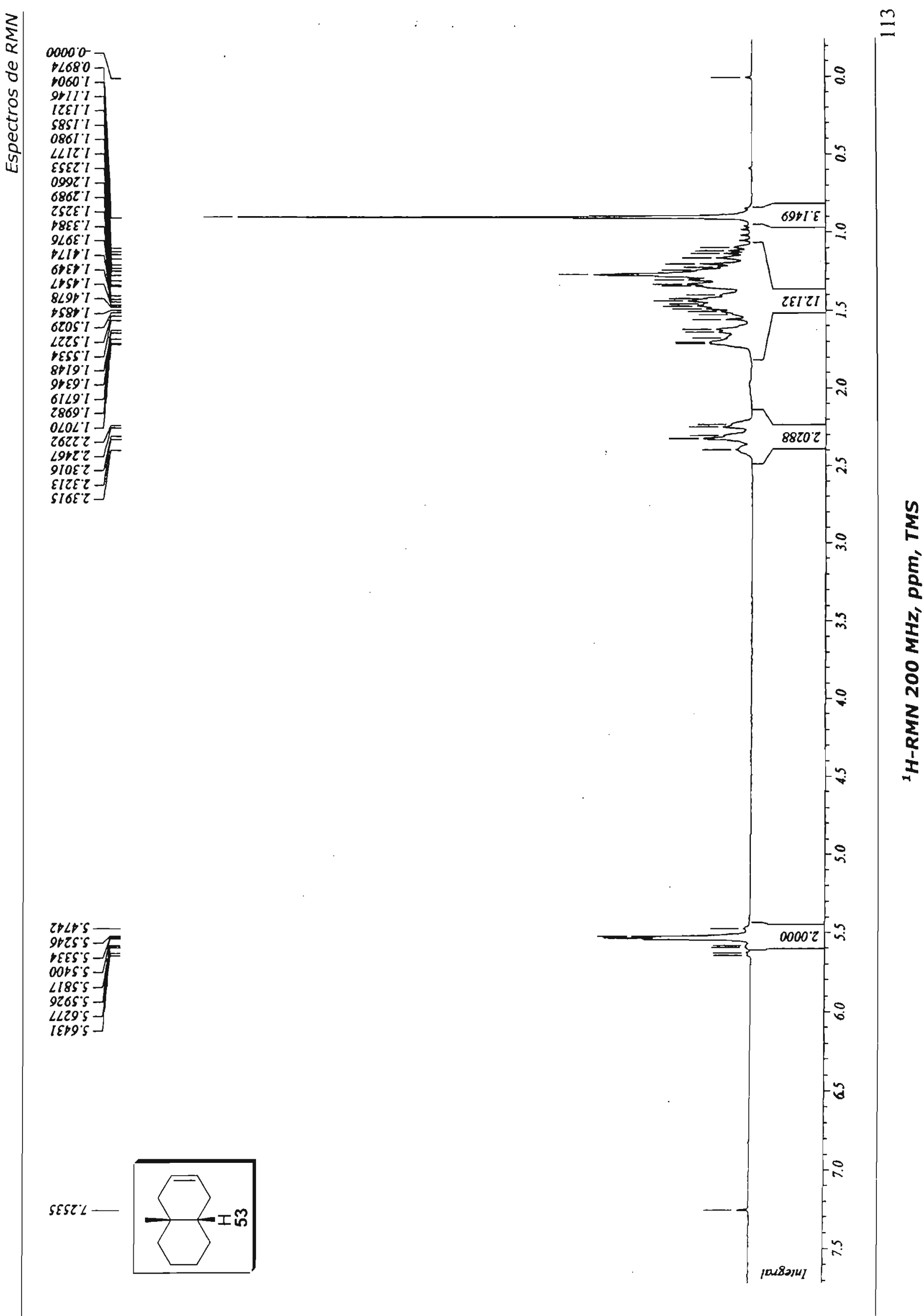
3
$\Sigma$
0
0
0
0
0
0
0
0
4
4

STE9 Z

124

6519.62

El60.0E

OE85. IE

166566

zILZO

$\angle 069.9$

$00<2<1-5$

E606 21$]$

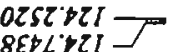

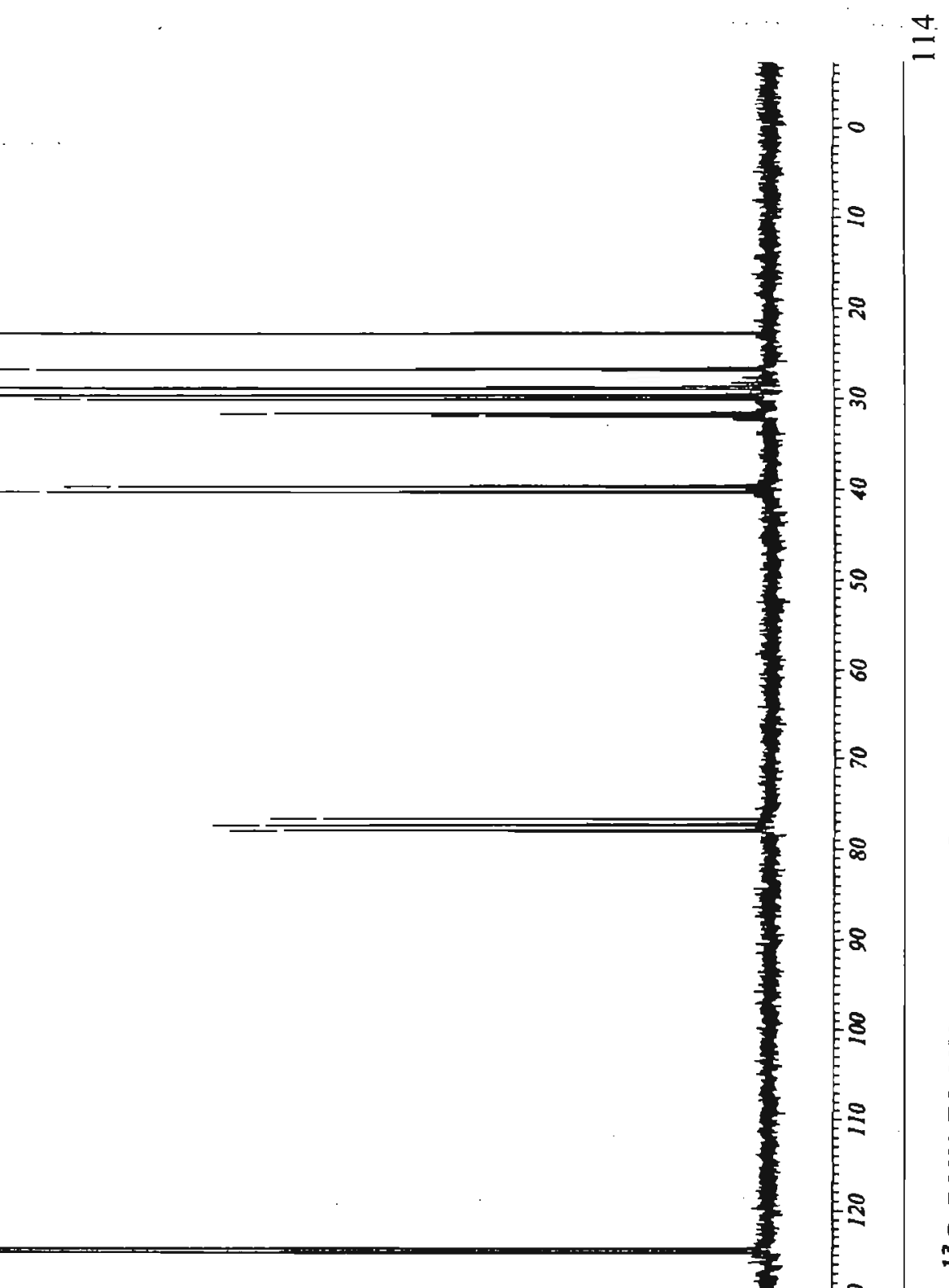

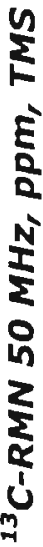

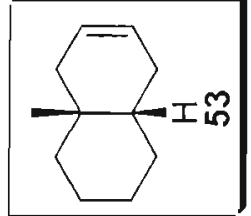




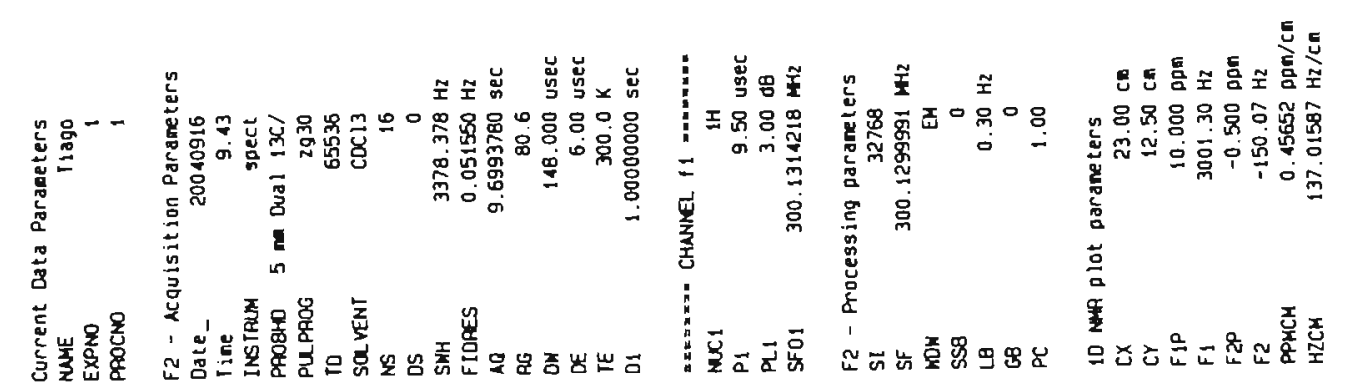

$6986^{\circ} 0$

8ट66 07

घ95E :

$\left.\theta L E^{\circ} \square\right]$

96LE []

906E. $[$ -

दБ6E

9EOR. $[7$

$6856 \cdot 7$

$6005^{\circ},-$

$\angle D O S^{\circ} \cdot-$

6टEG

SLOS'

टSLS '

DLOL':

$\triangle 2 \angle L^{\circ}$

รE\&L 1

S518.

LOEI' $2-$

BLSI' 2$] / / F$

$6520^{\circ} E-$

БCEO ${ }^{\circ}$

$0950^{\circ} \mathrm{E}-$

टE日ट ' $E-$

6Ө口E' $E$

टSSE 'E

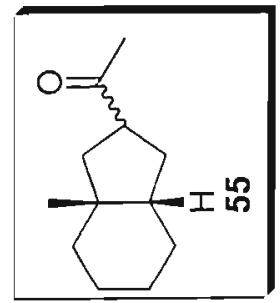




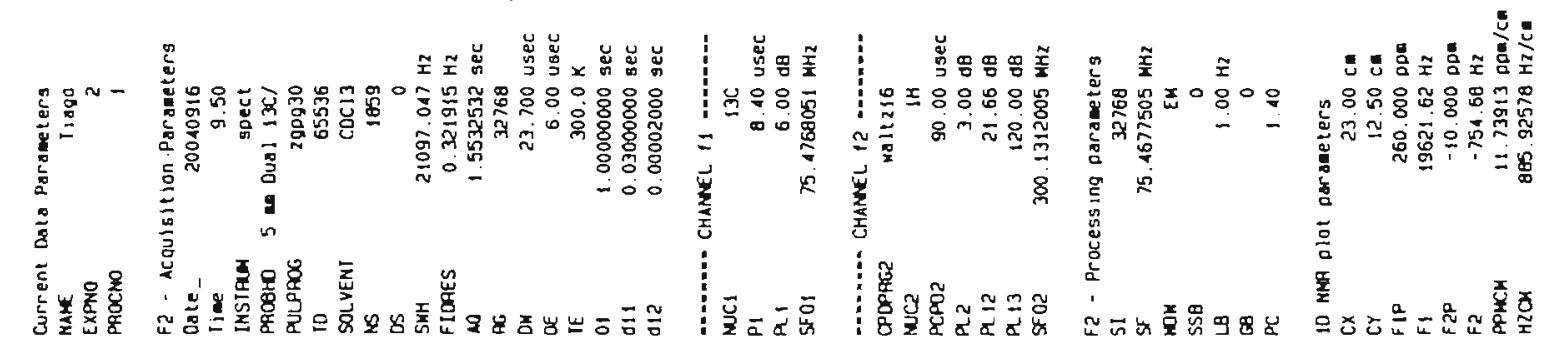

6ES 12

695. 52

$\mathrm{ILC} \cdot 5 \mathrm{~J}$

टडब टट

GIE SE

LEL 55

OEG 25

$996.95-2$

$\nabla \angle 9.82$

ESG OE F

हE० टह -

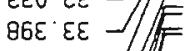

BSC ' $\triangle E$

$92 L^{\circ} \sigma E$

ESO 10

$\angle \varepsilon C^{\prime} \mathrm{ZD}$

dLC. DO

EOI $\mathrm{SP}$

EsG 8 b

$6 \angle 9^{\circ} 9 \angle-$

$500^{\circ} \angle L$

$\angle 2 D \cdot \angle L-$

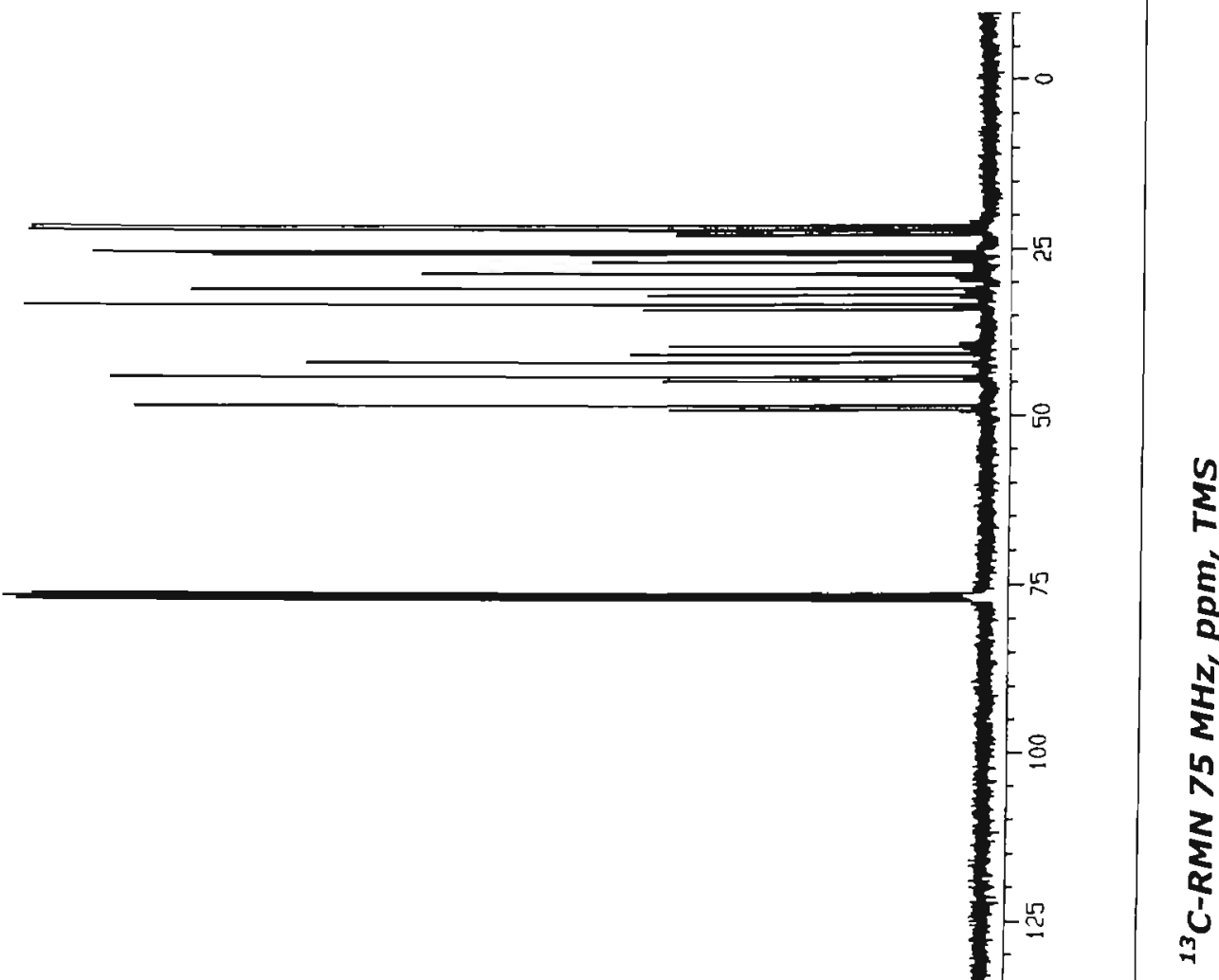

$962.012->$
$686.052-$

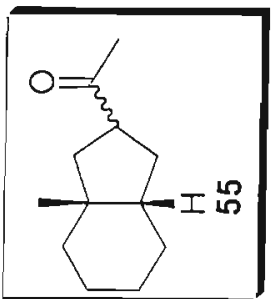


$0000^{\circ} 0-7$

SIEO 17

$90 \angle 5 \cdot 1]$

SOSE' $\}$

ВЕ I

OODE' : 7

86DE' : ᄀ

ट99E' I ᄀ

O८०E.

6E6E'

666E' 1

OELO :

डटटट०,

8 हैद '

s109.

$9<68$.

8ED6 \%

$9 D E F \cdot 2$

बा55.

$\angle 205 \cdot 5-$

$\varepsilon \angle G \bar{z}-$

$0895 \cdot 5$

ODOL'E -

ट6L $\angle \cdot E$

$\varepsilon \angle E L \cdot E$
$E \angle 9 C^{\prime} \angle-$

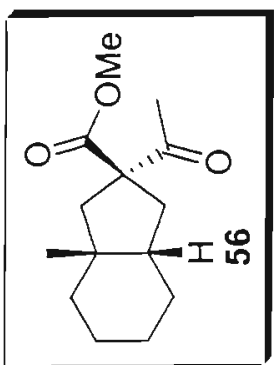




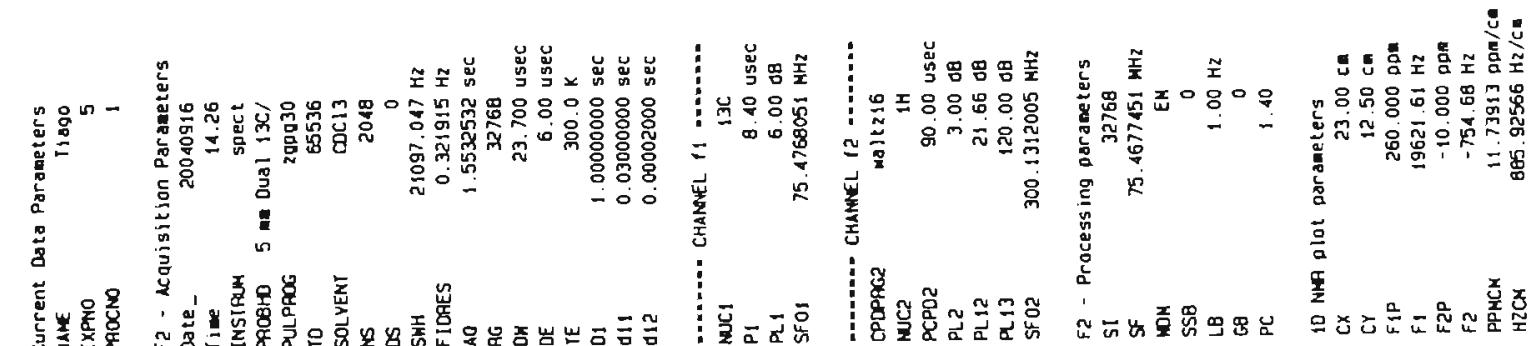

$000^{\circ} 0$

DEC. IC

OEE 52

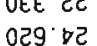

ธ९و. जट

$\angle 99^{\circ} 92$

DS.

$9 \angle 0^{\circ} .9 E$

$659^{\circ} 00$

G8E. D० =

टा8. 5

$6 \angle 9^{\circ} \mathrm{2S}-$

$8 \angle 9 \cdot 89$

$609 \cdot 9 L$

IEO $\angle L$

$\csc 0^{\circ}<L$

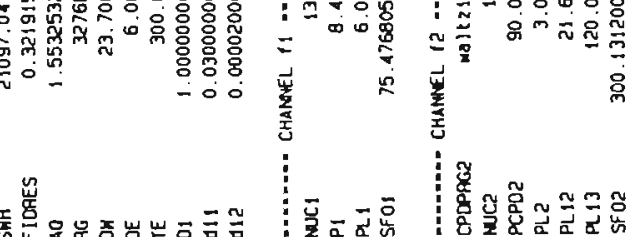

$099^{\circ} \circ \angle 1-$

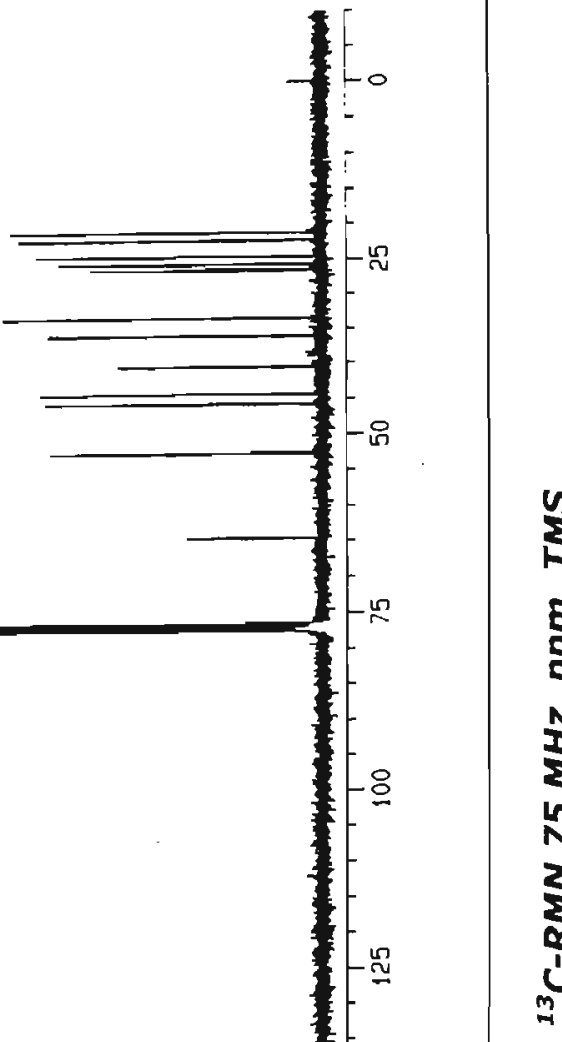

$06 s^{\circ} \varepsilon 02$

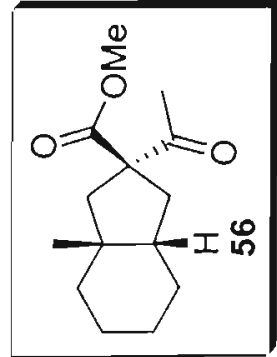

$\frac{G}{\Sigma}$
$k$
$\frac{1}{2}$
$\frac{1}{2}$
$\frac{N}{2}$
$\frac{1}{2}$
$\frac{1}{2}$
$\frac{\alpha}{2}$
$\frac{1}{2}$ 


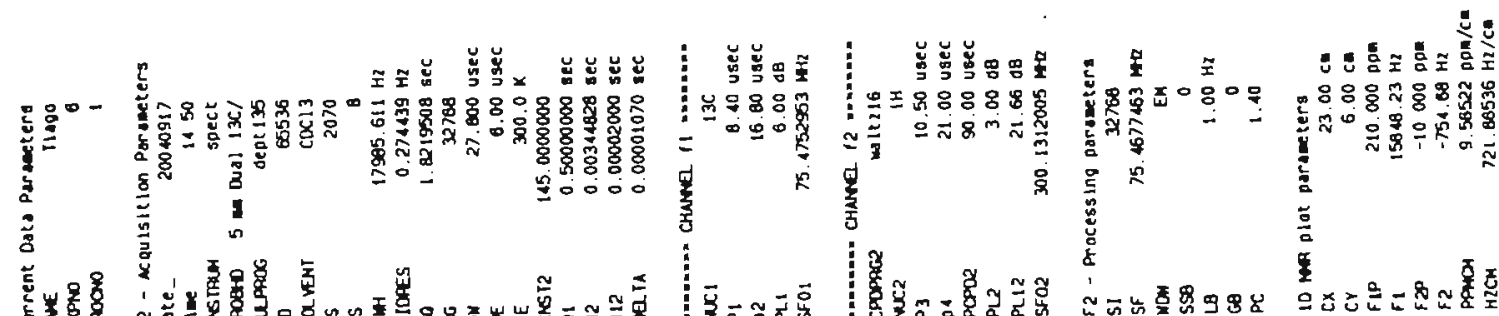

EรEट : เ

ГटEE 25 $6 ट 29 \cdot \nabla ट$

8टక9. Gट

SE95.92-

BLSG' EE

16 $\angle 0^{\circ} \mathrm{9E}$

ELBE'

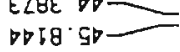

$0 \mathrm{Q} \angle S^{\circ} 2 \mathrm{~s}$
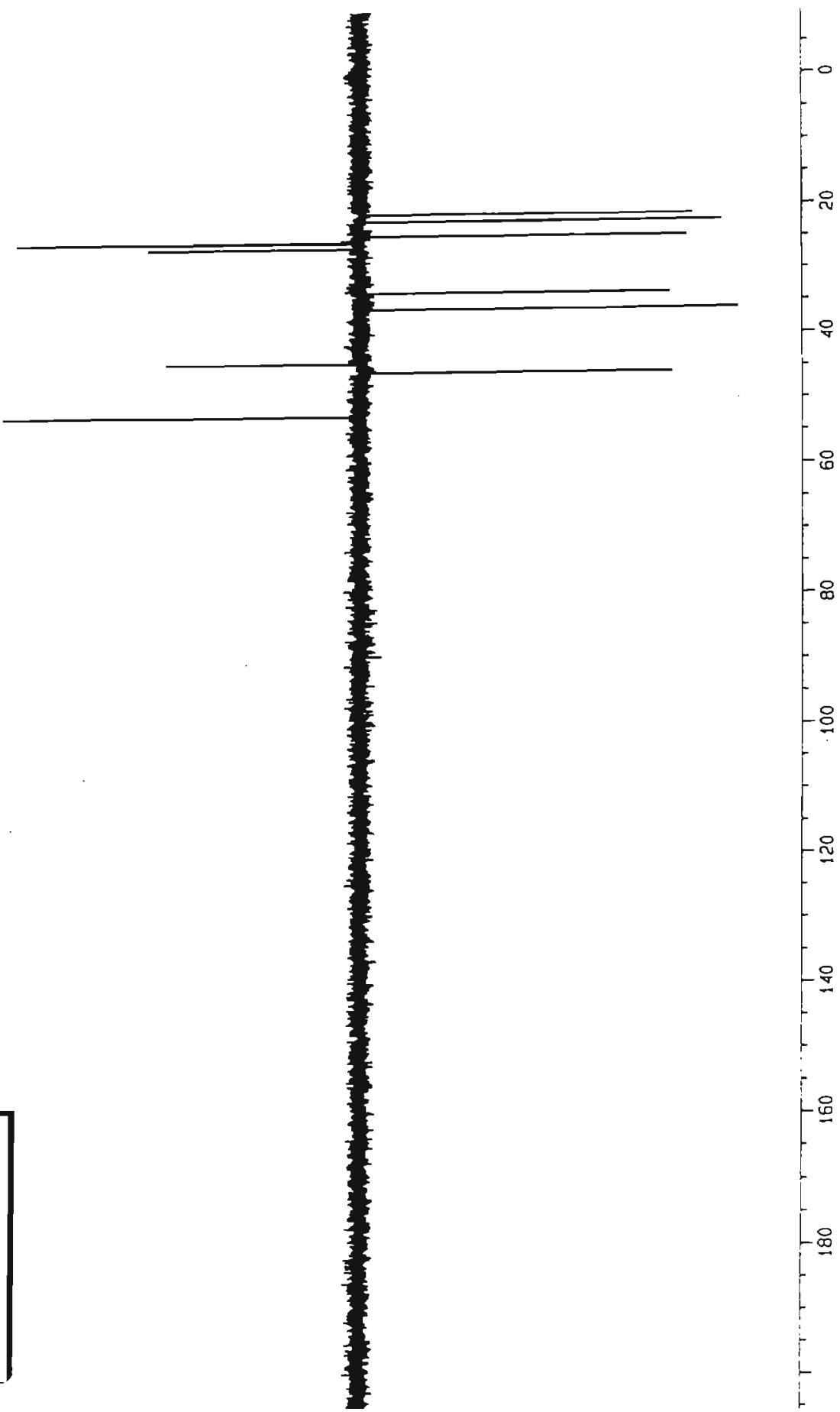

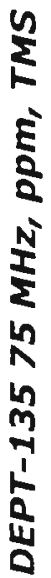

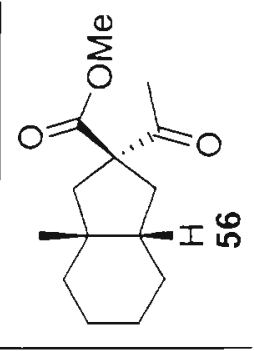



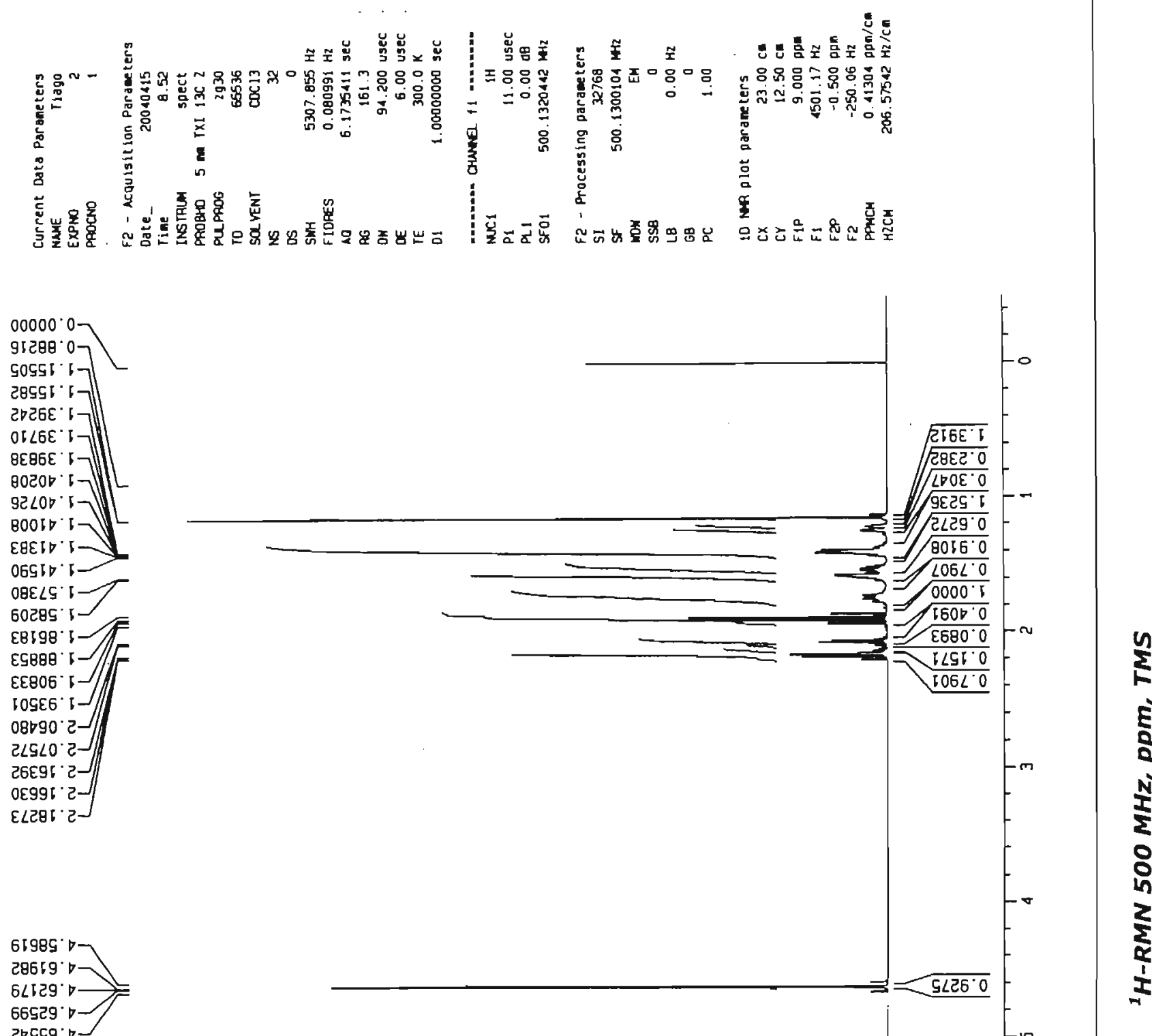

टb $599^{\circ}$

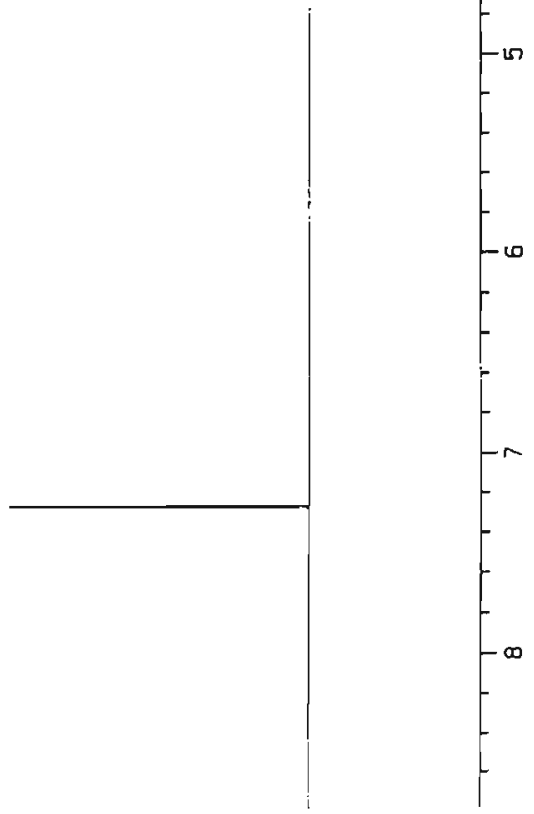




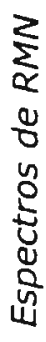

$0<0<02$

$\varepsilon 9+\varepsilon \cdot 2 \tau$

$\$ 9 \varepsilon 6^{\circ} \varepsilon 2 \div$

$6 r 08: 2 \varepsilon$

$\angle 660^{\circ} 0{ }^{\circ}-$

0861 ' $\mathrm{tP}$

E962' $S t-$

PI81 $6 \mathrm{H}$

$\angle 959^{\circ} 15-$

ЯIIE ZL

ILLE' $9 \angle$

$0000 \% L-$

$E 6 E 9^{\circ} \angle L$

$\$ 5+0.621-$
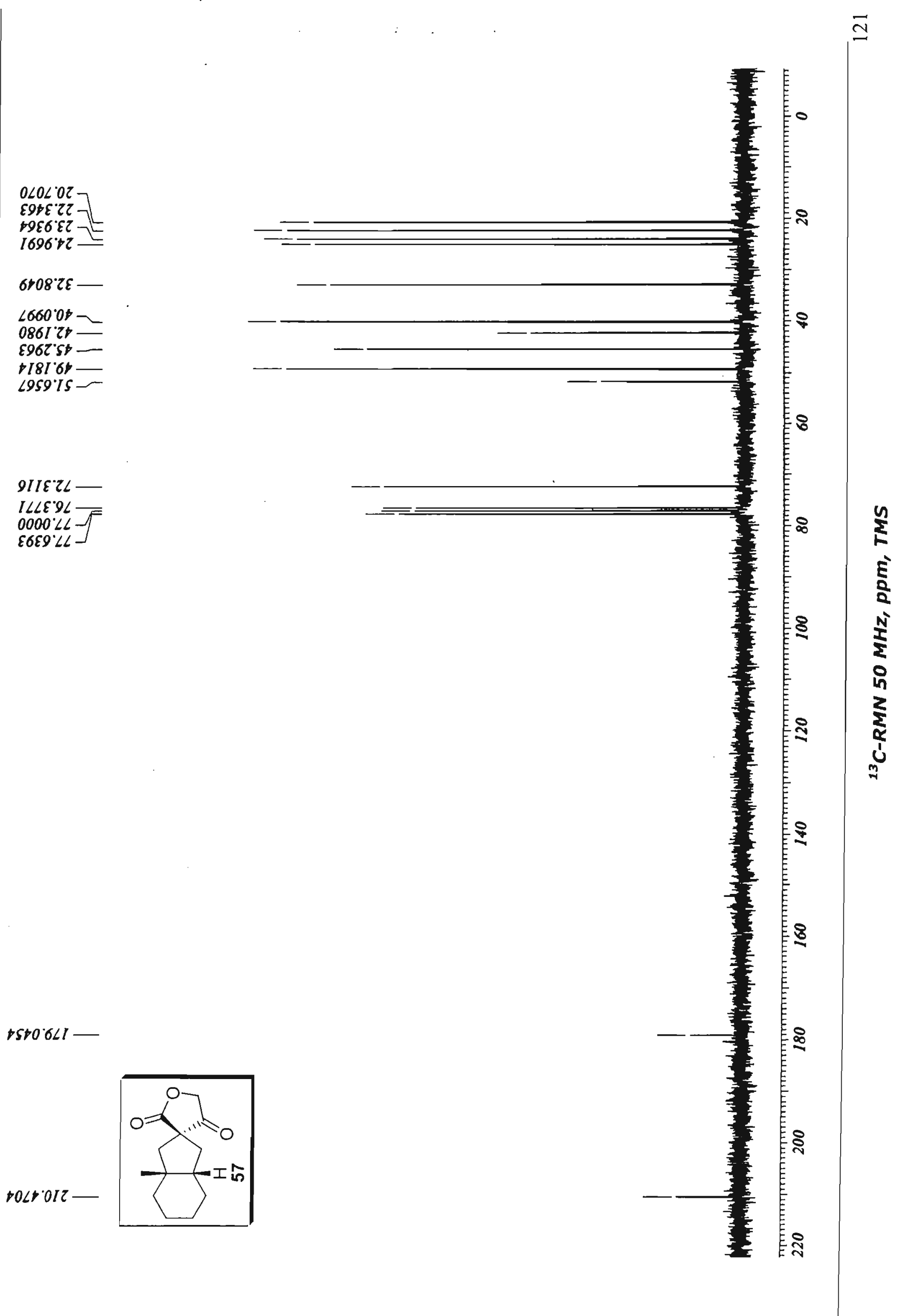


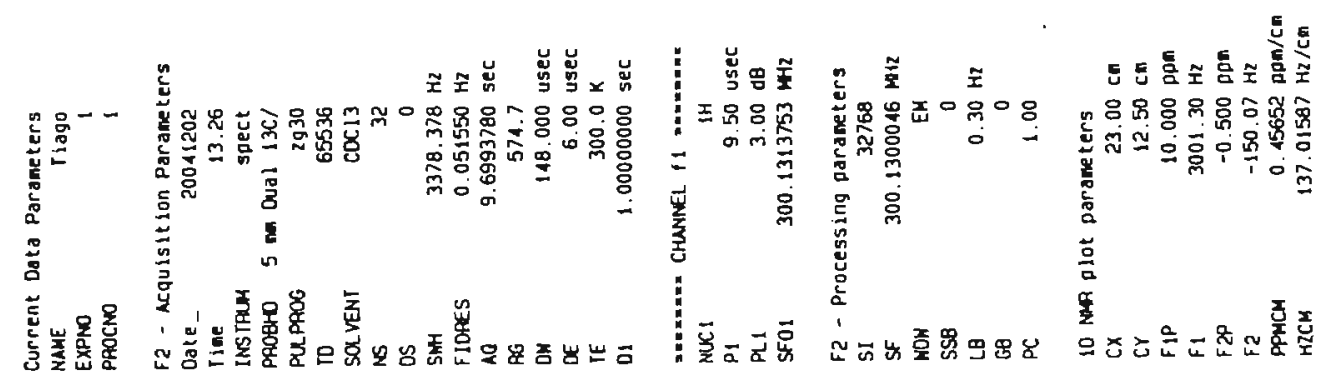

00000.0

$010 \angle 0^{\circ} 0$

SSEE ' 17

LOESE ' $[7]$

Dट6GE [7]

9869E : $]$

GIGLE' $\backslash$

EGSQE '

$\angle E 005^{\prime} \mathrm{C}$

600 $55^{\circ}:-1$

टदSL $\angle \cdot L$

$0 \angle L L L$.

$2002 L$

จाटटL: $1-1$

geb0Q: $1-$

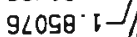

$\varepsilon 5000^{\circ} 5-1$

$196<0_{0} 57$

$60095 \cdot 5-1$

$8996.5-$

$28 \mathrm{c}[5 \cdot 5]$

$09999 \cdot \varepsilon$

$0 S 9 \angle 9^{\circ} \varepsilon-$

$\nabla \angle 989^{\circ} \varepsilon-$

$\angle 620 \angle \varepsilon-$

IEBI $L \cdot E-$

DCEVB $\square-$

GS $\angle \nabla \theta^{\circ} \circ-$

BSISB.

$\angle 8998 \cdot \square-$

OEOSQ $\rightarrow-$

$00096 \cdot$

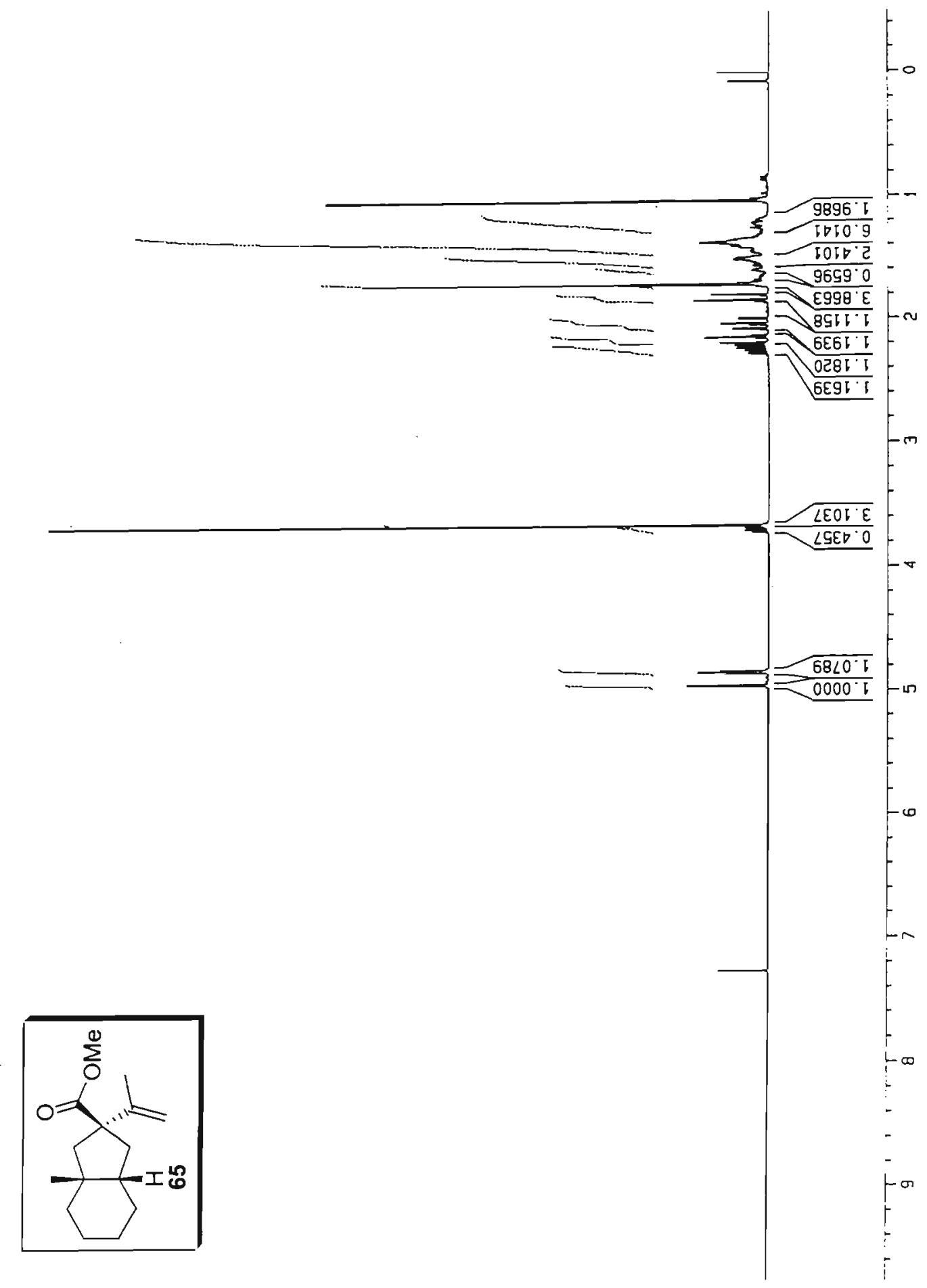

22992 $L$ 


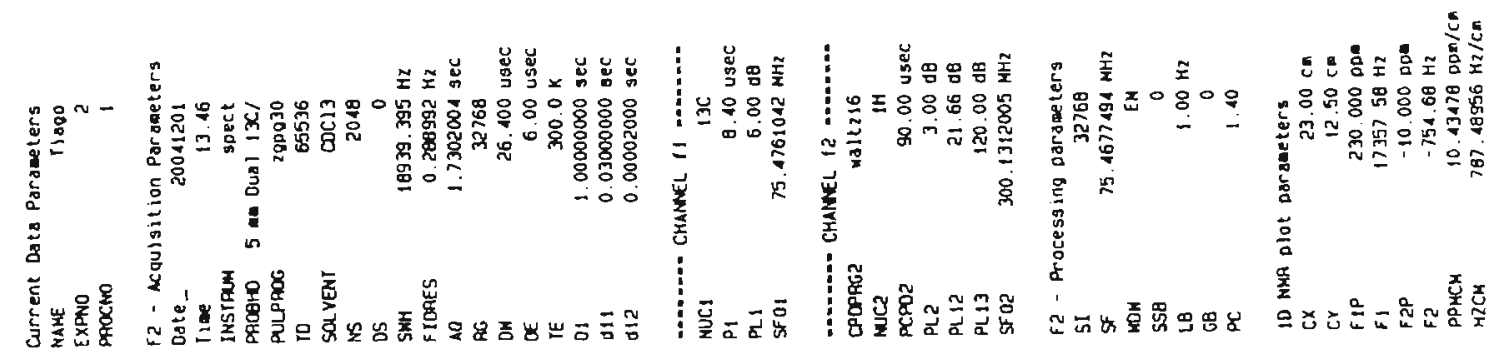

880.12

ges 157

ESG टट

$\angle E S^{\circ} \nabla 2$

$62 L$ SE

SEट $E$

68r.

$68 \mathrm{I}^{\circ} \mathrm{BE}-$

ट५6 $\varepsilon \nabla$

$\angle B 9^{\circ} \theta$

D62.25

$E \nabla 9 \cdot \angle 5$

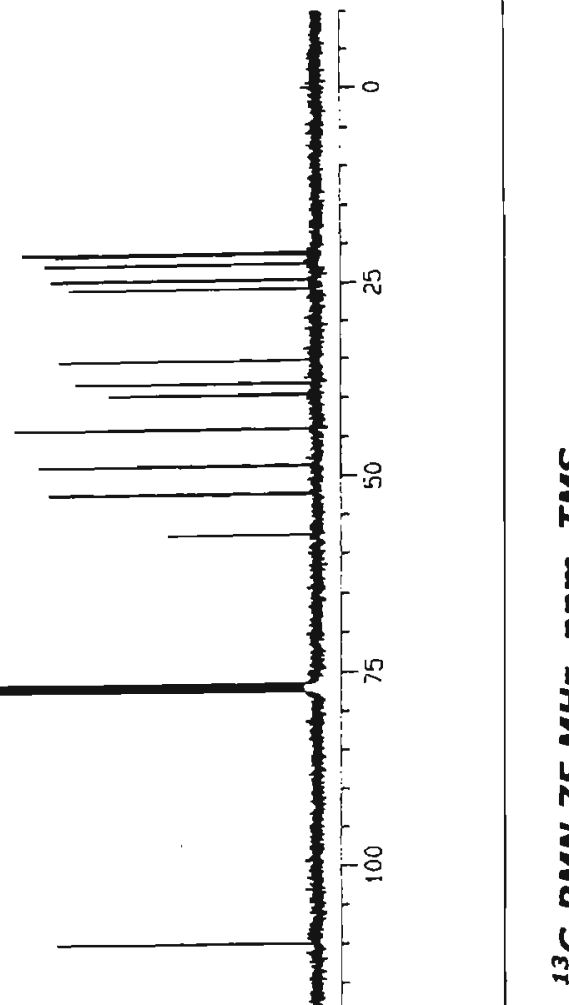

$\nabla \angle \mathcal{G}^{\circ} 9 L$

$866 \cdot 9 L$

เ2) $\angle L$

$596 \cdot 60 i$

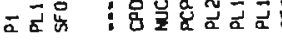

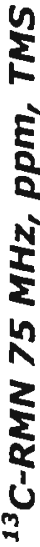

$909^{\circ} \angle D I$

$55 D^{\circ} \angle L i$
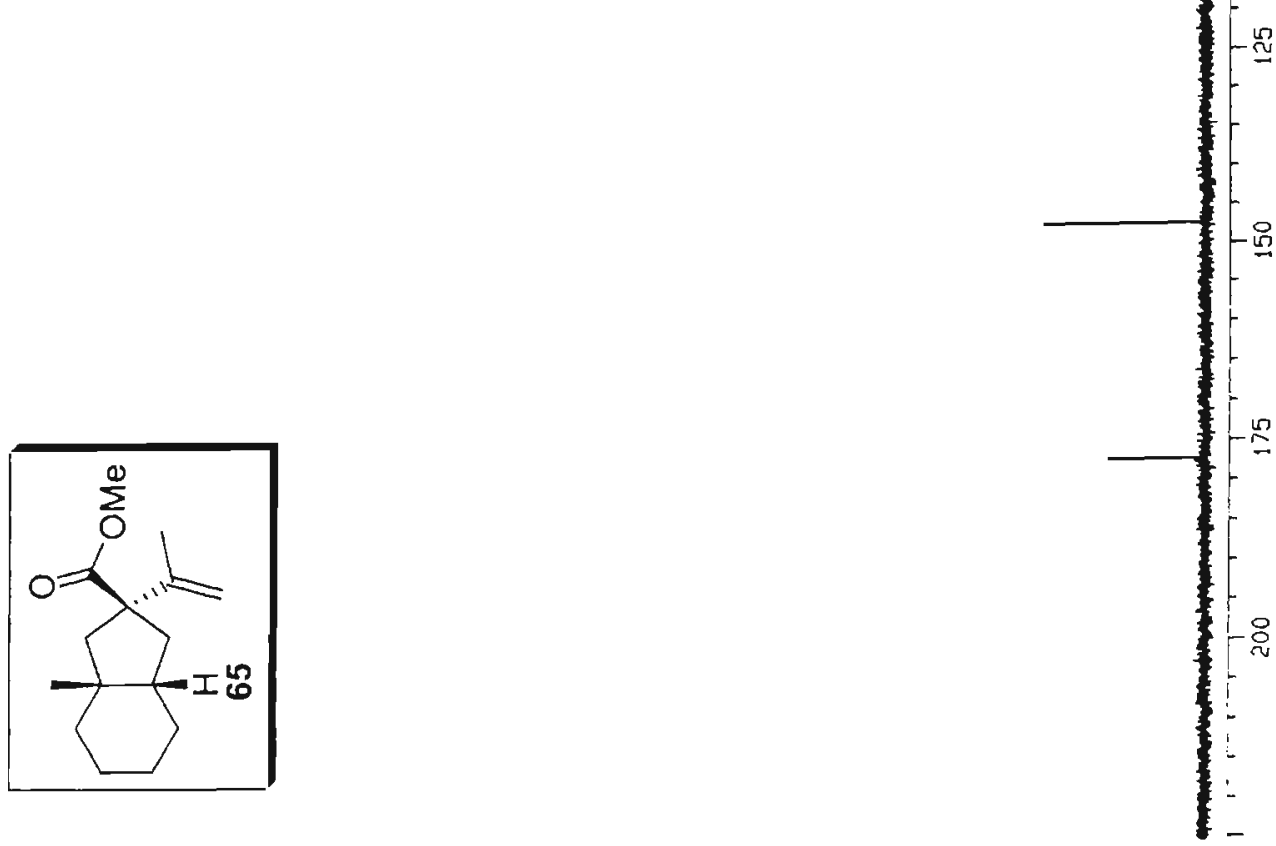
$\triangle 80.12$

$\angle E 2$ L

ESS 22

म०S. मर

БEट $G E$

ธEट $\mathcal{G E}=$

$\angle \subseteq 6^{\circ} \varepsilon \square$

म००

Б62. 29

$0 \angle 6^{\circ} 605$

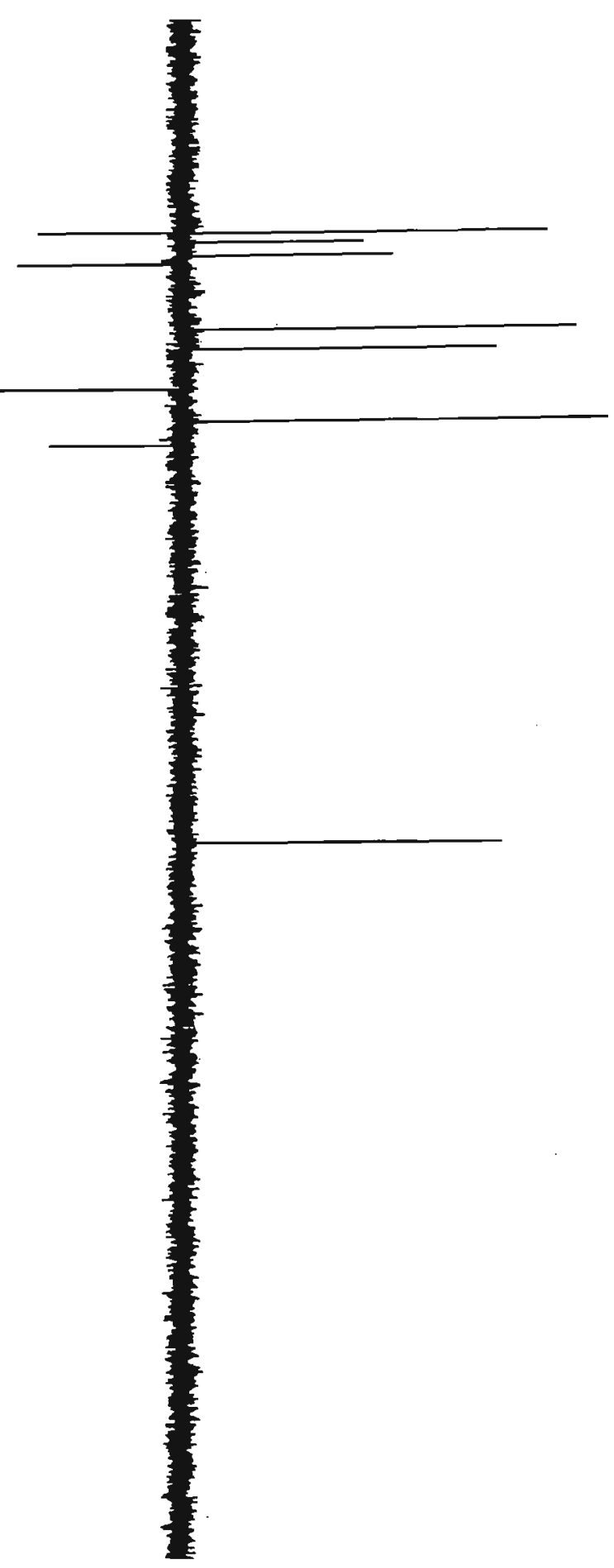




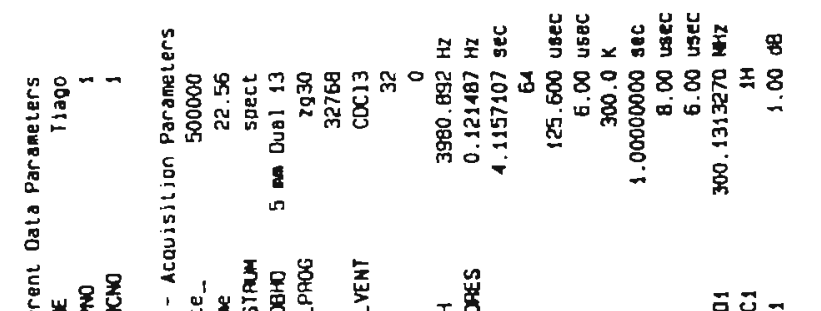
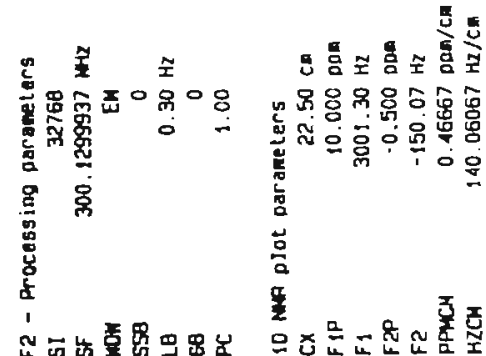

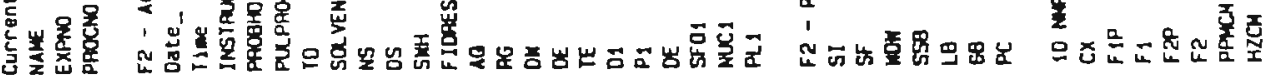
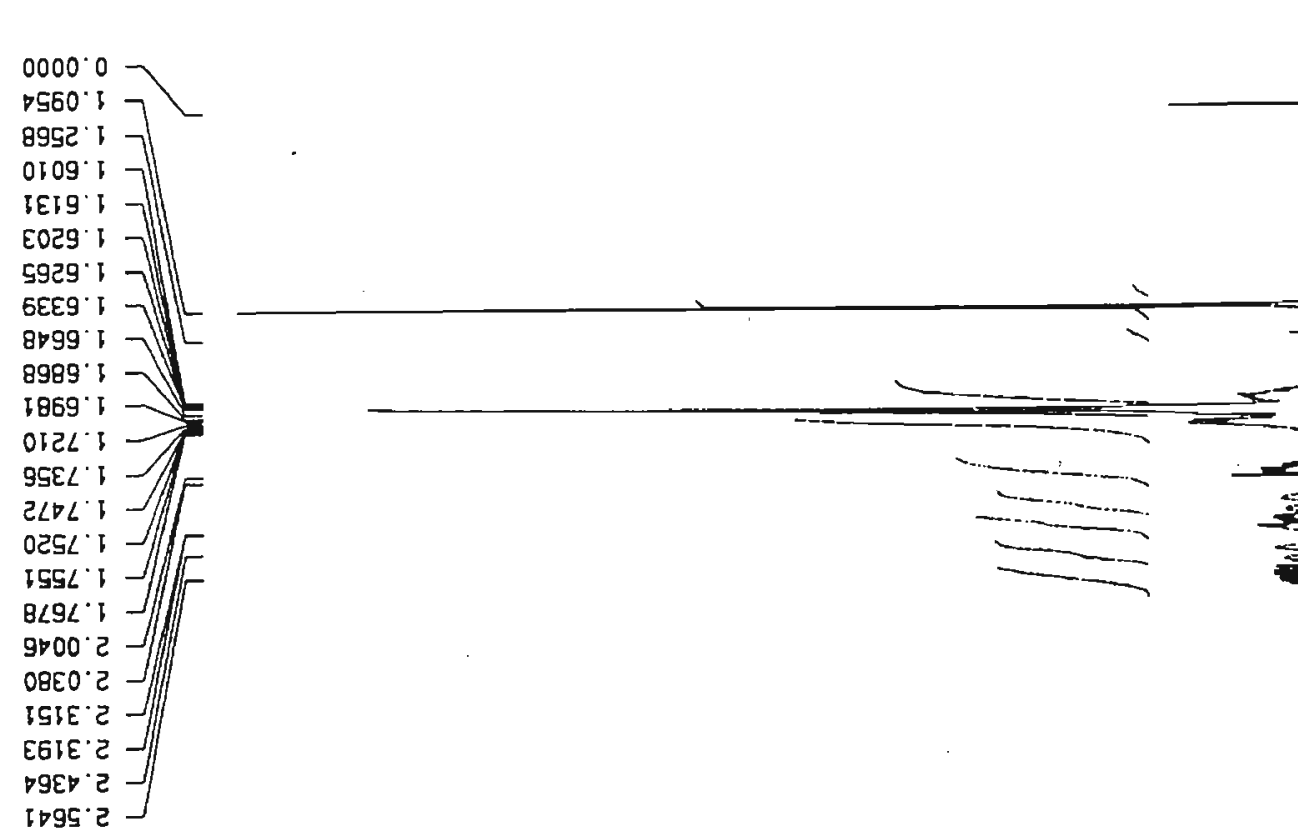


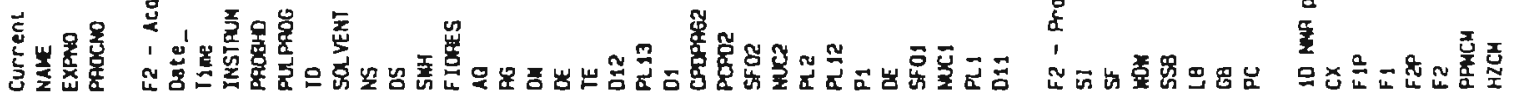
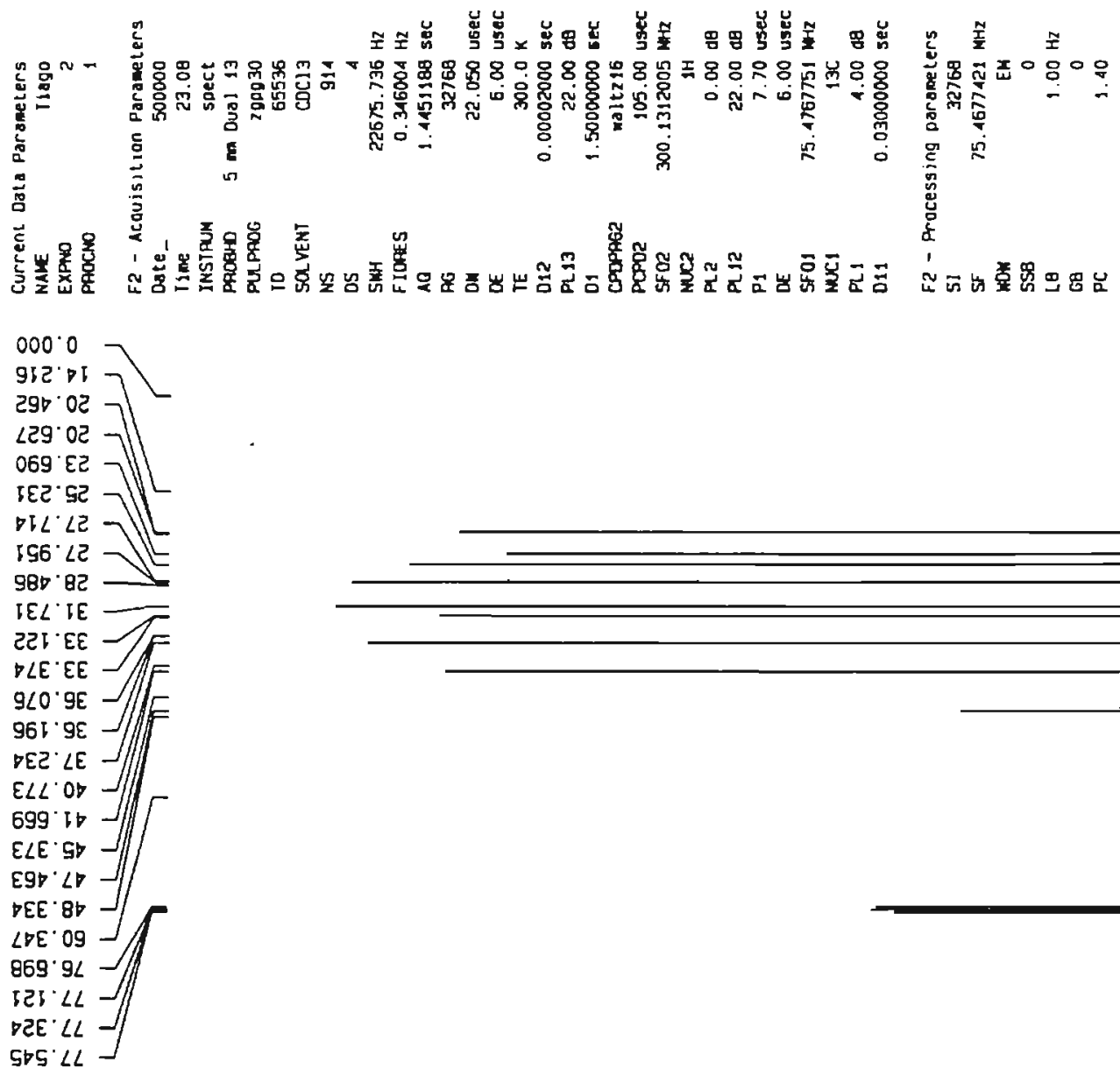

E

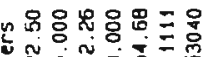

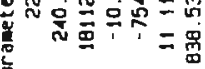

806.965

SQT.

$62 L 625$

926.051

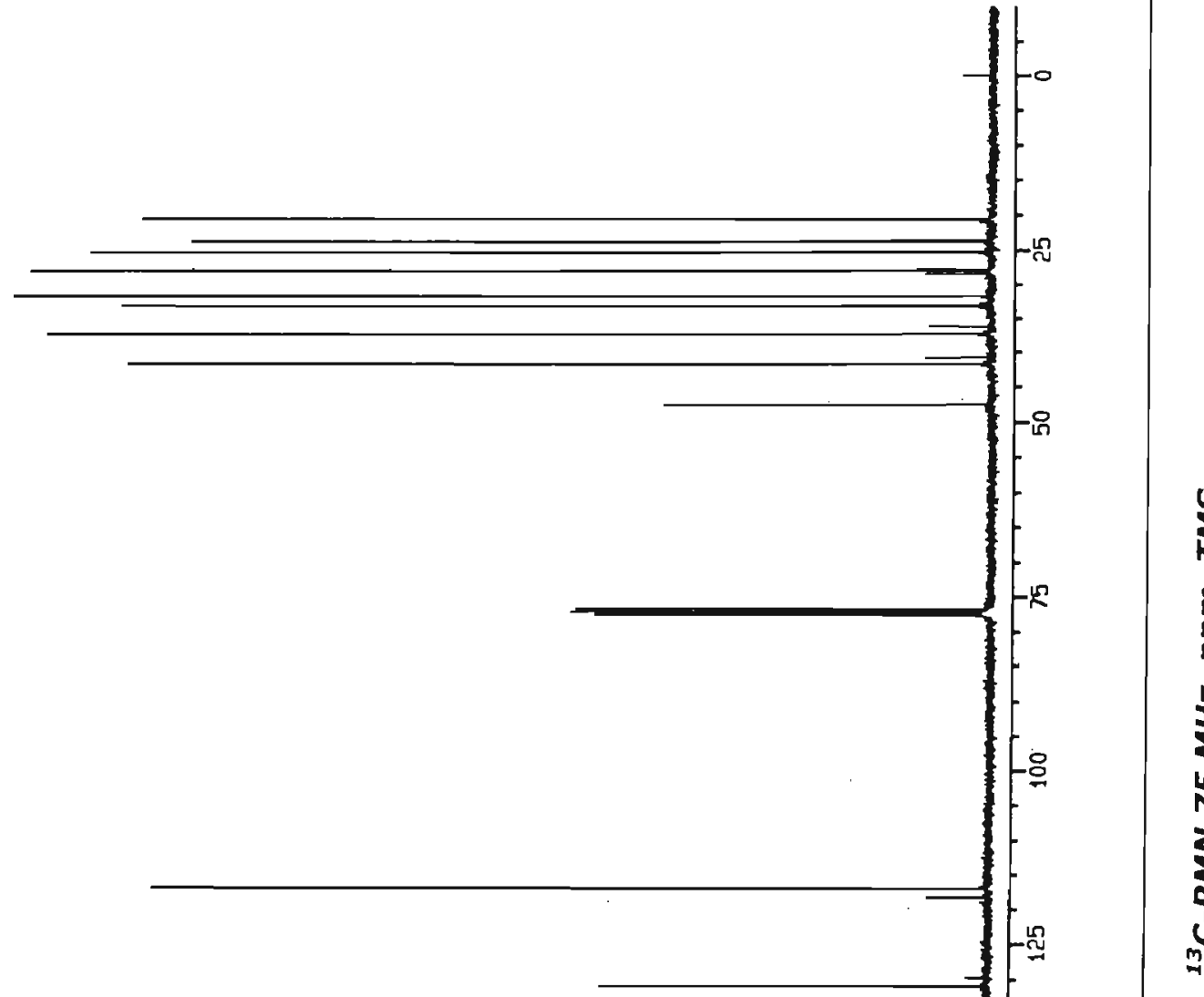

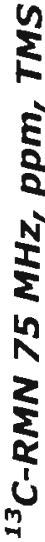

IIT 5 LCD $68 b \cdot 512$
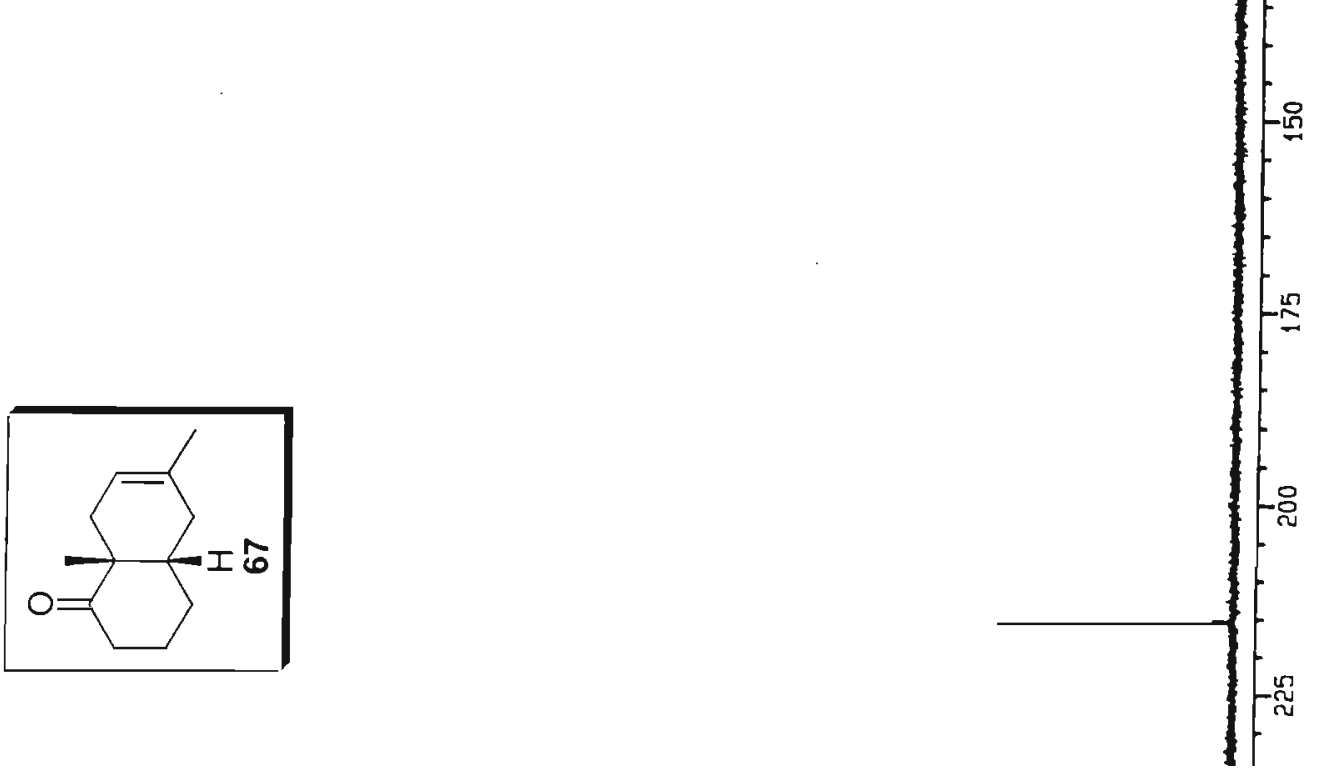


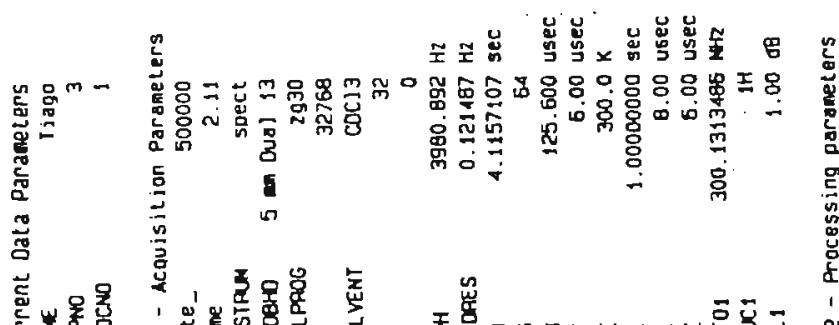

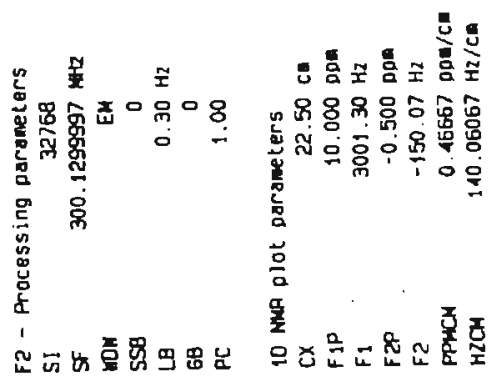

$0000^{\circ}$

टELB 0

E68ट ' ?

DIOE' I

9605 '

日Iटद. '

$\angle 699^{\circ}$ '

$\angle L S^{\circ}$ '

ट189. 6

ᄂ $\angle$ B '

>069. 1

9669' ?

EEES ।

6ES9 I

$0 ट \angle 9$ ' I

$6 \angle \angle 9^{\circ}$ ?

6669 '

$8 \square 0<' 1$

GSi $\angle \circ$

$\angle 902$ '

$\checkmark \angle L C ' z$

टOLC' 2

$\angle \angle L 6^{\circ} E$

Qดट6. $E$

58ट6. $\mathrm{E}$

IDEE 'E

GBE6 $' E$

$\angle E D 5^{\circ} \mathrm{E}$

9ES6 $E$

QLG5' $E$

$\angle \supset 96^{\circ} \varepsilon$

cone's

IOBC: 9

LABC'G -

GESE' 9

2८52:5
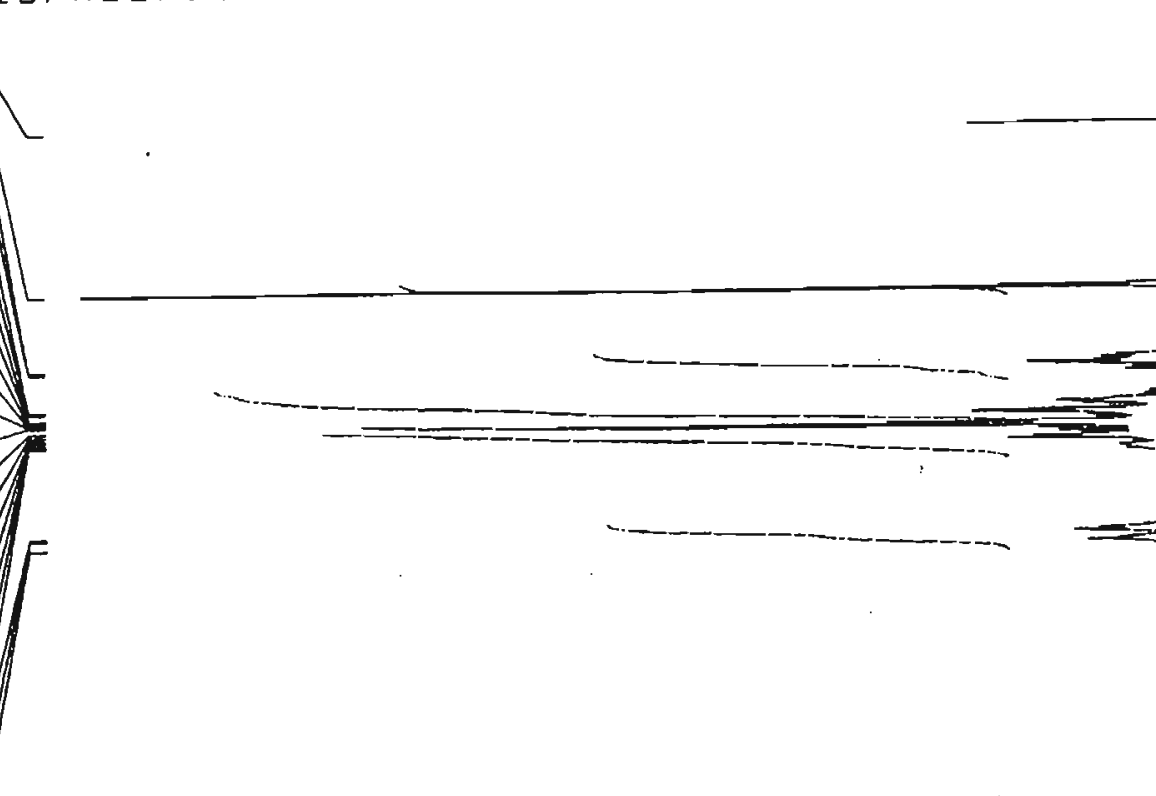


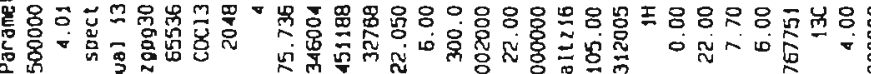
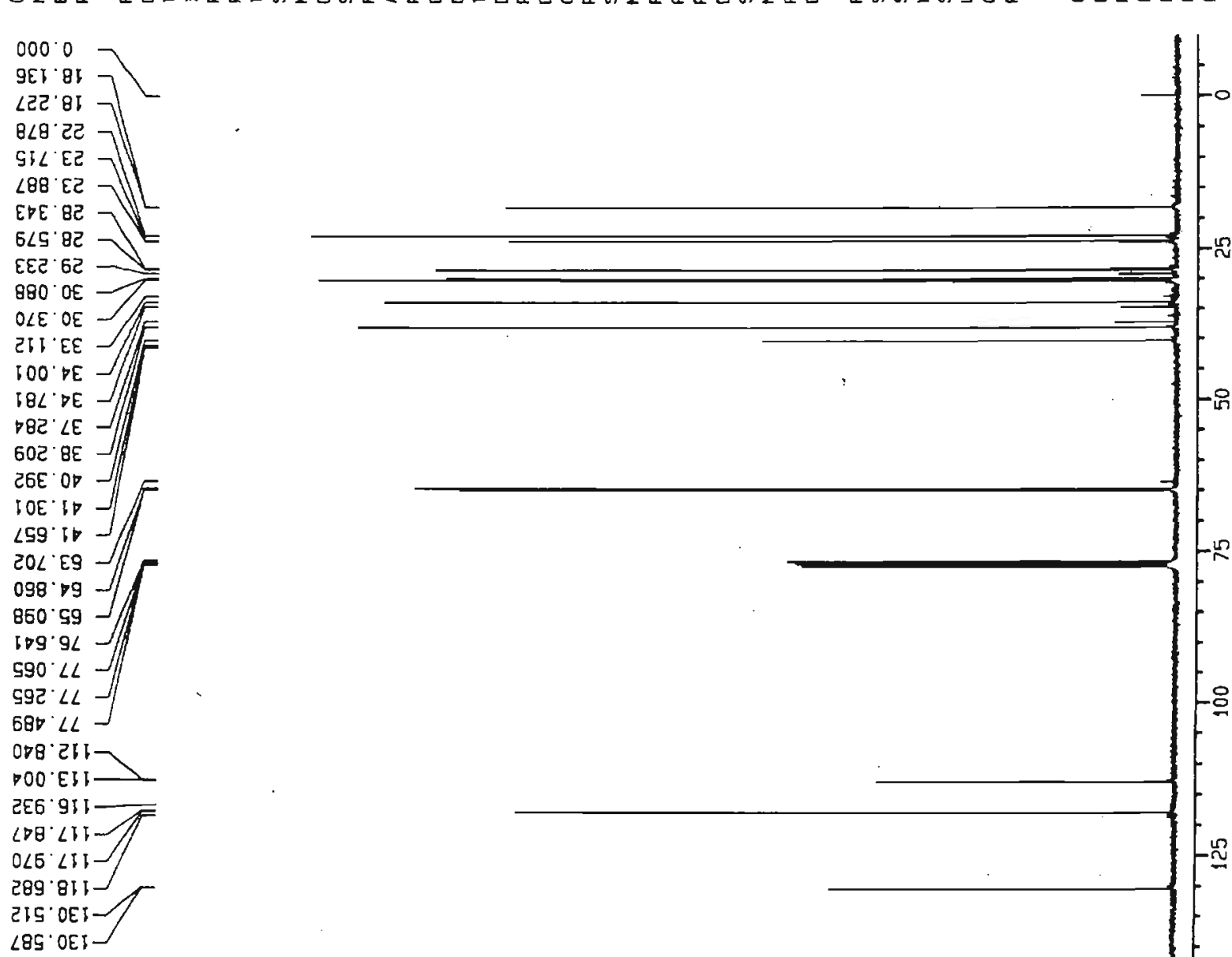


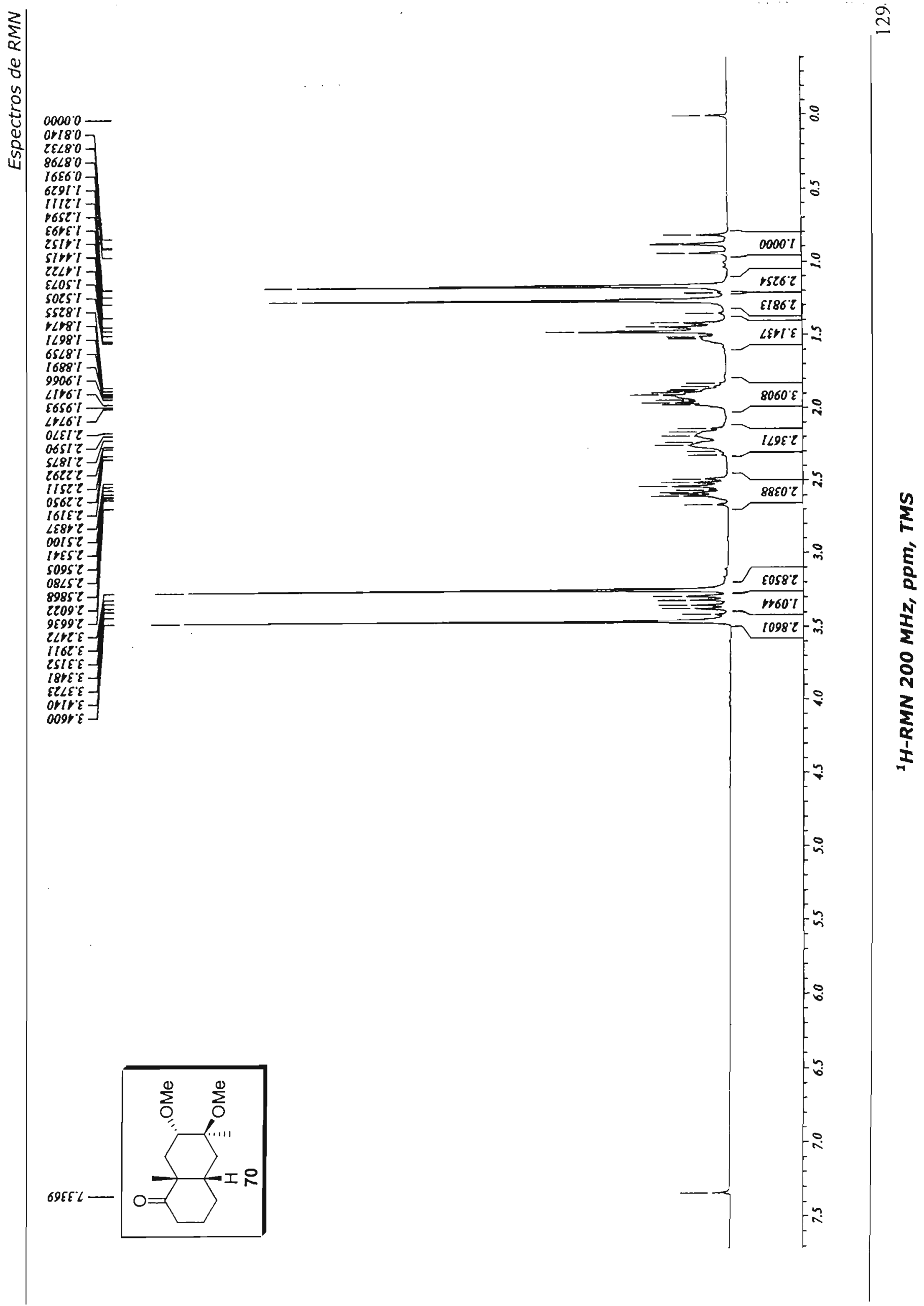




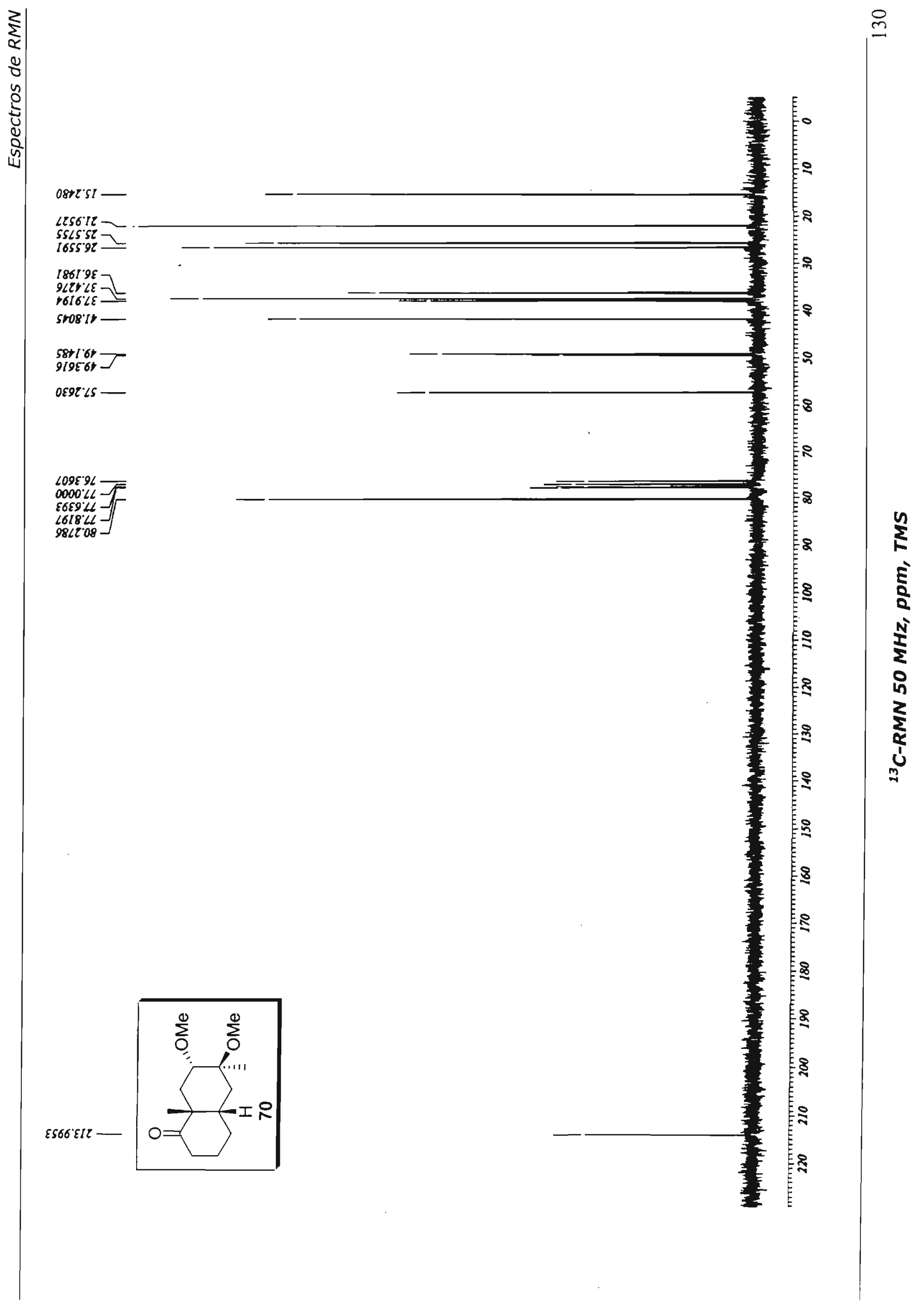


081251

L256:72

Lers'sz -

8165.92

$5050 \% 2$

oEtr:LE-

2SSL'TH-

$8+9160$

$8292<5$
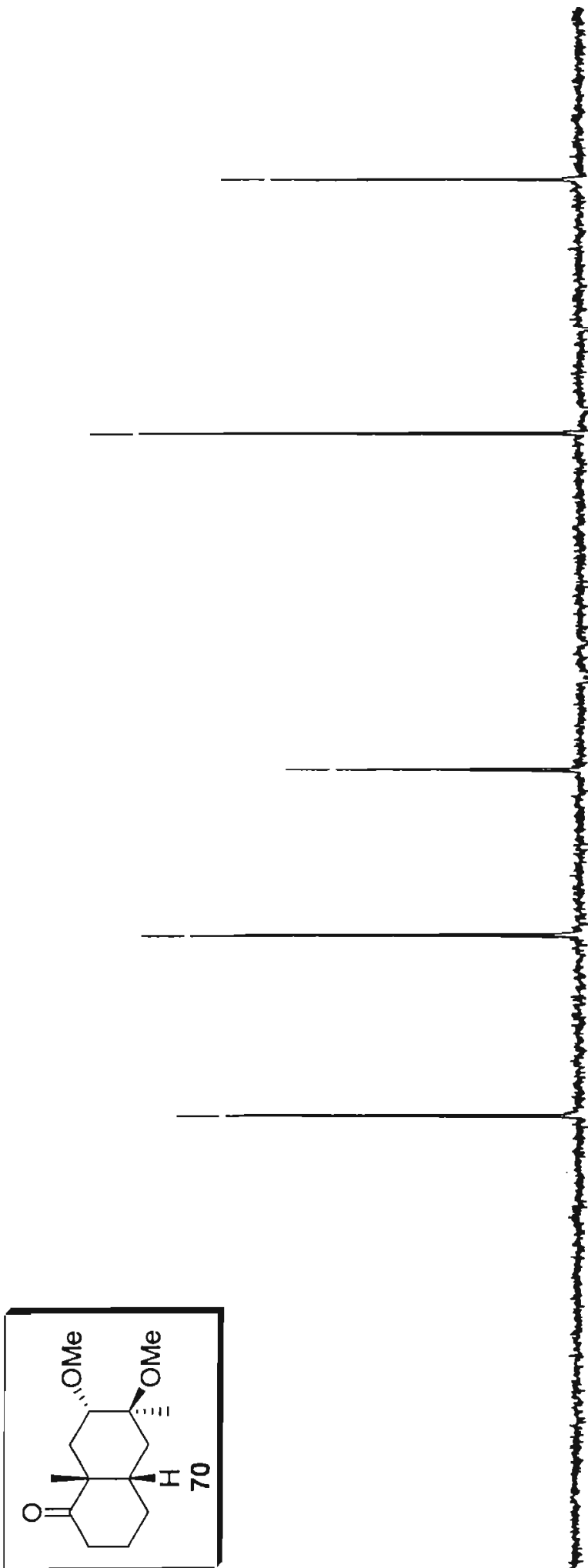

응

$\approx$

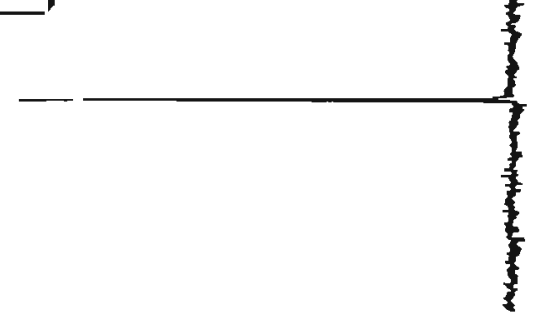


EStI I-

$629[1$

9E6 T T -

storl-

Tile?

rose't

GOLZT

I8SE'

$868 \%$

2205'

ISEST:

EETST

$260{ }^{\circ} \mathrm{T}-$

$\angle 8+\angle{ }^{\circ} \mathrm{C}-$

OSLL 7

$\angle 56<\cdot]$

29187

$8290^{\circ} 1$

$\angle P 88^{\circ} 1$

9906 ' I

$\angle 2560^{\circ}$

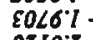

02102

Iszo'

$08+12$

$559 I^{2} \mathrm{Z}$

$\angle 68{ }^{\circ} \mathrm{T}$

शII

मIEZ'

$68+27-$

LLSEZ -

$60127-$

$8182 \pi=$

core? -

LSTET-

ress' -

sobs'

EI6S:

SLIS: -

$0<59.2-$

5969.

roSI' $E$ -

rOLI'

SroI E-

รEOZ' $\varepsilon$ -

ErIE $E-$

$\angle 982 E-$

$986 E^{\circ} \mathrm{E}-$

$\angle Z Z+\cdot \varepsilon-$

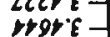

ozsr:

orlste

OSESE -

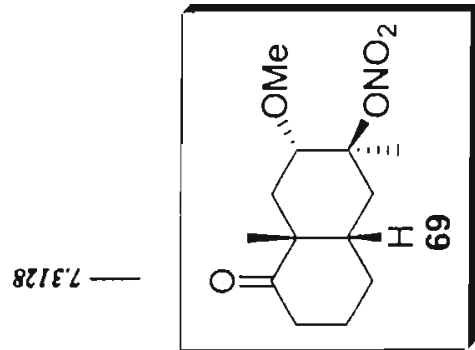




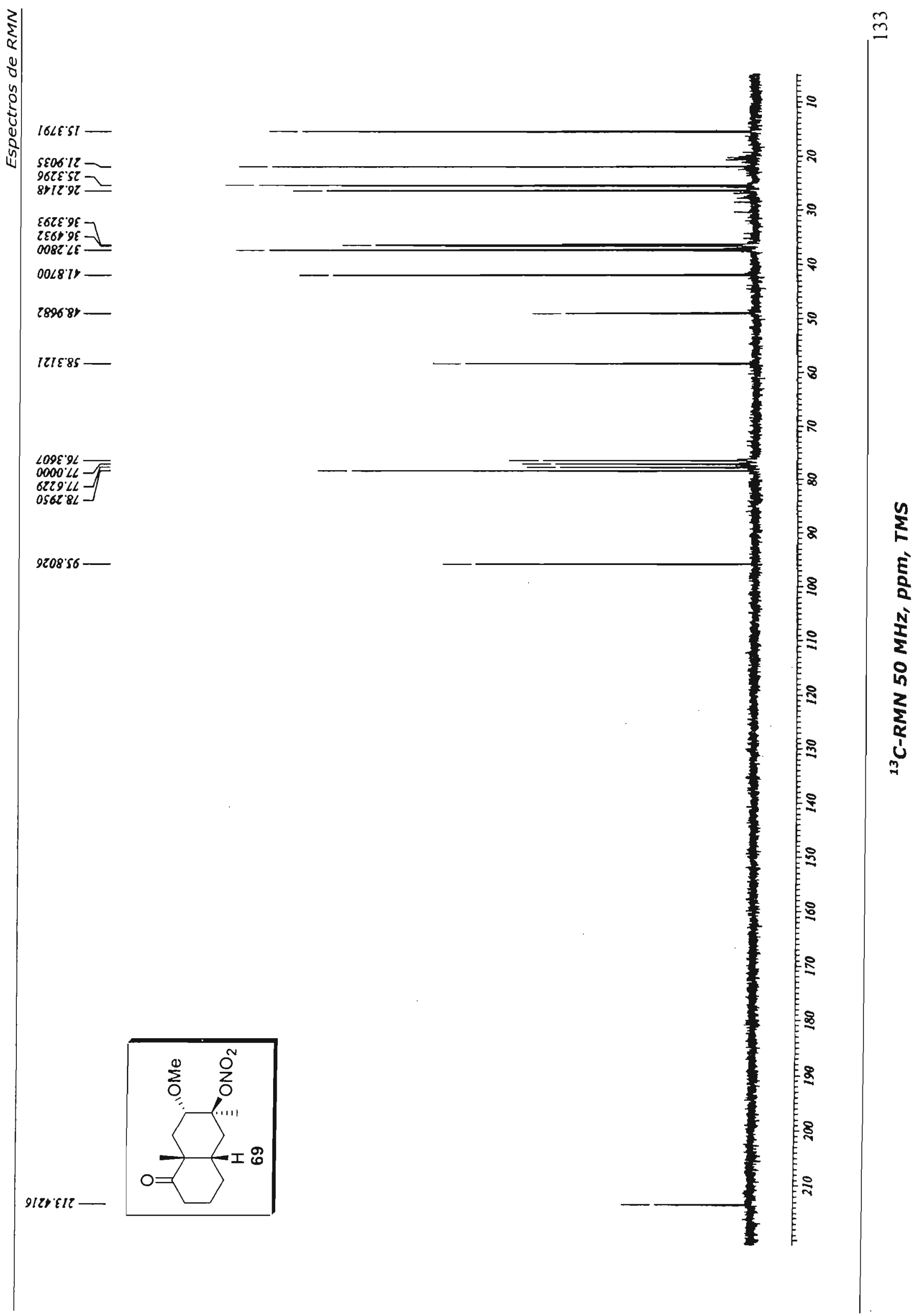




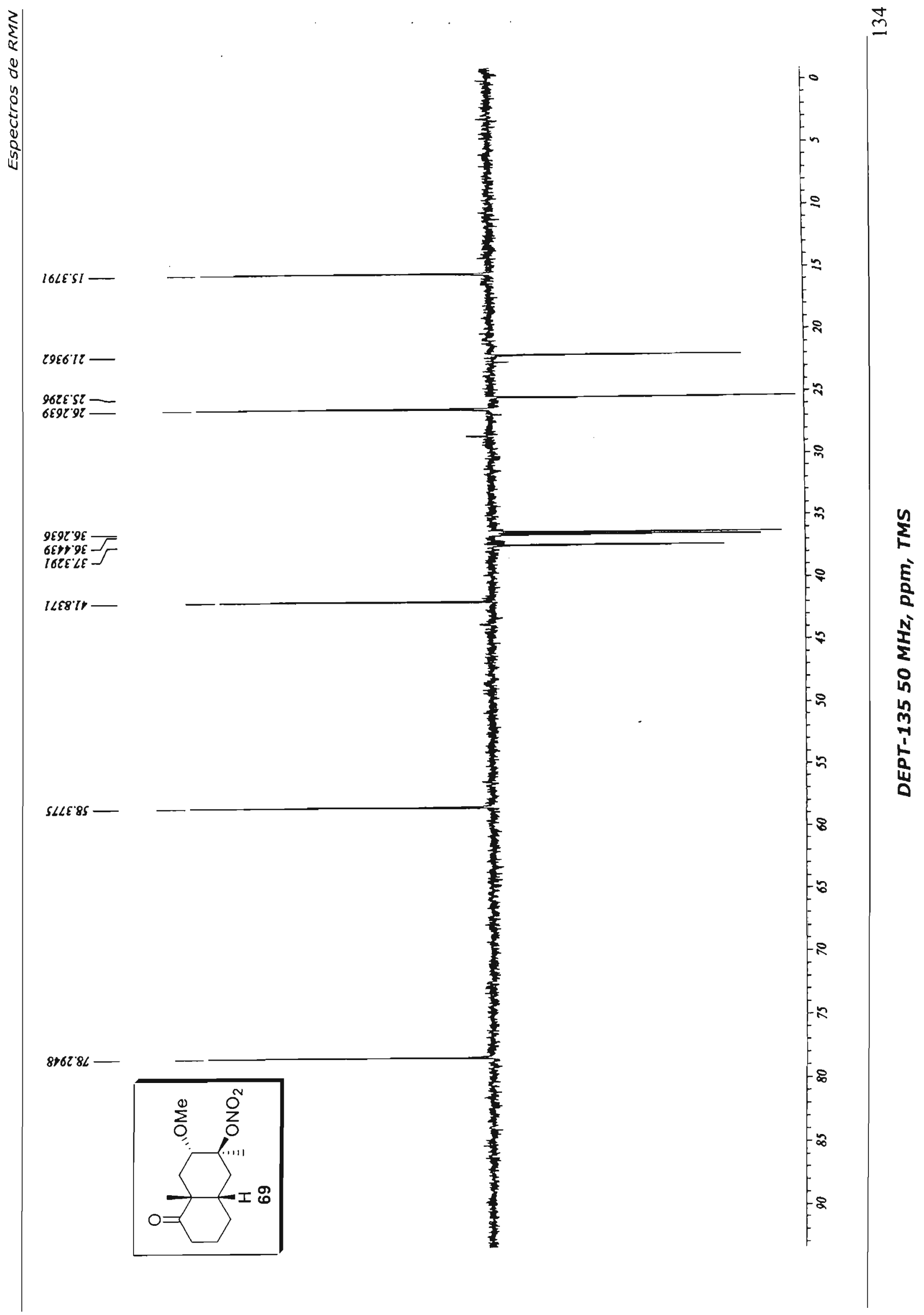




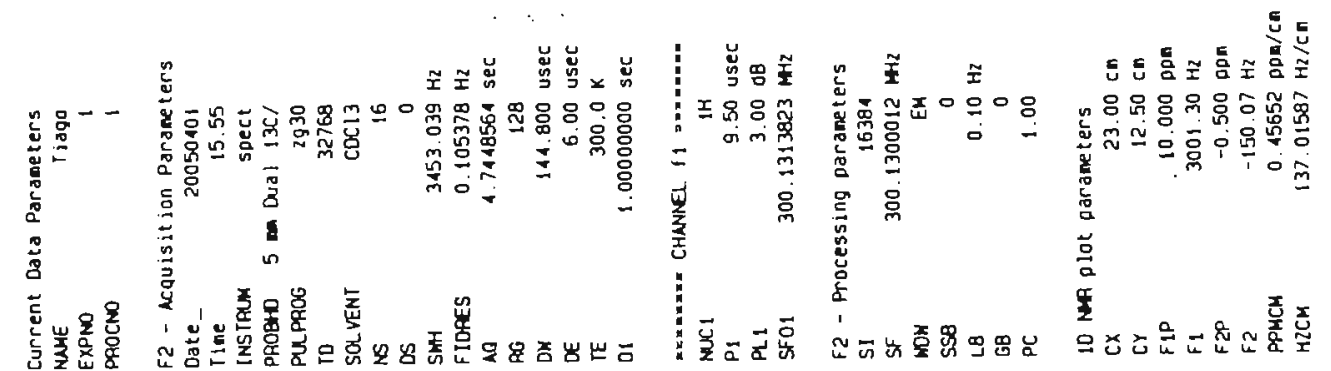
0000007

DSG50.7

टDL10. 17

टLDCE' I

८9бहट : -

IO6PC' :

6ठट乌' !

LEgG i

IOSLC :

टө185

OI LCS I

gLLOS :

DESES :

68209 .

G $\angle 899^{\circ}$.

66289. I-

6GE0 $[1-$

$9 \angle 60<:-1$

टटबा L $1-$

GSEE I $2-$

6己 $\angle 62{ }^{\prime} E$

ธEEIE'

GOSEE $E-$

$\angle B G D E^{\circ} E-$

$90 \angle 9)^{\prime} \mathrm{C}$

$\angle 20 \angle C^{\circ} \mathrm{G}$

$028<2 \cdot 5$

$08 G \angle 2 \angle$
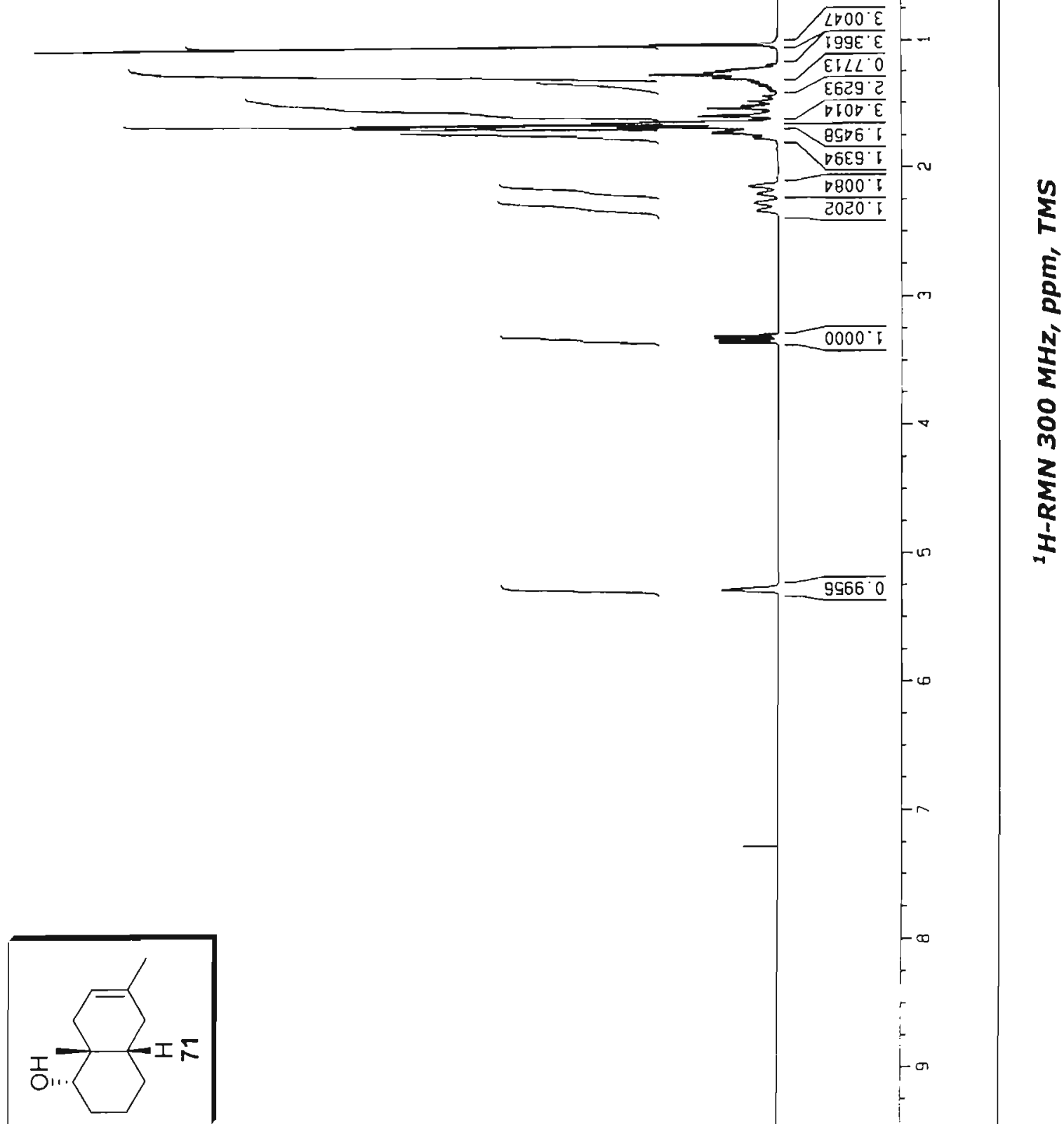


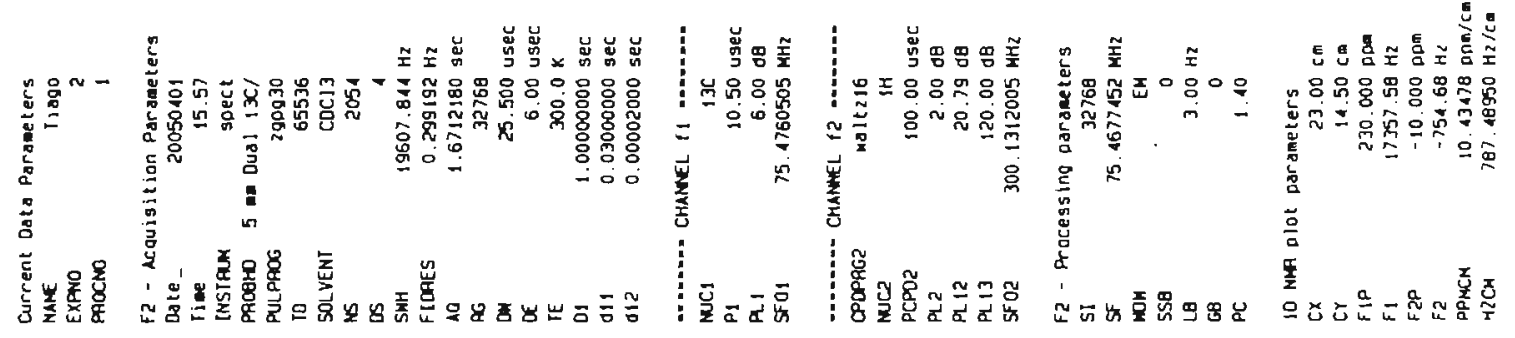
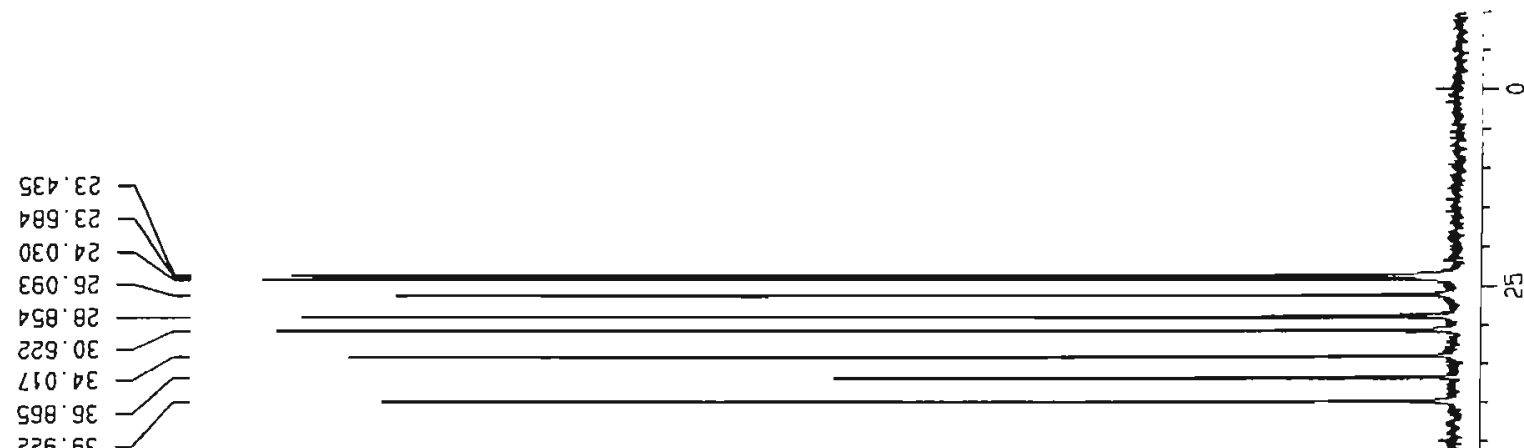

$9 \nabla 9 \cdot 9$

$690^{\circ} \angle L$

$\varepsilon 60^{\circ} \angle L$

$88 \zeta^{\circ} B L$

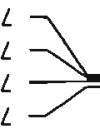

L8g $\angle b$

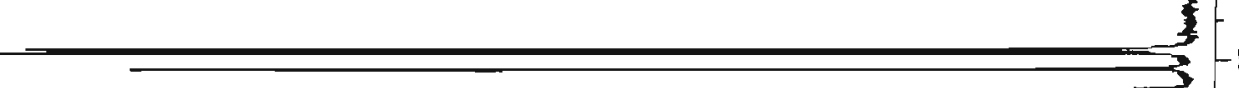

$O L \angle O E \square$
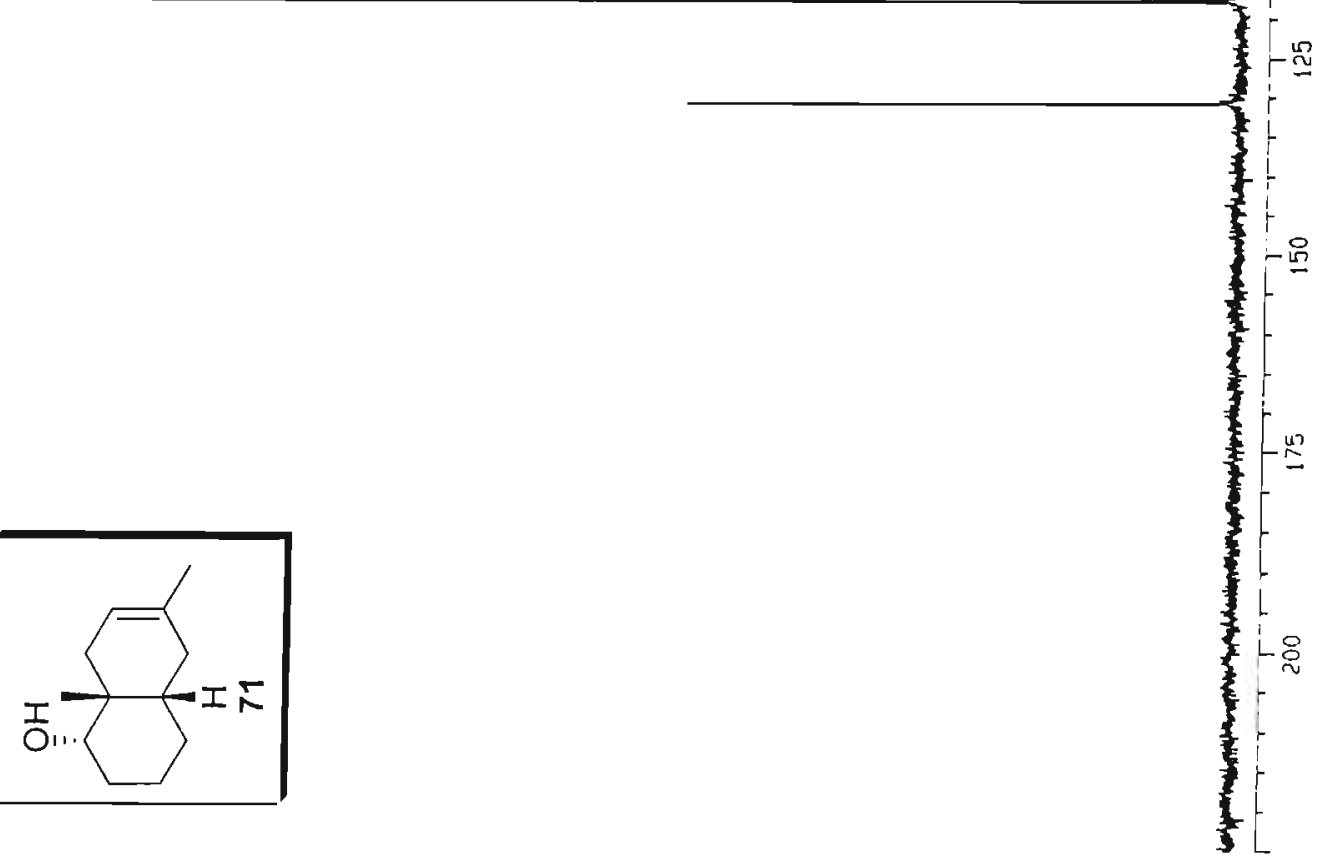


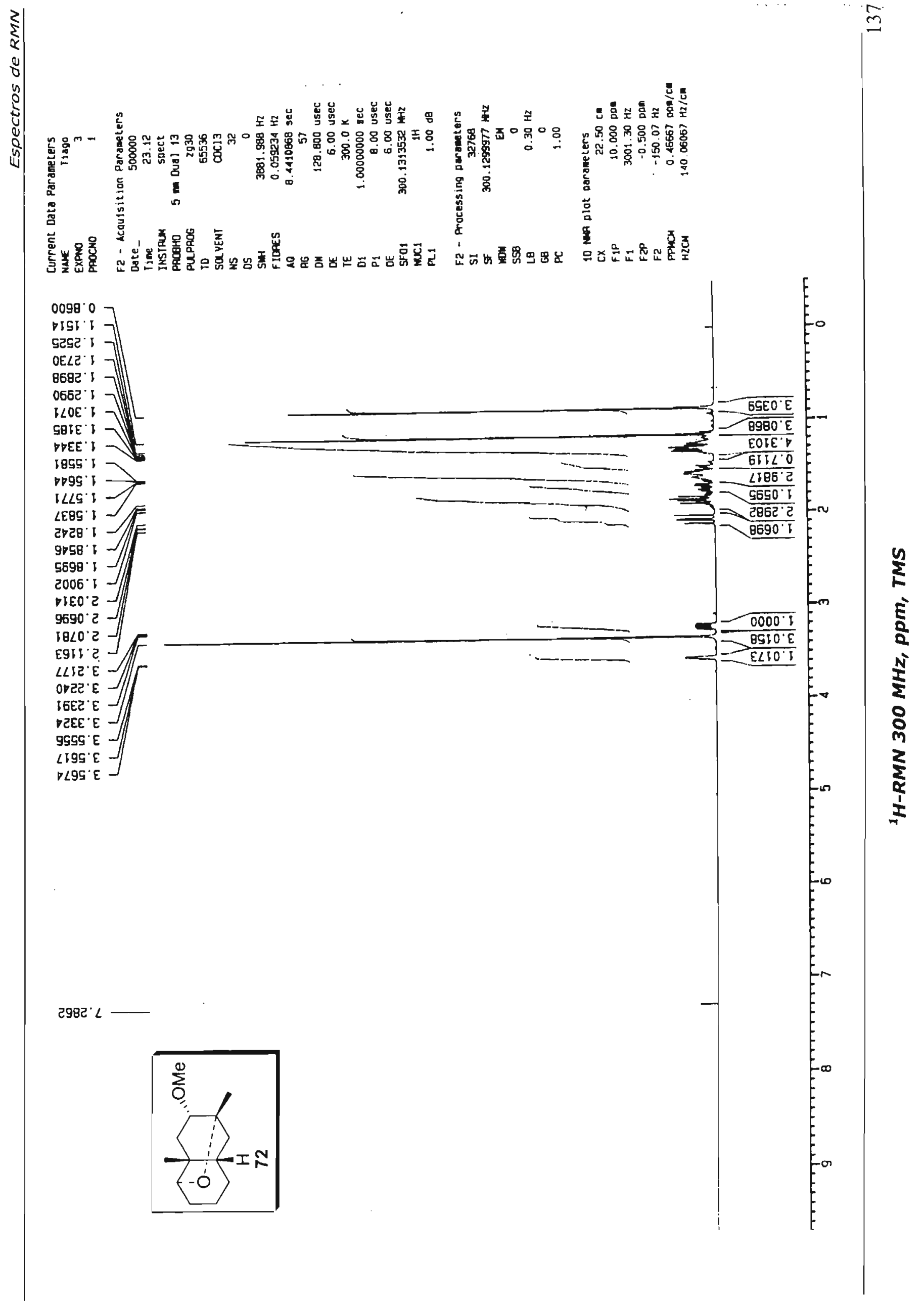


总

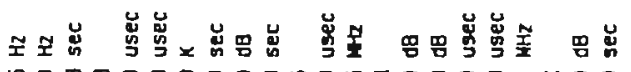

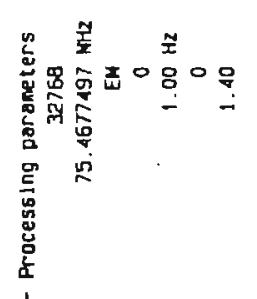

ง

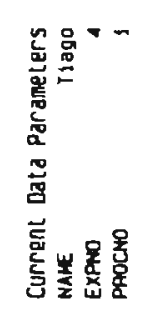

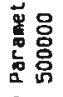

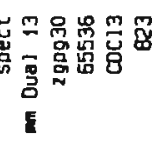

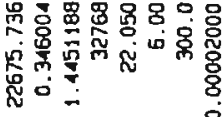

葛

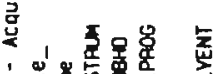

岁

हैenten

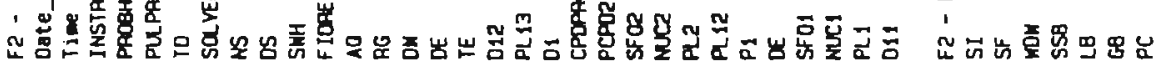
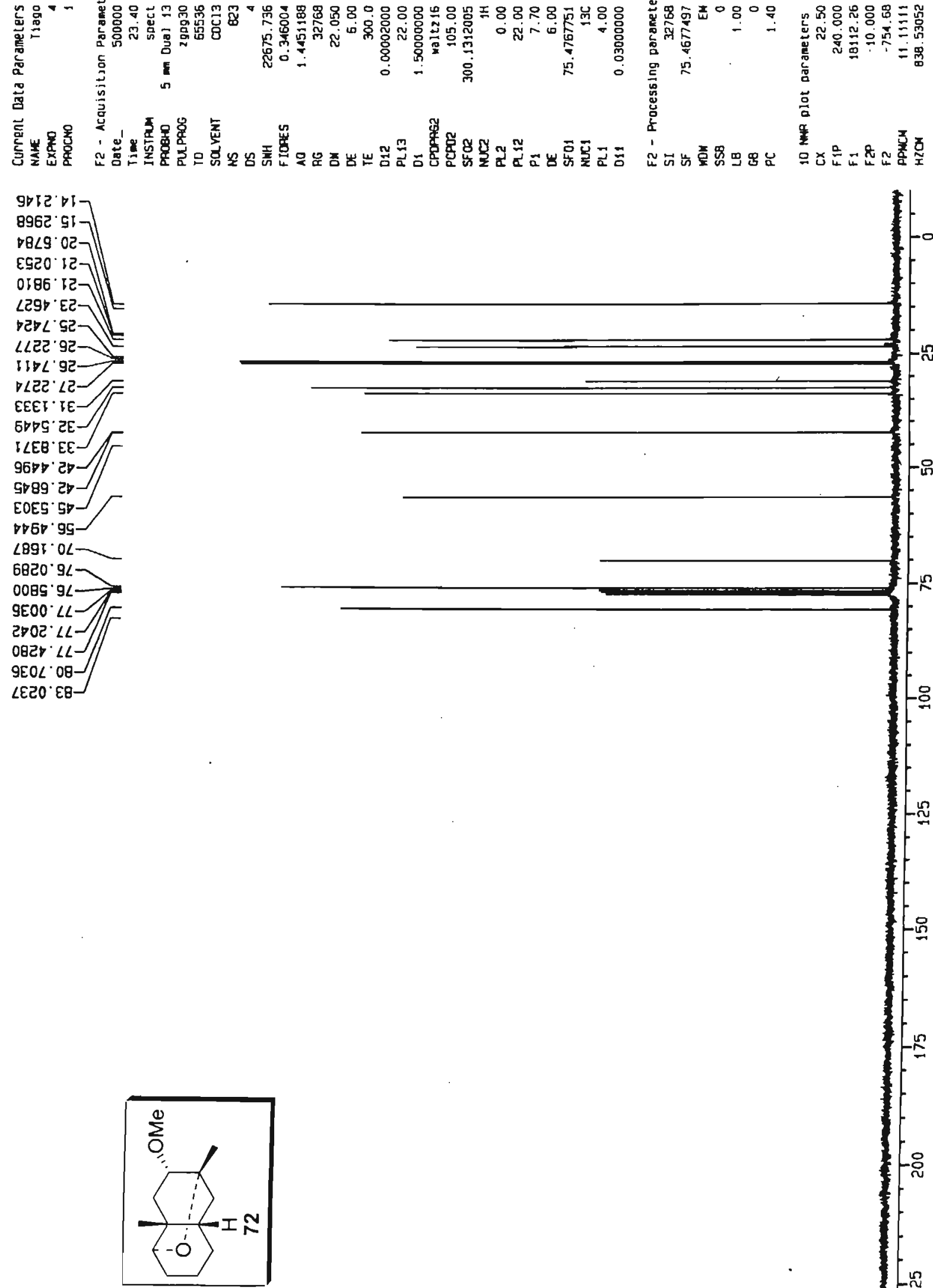

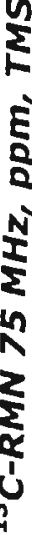




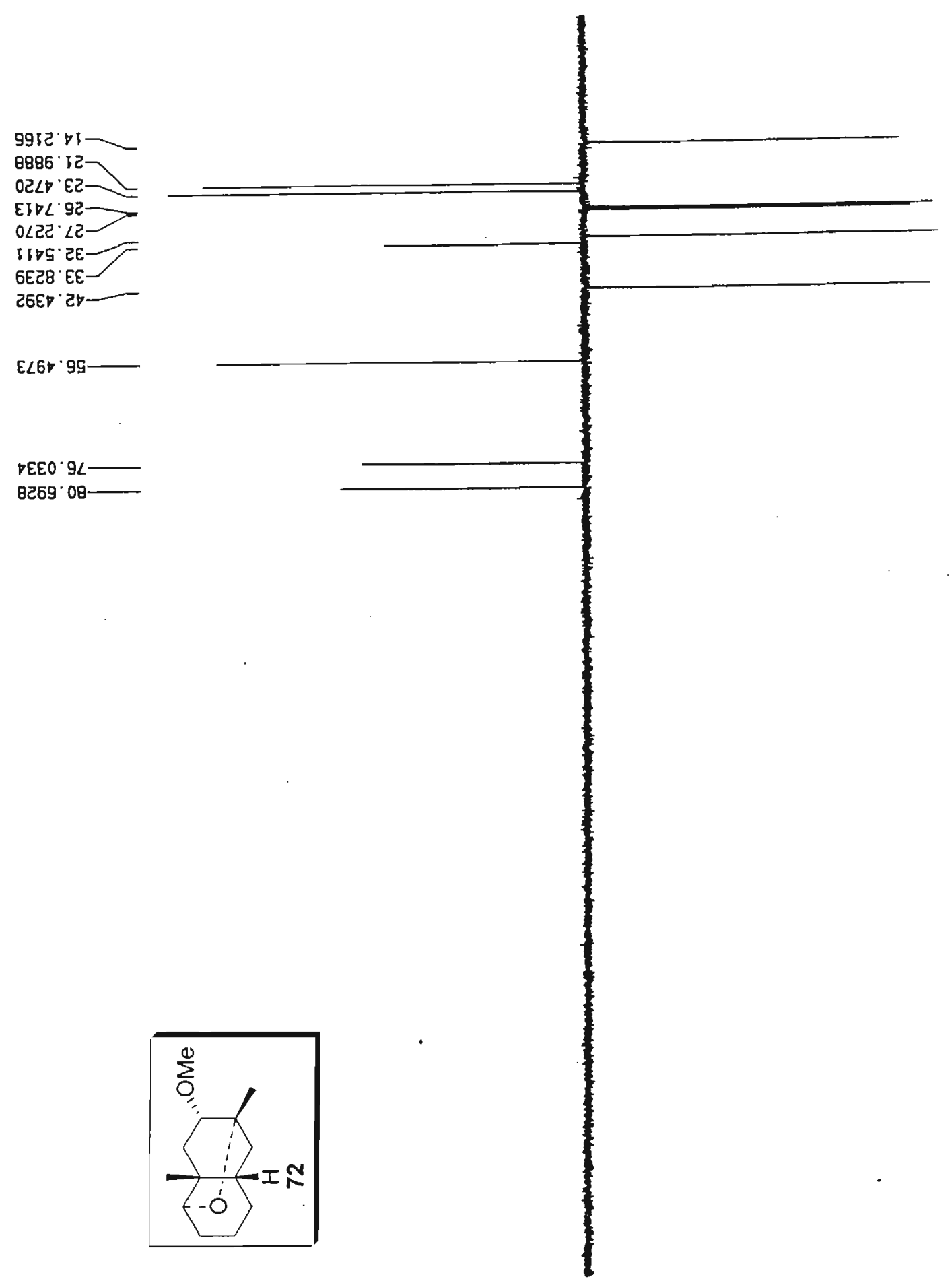




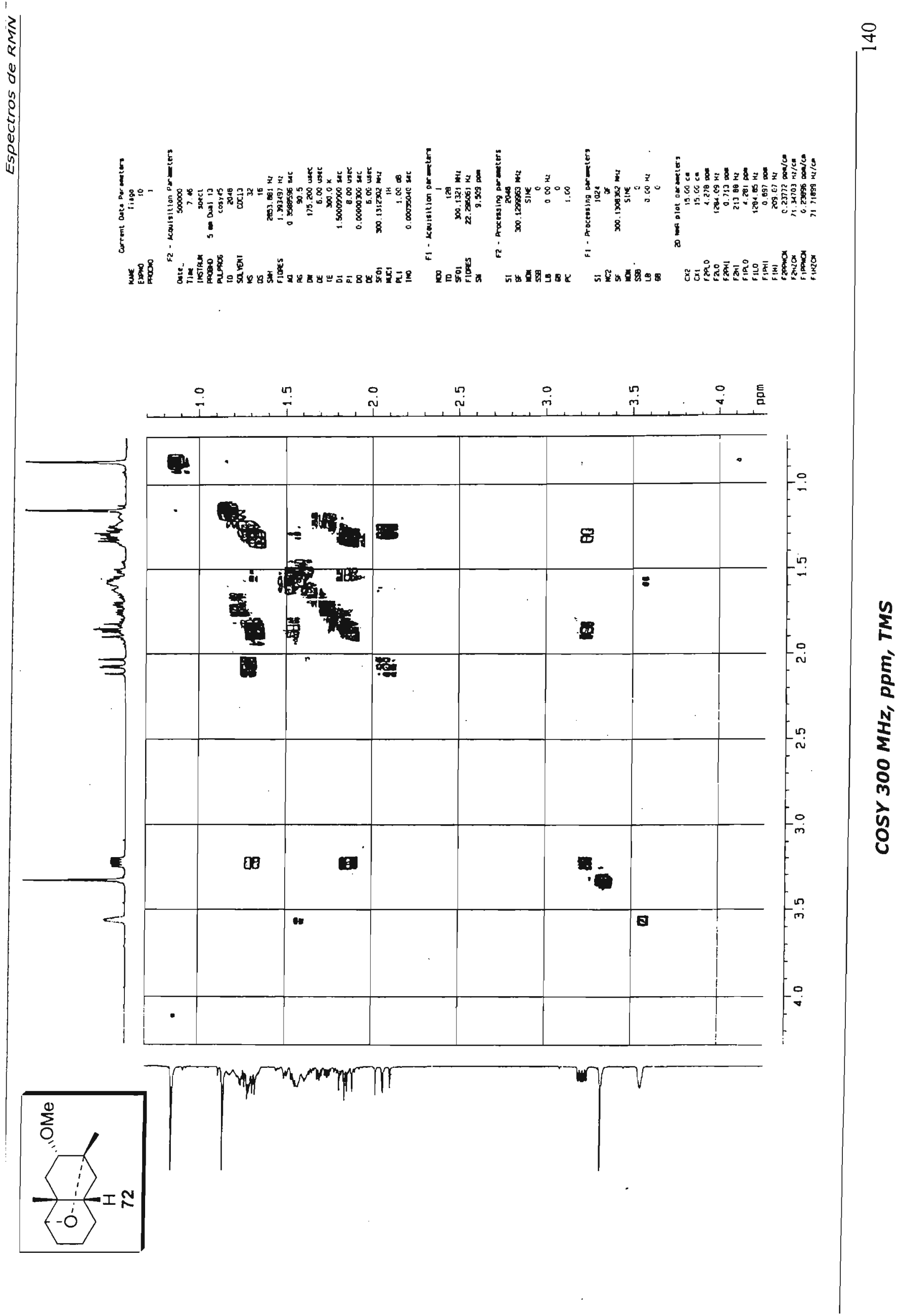


5 8.

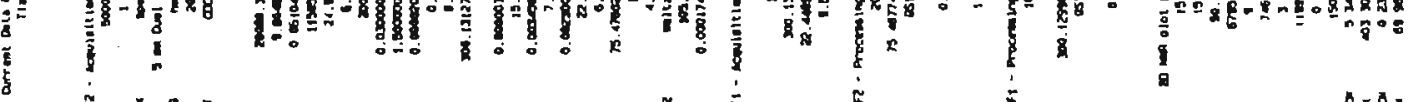

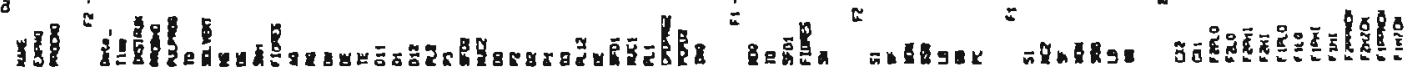

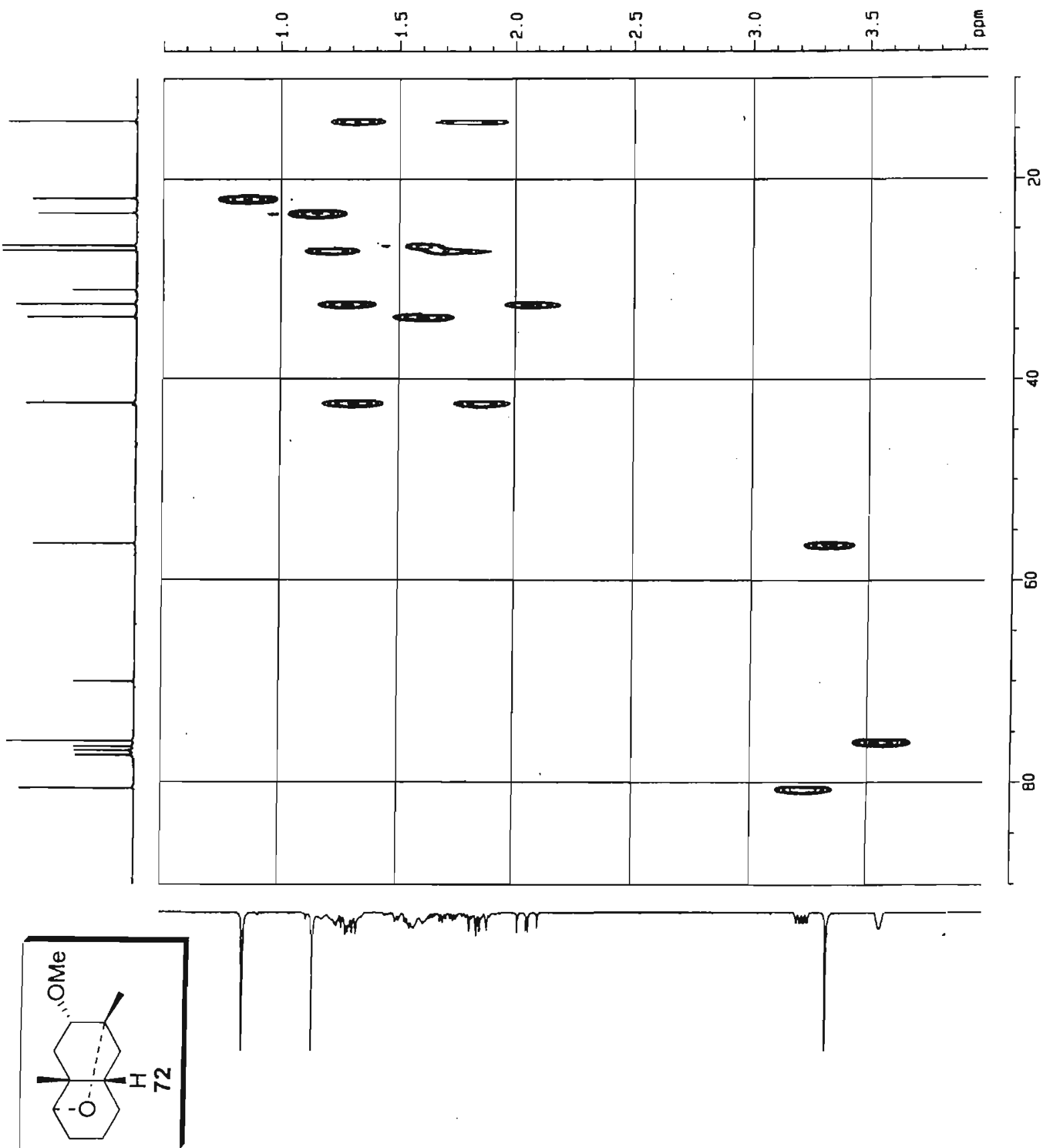




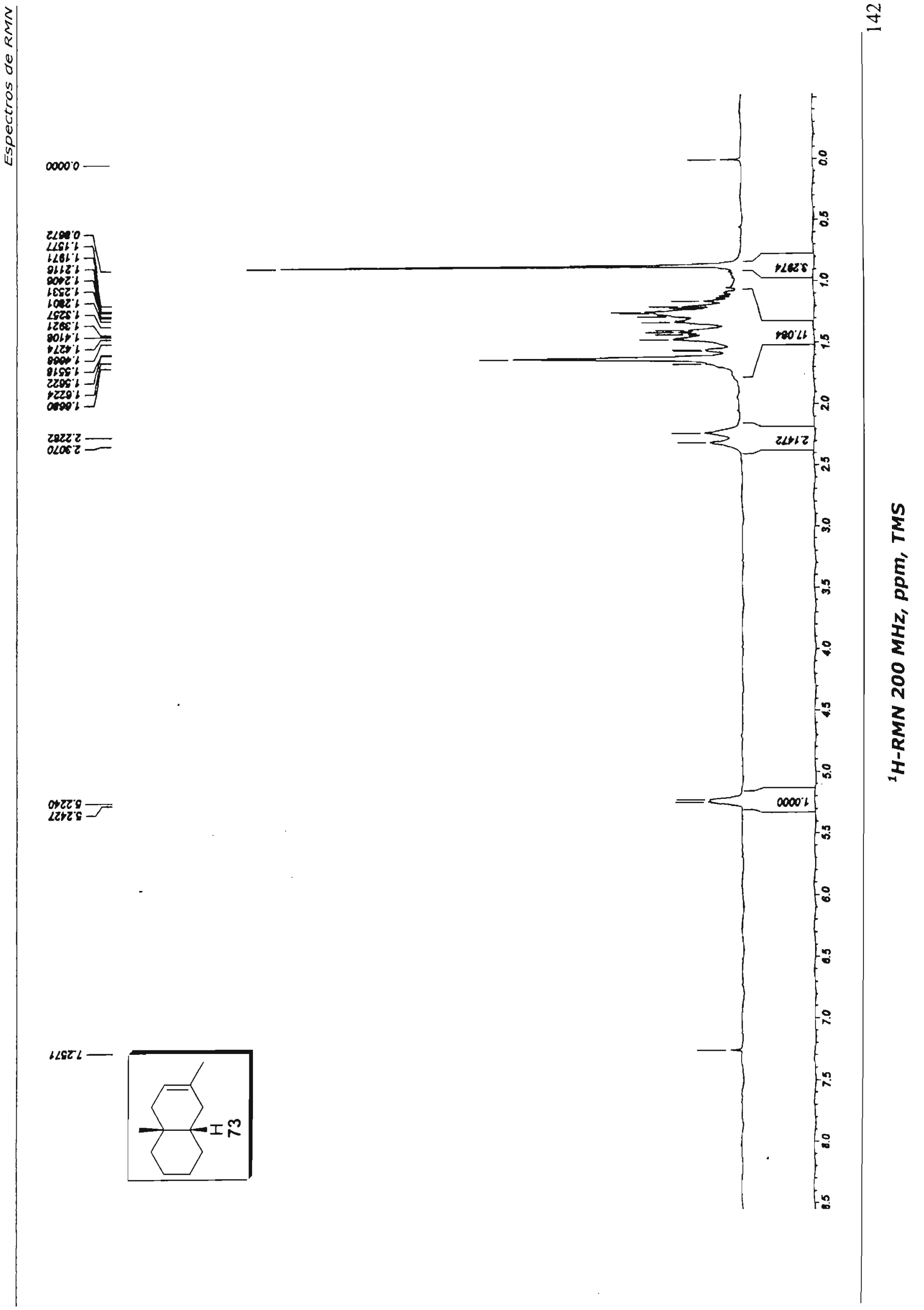




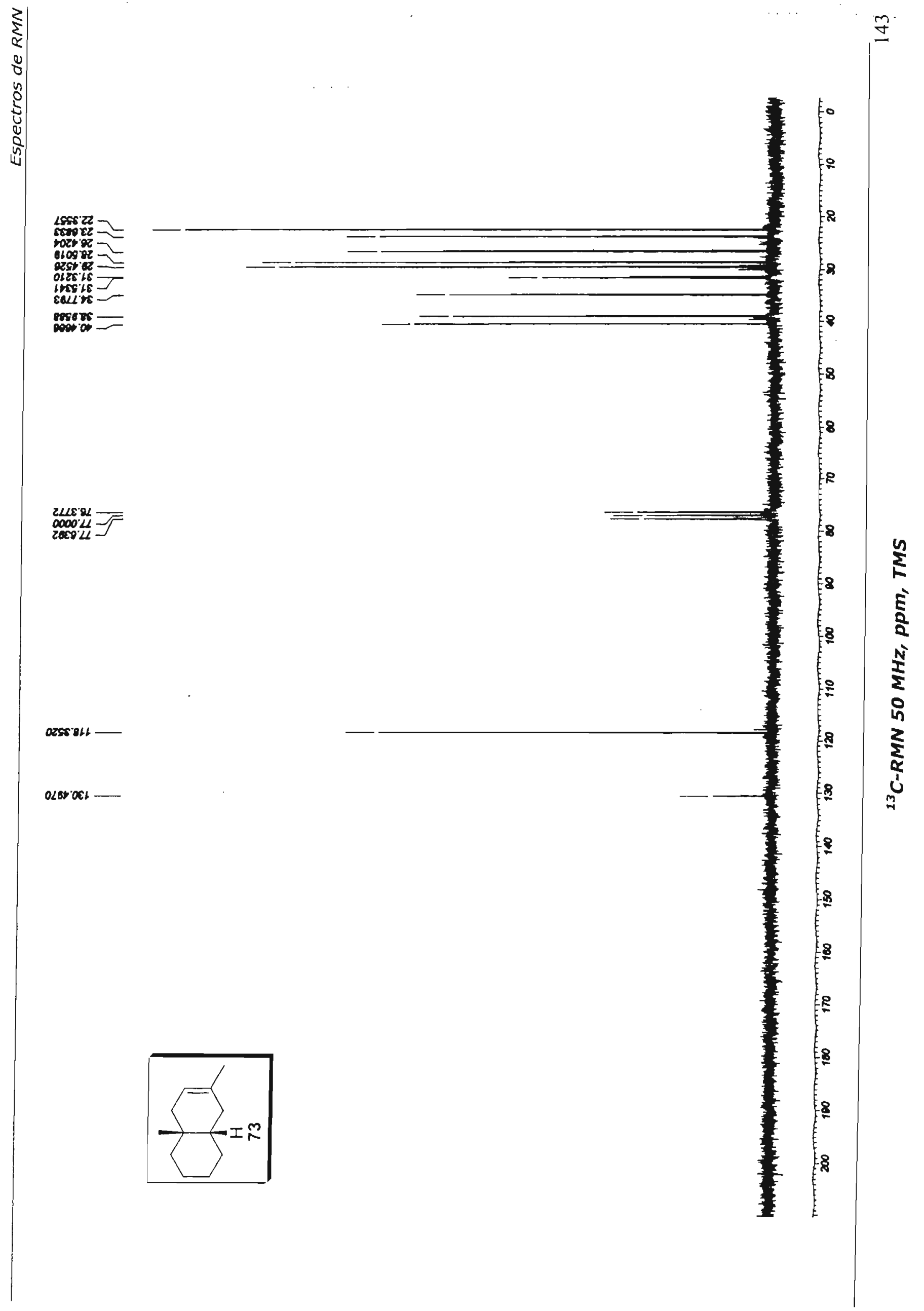




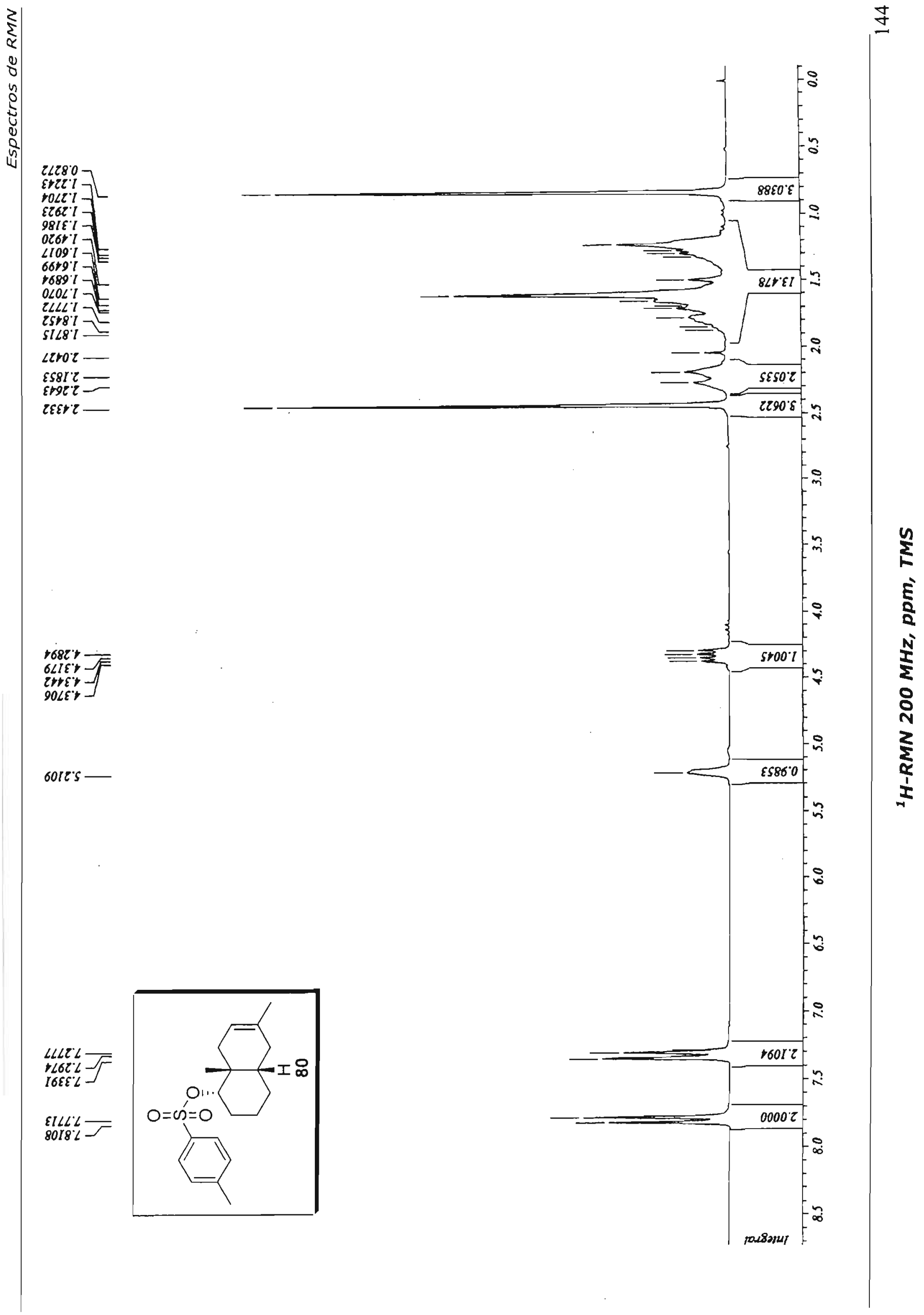


$\angle E 6 r \cdot I T$

LLtE $\varepsilon 2$

I82+1EZ

$9 \angle 59)^{\circ}$

$5++r .92$

$000182]-$

OZLLEE -

CO\$O' $9 E$

rEETOH

ILCE' 9

$0000<1-5$

E689: $\angle L$

646006

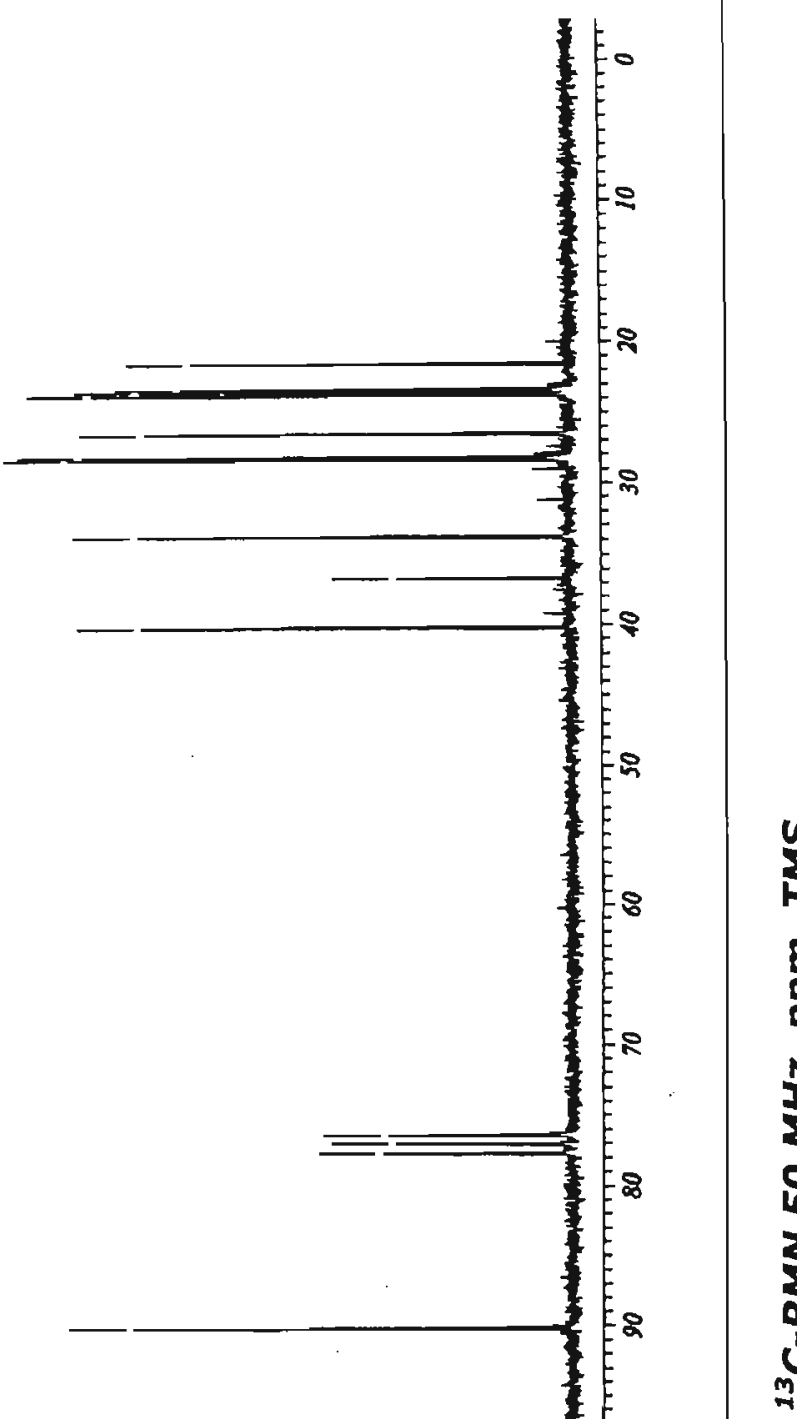

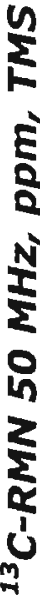

rEII $L I I-$

IZLS:ZI

orso.28I

ozLS $621-$

Orol OEl

$0866^{\circ} \mathrm{REI}-$

LI9I'HI -
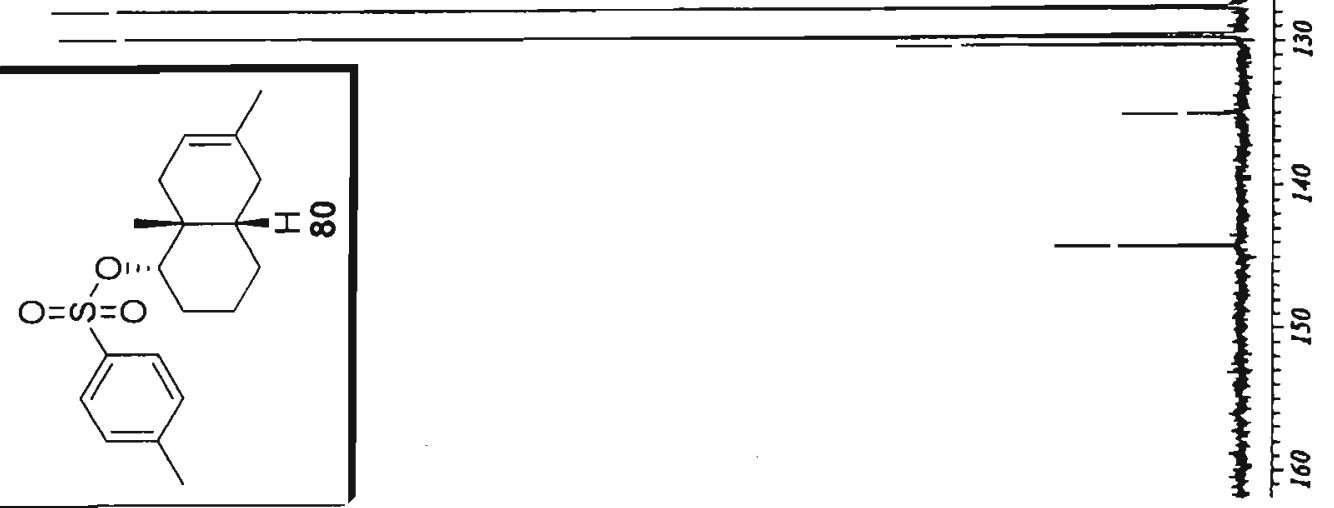
$05917-$

92817

I00Z $I$

ereti -

96E27

(2)

SLEe

HIEI I

CSEET

roor 17

soet $[7]$

00L17 $]=$

ELOS 1

ILZST-E

trost

EEV9 $]=$

rot $47-=$

IIEL'T-

60si 7

0514

OSL2

4508

$6506{ }^{\circ}-$

$8186^{\circ}$

86ro

22806

\section{$0 \angle 69^{\circ} \varepsilon$}

080L'

s100:-

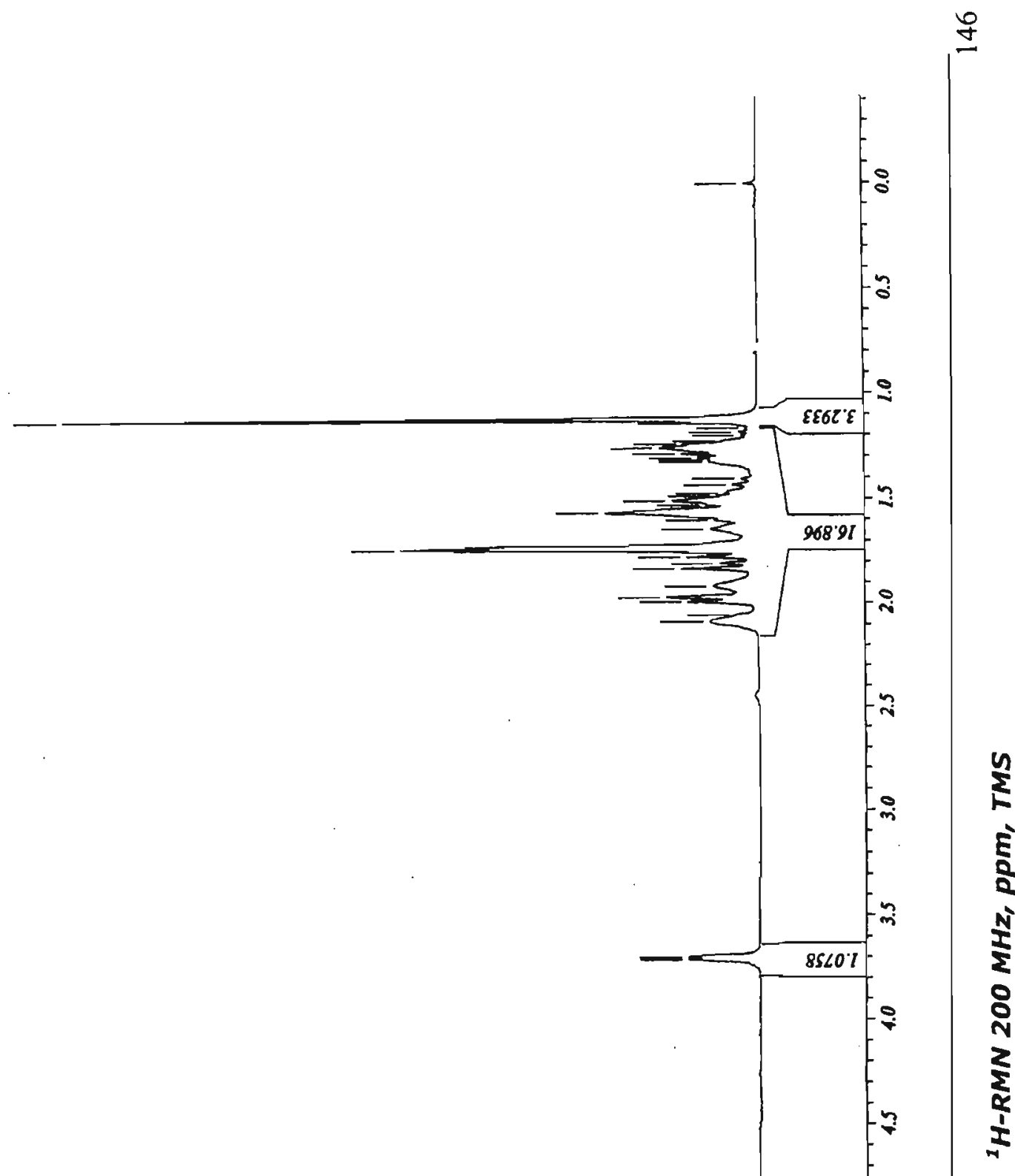

$I I L Z L$
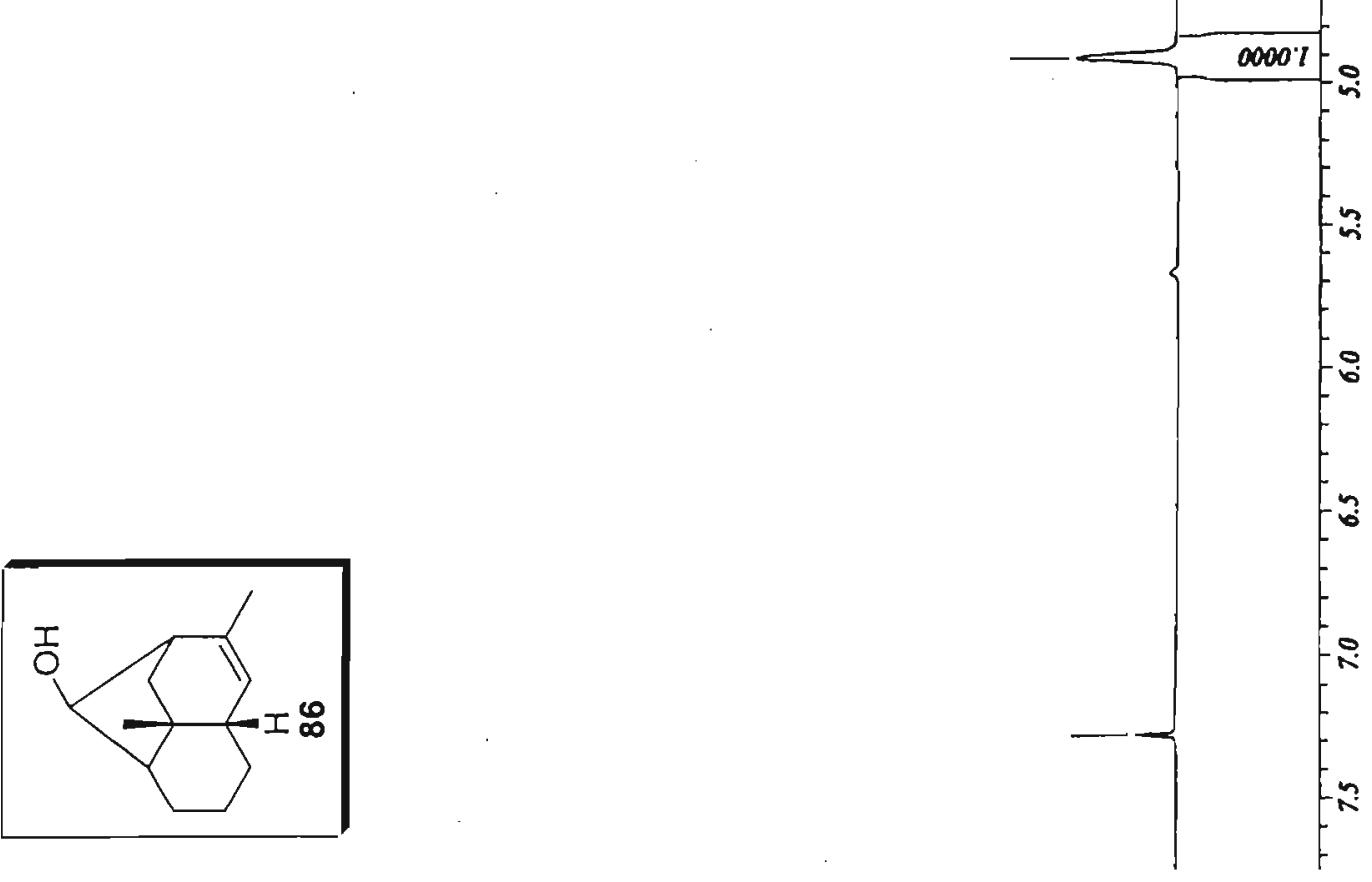
9ilite

${ }_{128192=}$

$210024=$

$6880^{\circ} 6 \mathrm{H}$

E\$86'55 -

$1<<E 92<-\bar{T}$

$0000 \mathrm{LL}$

$5559.28-$

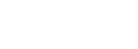

$\left.50 \angle 9^{\circ}\right) 2 I$
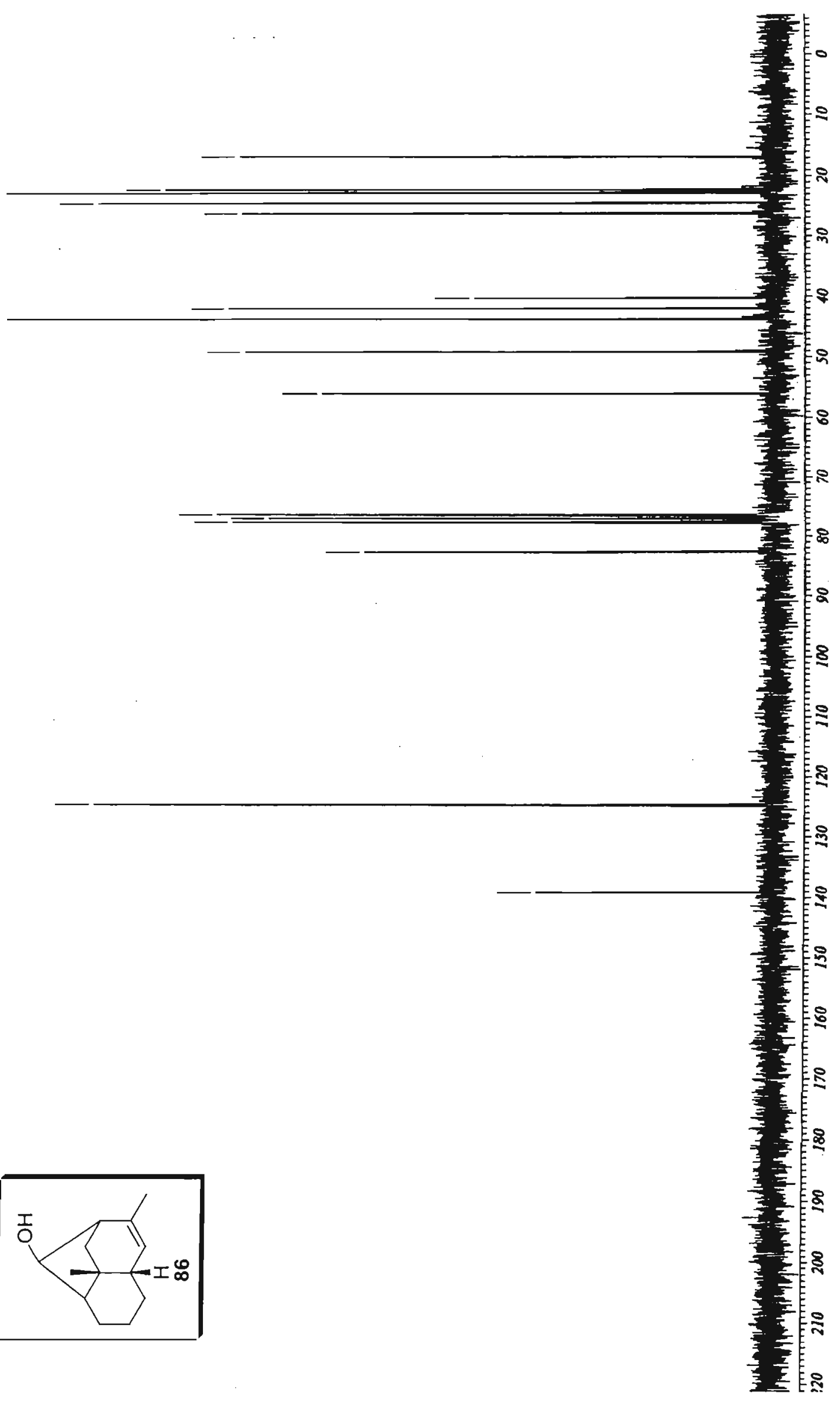


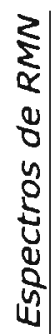

$66 \varepsilon<91-$

SEIETZ

sLL'VL -

$9861.92=$

$6+86 \%$

\& $\angle 9)^{\circ}$

855067

8816 ss -

555978
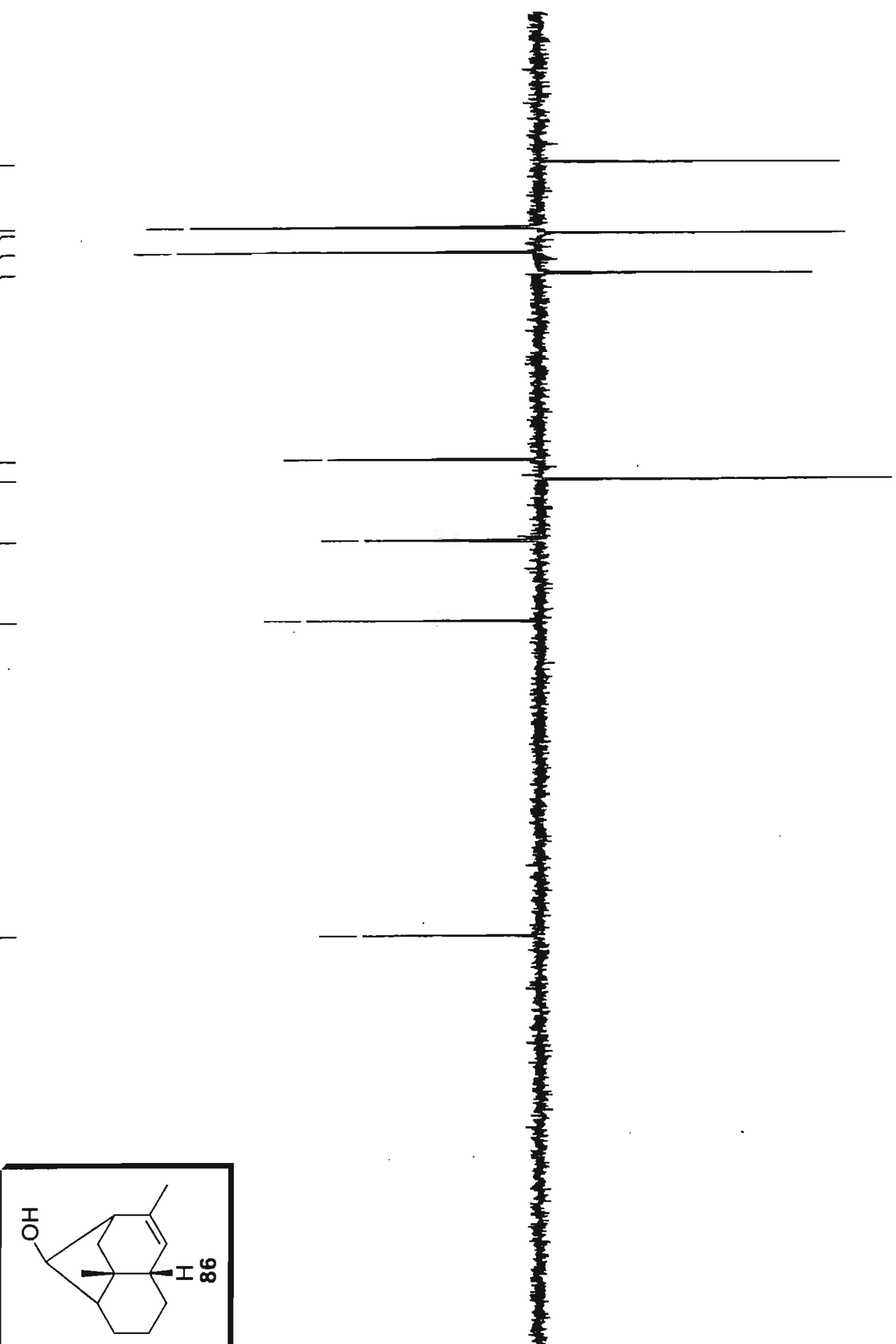

IEOL'RI

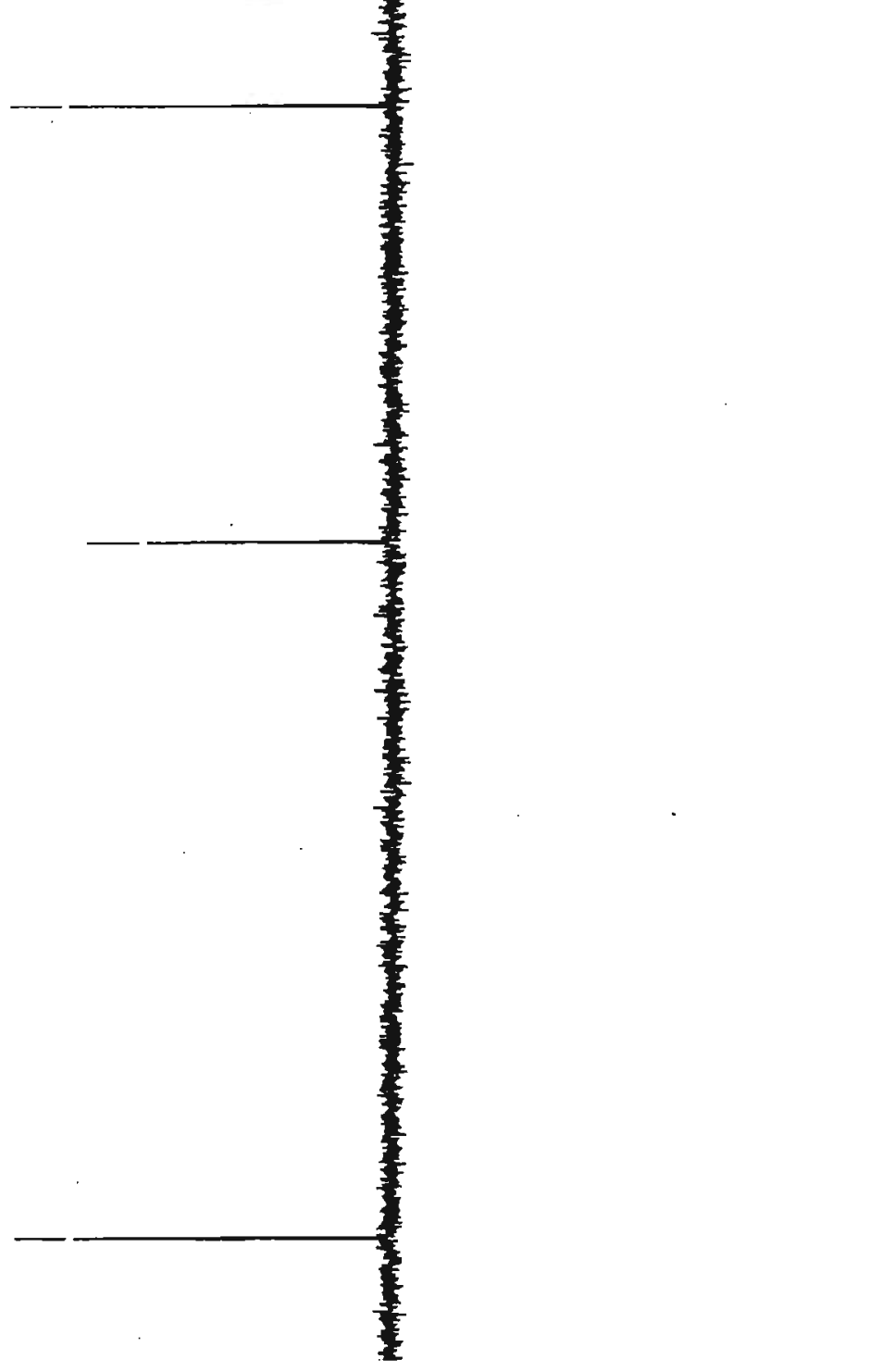

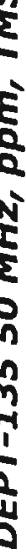




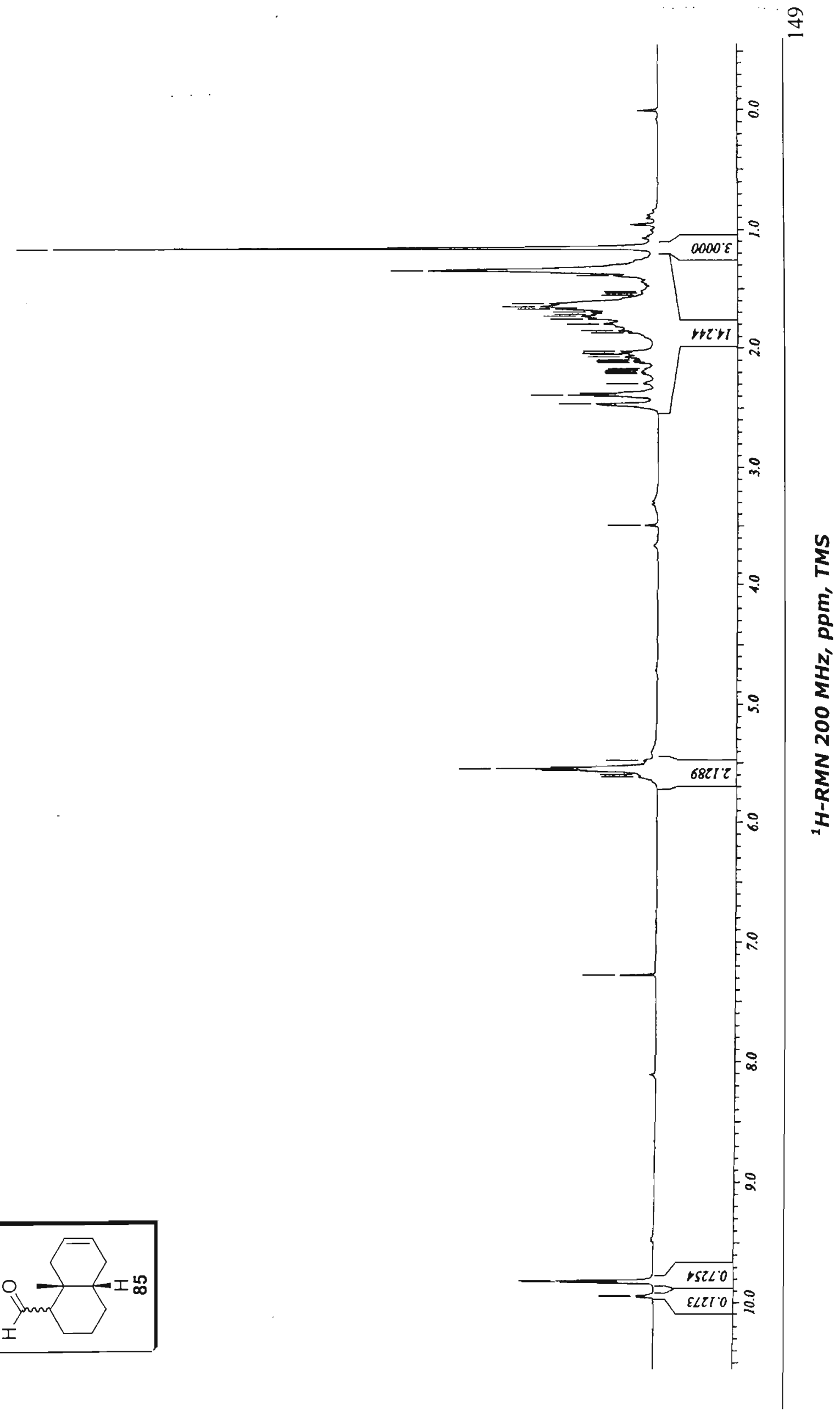

$96086-7$

05286

$\angle P E 6^{\prime} 6-$ $\angle S+6.6$

19245

thrs's -

$61955-$

87655

$E \varepsilon \angle Z \bullet$

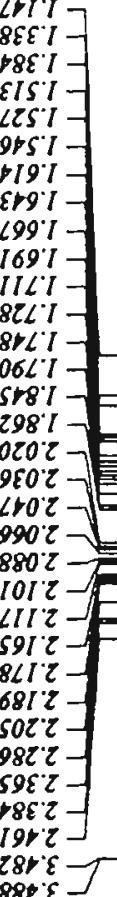

2

8

N

8

$\frac{3}{\alpha}$ 
$495 \mathrm{I}$

6509'I -

$819 \cdot 1$

$2699^{\circ} 1$

0969'

[2บL'T-

เor: 1

9r6L T

IIto'

80417

$8699^{\circ} 1$

86161

6161$]$

65961

2061

sIsor

9reor-

CeEI'

essit-

26262

EEST -

zect-

पDIE-

Itrez

2652

SI6E -

QLit -

$24+2$

solot

isZ5T-

19552

2z097]
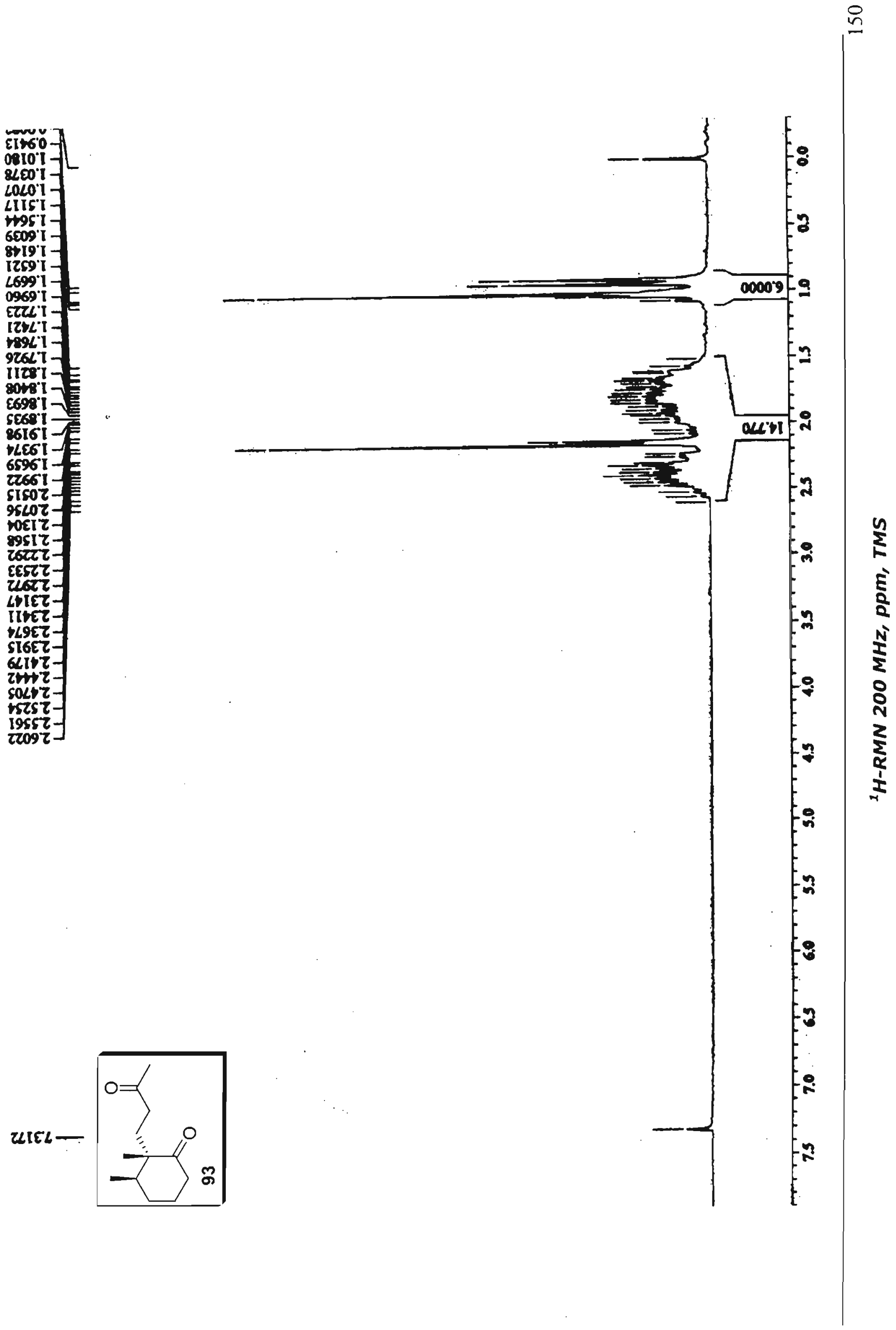


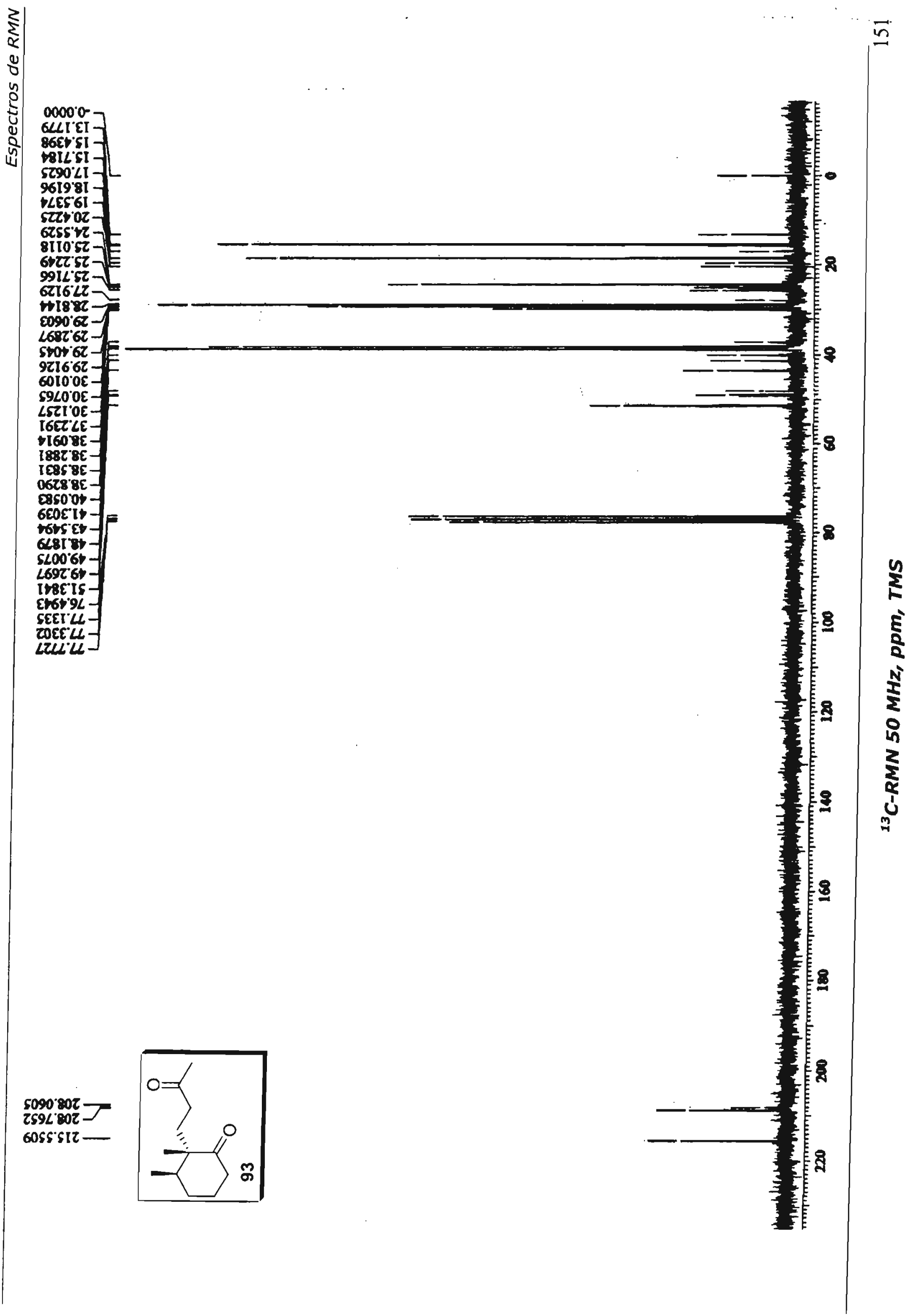




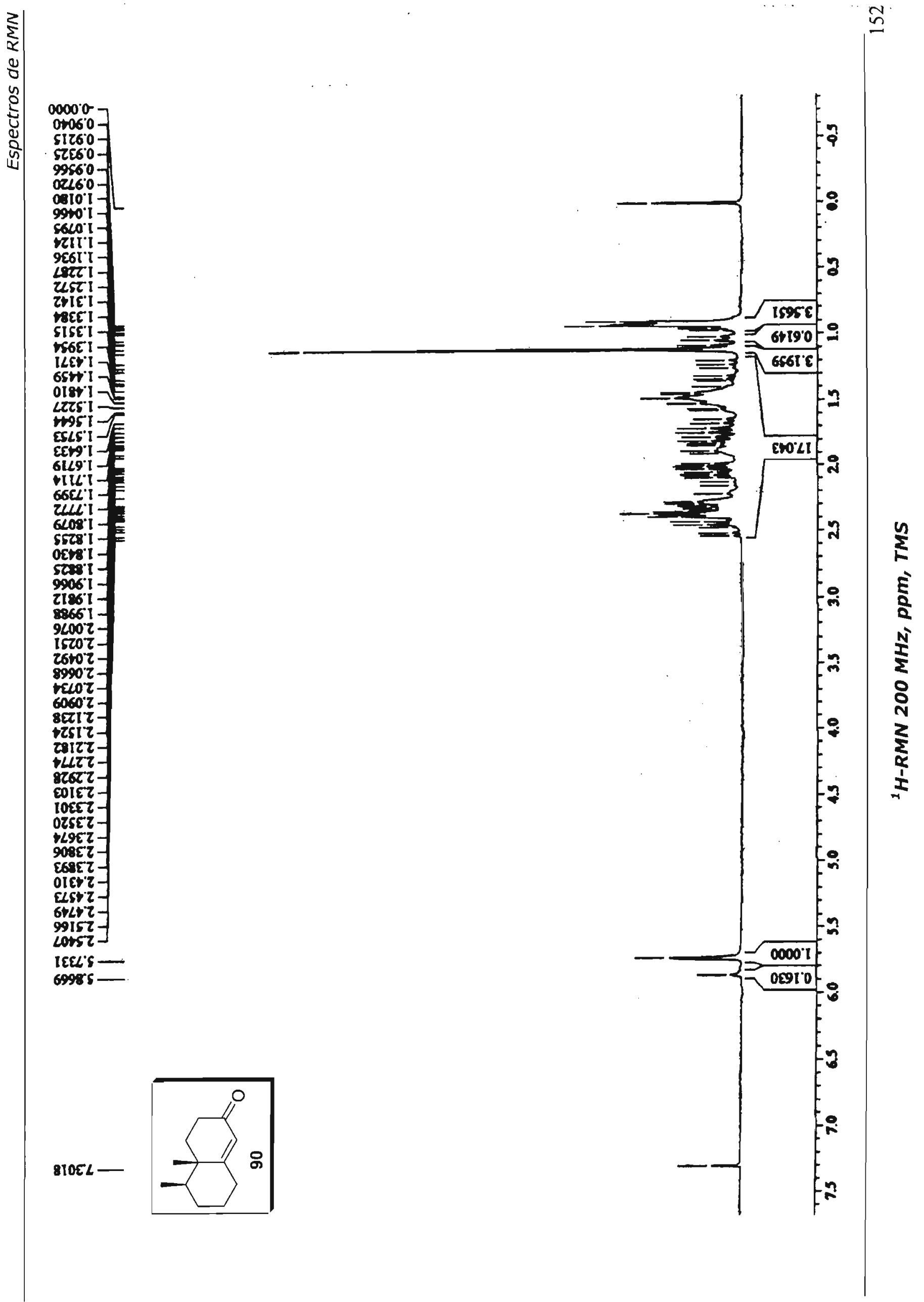


B I B L IOTECA

INSTITUTO DE QUIMICA

Universidade de São Paulo
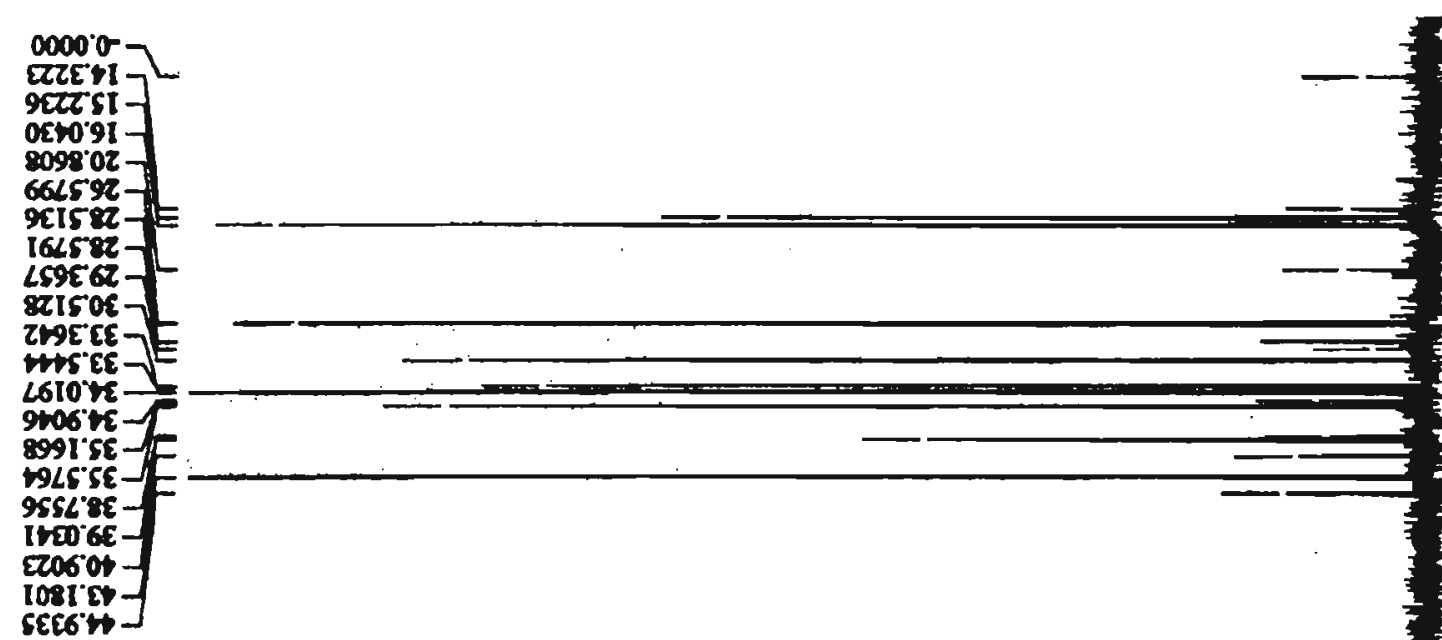

L42IIT-

SOS0.nI -

sstrut -

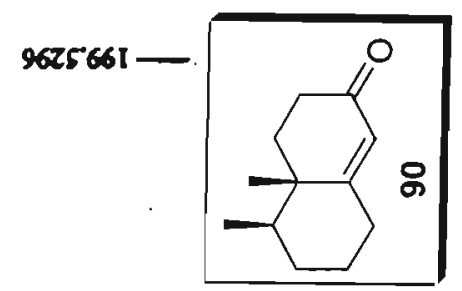



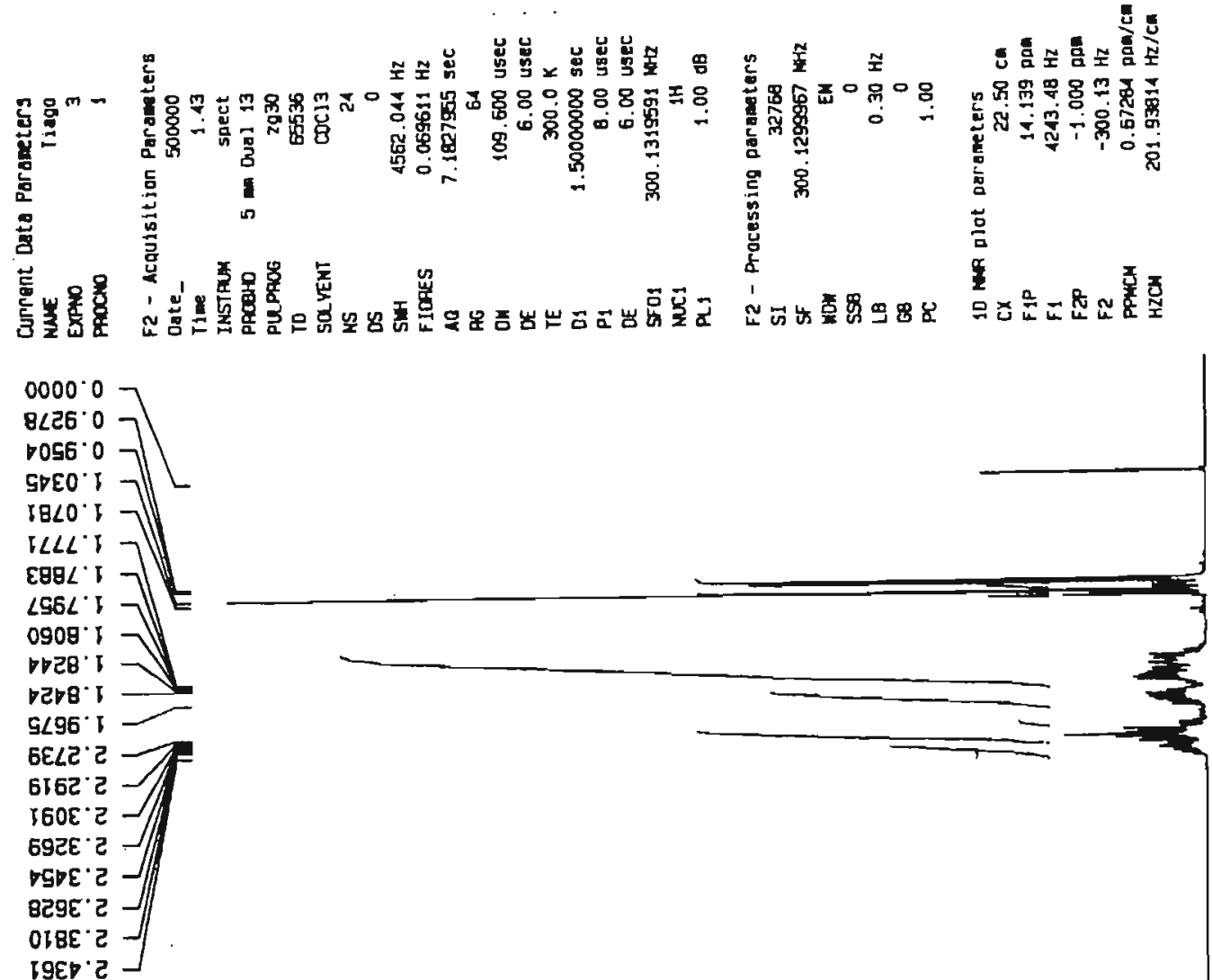

0062 L
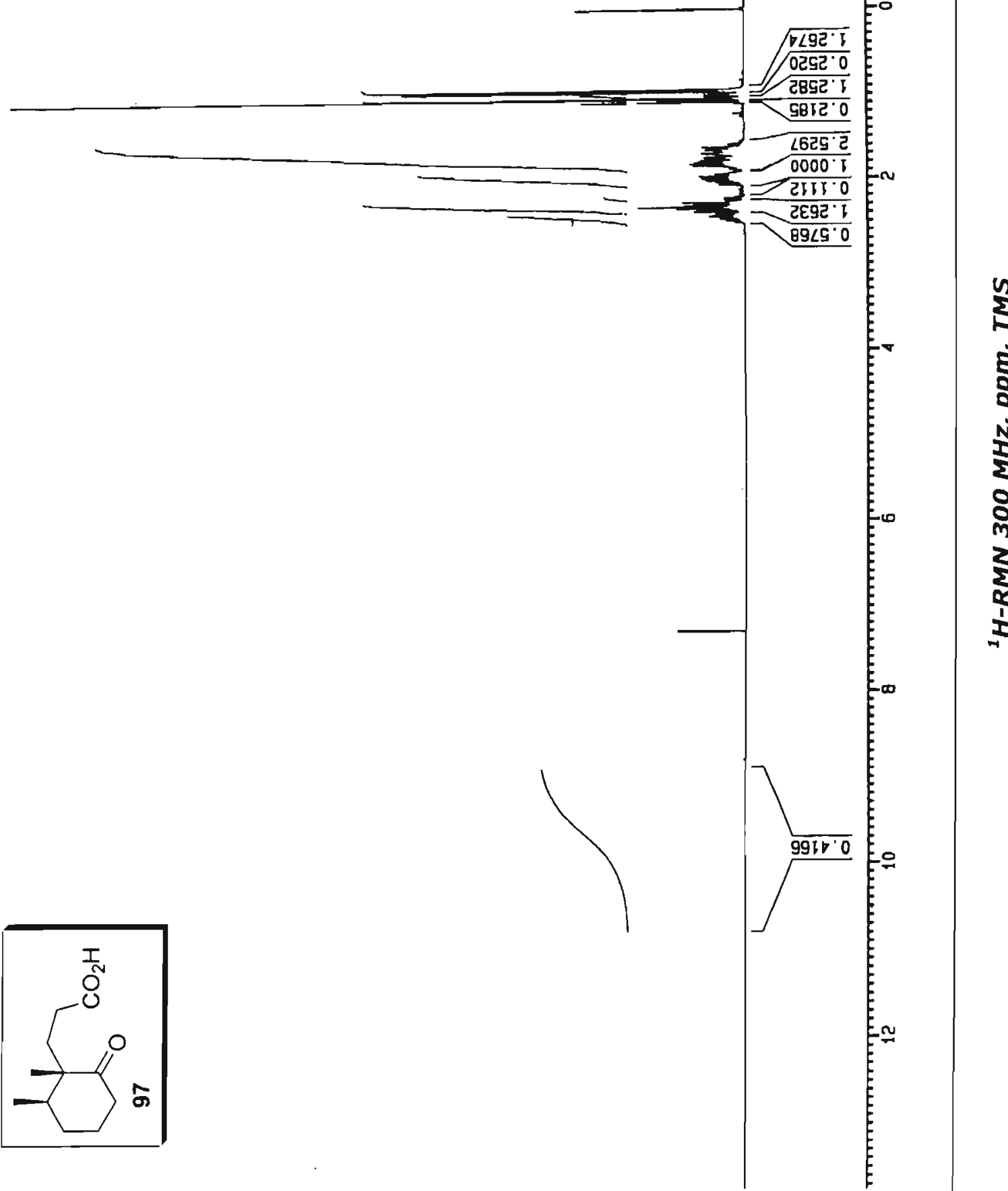

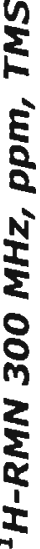




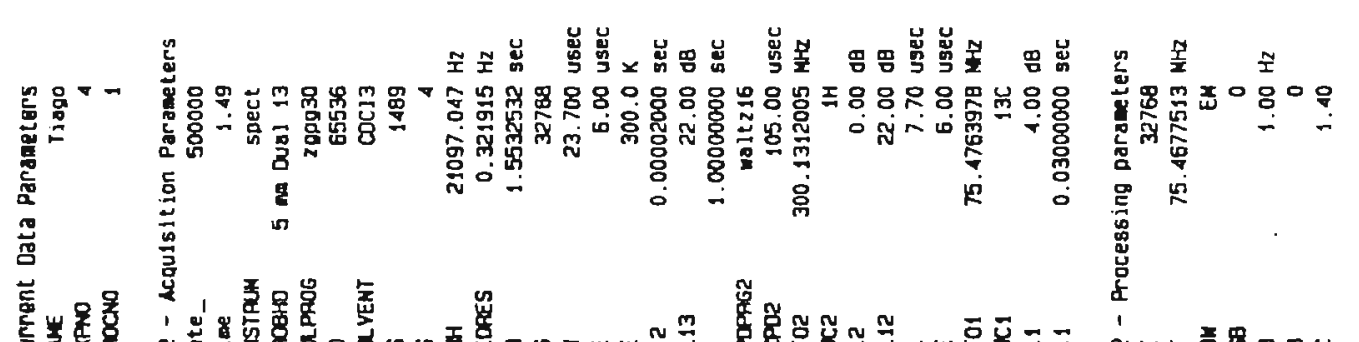

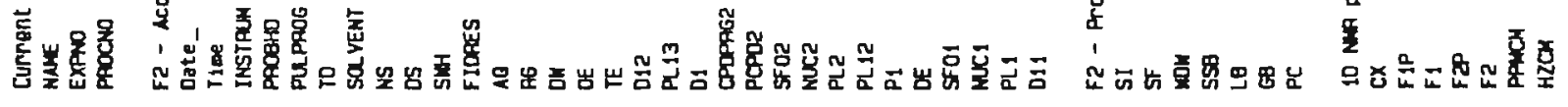

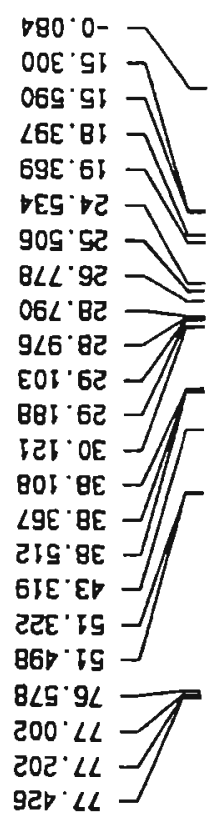

$962^{\circ} 6 \angle 5>$

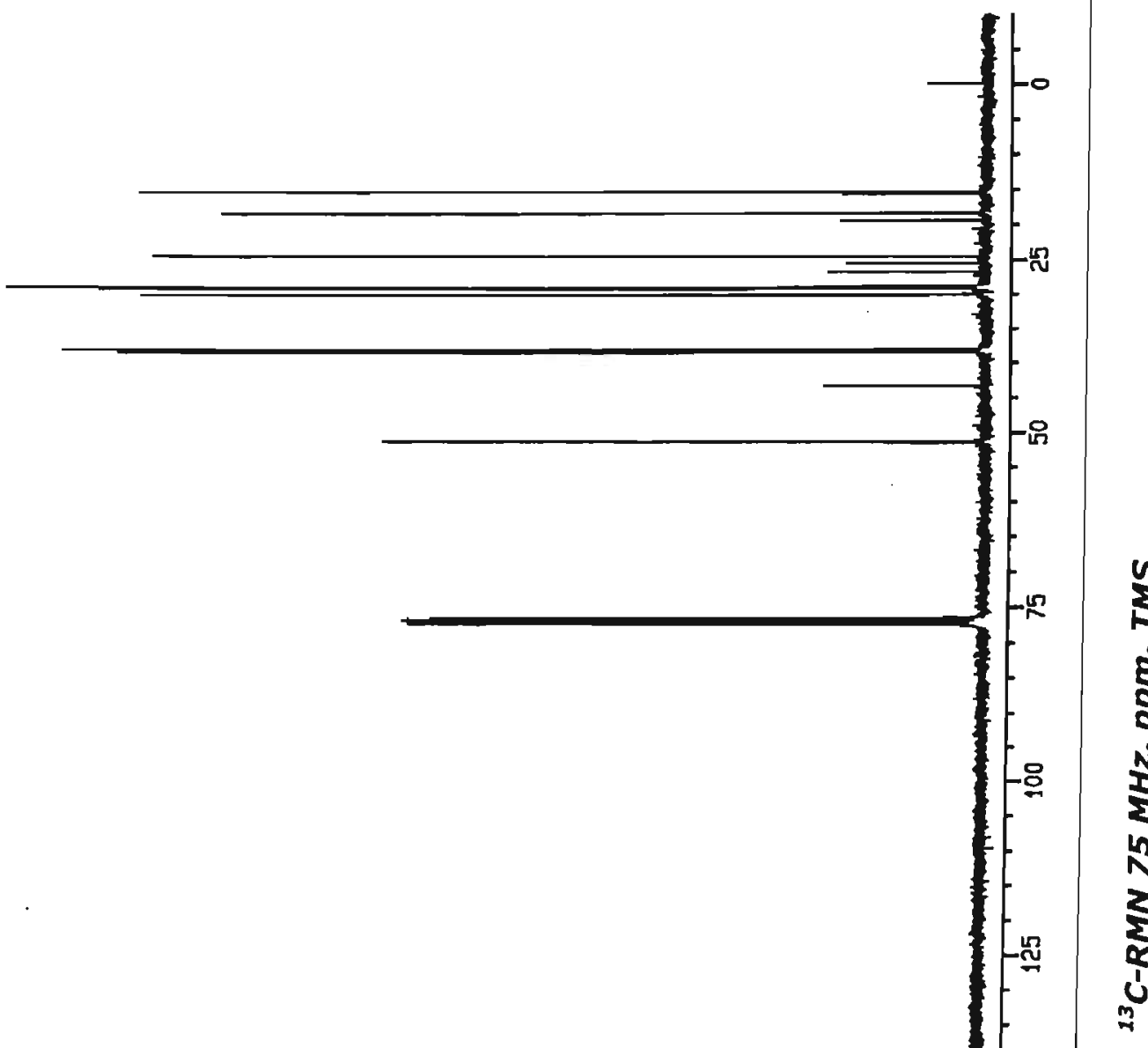

$169^{\circ} 6 \angle L>$

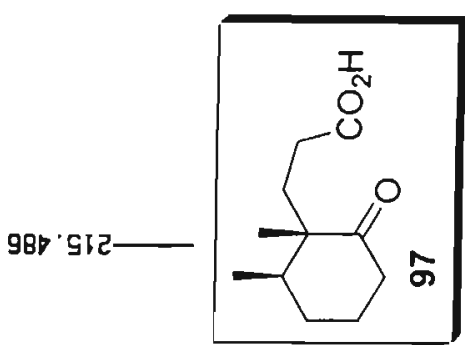

s 


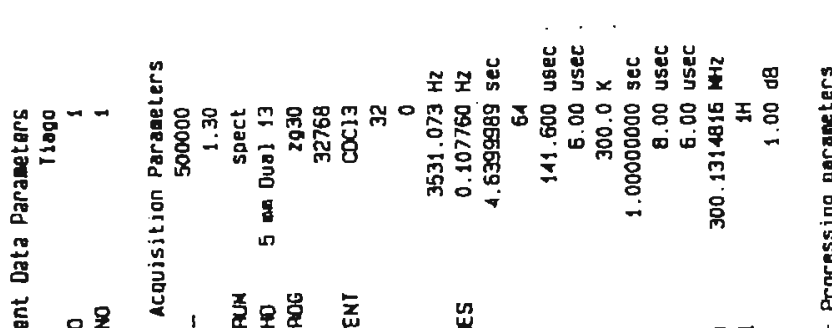
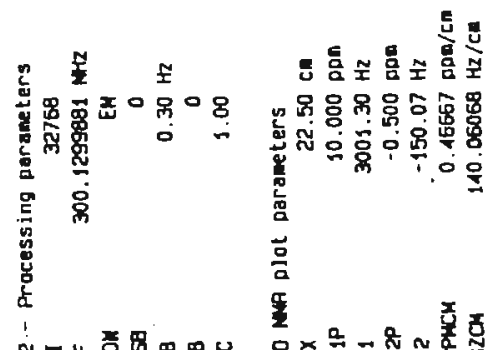

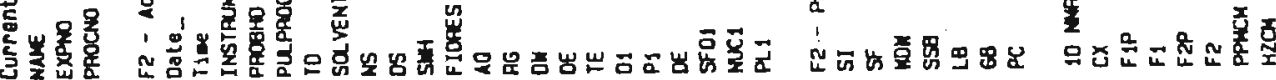

21006 0

ᄂ $\angle Q \nabla 6^{\circ} 0$

$\angle 0296^{\circ} \circ$

6I $\angle E O^{\circ} 1$

จ665\% 1

9LORS:

टr965'

606IS I

टDDES 1

i $\angle 79^{\circ}$

9L598 '

EOLLO 2

$51060^{\circ} \mathrm{C}$

E9860 2

SEDOL ?

$59601^{\circ} \mathrm{C}-$

6टा 万ा ट-

585टर 'ट-

ट9119. ट-

$5 \circ \angle 19 \cdot 2-$

EटIES $2-$

S9EE9. 5 -

$\checkmark 95 \square 9$ ' $2-$

$50299^{\circ} 2$

EI692 ' 5

Sᄂ b82 5

EI 562. 5
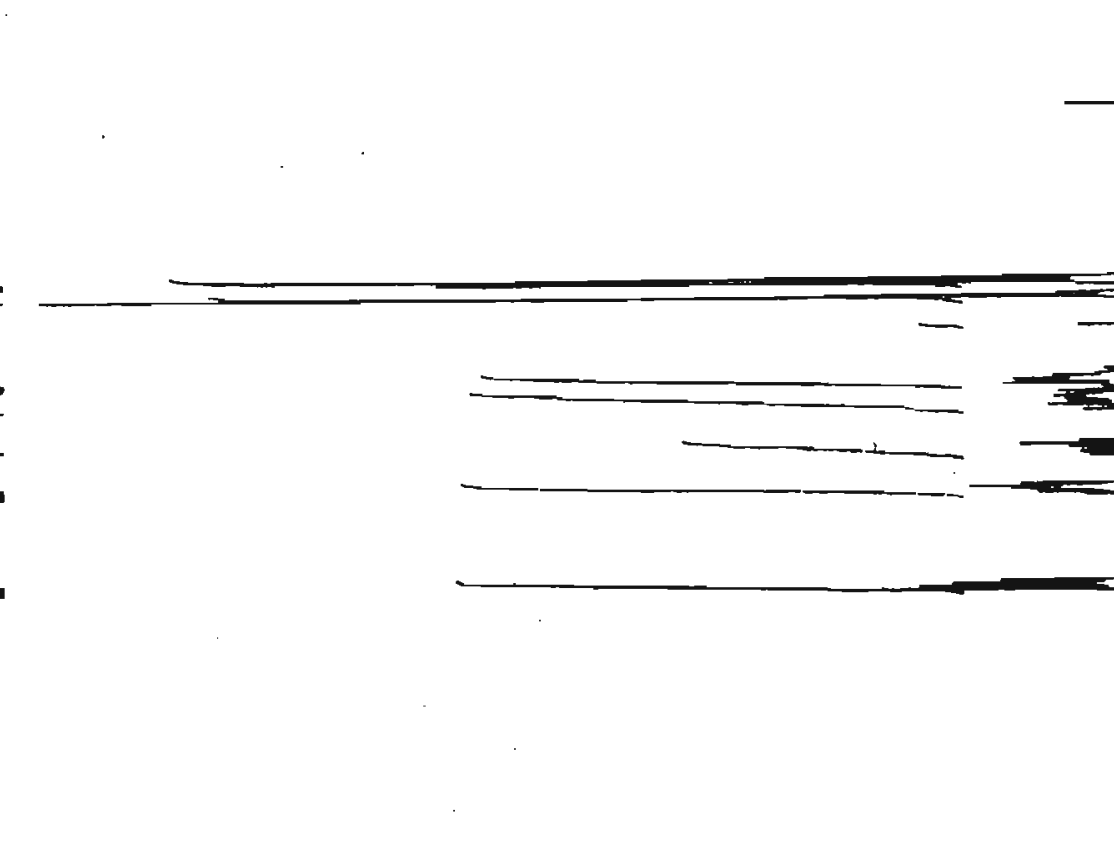


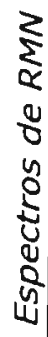

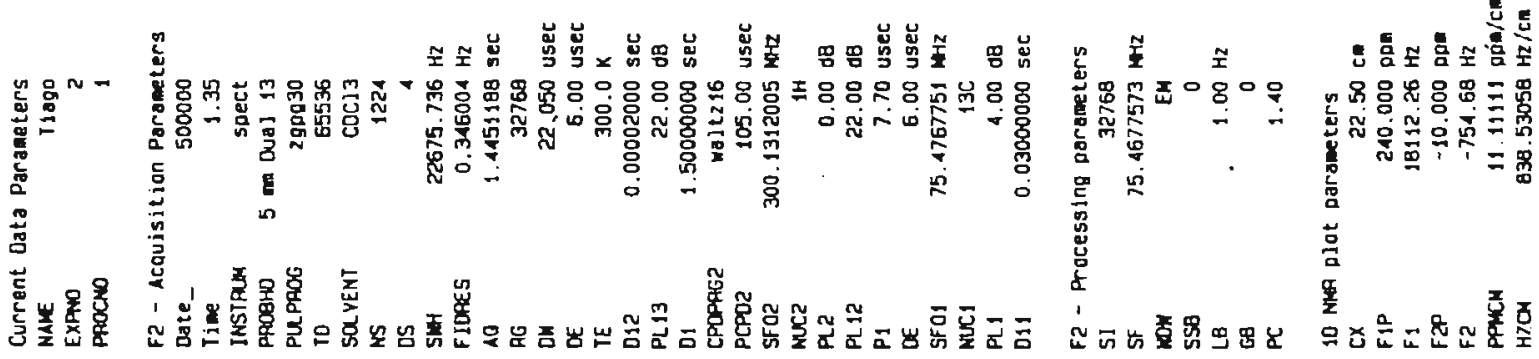

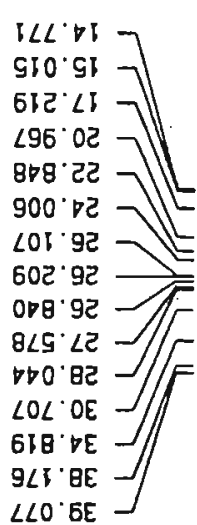

$E \angle S^{\circ} \cdot 9 L$

866. $9 L$

$561 . \angle L$

EटD $\angle L$

192' 901
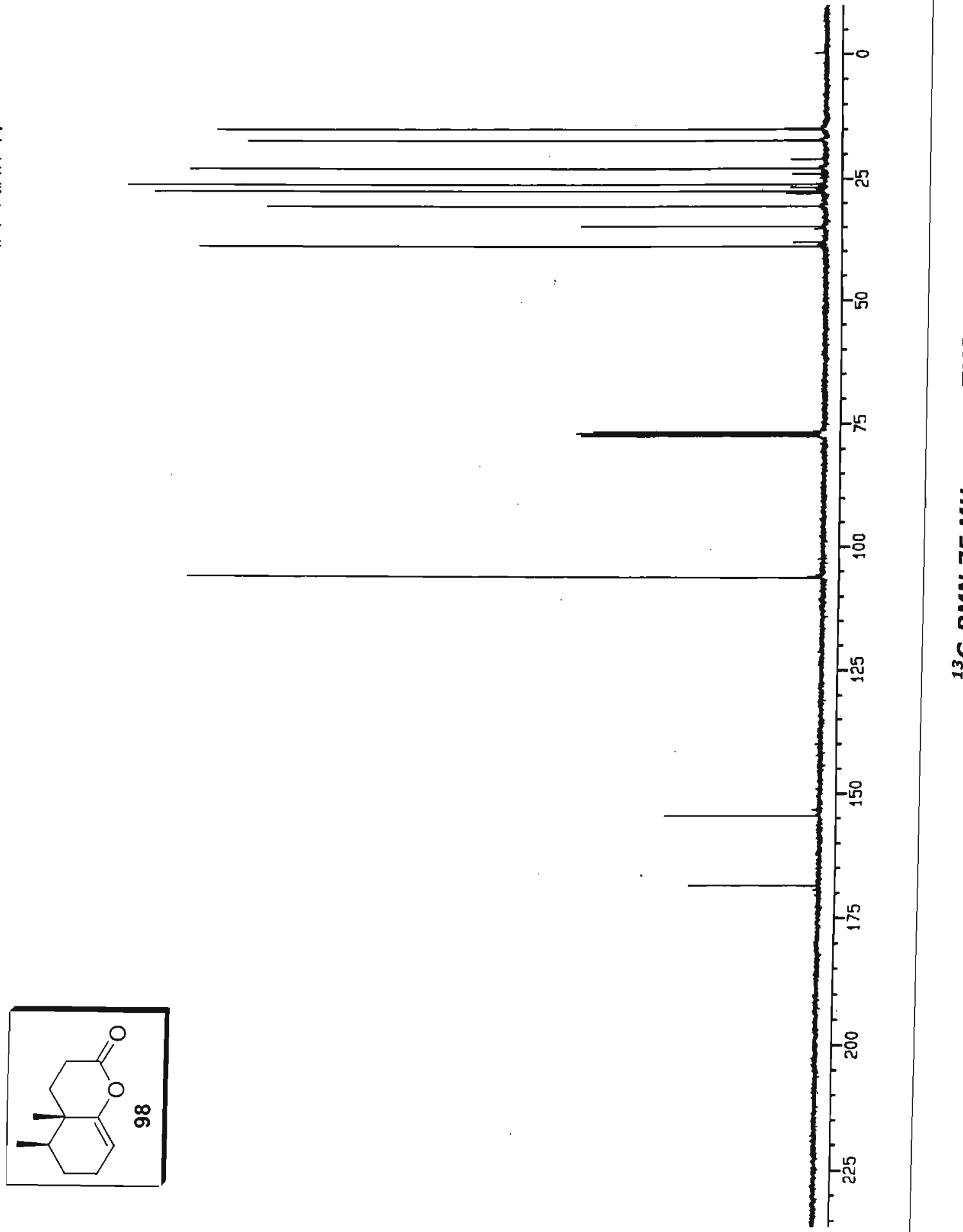
212I' I

L6ri'

680Z I -

69LC I -

EZG !

660E I

LZE

OSHE I -

EZ8E I

nse: 1$]$

อsz I

959t!

684 $[1$

E100' I-E

LLA I

0I16: $1-$

L2S6 I-

$166^{\circ}$

$6550 \%$

$8550 \%$

$0000 \%$

5200 '

s992 -

corer-

946I' $\varepsilon-1$

IET' -

6ols's-E

zos' 1

HSL $\varepsilon-$

OSLL'E-
OLBL'E

\section{acel}

2691 'S-

BS9R:5-
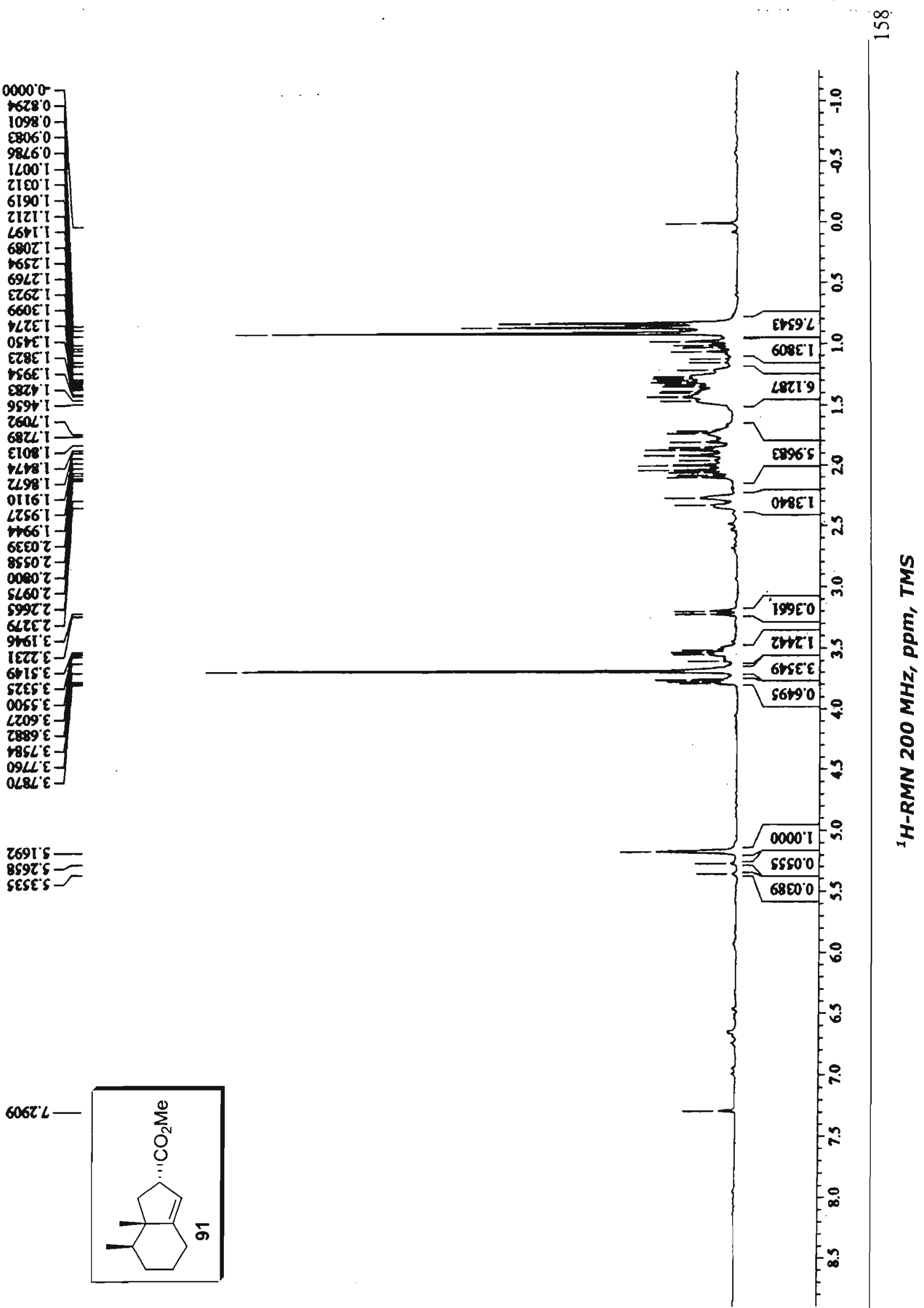


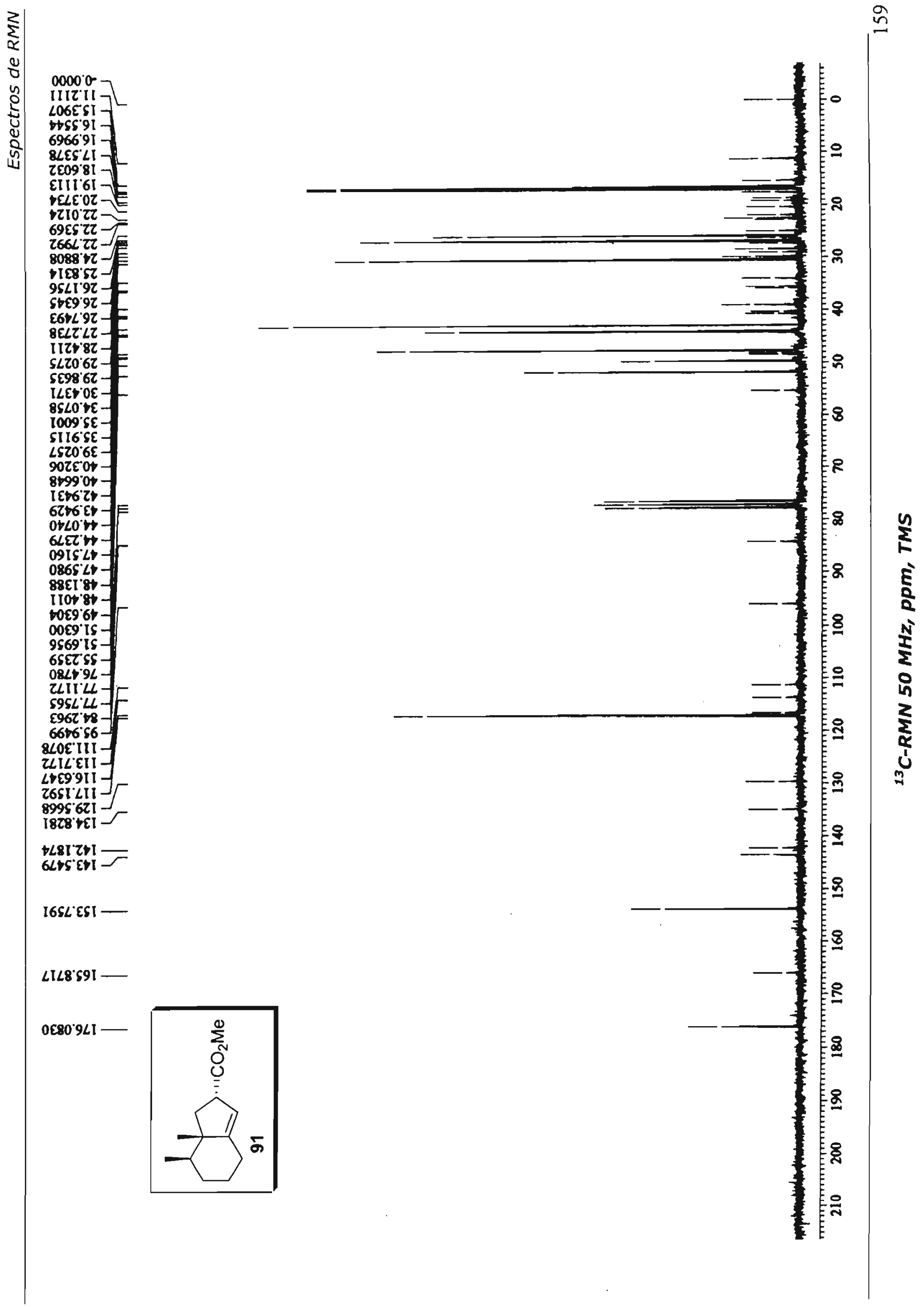



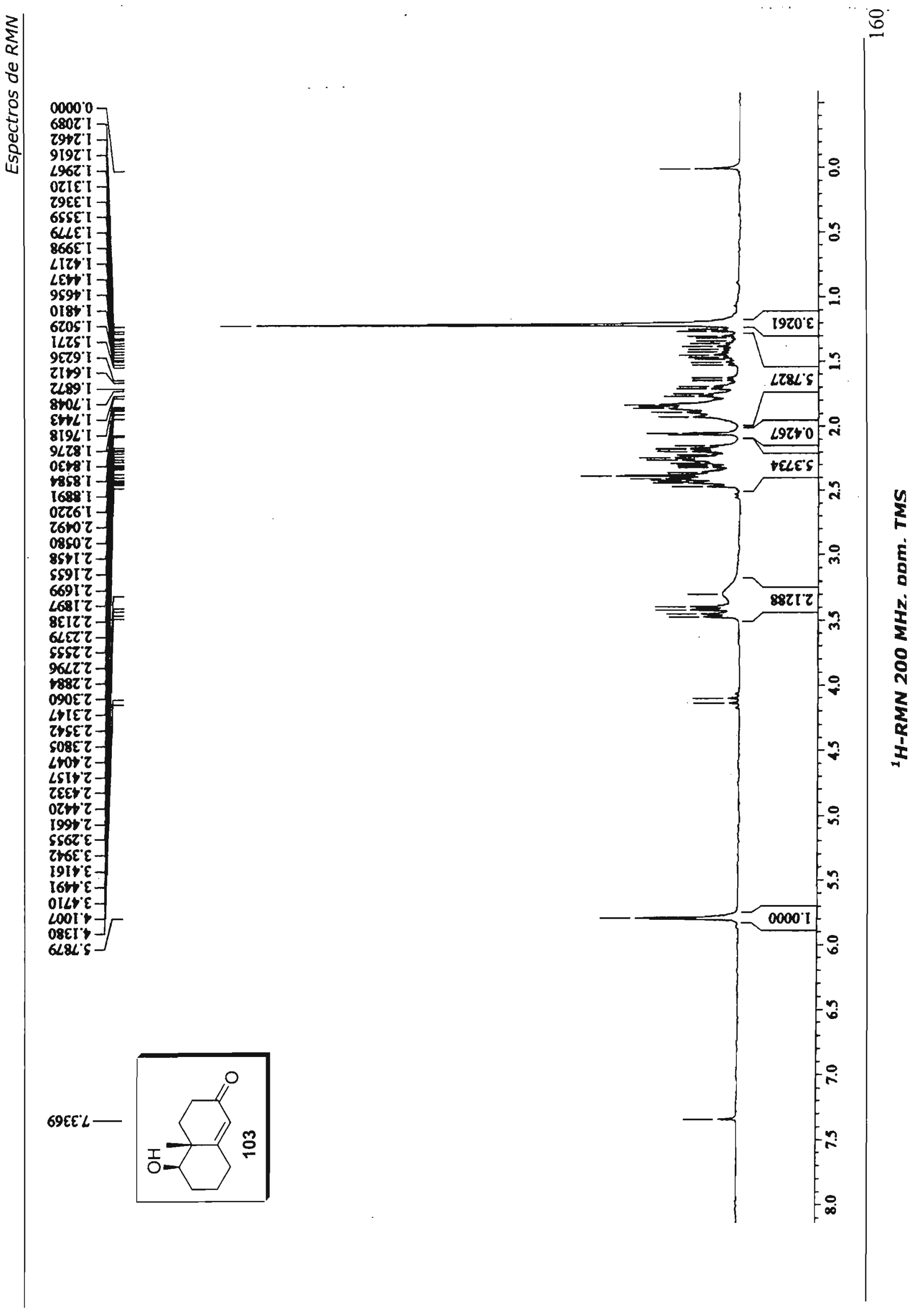


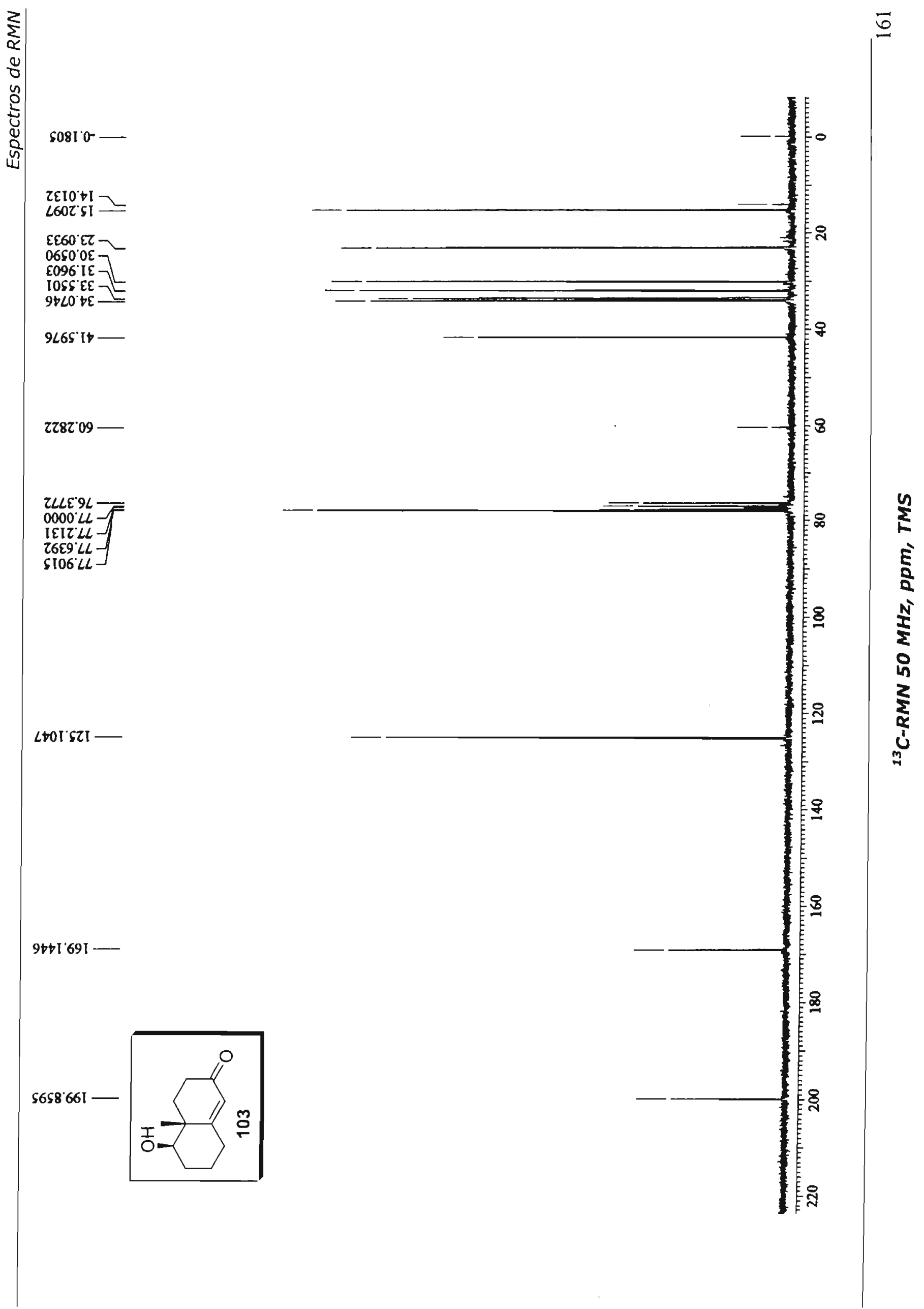




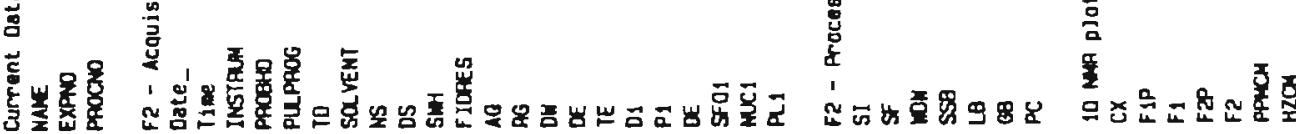

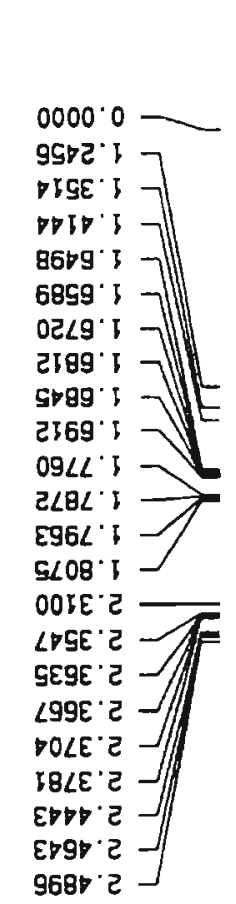

$981 / \cdot \mathrm{G}$

टहटl一⿻

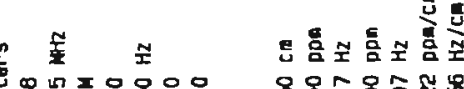

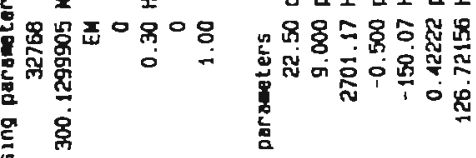

a
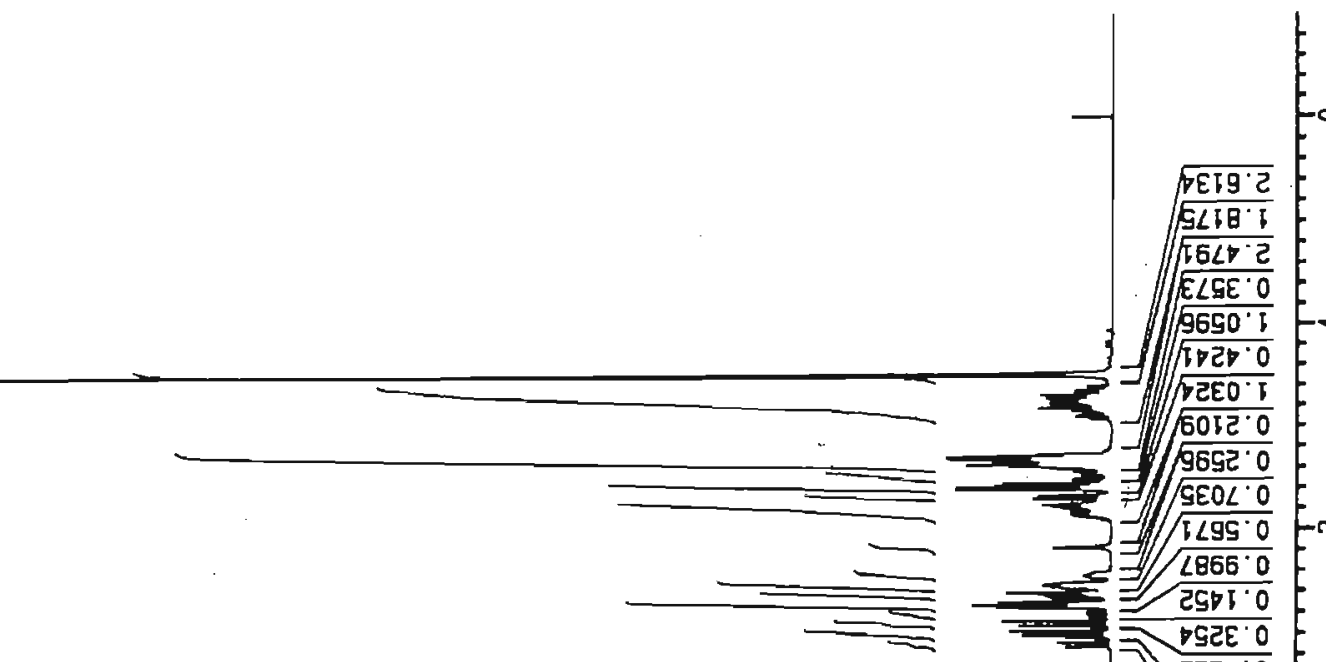

=

避 50

90IE' 2
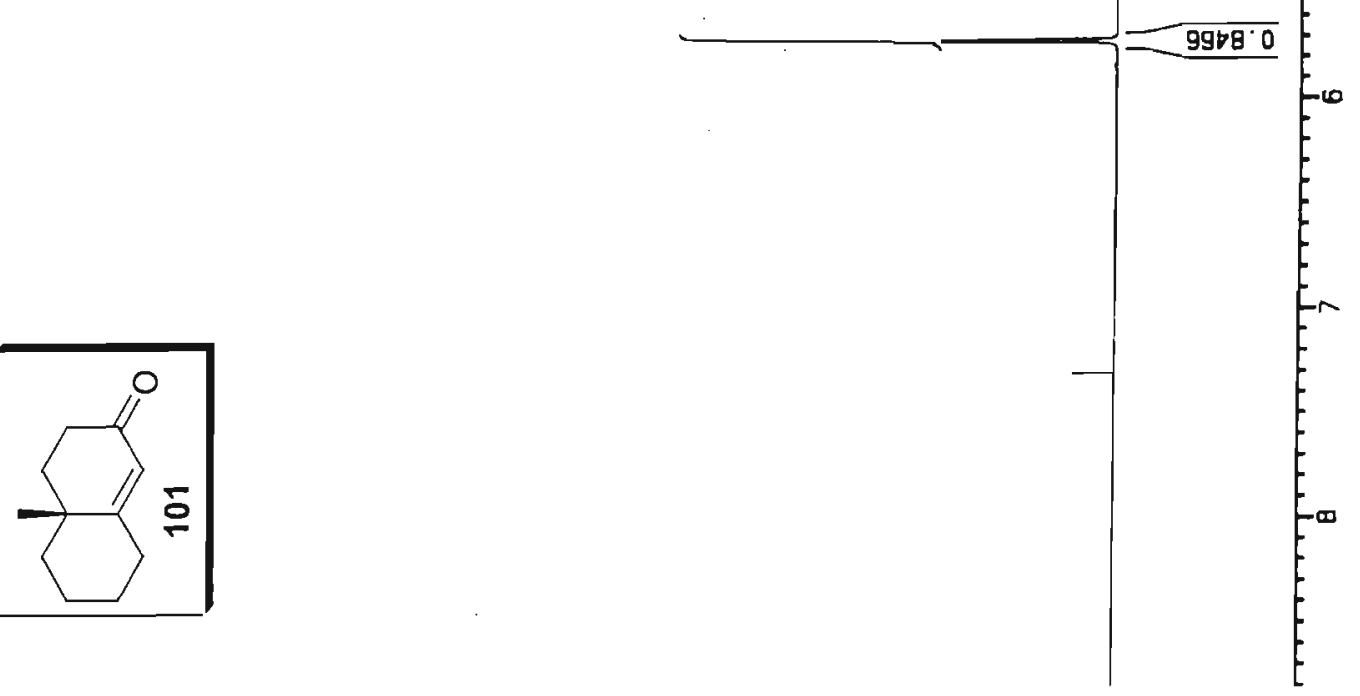

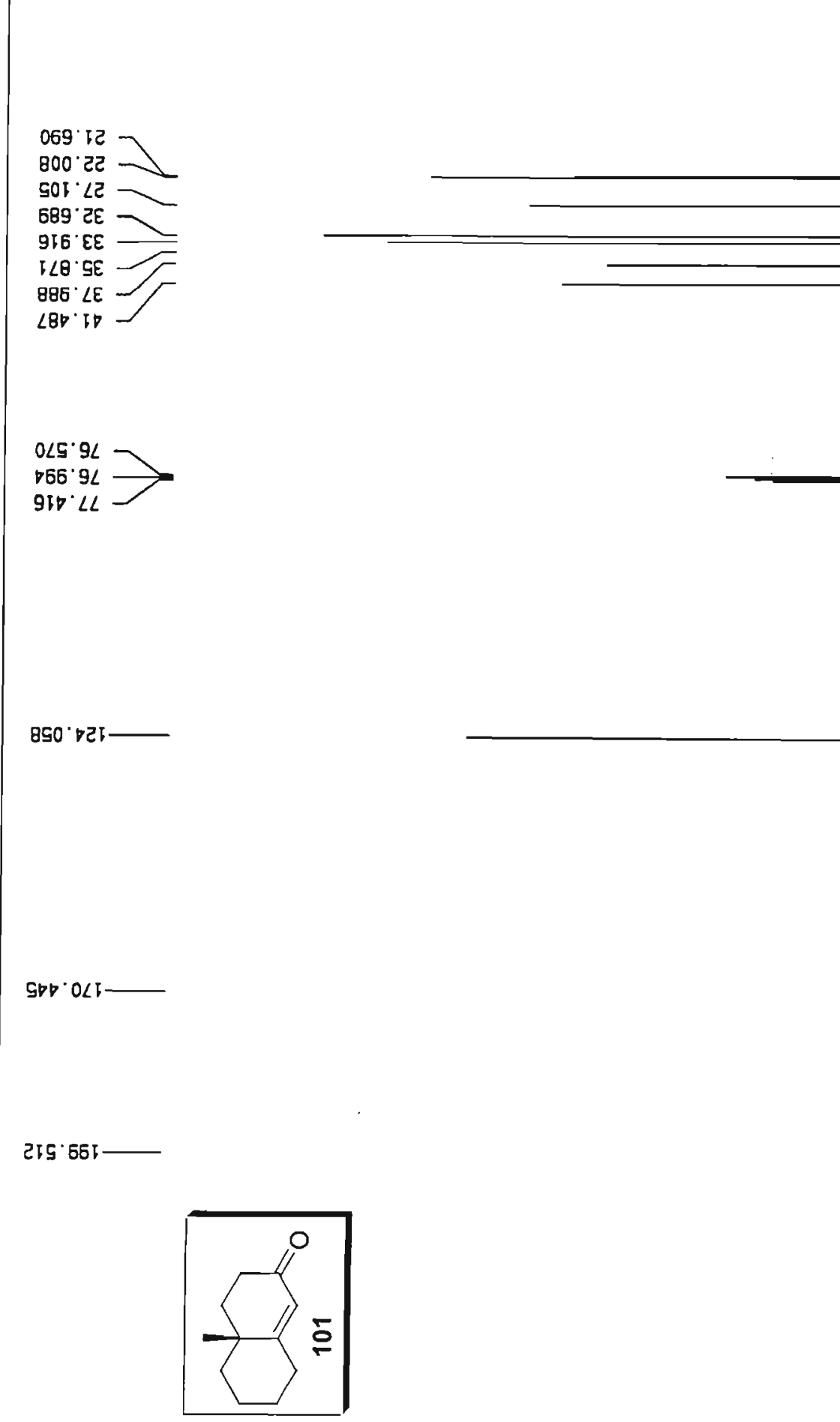
6EZt I -

EOSt I -

$959+1$ -

E96t I -

6EIS'I -

E6ZS' I -

ESLS

2619.1

$\left.\angle \angle 49^{\circ} 1\right]$

9089

$9169^{\prime} \mathrm{T}$

$26041-$

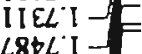

$82 \angle 4$.

$\angle \$ 6 L 1$ -

EZI8 I -

98E8 I-

$58581-$

[9EO Z -

8EZI'Z-

$965 I Z$

ZELE'

$806 \varepsilon^{\circ}$.

E80t' $\varsigma-F$

$589 S^{\circ} \varsigma$

0619.5

$8016 \%$

$0656 \mathrm{~s}$

LSSZL

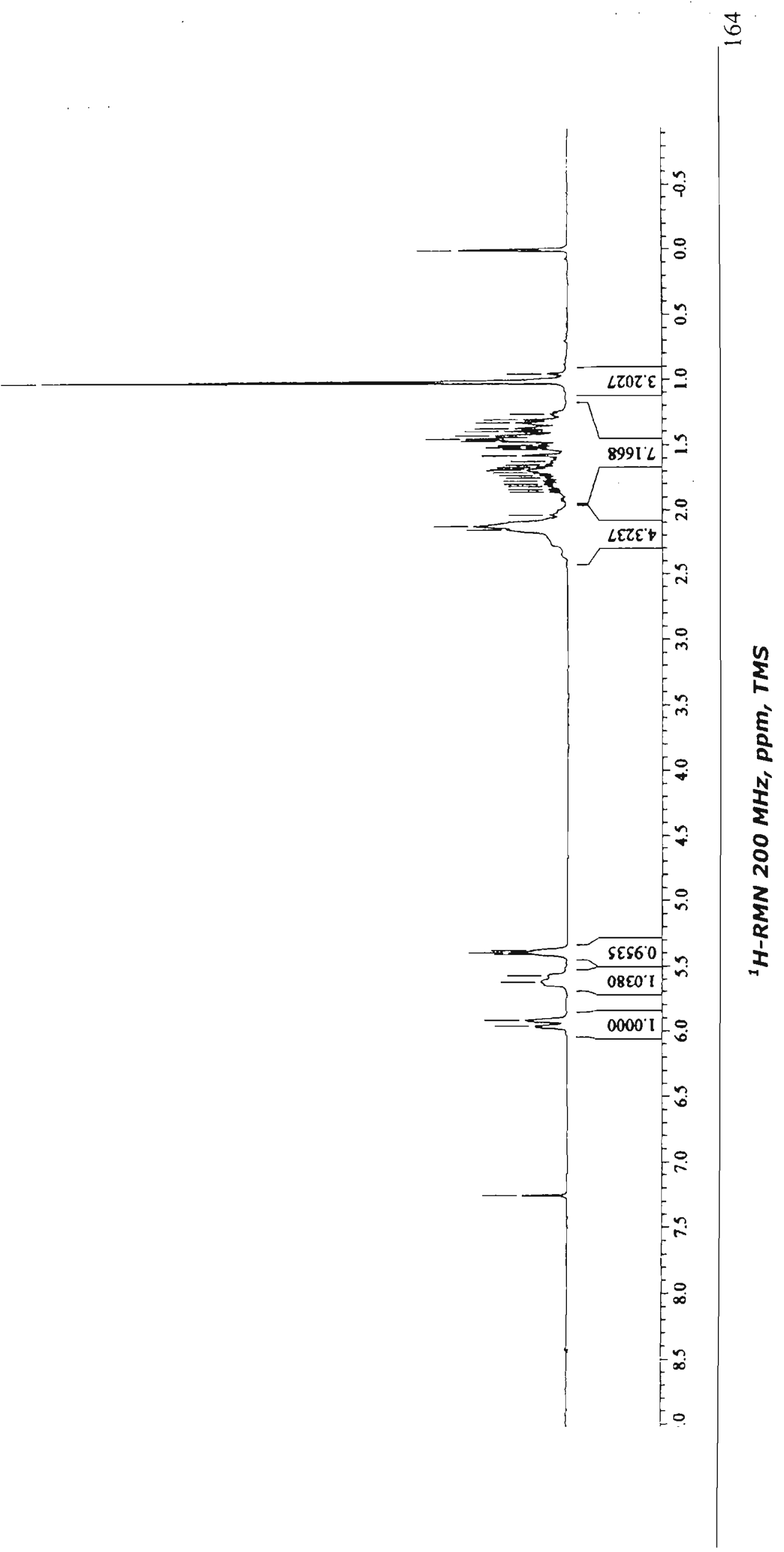




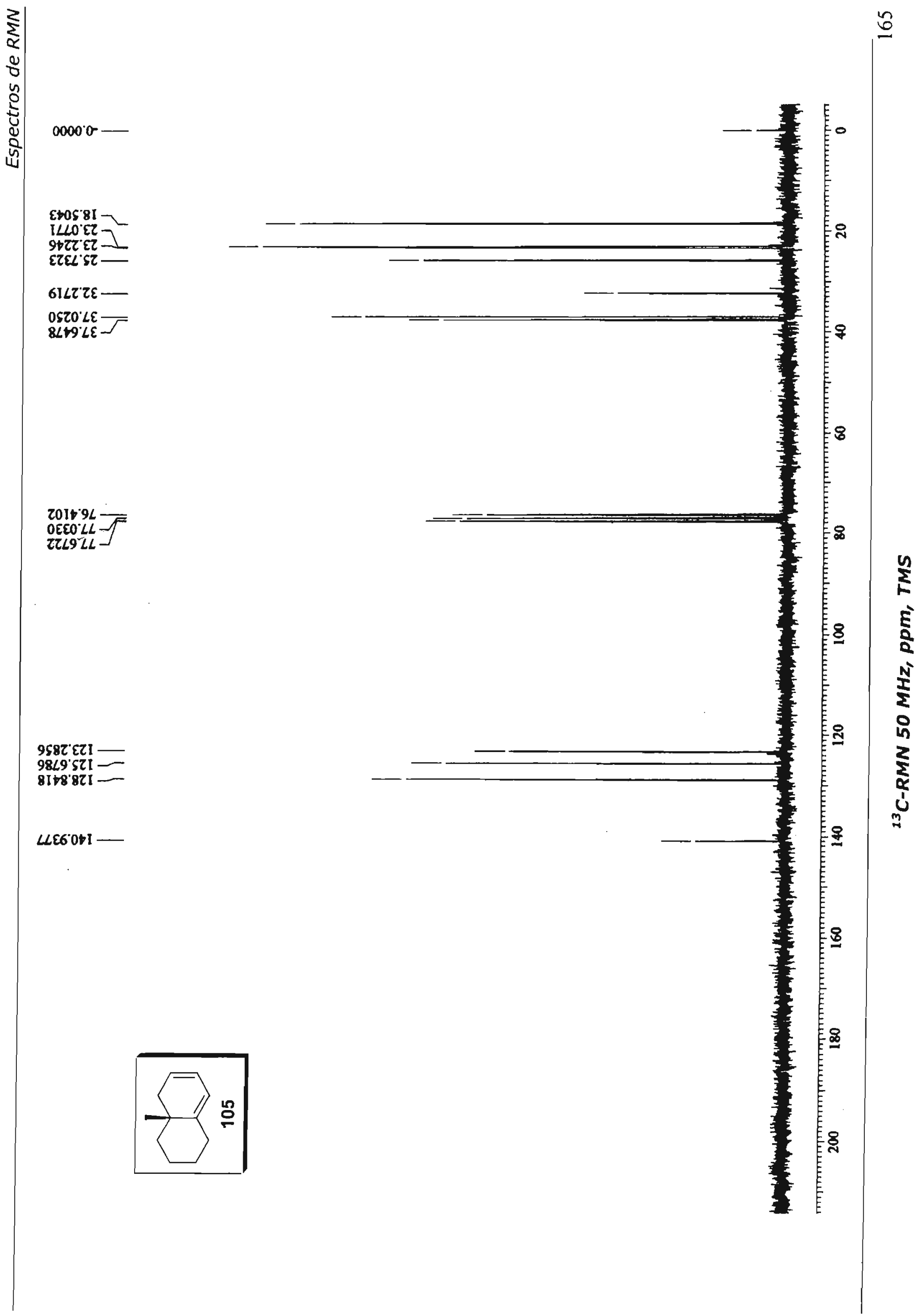




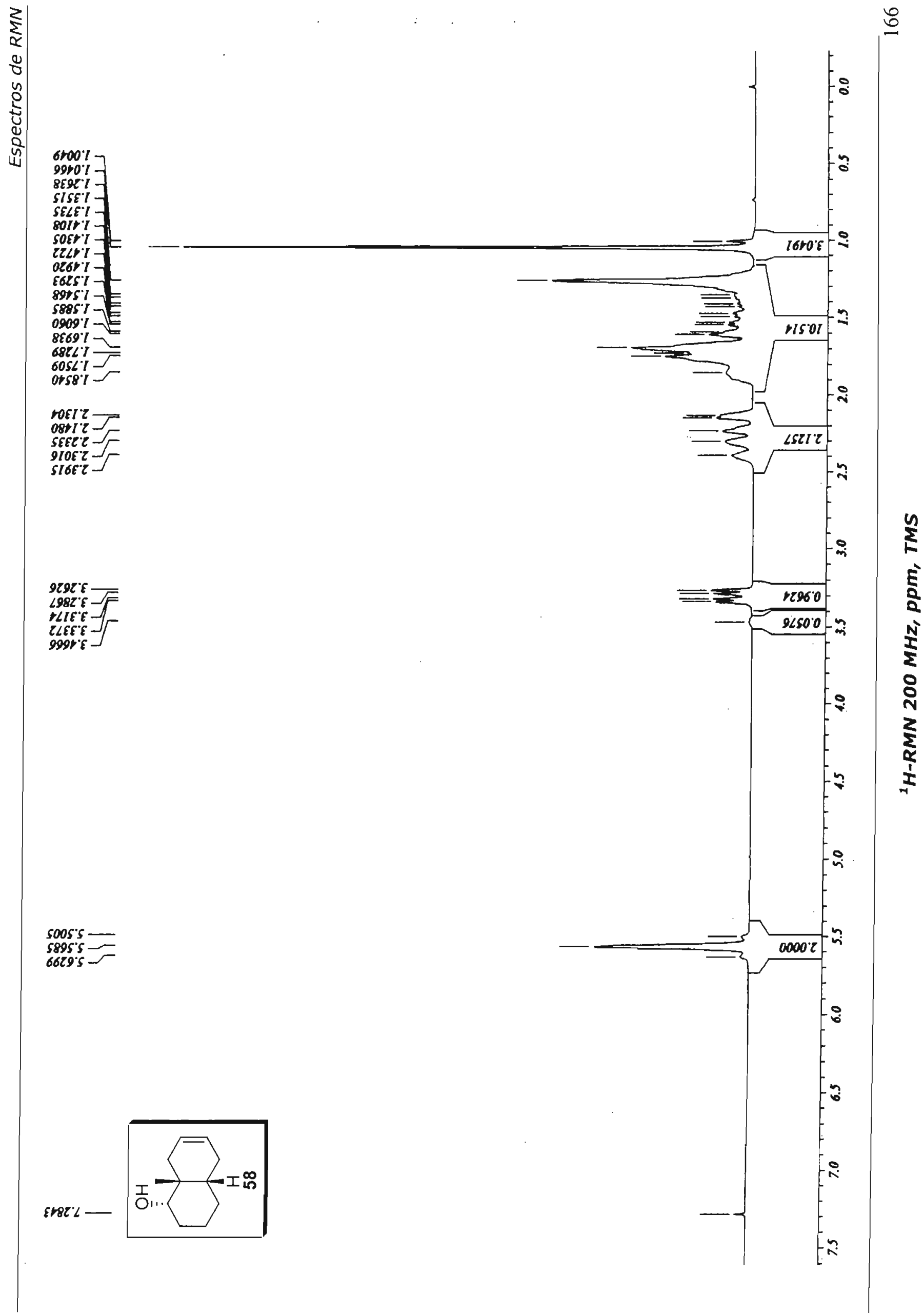




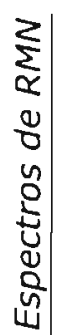

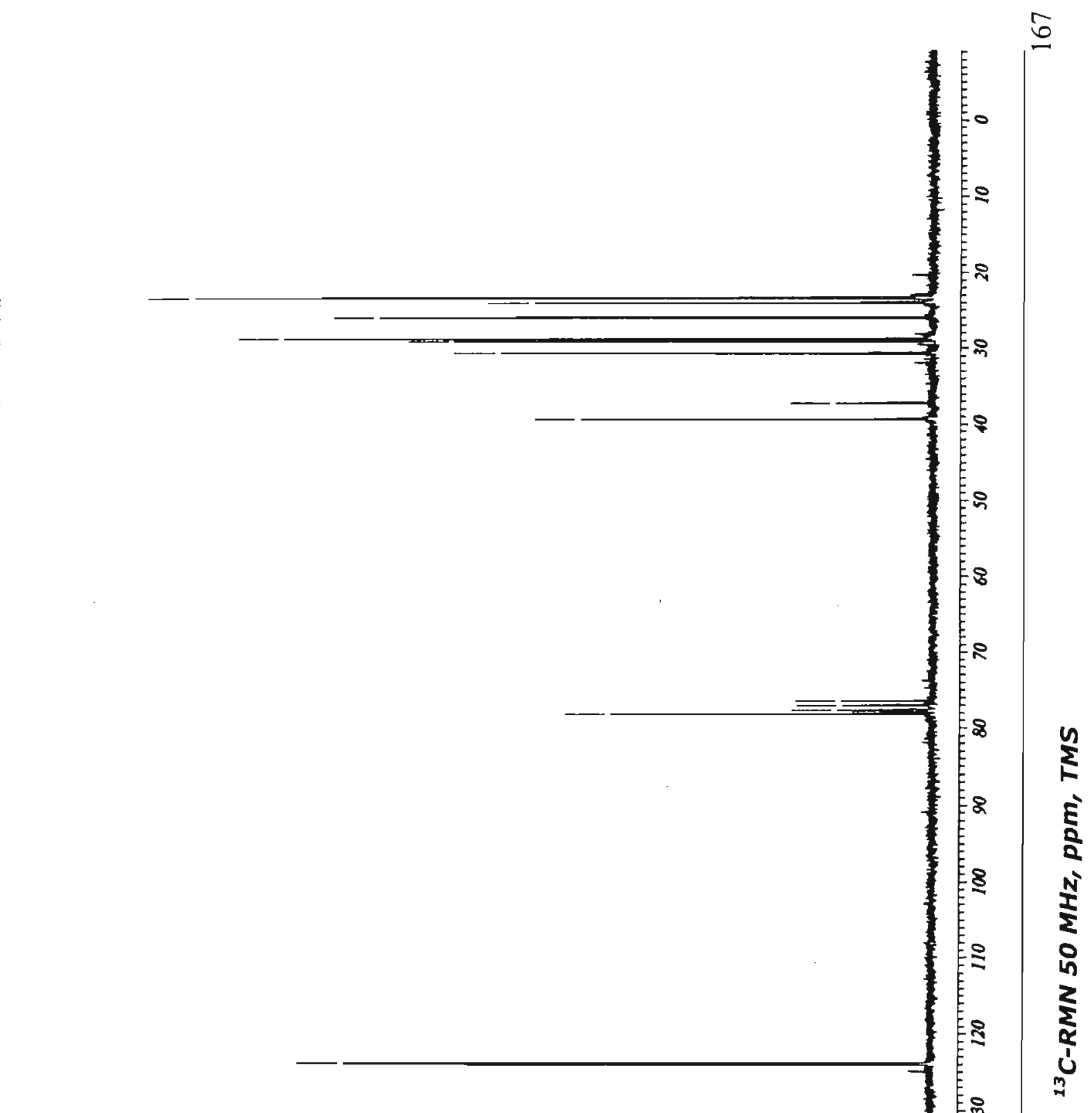

[818. 271
$810^{\prime} \mathrm{KI}$

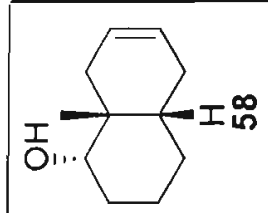

9256.22
$0<88.52$

$9+29.82$

889682

SZE I LE -

gEQR $6 E-$

ILLE 9

E6E9:LL

E860 \&L 


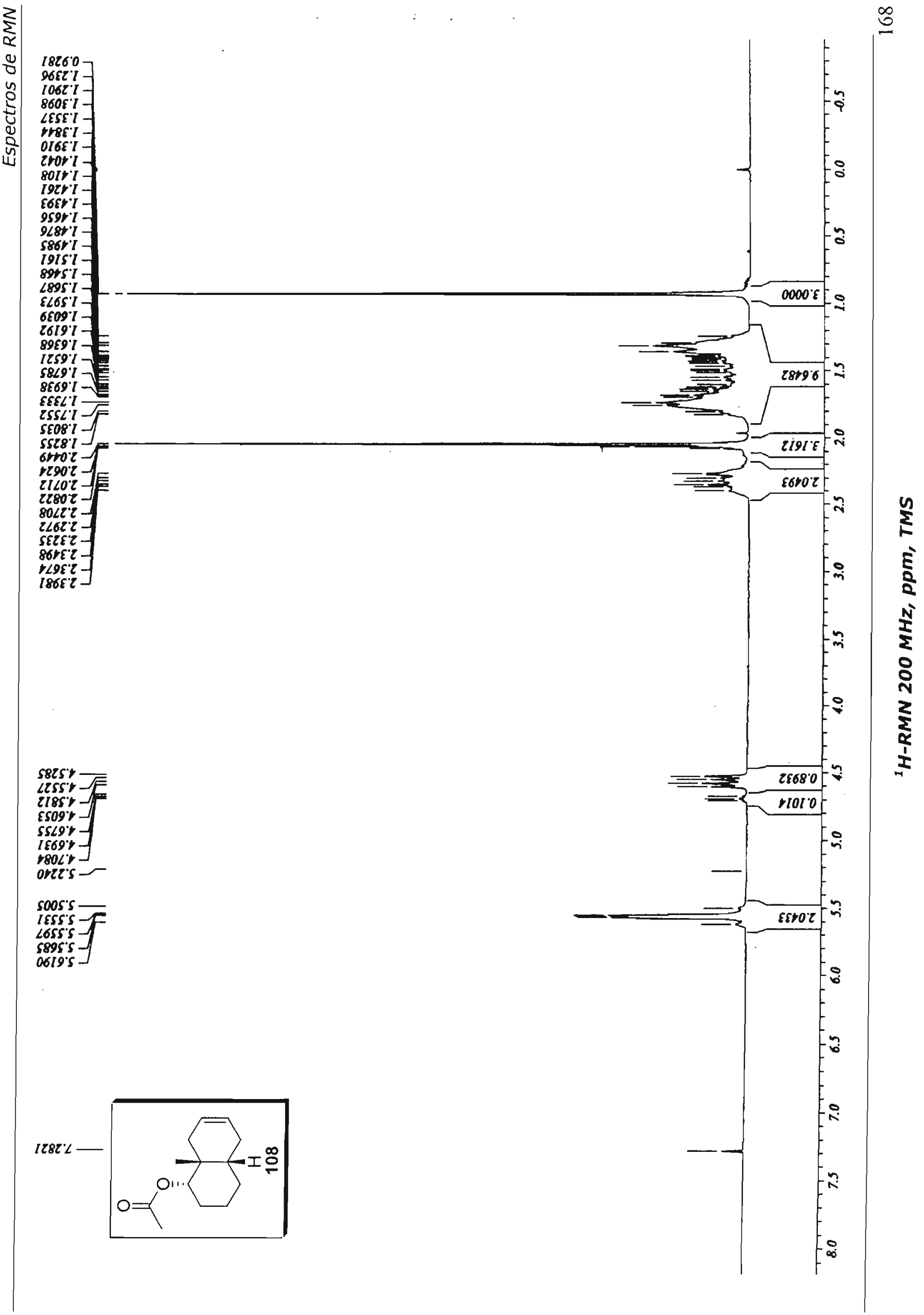




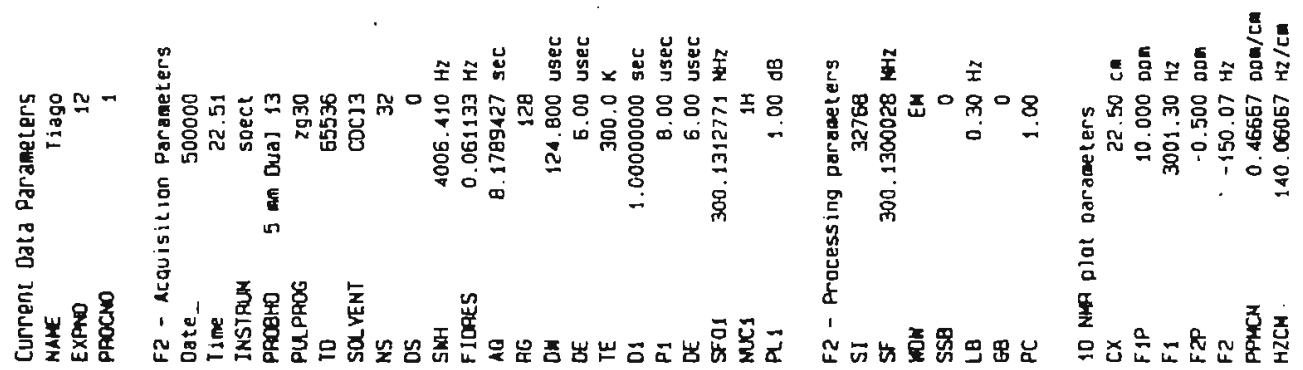

$00000^{\circ} 0$

09E68.07

20rge '

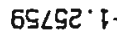

GLSLC !

[9582.

IBOLE' $:$

ELIBE ' I

จIEES '

DL989. I

$\nabla \angle \angle E G^{\circ}$ !

I G9E9 * I

Eโ899.

टLE89.1

ट9ट69: $1-/ F$

$\angle 922 L^{\circ} 1-$

$\checkmark 62 E L^{\circ} \cdot$

gBBEO $5-$

$\angle \forall 950^{\circ} 5-$

$89950^{\circ} 5-$

BEIST. $5-$

OEEIE'z-

68099 $b$

$10 \angle \angle G^{\circ} \square$

$08869^{\prime} b$

$92019 \circ$

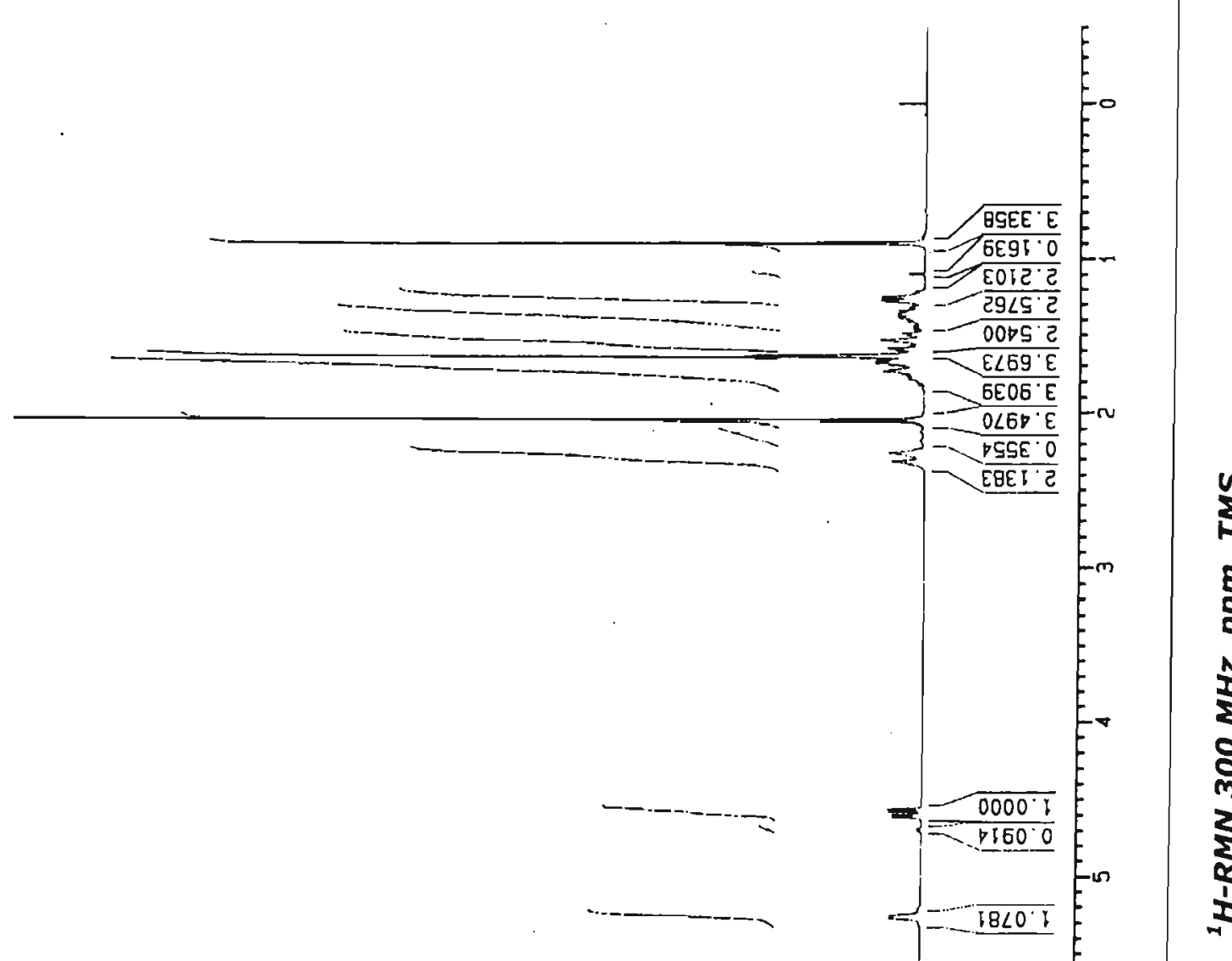

g6sç ' $9-$

gib92.

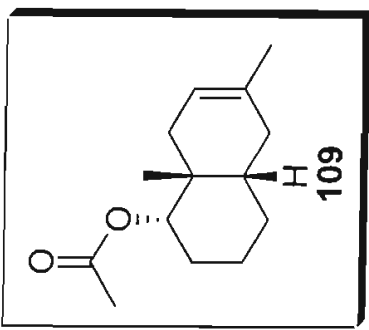




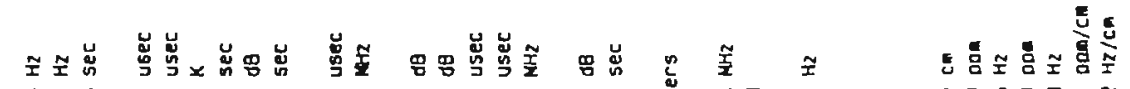

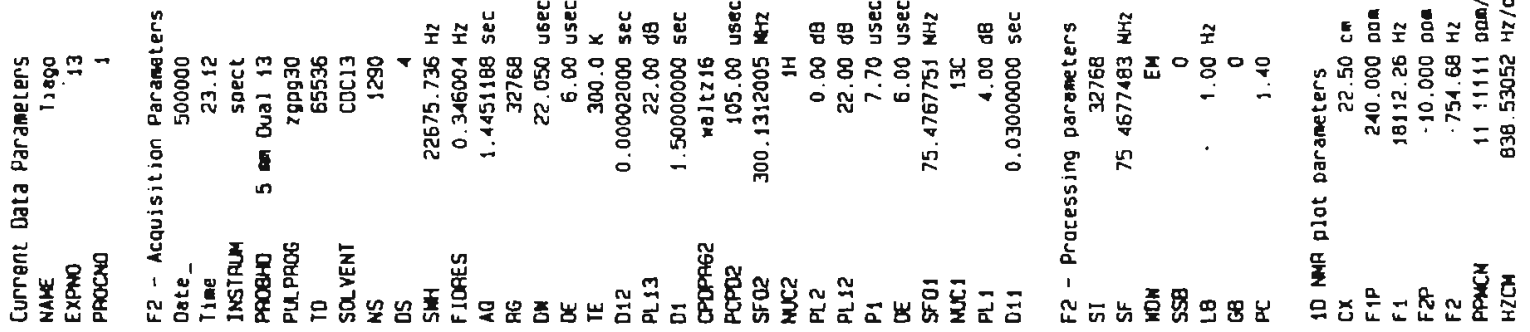

$0 \angle 9.02$

$291 \cdot 15$

OIE EZ

LLE'EZ

$56 \mathrm{~S}^{\circ} \mathrm{E2}-$

POL E己

$\checkmark 98^{\circ} \mathrm{EZ}$

$9 \angle 9 \cdot 92$

9ट6. 92

$\angle \nabla O \cdot \angle 2$

9EE'Bट

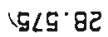

$6 \angle 0.62$

$069 \cdot 1 \varepsilon$

$\angle 88^{\circ} \mathrm{EE}-$

EเB. $S E$

$9 \varepsilon 0 \cdot \sigma \varepsilon$

$8 \nabla 5 \cdot 6 \varepsilon-$

Eट⿱ 口 ' $]$

$6<5 \cdot 9<$

$200 . \angle L$

$902 \cdot \angle L$

gzp $<1$

$610^{\circ} 08$

$660^{\circ} 08-$

568.945

6LE $\angle I T$

टIS $\angle$ II

$\angle B L \angle I I$

ZEI OEI

SSP. OE T-

OLE. IEI-

$188^{\circ} 0 \angle 3$
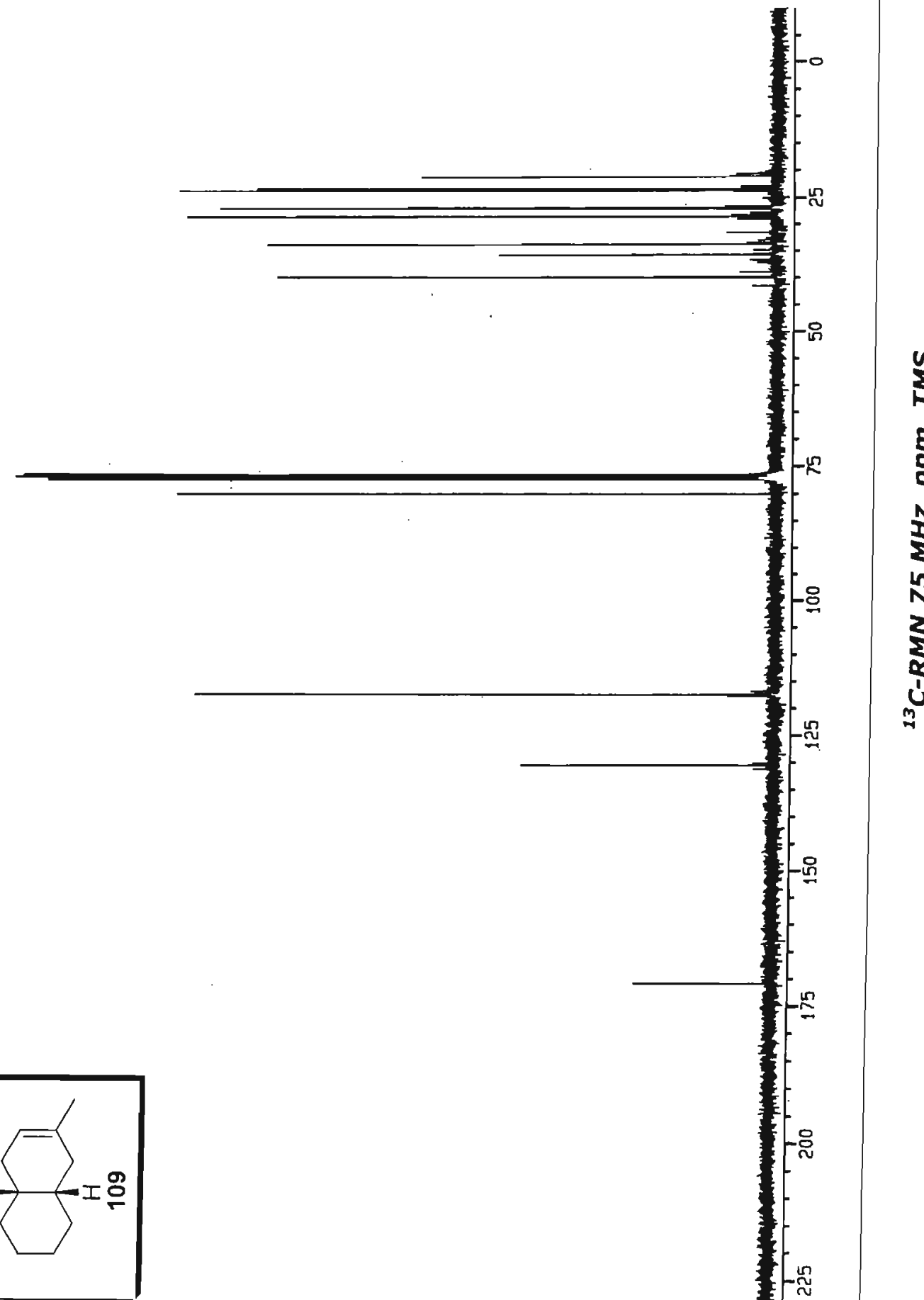

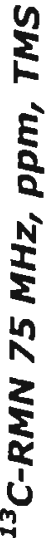




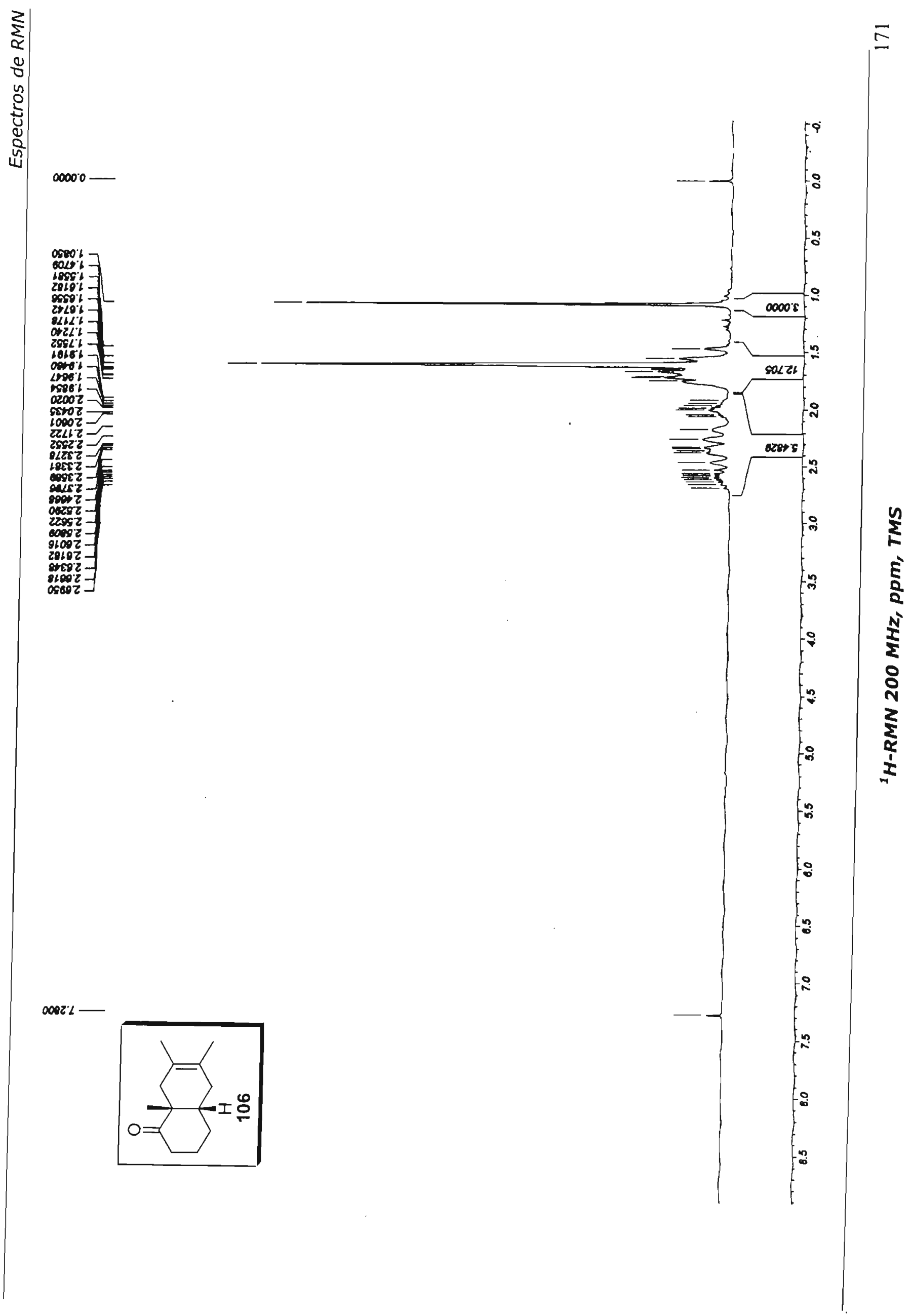



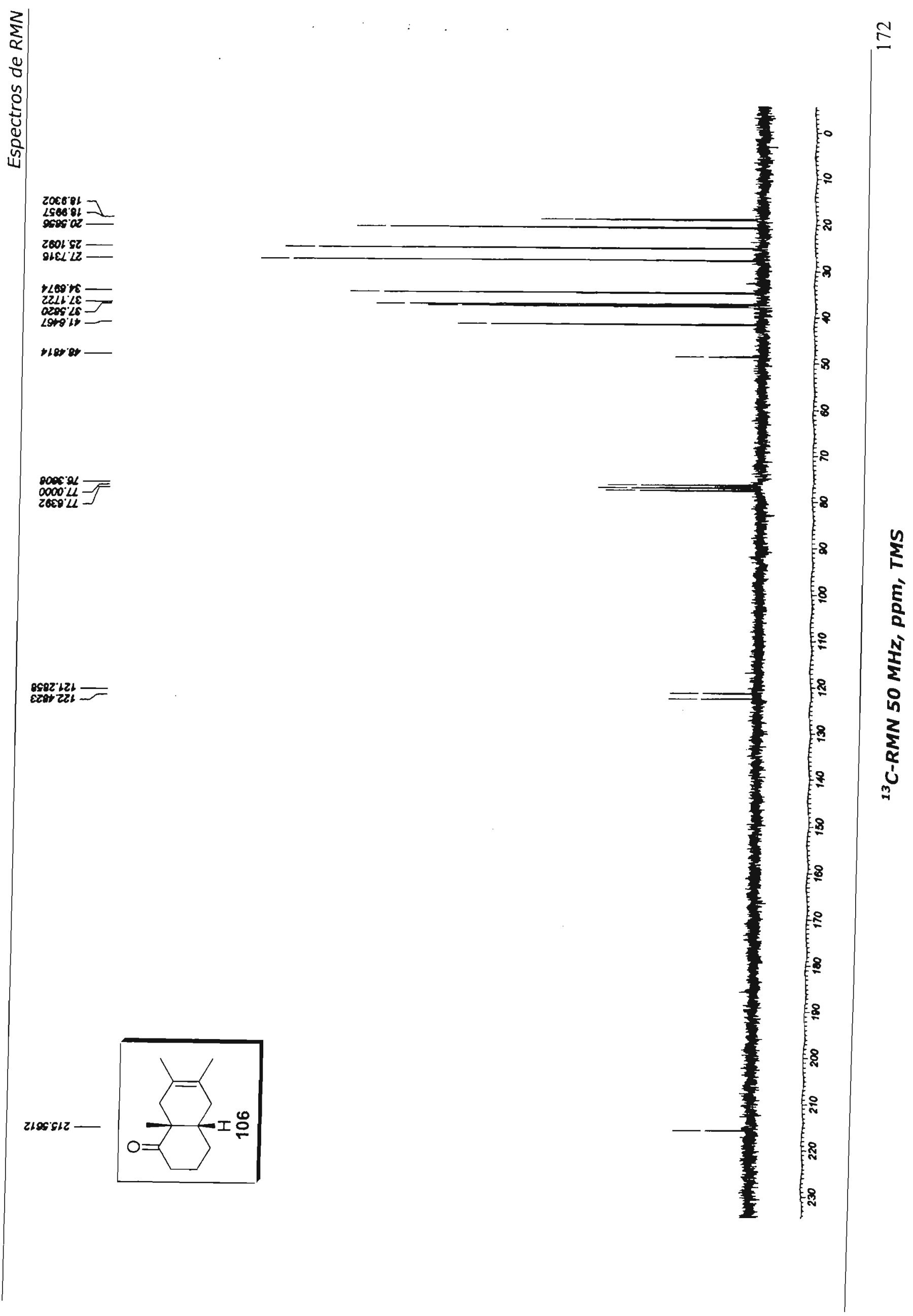


\section{Referências}

(1) Abe, N.; Onoda, R.; Shirahata, K.; Kato, T.; Woods, M. C.; Kitahara, Y. Tetrahedron Lett. 1968, 369.

(2) Naya, K.; Takagim, I.; Hayashi, M.; Nakamura, S.; Kobayashi, M.; Katsumura, S. Chem. Ind. 1968, 318.

(3) Jamieson, G. R.; Reid, E. H.; Turner, B. P.; Jamieson, A. T. Phytochemistry 1976, $15,1713$.

(4) Kano, K.; Hayashi, K.; Mitsuhashi, H. Chem. Pharm. Bull. 1982, 30, 1198.

(5) Nawrot, J.; Bloszyk, E.; Harmatha, J.; Novotný, L. J. Appl. Entomol. 1984, 98, 394.

(6) Nawrot, J.; Harmatha, J.; Novotný, L. Biochem. Syst. Ecol. 1984, 12, 99.

(7) Nawrot, J.; Bloszyk, E.; Harmatha, J.; Novotný, L.; Drozdz, B. Acta Entomol. Bohemoslov. 1988, 83, 327.

(8) Kreckova, J.; Krecek, J.; Harmatha, J. Pr. Nauk. Ins. Chem. Org. Fiz. Politech. Wroclaw. 1988, 33, 105.

(9) Rosinski, R.; Bloszyk, E.; Harmatha, J.; Knapik, A. Pr. Nauk. Ins. Chem. Org. Fiz. Politech. Wroclaw. 1988, 33, 91.

(10) Nawrot, J.; Koul, O.; Isman, M. B.; Harmatha, J. J. Appl. Entomol. 1991, 112, 194.

(11) Harmatha, J.; Nawrot, J. J. Appl. Entomol. 1984, 12, 95.

(12) Novotný, L.; Kotva, K.; Toman, J.; Herout, V. Phytochemistry 1972, 11, 2795.

(13) Silva Jr, L. F. Synthesis 2001, 671.

(14) Evans, D. A.; Sims, C. L. Tetrahedron Lett. 1973, 4691.

(15) Evans, D. A.; Sims, C. L.; Andrews, G. C. J. Am. Chem. Soc. 1977, 99, 5453.

(16) Greene, A. E.; Coelho, F.; Deprés, J.-P.; Brocksom, T. J. An. Acad. Brasil. Ciênc. $1985,57,521$.

(17) Back, T. G.; Payne, J. E. Org. Lett. 1999, 1, 663.

(18) Back, T. G.; Nava-Salgado, V. O.; Payne, J. E. J. Org. Chem. 2001, 66, 4361.

(19) Reddy, D. S. Org. Lett. 2004, 6, 3345.

(20) Hayashi, K.; Nakamura, H.; Mitsuhashi, H. Chem. Pharm. Bull. 1973, 21, 2806.

(21) Da Silva, G. V. J. Tese de Doutorado, Universidade de São Paulo, 1984.

(22) Reddy, D. S.; Kozmin, S. A. J. Org. Chem. 2004, 69, 4860.

(23) Greene, A. E.; Coelho, F.; Deprés, J. P.; Brocksom, T. J. Tetrahedron Lett. 1988, 29,5661 . 
(24) Brocksom, T. J.; Coelho, F.; Deprés, J.-P.; E., G. A.; De Lima, M. E. F.; Hamelin, O.; Hartmann, B.; Kanazawa, A. M.; Yanyun, W. J. Am. Chem. Soc. 2002, 124, 15313.

(25) Piers, E.; Britton, R. W.; de Waal, W. Can. J. Chem. 1969, 47, 831.

(26) Srikrishna, A.; Reddy, T. J.; Nagaraju, S.; Sattigeri, J. A. Tetrahedron Lett. 1994, 35,7841 .

(27) Srikrishna, A.; Nagaraju, S.; Sharma, V. R. J. Chem. Soc., Cehm. Commu. 1993, 285.

(28) Ferraz, H. M. C.; Silva, L. F., Jr.; Vieira, T. d. O. Synthesis 1999, 2001.

(29) Ferraz, H. M. C.; Silva, L. F., Jr. Quim. Nova 2000, 23, 216.

(30) McKillop, A.; Taylor, E. C. In Organic Synthesis by Oxidation with Metal Compounds; Miss, W. J., De Jonge, Cornelis, R. H. I., Eds.; Plenum: New York, $1986, \mathrm{p} 695$.

(31) McKillop, A.; Taylor, E. C.; Hunt , J. D.; Kienzle, F. Tetrahedron Lett. 1970, 5275.

(32) McKillop, A.; Hunt, J. D.; Kienzle, F.; Bigham, E.; Taylor, E. C. J. Am. Chem. Soc. 1973, 95, 3635.

(33) Vieira, T. O. Synlett 2002, 1017.

(34) Ferraz, H. M. C.; Brocksom, T. J.; Pinto, A. C.; Abla, M. A.; Zocher, D. T. H. Tetrahedron Lett. 1986, 27, 811.

(35) Ferraz, H. M. C.; Ribeiro, C. M. R.; Grazini, M. V. A.; Brocksom, T. J.; Brocksom, U. Tetrahedron Lett. 1994, 35, 1497.

(36) Ferraz, H. M. C.; Grazini, M. V. A.; Ribeiro, C. M. R.; Brocksom, U.; Brocksom, T. J. J. Org. Chem. 2000, 65, 2606.

(37) Ferraz, H. M. C.; Sano, M. K.; Ribeiro, C. M. R. Quim. Nova 1993, 16, 548.

(38) Ferraz, H. M. C.; Longo, L. S., Jr.; Zukerman-Schpector, J. J. Org. Chem. 2002, $67,3518$.

(39) Ferraz, H. M. C.; Longo Jr., L. S. Org. Lett. 2003, 5, 1337.

(40) Ferraz, H. M. C.; Ribeiro, C. M. R. Synth. Commun. 1992, 22, 399.

(41) Silva Jr, L. F. Tetrahedron 2002, 58, 9137.

(42) Ferraz, H. M. C.; Silva, L. F., Jr. Tetrahedron Lett. 1997, 38, 1899.

(43) Ferraz, H. M. C.; Silva, L. F., Jr. J. Braz. Chem. Soc. 2001, 12, 548.

(44) Ferraz, H. M. C.; Silva, L. F., Jr. J. Org. Chem. 1998, 63, 1716.

(45) Ferraz, H. M. C.; Silva, L. F., Jr.; Aguilar, A. M.; Vieira, T. O. J. Braz. Chem. Soc. 2001, 12, 680 .

(46) Ferraz, H. M. C.; Silva, L. F., Jr.; Vieira, T. O. Tetrahedron 2001, 57, 1709.

(47) Ferraz, H. M. C.; Aguilar, A. M.; Silva Jr, L. F. Synthesis 2003, 1031.

(48) Ferraz, H. M. C.; Aguilar, A. M.; Silva Jr, L. F. Tetrahedron 2003, 59, 5817.

(49) Silva Jr, L. F.; Sousa, R. M. F.; Ferraz, H. M. C.; Aguilar, A. M. J. Braz. Chem. Soc., no prelo. 
(50) Ferraz, H. M. C.; Santos, A. P.; Silva, L. F., Jr.; Vieira, T. O. Synth. Commun. $2000,30,751$.

(51) Ferraz, H. M. C.; Silva, L. F., Jr. Tetrahedron 2001, 57, 9939.

(52) Silva Jr, L. F.; Craveiro, M. V. Molecules, no prelo.

(53) Hua, D. H.; Chen, Y.; Sin, H.-S.; Maroto, M. J.; Robinson, P. D.; Newell, S. W.; Perchellet, E. M.; Ladesich, J. B.; Freeman, J. A.; Perchellet, J.-P.; Chiang, P. K. J. Org. Chem. 1997, 62, 6888.

(54) Nagakura, I.; Ogata, H.; Ueno, M.; Kitahara, Y. Bull. Chem. Soc. Jpn. 1975, 48, 2995.

(55) Angell, E. C.; Fringuelli, F.; Pizzo, F.; Taticchi, A.; Wenkert, E. J. Org. Chem. 1988, 53, 1224.

(56) Schumuff, N. R.; Trost, B. M. J. Org. Chem. 1983, 48, 1404.

(57) Hutchins, R. O.; Milewski, C. A.; Maryanoff, B. E. J. Org. Chem. 1973, 95, 3662.

(58) Volkman, R. A.; Andrews, G. C.; Johnson, W. S. J. Am. Chem. Soc. 1975, 97, 477.

(59) Ellison, R. A.; Lukenbach, E. R.; Chiu, C.-W. Tetrahedron Lett. 1975, 499.

(60) Kleinfelter, D. C.; R. Schleyer, P. R. Org. Synth. 1962, 42, 79.

(61) Mori, K.; Matsushima, Y. Synthesis 1995, 845.

(62) Boeckman, R. K.; Starrett, J. E.; Nickell, D.; Sum, P.-E. J. Am. Chem. Soc. 1986, $108,5549$.

(63) McCormick, J. P.; Tomasik, W.; Johnson, M. W. Tetrahedron Lett. 1981, 22, 607.

(64) Sharpless, K. B.; Amberg, W.; Bennani, Y. L.; Crispino, G. A.; Hartung, J.; Jeong, K.-S.; Kwong, H.-L.; Morikawa, K.; Wang, Z.-M.; Xu, D.; Zhang, X.-L. J. Org. Chem. 1992, 57, 2768.

(65) Paquete, V.; Lebel, H. Synthesis 2005, 1901.

(66) Ferraz, H. M. C.; Muzzi, R. M.; Vieira, T. O.; Viertler, H. Tetrahedron Lett. 2000, $41,5021$.

(67) Ferraz, H. M. C. Dissertação de Mestrado, Universidade de São Paulo, 1973.

(68) Bermejo, F.; Sandoval, C. J. Org. Chem. 2004, 69, 5275.

(69) Sekizaki, H.; Ito, M.; Inoue, S. Bull. Chem. Soc. Jpn. 1978, 51, 2439.

(70) Wiberg, K. B.; Koch, W. Tetrahedron Lett. 1966, 1779.

(71) Smith, M. B. Organic Synthesis; First ed.; McGRAW-HILL International Editions, 1994.

(72) Nagakura, I.; Maeda, S.; Ueno, M.; Funamizu, M.; Kitahara, Y. Chem. Lett. 1975, 1143.

(73) Kocovský, P.; Pour, M. J. Org. Chem. 1990, 55, 5580.

(74) Díaz, S.; Cuesta, J.; González, A.; Bonjoch, J. J. Org. Chem. 2003, 68, 7400.

(75) Pennanen, S. Acta Chem. Scand. B 1980, 34, 261.

(76) Marshall, J. A.; Cohen, G. M. J. Org. Chem. 1971, 36, 877. 
(77) Mori, K.; Ebata, T. Tetrahedron 1986, 42, 3471.

(78) Paquette, L. A.; Wang, T.-Z.; Phillippo, C. M. G.; Wang, S. J. Am. Chem. Soc. 1994, 116, 3367.

(79) Berger, C.; Franck-Neumann, M.; Ourisson, G. Tetrahedron Lett. 1968, 3451.

(80) Piers, E.; Britton, R. W.; de Waal, W. Can. J. Chem. 1969, 47, 4307.

(81) Pinder, A. R.; Torrence, A. K. J. Chem. Soc. (C) 1971, 3410.

(82) Kelly, R. B.; Zamecnik, J.; Beckett, B. A. Can. J. Chem. 1972, 50, 3455.

(83) Zoretic, P. A.; Golen, J. A.; Saltzman, M. D. J. Org. Chem. 1981, 46, 3554.

(84) Huffman, J. W.; Potnis, S. M.; Satish, A. V. J. Org. Chem. 1985, 50, 4266.

(85) Duhamel, P.; Dujardin, G.; Hennequin, L.; Poirier, J.-M. J. Chem Soc. Perkin Trans. 1 1992, 387.

(86) Boeckman Jr., R. K. J. Am. Chem. Soc. 1973, 95, 6867.

(87) Boeckman Jr., R. K.; Blum, D. M.; Ganem, B. Org. Syn. 1978, 58, 158.

(88) Boeckman Jr., R. K. Tetrahedron 1983, 39, 925.

(89) Boeckman Jr., R. K.; Blum, D. M.; Ganem, B.; Halvey, N. Org. Syn. 1978, 58, 152.

(90) Bonjoch, J.; Cuesta, J.; Díaz, S.; González, A. Tetrahedron Lett. 2000, 41, 5669.

(91) Jenniskens, L. H. D.; De Groot, A. Tetrahedron 1998, 54, 5617.

(92) Buchschacher, P.; Fürst, A. Org. Synth. 1985, 63, 37.

(93) Bui, T.; Barbas III, C. F. Tetrahedron Lett. 2000, 41, 6951.

(94) Cuesta, X.; González, A.; Bonjoch, J. Tetrahedron: Asymmetry 1999, 10, 3365.

(95) Schenato, R. A.; Santos, E. M.; Tenius, B. S. M.; Costa, P. R. R.; Caracelli, I.; Zukerman-Schpector, J. Tetrahedron: Asymmetry 2001, 12, 579.

(96) Krafft, M. E.; Holton, R. A. Tetrahedron Lett. 1983, 24, 1345.

(97) Cazeau, P.; Moulines, F.; Laporte, O.; Duboudin, F. J. Organometal. Chem. 1980, 201, C9.

(98) Taishi, T.; Takechi, S.; Mori, S. Tetrahedron Lett. 1998, 39, 4347.

(99) Miller, R. D.; McKean, D. R. Synthesis 1979, 730.

(100) Dagneau, P.; Canone, P. Tetrahedron: Asymmetry 1998, 7, 2817.

(101) Johnson, F. Chem. Rev. 1968, 68, 375.

(102) Mincione, E.; Bovicelli, P.; Gil, J. B.; Forcellese, M. L. Gazz. Chim. Ital. 1985, 115, 37.

(103) Prakash, O. Aldrichimica Acta 1995, 28, 63.

(104) Varma, R. S.; Kumar, D. Synthesis 1999, 1288.

(105) Stetter, H. Angew. Chem. 1955, 67, 769.

(106) Ramachandran, S.; Newman, M. S. Org. Synth. Coll. 5 1973, 486.

(107) Boyce, C. B. C.; Whitehurst, J. S. J. Chem. Soc. C 1960, 621.

(108) Uemura, S.; Tabata, A.; Okano, M.; Ichikawa, K. J. Chem. Soc., Chem. Commun. 1970, 1630 . 
(109) Uemura, S.; Miyoshy, H.; Tabata, A.; Okano, M. Tetrahedron 1981, 37, 291.

(110) Murakami, M.; Nishida, S. Chem. Lett. 1981, 997.

(111) Rigby, J. H.; Pigge, F. C. J. Org. Chem. 1995, 60, 7392.

(112) Heathcock, C. H.; Ellis, J. E.; McMurry, J. E.; Coppolino, A. Tetrahedron Lett. $1971,4995$.

(113) Singh, V.; Iyer, S. R.; Pal, S. Tetrahedron 2005, 61, 9197.

(114) Anderson, J. C.; Blake, A. J.; Graham, J. P.; Wilson, C. Org. Biomol. Chem. 2003, 1, 2877.

(115) Chênevert, R.; Courchesne, G.; Jacques, F. Tetrahedron: Asymmetry 2004, 15, 3587.

(116) Murry, J. E. M.; Musser, J. H.; Ahmad, M. S.; Blaszczak, L. C. J. Org. Chem. 1975, 40, 1829. 